UNIVERSIDADE DE SÃO PAULO

FACULDADE DE ECONOMIA, ADMINISTRAÇÃO E CONTABILIDADE DEPARTAMENTO DE ADMINISTRAÇÃO PROGRAMA DE PÓS-GRADUAÇÃO EM ADMINISTRAÇÃO

A INFLUÊNCIA DOS PADRÕES PARA SISTEMAS DE GESTÃO NO DESEMPENHO DAS EMPRESAS

Fabrizio Giovannini

Orientador: Prof. Dr. Isak Kruglianskas

SÃO PAULO 
Profa. Suely Vilela

Reitora da Universidade de São Paulo

Prof. Carlos Roberto Azzoni

Diretor da Faculdade de Economia, Administração e Contabilidade

Prof. Isak Kruglianskas

Chefe do Departamento de Administração

Prof. Lindolfo Galvão de Albuquerque

Coordenador do Programa de Pós Graduação 


\section{A INFLUÊNCIA DOS PADRÕES PARA SISTEMAS DE GESTÃO NO DESEMPENHO DAS EMPRESAS}

Tese apresentada ao Departamento de Administração da Faculdade de Economia, Administração e Contabilidade da Universidade de São Paulo para a obtenção do título de Doutor em Administração.

Orientador: Prof. Dr. Isak Kruglianskas

\section{SÃO PAULO}


Dissertação defendida e aprovada no Departamento de Administração da Universidade de São Paulo - Programa de Pós-Graduação em Administração, pela seguinte banca examinadora:

\section{Giovannini, Fabrizio}

A influência dos padrões para sistemas de gestão no desempenho das empresas / Fabrizio Giovannini. -- São Paulo, 2008.

$209 \mathrm{p}$.

Tese (Doutorado) - Universidade de São Paulo, 2008

Bibliografia.

1. Desempenho organizacional 2. Normas técnicas 3. Estrutura organizacional 4. Complexidade I. Universidade de São Paulo. Faculdade de Economia, Administração e Contabilidade II. Título.

CDD - 658.402 
A primeira pessoa a quem quero agradecer é minha esposa, Márcia, à qual também dedico este trabalho, por seu apoio, e por sua dedicação à nossa família que me trouxe a tranqüilidade necessária para realizar este trabalho.

Agradeço também a meus pais, pelo empenho em me dar todas as condições necessárias para desbravar meus caminhos.

Agradeço aos meus companheiros de trabalho da Torcomp Usinagem e Componentes Ltda., com os quais aprendi muito e cuja competência e empenho no trabalho me permitiram dedicar tempo e esforço a esta tese. Espero poder retribuir com a mesma competência.

Quero agradecer também à empresa Serasa S.A. pela sua inestimável colaboração, sem a qual este trabalho não teria sido possível. Essa empresa é um exemplo de responsabilidade social e de genuína preocupação com o desenvolvimento do Brasil.

Finalmente, agradeço aos professores que me marcaram pela sua competência, inteligência, profissionalismo, e entusiasmo e cuja contribuição foi fundamental para minha pesquisa: meu orientador Prof. Isak Kruglianskas, Prof. Abraham Sin Oih Yu, Prof. Decio Zylbersztajn e Prof. Isaías Custódio. 


\section{RESUMO}

As empresas precisam de sistemas de regras, formais ou não, para serem administradas. Os sistemas de regras para a administração são aqui chamados de sistemas de gestão. Entre as funções do administrador está, portanto, a construção de sistemas de gestão que atendam às necessidades dos stakeholders da empresa e que assegurem a sobrevivência e a prosperidade da mesma. O problema pode ser dividido em duas partes: que tipo de sistema é o melhor para a organização e qual a melhor forma de implantá-lo. No corpo do conhecimento da administração há inumeráveis soluções propostas para esses problemas, embasadas em diferentes abordagens e teorias, e dirigidas a diferentes tipos de empresas e contextos. Entre os esforços para a busca de soluções cada vez melhores ganhou ímpeto, nos últimos 15 anos, um movimento de criação de Padrões para Sistemas de Gestão (PSGs). O padrão que se tornou mais conhecido é a norma ISO 9.000, voltado à criação de sistemas de gestão da qualidade. Depois desse padrão pioneiro, outros foram e estão sendo criados com o objetivo de abranger a maioria das áreas dos sistemas de gestão: meio ambiente, saúde e segurança do trabalho, responsabilidade social, governança, demonstrações financeiras e contabilidade, entre outros. Apesar de um número crescente de organizações estar optando por usar estes padrões para criar seus sistemas de gestão, há dúvidas e controvérsias sobre sua eficiência e eficácia. Esta tese investiga a influência dos PSGs sobre o desempenho das empresas. Através de uma pesquisa quantitativa compara o desempenho, ao longo de 4 anos, de empresas com diferentes níveis de adoção de PSGs. A pesquisa foi feita com todas as indústrias de autopeças brasileiras permitindo, dessa forma, certo controle das variáveis intervenientes. A qualidade dos dados contou com a inestimável colaboração da empresa de informações comerciais Serasa S.A. que forneceu os dados de desempenho financeiro e de outras variáveis intervenientes. Utilizando-se técnicas estatísticas uni e multivariadas, entre elas a Modelagem de Equações Estruturantes, rejeitou-se a hipótese nula de que não há influência dos PSGs sobre o desempenho das empresas. Esse resultado, em conjunto com outras evidências estatísticas, permite afirmar - dentro dos limites do modelo conceitual da pesquisa - que a adoção de PSGs influencia positivamente o desempenho das indústrias de autopeças brasileiras. Há também indícios de que empresas pequenas e médias se beneficiam mais da adoção de PSGs do que as grandes empresas. Portanto, Padrões para Sistemas de Gestão podem ser recomendados como uma ferramenta potencialmente eficaz, especialmente para empresas industriais. 


\begin{abstract}
Firms, to be managed, need systems of rules, formal or not. The systems of rules for business management are called here management systems. Among the functions of the manager there is, therefore, the construction of management systems that fulfill the firm's stakeholder's necessities and that secure the survival and prosperity of the firm. The problem can be divided into two parts: what kind of system is the best for the organization and which is the best way to implement it. In the administration's body of knowledge there are innumerable proposed solutions to these problems, based in different approaches and theories, and directed to different kinds of firms and contexts. Among the efforts for the search of better solutions it is getting stronger, in the last 15 years, a movement for the creation of Management Systems Standards. The Standard that became mostly known is the ISO 9.000 norm, dedicated to the creation of quality management systems. After this pioneer Standard, other where and are being created with the goal of enclosing the majority of the areas where management systems are applied: environment, health and safety, social responsibility, governance, finance and accounting, among others. Although a growing number of organizations is opting to use these Standards to create their own management systems, there are doubts and controversies regarding its efficiency and effectiveness. This thesis investigates the influence of Management Systems Standards over the firm's performance. Trough a quantitative research it compares the performance, in a 4 years period, of firms with different levels of Management Systems Standard. The research was done with all the auto parts manufacturers of Brazil allowing, in this manner, a measure of control over the intervenient variables. The quality of the data is due to the inestimable collaboration of the commercial information firm Serasa S.A. that supplied the data of financial performance and other intervenient variables. Using uni and multivariate statistical techniques, the null hypothesis that there is no influence of Management Systems Standards over firm's performance was rejected. This result, joined with other statistical evidence, allows affirming - within the limits of the conceptual framework - that the adoption of Management Systems Standards positively influences the performance of the Brazilian auto parts manufacturers. There are also clues that small and medium companies benefit more from the adoption of Management System Standards than large firms. Therefore, Management Systems Standards can be recommended as a potentially effective tool, especially for manufacturing firms.
\end{abstract}




\section{SUMÁRIO}

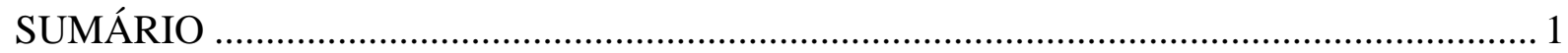

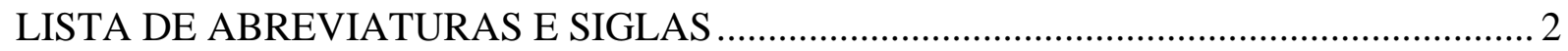

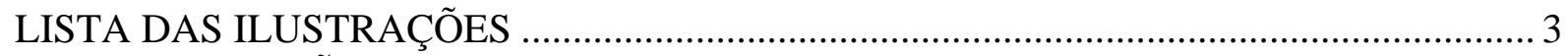

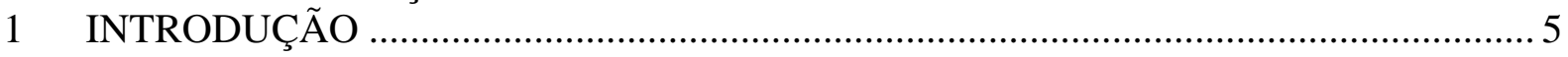

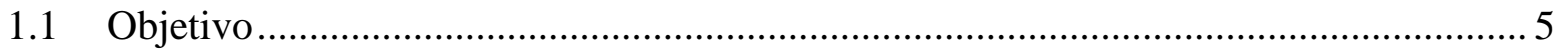

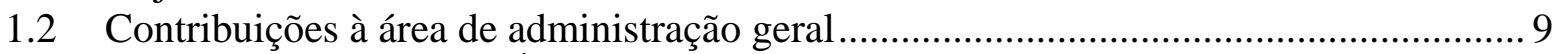

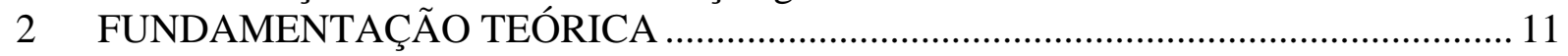

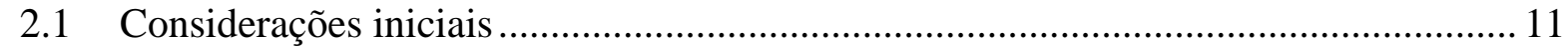

2.2 Administração, organizações e Padrões para Sistemas de Gestão ................................ 16

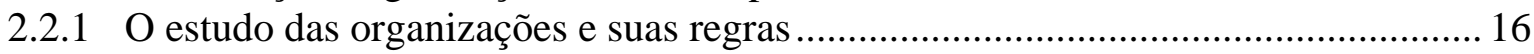

2.2.2 A relação da estrutura organizacional com o desempenho da empresa .................... 23

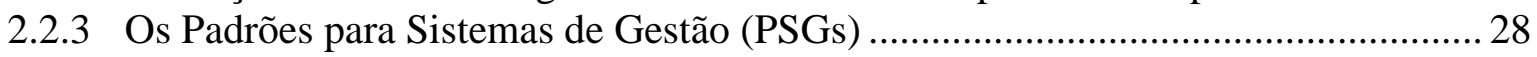

2.2.4 Breve histórico dos PSGs no setor de Autopeças ..................................................... 38

2.3 Os Padrões para Sistemas de Gestão e o desempenho das organizações..................... 40

2.3.1 As diferentes abordagens no estudo das organizações......................................... 41

2.3.1.1 A abordagem da economia no estudo das organizações.................................. 41

2.3.1.2 A abordagem da administração no estudo das organizações............................ 43

2.3.1.3 A abordagem da psicologia no estudo das organizações ................................... 44

2.3.1.4 A abordagem da sociologia no estudo das organizações................................... 44

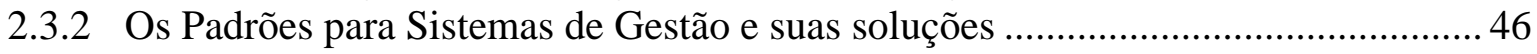

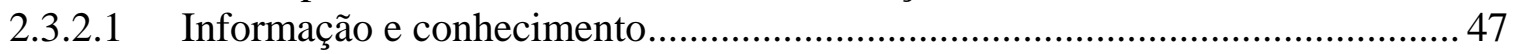

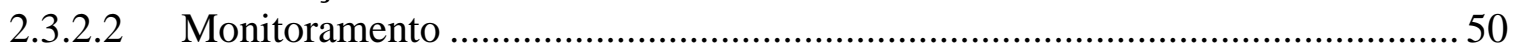

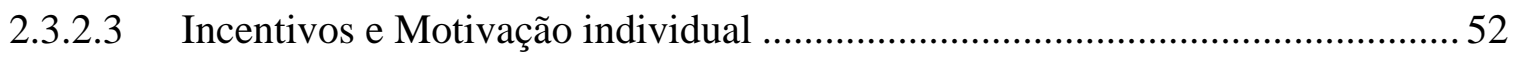

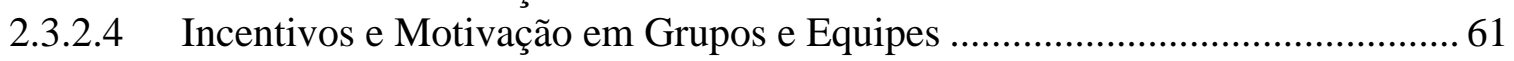

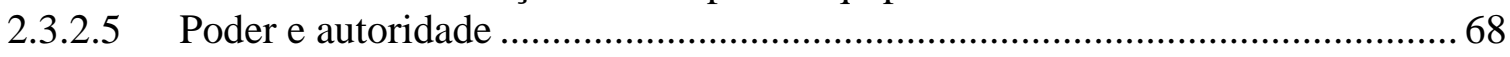

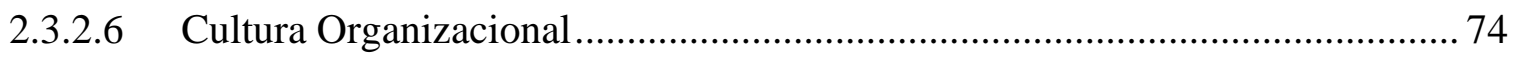

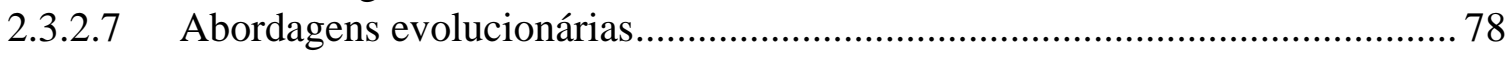

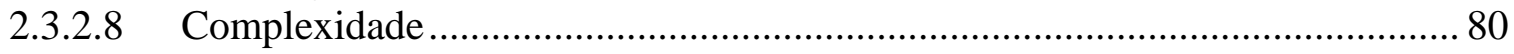

2.4 Pesquisas empíricas sobre Padrões para Sistemas de Gestão ....................................... 84

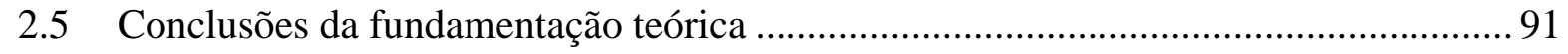

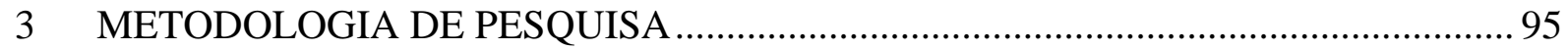

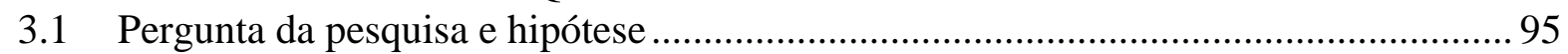

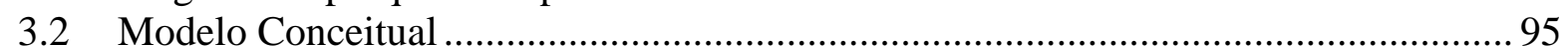

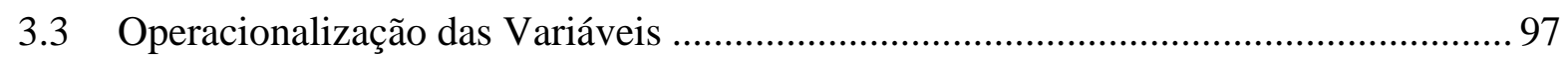

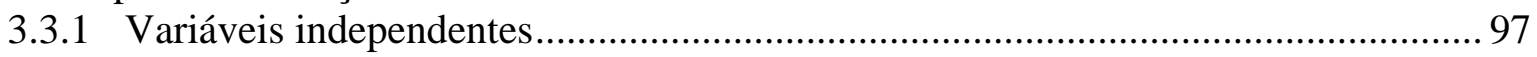

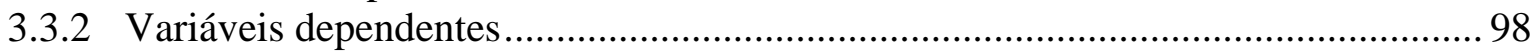

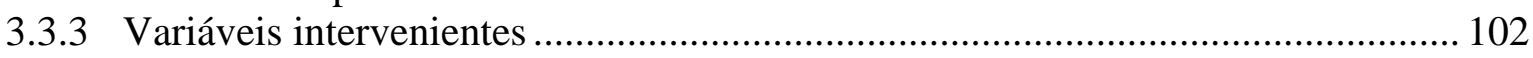

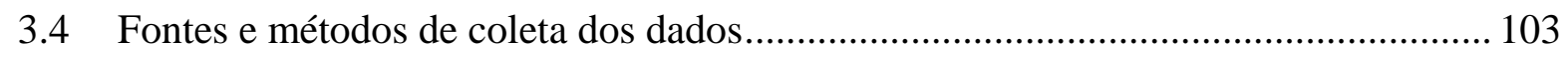

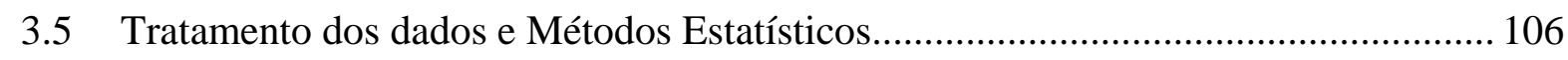

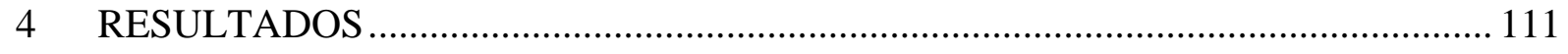

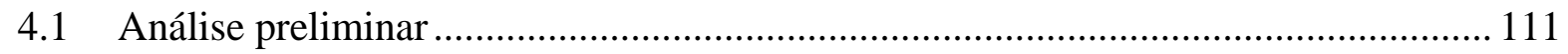

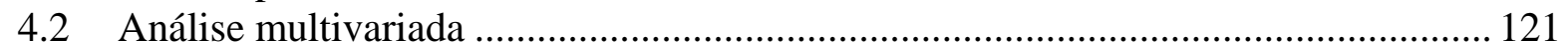

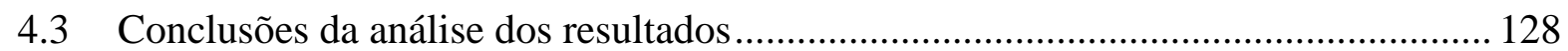

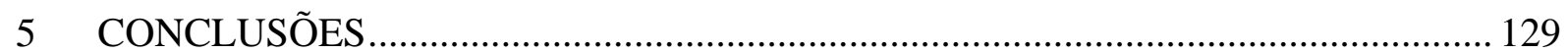

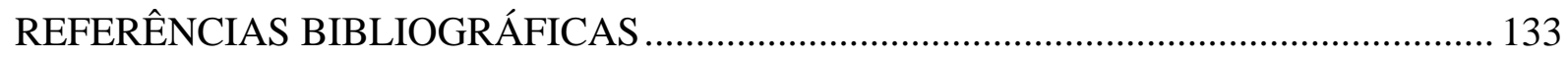




\section{LISTA DE ABREVIATURAS E SIGLAS}

ABIQUIM: Associação Brasileira da Indústria Química

ABNT: Associação Brasileira de Normas Técnicas

ABRACICLO: Associação Brasileira dos Fabricantes de Motocicletas, Ciclomotores, Motonetas, Bicicletas e Similares.

ANFAVEA: Associação Nacional dos Fabricantes de Veículos Automotores

ANSI: American National Standards Institute

BSC: Balanced Scorecard

BSI: Britsh Standards Institution

CCQ: Círculo de Controle de Qualidade

CEN: Comité Européen de Normatisation

CNPJ: Cadastro Nacional de Pessoas Jurídicas

CRC: Conselho regional de Contabilidade

DIN: Deutches Institut für Normung

DNA: Ácido desoxirribonucléico

ERP: Enterprise Resource Planning

FNQ: Fundação Nacional da Qualidade

IATF: International Automotive Task Force

IASB: International Accounting Standards Board

ISO: International Organization for Standardization

JAMA: Japanese Manufacturers Association

LAJIDA: Lucro Antes de Juros, Impostos. Depreciações e Amortizações

MBC: Movimento Brasil Competitivo

MCAR: Missing Completely At Random

MEG: Modelo de Excelência de Gestão

MPD: Multi-persons Prisoners Dilemma

NIE: New Institutional Economics

OHSAS: Occupational Health and Safety Advisory Service

ONG: Organização Não Governamental

PNQ: Prêmio Nacional da Qualidade

PSG: Padrão para Sistema de Gestão

QSA: Quality Strategic Advantage

SINDIPEÇAS: Sindicato Nacional da Indústria de Componentes para Veículos Automotores

SA: Social Accountability

SAI: Social Accountability International

SEM: Structural Equation Modeling

SPSS: Statistical Package for the Social Sciences

SSO: Saúde e Segurança Ocupacional

TCE: Transaction Cost Economics

TQM: Total Quality Management

UFPR: Universidade Federal do Paraná 


\section{LISTA DAS ILUSTRAÇÕES}

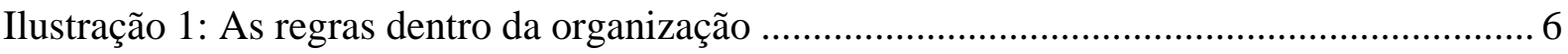

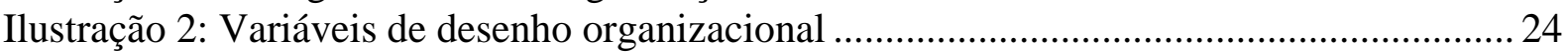

Ilustração 3: A influência dos PSGs na eficácia organizacional ............................................. 25

Ilustração 4: Modelo de um sistema de gestão da qualidade baseado em processos ................ 33

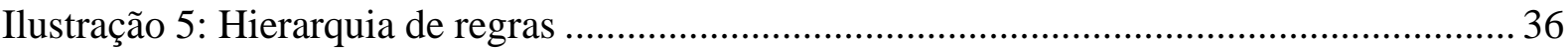

Ilustração 6: Modelo ligando melhorias de qualidade com desempenho do negócio............... 85

Ilustração 7: Modelo conceitual ligando gestão e performance ambiental com valor da

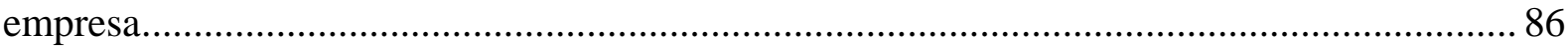

Ilustração 8: Relação esperada entre certificação ISO 9.000 e desempenho do negócio.......... 89

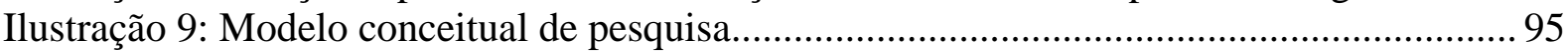

Ilustração 10: Definindo os domínios da performance da empresa ......................................... 100

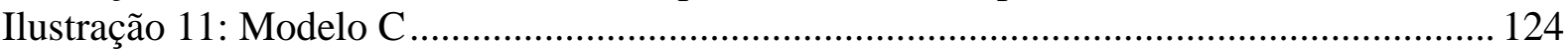




\section{INTRODUÇÃO}

\section{$1.1 \quad$ Objetivo}

Esta tese trata das regras da organização. March e Simon definem abaixo, resumidamente, os tipos de regras que são o assunto deste estudo:

[...] para que uma organização se comporte de forma adaptativa, ela precisa de alguns regulamentos e procedimentos estáveis que pode empregar ao desempenhar suas práticas de adaptação. Assim, a todo o momento, os programas da organização para desempenhar suas tarefas são parte de sua estrutura, mas a parte menos estável. Pouco mais estáveis são as regras de troca que determinam quando aplicar um programa, e quando outro. Ainda mais estáveis são os procedimentos que usa para desenvolver, elaborar, instituir e revisar programas. ${ }^{1}$ (MARCH; SIMON, 1993, p.191-192).

O maior interesse da tese repousa sobre "os procedimentos que [a organização] usa para desenvolver, elaborar, instituir e revisar programas”. Esse tipo de regra, devido à sua natureza, será chamado aqui de Metaregra (GIOVANNINI, 2002; GIOVANNINI; KRUGLIANSKAS, 2004).

É importante notar que March e Simon consideram a existência de "regulamentos e procedimentos estáveis" necessária para que a “organização se comporte de forma adaptativa”. Nesse sentido, esta tese encara a existência de regras como necessária para a criação da identidade e das fronteiras da organização e, ao mesmo tempo, necessária também para a sua capacidade de adaptação.

As regras da organização - Metaregras ou não - são parte importante da estrutura organizacional e é a partir dela que geram seus efeitos sobre as atividades da empresa. Dada a diversidade de definições de estrutura organizacional existentes na literatura, convém esclarecer o que se entende por estrutura organizacional nesse estudo:

A estrutura de uma organização pode ser definida como o resultado de um processo através do qual a autoridade é distribuída, as atividades desde os níveis mais baixos até a alta administração são especificados e um sistema de comunicação é delineado permitindo que as pessoas realizem as

\footnotetext{
${ }^{1}[\ldots]$ in order for an organization to behave adaptively, it needs some stable regulations and procedures that it can employ in carrying out its adaptive practices. Thus, at any given time an organization's programs for performing its tasks are part of its structure, but the least stable part. Slightly more stable are the switching rules that determine when it will apply one program, and when another. Still more stable are the procedures it uses for developing, elaborating, instituting, and revising programs
} 
atividades e exerçam a autoridade que lhes compete para o atingimento dos objetivos organizacionais. (VASCONCELLOS; HEMSLEY, 1997, p. 3).

Deve-se ressaltar que estrutura organizacional também deve ter, entre suas funções, a de garantir o controle das atividades das pessoas e a de promover a coordenação e cooperação entre elas (BARNARD, 1968; MILGROM; ROBERTS, 1992).

Assim como as regras da organização fazem parte da estrutura organizacional, essa última faz parte de um conjunto maior: a organização em si, entendida aqui como o conjunto formado pela estrutura organizacional e todos os recursos - tangíveis e intangíveis - agregados a ela. Nesse trabalho, organização e empresa são tratadas como sinônimos. Apesar dos termos não representarem exatamente a mesma coisa, já que há organizações que não são empresas, esta convenção foi adotada já que a maioria dos autores pesquisados usa o termo organização para se referir também às empresas.

A figura 1 abaixo procura resumir, de forma extremamente simplificada, as colocações anteriores:

Organização ou Empresa

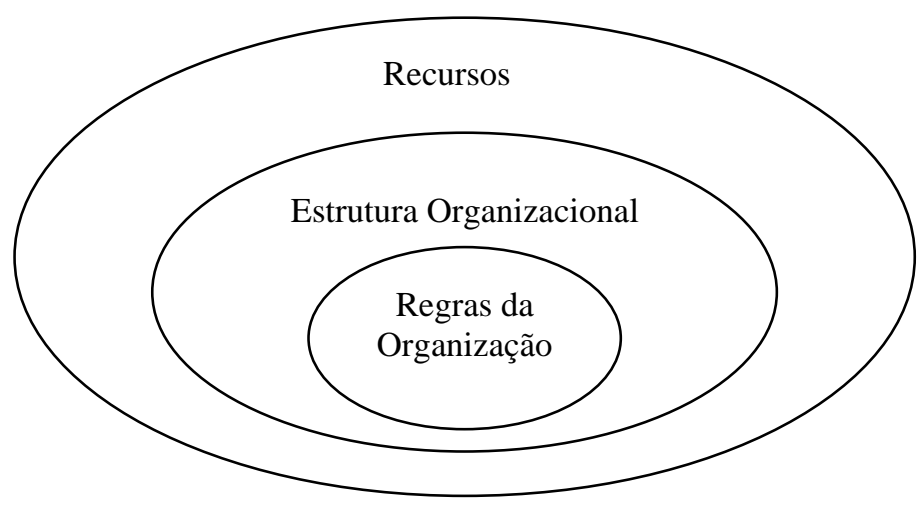

Ilustração 1: As regras dentro da organização

O que levou à escolha das regras organizacionais como assunto da tese foi o fato de que uma grande quantidade de organizações, com o objetivo de melhorar o seu desempenho, está passando a usar padrões (Standards) criados por terceiros para criar as suas próprias regras organizacionais (BRUNSSON; JACOBSSON, 2005). Entre os padrões mais conhecidos adotados para esse fim estão os seguintes:

a) Normas ISO 9001 (ABNT, 2000) e ISOTS 16949 (ISO, 2002) para sistemas de gestão da qualidade; 
b) Norma ISO 14001 (ABNT, 2004) para sistemas de gestão ambiental;

c) Norma OHSAS 18001(UFPR, 2008) para sistemas de gestão de saúde e segurança no trabalho e;

d) Norma SA 8000 (SAI, 2008) para sistemas de gestão da responsabilidade social.

Há outros padrões para outros processos de gestão e o objetivo de todos é melhorar a eficiência e a eficácia das organizações em alguma determinada dimensão. Esses padrões recebem vários nomes genéricos como, por exemplo: Sistemas de Gestão, Normas de Gestão, Standards Administrativos, Standards de Processos Administrativos e Padrões de Práticas Gerenciais. O termo que será usado nesta tese, por melhor representar o tipo de padrão estudado, é “Padrões para Sistemas de Gestão” ou, abreviadamente, PSGs.

O tema da tese é a influência da introdução desses padrões na eficácia das estruturas organizacionais e, conseqüentemente, no desempenho da organização. A escolha desse tema se deve, de um lado, à necessidade de conhecimento sobre as reais conseqüências da introdução dos PSGs e, de outro, pelas controvérsias sobre a sua utilidade e viabilidade (BRUNSSON; JACOBSSON, 2005). Os PSGs, pela sua aparente similaridade com as regras da burocracia weberiana (GERTH; MILLS, 1961), podem ser vistos como prejudiciais à flexibilidade e à criatividade nas organizações. Alguns acadêmicos também questionam que os conceitos que embasam os PSGs são datados e não têm sido influenciados pelos mais recentes avanços da teoria das organizações:

Padrões sempre possuem alguma fundamentação em conhecimento. Nós comparamos ISO 9000 com o pensamento acadêmico e com a sabedoria convencional da cultura gerencial popular. A última parece ter se tornado o Padrão. Nossa análise indica que certos tipos de conhecimento, em vez de outros, mais prontamente encontram caminho para dentro de um Padrão. O conhecimento subjacente aos Padrões não necessariamente reflete uma realidade empírica: é altamente questionável se o Standard ISO 9000 realmente codifica as práticas existentes de organizações de sucesso. ${ }^{2}$ (FURUSTEN, 2005, p. 83).

Entretanto, há indícios que os resultados trazidos pelos PSGs, por serem positivos para diversas áreas das empresas (CHAPMAN et al, 1997; FELDMAN et al, 1997; EASTON; JARREL, 1998; GIOVANNINI; KRUGLIANSKAS, 2004), vêm estimulando sua

\footnotetext{
${ }^{2}$ Standards always have some foundation in knowledge. We have compared ISO 9000 with academic thinking and with the conventional wisdom of popular management culture. The latter appear to have become the standard. Our analysis indicates that certain kinds of knowledge, rather than others, more readily find their way into the standard. The knowledge underlying standards does not necessarily reflect an empirical reality: it is highly questionable whether the ISO 9000 standard really codifies the existing practices of successful organizations.
} 
disseminação (ver gráfico 1). O número de empresas certificadas nos diversos PSGs não para de crescer e há estudos (FNQ, 2008) sobre empresas que adotaram algum tipo de PSG, inclusive a combinação de dois ou mais, e que colheram e continuam colhendo bons resultados em vários indicadores de desempenho, inclusive financeiros. Há associações de empresas - como, por exemplo, o Movimento Brasil Competitivo (MBC, 2008) e a Associação Brasileira da Indústria Química (ABIQUIM, 2008) - que promovem a excelência de gestão e recomendam a adoção de PSGs para esse fim.

Entretanto, poucos desses indícios, estudos e recomendações são baseados em pesquisas metodologicamente robustas. Faltam pesquisas de cunho científico sobre a relação entre a adoção de PSGs e os resultados das empresas. Essa escassez de pesquisas sobre a questão não se limita ao Brasil, como foi possível verificar através da revisão da bibliografia. Assim, dada a ampla disseminação de PSGs, a pergunta que este estudo se propõe a responder é:

Há alguma influência da adoção de Padrões para Sistemas de Gestão sobre o desempenho das empresas?

A falta de conhecimento científico sobre essa influência dificulta a tomada de decisão dos administradores sobre a conveniência ou não de adotar PSGs. Há situações em que essa decisão implica, também, continuar ou não em determinados mercados cujos clientes exigem a adoção de algum PSG por questões, entre outras, de segurança, de qualidade ou de proteção do meio-ambiente.

Pode-se somar a esses interesses o da sociedade, que espera que as empresas desempenhem seu papel de forma eficiente e eficaz frente a todos seus stakeholders. Há, também, muitas organizações não-governamentais - ABNT, ISO, FNQ, MBC, ABIQUIM, entre outras - que se dedicam à construção e disseminação dos PSGs e que devem ter interesse e conhecer os resultados finais de seus esforços. Dada essa demanda e o interesse do autor no assunto, esta tese tem como objetivo contribuir na construção desse conhecimento através de uma pesquisa quantitativa sobre um inteiro setor industrial.

A fonte de dados empíricos para a pesquisa é a indústria de autopeças brasileira, que foi escolhida por diversas razões. A primeira delas é a familiaridade do autor com o setor. São 25 anos ininterruptos atuando como empresário industrial na fabricação de autopeças e 
acessórios. Outra razão é a disponibilidade de dados. Sendo um setor antigo e razoavelmente organizado em torno de seu sindicato patronal, o SINDIPEÇAS (Sindicato Nacional da Indústria de Componentes para Veículos Automotores), é possível, através dele, saber quem são as empresas do setor e obter diversas informações importantes para a pesquisa. Esse banco de dados também fornece os contatos necessários para a checagem das informações junto às empresas.

Adicionalmente, devido às exigências de oligopólios de fornecedores (siderúrgicas e petroquímicas, por exemplo) e oligopsônios de clientes (montadoras), as empresas têm sido obrigadas a desenvolver um nível de precisão e transparência em suas demonstrações financeiras cada vez maior. Frente aos fornecedores essa atitude tem como objetivo garantir crédito a cotas de fornecimento e, perante os clientes, tem como objetivo demonstrar solidez financeira para assegurar sua capacidade de fornecimento. Assim, empresas de informações comerciais como a Serasa S.A. possuem bancos de dados razoavelmente completos e com informações confiáveis de balaços e demonstrações de resultados destas empresas.

Outro motivo para a escolha deste setor é a existência de um número considerável de empresas que adotaram PSGs - em número e tipos diferentes - e, inclusive, empresas que não adotaram nenhum PSG (SINDIPEÇAS, 2007), permitindo, assim, comparações entre empresas com diferentes níveis de adoção de PSGs (ver seção 2.2.4).

Finalmente, as empresas do setor, no período analisado (2002 a 2005), desfrutaram de condições relativamente estáveis e favoráveis de mercado em todos os sub-setores de atuação (SINDIPEÇAS, 2003, 2004, 2005, 2006, 2007), permitindo um bom controle das variáveis intervenientes.

\subsection{Contribuições à área de administração geral}

Regras organizacionais, estrutura organizacional e organização são temas centrais na área de administração geral. A escolha de uma ferramenta ou técnica de apoio para o desenvolvimento de organizações mais eficazes é uma decisão que tem conseqüências que praticamente permeiam toda a empresa e sua relação com o ambiente externo. Esse ambiente, 
por sua vez, coloca desafios cada vez maiores diante dos administradores, com especial ênfase no que se refere aos resultados financeiros, à qualidade dos produtos e serviços, à preservação do meio ambiente, aos cuidados com a saúde e segurança das pessoas e à responsabilidade social.

Para auxiliar os administradores nessa tarefa, há organizações e pesquisadores que trabalham há anos na criação de diretrizes na forma de Metaregras para determinados setores ou processos gerenciais. Essas Metaregras, na forma de PSGs, vêm sendo adotadas de forma predominantemente voluntária por muitas empresas e inteiros setores (BRUNSSON; JACOBSSON, 2005). Este estudo pode, portanto, contribuir para a área da administração geral no sentido de:

a) Auxiliar o trabalho das organizações e pesquisadores citados acima;

b) Divulgar, na academia e nas empresas, as possibilidades de aplicação e os resultados dos PSGs;

c) Auxiliar os administradores em suas decisões sobre desenvolvimento organizacional;

d) Contribuir para a criação de organizações mais responsáveis sob as perspectivas sociais e ambientais;

e) Indicar novas alternativas de pesquisa na área. 


\section{FUNDAMENTAÇÃO TEÓRICA}

\subsection{Considerações iniciais}

Esta tese tem como ponto de partida a idéia de que regras são importantes para dar identidade, definir as fronteiras, garantir o controle, estabelecer a coordenação e promover a cooperação de forma eficiente e eficaz. As regras que regem a organização podem ser formais ou informais (GERTH; MILLS, 1961) e, apesar deste estudo se concentrar nas primeiras, não ignora o efeito das últimas.

Criar regras que funcionem não é uma coisa simples. Da mesma forma que regras moldam as organizações e as pessoas, as pessoas e as organizações influenciam a escolha, a evolução e a troca de suas regras. Em 1767, o pensador liberal escocês Adam Ferguson já expressava a sua visão de que a criação das instituições humanas - que são baseadas em regras negociadas dentro da sociedade ou grupos - refletia uma dinâmica complexa:

O conjunto da humanidade é dirigido em suas instituições e medidas, pelas circunstâncias nas quais estão inseridos; e raramente são desviados de seu caminho para seguir o plano de qualquer projetista único.

Cada passo e cada movimento da multidão, mesmo nas que se chamam de eras iluminadas, são feitos com igual cegueira para o futuro; e nações tropeçam sobre instituições, as quais são de fato resultados da ação humana, mas não a execução de projeto humano. ${ }^{3}$ (FERGUSON, 1999, p. 119).

Ferguson expressa a idéia de que as ações que definem as regras (leis, acordos, contratos) que formam as instituições humanas, dada a efetiva “cegueira” em relação ao futuro, não são fruto de decisões de indivíduos conscientes das conseqüências plenas de seus atos. Regras e sociedade evoluem em conjunto, paralelamente, em um processo de mútua causalidade, em que regras básicas sobre moral e ética servem de guia fundamental que dirige a sociedade na criação de regras que fundamentam a suas instituições. Essas são testadas na prática e as mais eficazes permanecem, sem a necessidade de interferência de um poder central promotor de um "projeto humano".

\footnotetext{
3 The crowd of mankind, are directed in their establishments and measures, by the circumstances in which they are placed; and seldom are turned from their way, to follow the plan of any single projector.

Every step and every movement of the multitude, even in what are termed enlightened ages, are made with equal blindness to the future; and nations stumble upon establishments, which are indeed the result of human action, but not the execution of human design
} 
Em contraposição a essas idéias, está a linha de pensamento que considera possível e necessária a existência de um planejamento e um controle central nas instituições para lhes dar uma direção e garantir a sua eficácia. As estruturas burocráticas centralizadoras de decisões e a ampla adoção de regras impostas pelo topo, seguidas de forma disciplinada, são a expressão mais evidente dessa tradição nas organizações. Por sua ligação com a idéia de “machine bureaucracy” (MINTZBERG, 1993, p. 163), as regras são, portanto, vistas, com freqüência, como sinônimo de rigidez organizacional e estruturas centralizadas de comando e controle.

Apesar de ainda presente em inúmeras organizações, a capacidade de uma estrutura organizacional burocrática se adaptar a um ambiente de negócios fluido e em rápida mutação tem sido freqüentemente colocada em dúvida. Os problemas levantados são muitos e, entre eles, pode-se destacar:

a) Surgem problemas de coordenação dado o distanciamento físico entre os agentes e devido ao tempo necessário para as informações fluírem e serem compreendidas;

b) Surgem problemas de cooperação dada a dificuldade de compreensão dos objetivos organizacionais e os conflitos de interesse gerados pelas regras;

c) Regras vistas como um fim em si mesmo, promovem a proliferação de regras desconectadas dos objetivos organizacionais;

d) Administradores contratados usam a burocracia para promover seus interesses em detrimento dos interesses da organização e dos acionistas;

e) A racionalidade limitada dos agentes, agravada pela estrutura que encobre ainda mais as relações de causa-efeito, impede decisões eficientes e eficazes;

f) A sensibilidade às condições iniciais, a não-linearidade e o intervalo de tempo entre ações e conseqüências originam um ambiente complexo que impede previsões sobre as conseqüências de ações no médio e longo prazo.

A lista acima foi elaborada com base, principalmente, nos seguintes autores que se debruçaram sobre uma ou mais destas questões: Hayek (1945), Gerth e Mills (1961), Barnard (1968), Arrow (1974), Alchian e Demsetz (1972), Jensen e Meckling (1976), Galbraith (1997), Klein et al (1978), Weber (1978), March (1988), Mintzberg (1989 e 1993), Cyert e March (1992), Milgrom e Roberts (1992), Perrow (1993), March e Simon (1993), Williamson 
(1996), Simon (1997), Forrester (1999 (a) e (b)), Axelrod e Cohen (1999), Sterman (2000), Stacey (2001) e Giovannini e Kruglianskas (2004).

Dada essa situação, as organizações estão, há muito tempo, à procura de alternativas que combinem a relativa segurança e familiaridade das estruturas burocráticas, com formas de administrar que minimizem ou eliminem os problemas acima citados.

Neste sentido, o presente estudo se propõe a desenvolver argumentos para sustentar a hipótese de que certos tipos de regras podem promover a sobrevivência, a eficiência e a eficácia das organizações. Esses tipos de regras não são as regras organizacionais em si, mas regras a serem seguidas para a criação e enforcement dos sistemas de regras organizacionais. Daí a sua classificação como Metaregras. Todos os padrões de regras que possuem estas características são chamados nesta tese de Padrões para Sistemas de Gestão (PSGs). Ao longo da revisão bibliográfica serão expostas e comentadas as teorias que embasam essa hipótese.

Teorias, escolas, abordagens, conceitos e técnicas como, por exemplo, o Balanced Scorecard (KAPLAN; NORTON, 1996), o Six Sigma (DE FEO; BARNARD, 2004) e o The Fifth Discipline Fieldbook (SENGE et al, 1994) não são considerados, aqui, PSGs.

O mais amplo PSG divulgado no Brasil - mas não o mais divulgado - é, provavelmente, o Modelo de Excelência de Gestão (MEG) da Fundação Nacional de Qualidade (FNQ, 2008). Esse PSG abrange toda a estrutura organizacional da empresa e pode ser considerado como uma evolução dos conceitos difundidos pelo movimento do Total Quality Management (TQM) (EASTON; JARREL, 1998). Derivadas desse movimento, também são as normas ABNT/ISO (ABNT, 2000a e 2004; ISO, 2002) e muitos outros PSGs. Os detalhes relevantes do TQM, do MEG e das normas ABNT/ISO serão explorados mais à frente, mas agora é necessário destacar alguns conceitos chave.

Em primeiro lugar, deve-se considerar que empresas podem optar por criar suas próprias Metaregras, sem precisar adotar PSGs em seu lugar. Mas esse é um trabalho que tem sido sub-contratado com cada vez maior freqüência devido, possivelmente, a quatro principais motivos 
O primeiro é a economia de escala. Entidades como a Fundação Nacional da Qualidade (FNQ), Associação Brasileira de Normas Técnicas (ABNT) e a International Organization for Standardization (ISO) se dedicam a isso há anos e têm conseguido elaborar PSGs adotados nos mais diferentes setores e empresas de todos os tamanhos. Uma empresa que desejasse desenvolver seu próprio conjunto de Metaregras arcaria com custos significativos e com uma maior incerteza sobre os resultados. Soma-se o fato de que as organizações citadas acima não têm fins lucrativos, são custeadas por governos, associados e doações, e disponibilizam gratuitamente seus PSGs. Além disso, dado que a adesão a esses padrões é voluntária, seu sucesso depende, também, de uma qualidade que atenda as necessidades do público alvo. Pode-se supor assim, dada sua disseminação, que esses PSGs têm atendido as essas necessidades. Mesmo nos casos de imposição de PSGs por exigência de clientes, o fato dos clientes sacrificarem voluntariamente sua amplitude de escolha a fornecedores que adotam os PSGs exigidos, significa que esperam resultados positivos dessa imposição.

O segundo motivo possível é acesso ao conhecimento. Nas entidades citadas acima, por agregarem pessoas e grupos interessados na criação de padrões e na divulgação das melhores práticas organizacionais para benefício mútuo, flui de forma relativamente livre o conhecimento gerado e acumulado por profissionais atuando nas mais diversas organizações. Assim, as práticas e técnicas administrativas são testadas e melhoradas no dia-a-dia das empresas onde esses profissionais atuam e, se consideradas eficientes e eficazes, são incorporadas aos PSGs após análise e aprovação por instâncias coletivas dentro de cada entidade. Uma empresa dificilmente teria acesso ao conhecimento gerado por concorrentes até mesmo por empresas de outros setores sem interesse e tempo para divulgar suas práticas a terceiros - e ficaria limitada às suas próprias experiências ou de profissionais contratados.

O terceiro motivo é a facilitação da coordenação e da cooperação. Criando homogeneidade e similaridade de linguagem e procedimentos, os PSGs facilitam a coordenação e cooperação entre pessoas - de empresas do mesmo grupo ou entre clientes e fornecedores - com culturas diferentes ou fisicamente distantes. Criam, dessa forma, um forte elemento de ordem global (BRUNSSON; JACOBSSON, 2005).

Finalmente, sub-contratar um PSG libera a administração para se concentrar no negócio. Em um ambiente onde capacidade intelectual e tempo são recursos cada vez mais escassos, adotar um PSGs libera a administração da empresa para se concentrar nos aspectos estratégicos e na 
gestão de exceções e crises. PSGs bem implementados permitem transformar em rotinas relativamente auto-gerenciáveis diversos processos críticos para a eficácia da empresas reduzindo, o nível de atenção exigido pela administração e esses processos.

O segundo conceito chave é o da adequação de Metaregras padronizadas e genéricas para empresas e organizações diferentes. É possível um mesmo conjunto de Metaregras atender empresas dos mais diversos setores, regiões e tamanhos? Pode parecer impossível que um mesmo conjunto de Metaregras seja o melhor conjunto para qualquer empresa, mas essa não é provavelmente a melhor forma de colocar a questão. Para cada organização há um conjunto ideal de Metaregras único, diferente de qualquer outro, já que não existem organizações idênticas em contextos idênticos. Mas, como já se comentou acima, elaborar esse conjunto único de Metaregras teria possivelmente um custo demasiadamente elevado para a grande maioria das organizações.

Assim, as perguntas relevantes sobre a adequação de um conjunto padrão de regras para diferentes organizações devem ser voltadas para (1) a lógica interna das razões que indicam o uso de Metaregras nas organizações e (2) para a avaliação empírica dos resultados das empresas que os adotam comparados com as que não o fazem. Esta revisão bibliográfica procura responder a essas perguntas.

A primeira questão, mais ampla, será respondida em duas partes. Primeiro descrevendo onde os PSGs se encaixam na administração e na teoria das organizações (seção 2.2) e, posteriormente, como os PSGs podem melhorar o desempenho das organizações (seção 2.3). Nessa segunda parte o método adotado é o de descrever os desafios apontados pela literatura e mostrar como os PSGs apóiam os administradores na sua superação.

A segunda questão será respondida mostrando o que existe na literatura acadêmica sobre a influência dos PSGs (seção 2.4) no desempenho das organizações e, posteriormente, através de uma pesquisa empírica sobre a influência dos PSGs nas indústrias de autopeças brasileiro (seção 4). 


\subsection{Administração, organizações e Padrões para Sistemas de Gestão}

\subsubsection{O estudo das organizações e suas regras}

Como estudar as organizações e suas regras?

Na literatura ligada à administração, há inúmeras formas de se abordar as organizações já que elas despertam o interesse de disciplinas diversas. Desde as análises da divisão do trabalho feitas por Adam Smith (SMITH, 1979) até as mais recentes abordagens - economia das organizações e instituições, perspectivas evolucionárias e de ecologia de organizações, Teoria da Complexidade, entre outras - o conhecimento sobre as organizações vem se acumulando.

Apesar de "escolas” de pensamento sobre organizações surgirem continuamente, muitas delas são apenas reapresentações das mesmas idéias com outras palavras. Procurou-se, portanto, pesquisar os trabalhos que propuseram idéias originais - mas que já passaram pelo crivo de seus pares e da comunidade da administração - mesmo que nem todos sejam extremamente novos.

De qualquer forma, há, sem dúvida, abordagens recentes que expandiram o conhecimento na área e, a algumas delas, como se verá, têm aplicação na criação de novas técnicas e ferramentas de administração ligadas ao surgimento dos PSGs.

Algumas das melhores definições de organização para a administração - especialmente porque se preocupam com a necessidade de operacionalizar proposições para sujeitá-las a testes empíricos - são encontradas nos trabalhos dos teóricos e pesquisadores de organizações ligados à economia. Para esta tese, dada a natureza dos PSGs, deu-se prioridade às abordagens ligadas à Teoria de Sistemas e as que reconhecem as limitações da racionalidade nas decisões humanas. Essa abordagem pode ser resumida inicialmente pela frase abaixo:

“Organizações são sistemas de ação coordenada entre indivíduos e grupos cujas preferências, informação, interesses, ou conhecimento diferem.” 4 (MARCH; SIMON, 1993, p.2).

\footnotetext{
4 "Organizations are systems of coordinated action among individuals and groups whose preferences, information, interests, or knowledge differ"
} 
Essa definição ressalta alguns aspectos das organizações que merecem ser explorados. O primeiro é o fato de que as organizações são sistemas. Desde as primeiras expressões da Teoria de Sistemas que influenciaram a administração, a mais notável provavelmente representada por Bertalanffy (1998), tem ficado cada vez mais claro que as empresas são sistemas abertos, dinâmicos e adaptativos (SENGE, 1990; FORRESTER, 1999 (a), (b); STERMAN, 2000; SIMON, 2001). Nesse sentido, as práticas administrativas vêm sendo adaptadas para tratar as organizações como coleções de processos interligados entre si em com o ambiente externo. O caráter dinâmico e adaptativo desses processos também faz aumentar a importância tanto da rápida e segura obtenção, análise e armazenamento de dados, como também dos processos decisórios e da implementação das decisões.

O segundo aspecto ressaltado pela definição acima é o da coordenação. Na medida em que o trabalho é dividido, por necessidades de economias de escala ou especialização técnica, e na medida em que as empresas crescem, a coordenação das pessoas e de grupos se torna cada vez mais difícil e cara, reduzindo os ganhos obtidos pela própria divisão do trabalho. A degradação da coordenação e seus reflexos sobre a eficiência e a eficácia das empresas continuam estando entre as principais preocupações dos administradores na medida em que as empresas ficam cada vez maiores e o ambiente de negócios muda cada vez mais rápido:

Sob a maioria das circunstâncias, portanto, a qualidade da coordenação é o fator crucial na sobrevivência da organização. ${ }^{5}$ (BARNARD, 1968, p. 256).

O papel fundamental da administração em organizações é assegurar coordenação. A sobrevivência e sucesso da organização é crucialmente dependente em se alcançar efetivamente coordenação das ações de muitos dos indivíduos e subgrupos na organização, em assegurar que todos eles estão focando seus esforços em levar a cabo um plano de ação factível que irá promover as metas da organização, e em garantir que o plano está ajustado apropriadamente para permanecer factível e apropriado assim que mudam as circunstâncias. ${ }^{6}$ (MILGROM; ROBERTS, 1992, p. 114).

O terceiro aspecto ressaltado pela definição de March e Simon é o da ação. Já em 1938 Barnard (1968, p. 216 e 52) esclarecia: “As funções executivas servem para manter um sistema de esforço cooperativo” 7; “Cooperação requer algo para fazer” ${ }^{8}$. As empresas

\footnotetext{
${ }^{5}$ Under most circumstances, therefore, the quality of coordination is the crucial factor in the survival of the organization

6 The key role of management in organizations is to ensure coordination. The survival and success of the organization is crucially dependent on achieving effective coordination of the actions of the many individuals and subgroups in the organization, on making sure that they all are focusing their efforts on carrying out a feasible plan of action that will promote the organization's goals, and on assuring that the plan is adjusted appropriately to remain feasible and appropriate as circumstances change

7 "The executive functions serve to maintain a system of cooperative effort"

8 "Cooperation requires something to do"
} 
existem para fazer algo concreto, quer seja um serviço ou um produto, mas não é uma coisa trivial definir claramente o que a empresa deve fazer para ter sucesso e o que cada pessoa na organização deve fazer para contribuir para o "esforço cooperativo”. Quando se fala em ação, um dos primeiros autores que vem a mente é Frederick Taylor (MAXIMIANO, 1997) e seus estudos de sistematização do trabalho visando o aumento da eficiência. Mas, atualmente, quando se discutem as ações desenvolvidas dentro das organizações, é necessário envolver desde o processo de planejamento estratégico até o controle da eficácia e eficiência das ações.

É no processo de planejamento estratégico que se define o que a empresa pretende objetivamente alcançar e quais as ações que irão tornar isso realidade. A forma como se desenvolve o planejamento estratégico não é central para este estudo, mas a estrutura organizacional é influenciada pelas decisões estratégicas assim como ela as influencia. Esse tipo de relação causal também existe entre a estrutura organizacional e a eficiência e eficácia da empresa.

Sempre no tema "esforço cooperativo", há muitas práticas organizacionais atuais voltadas à melhora da eficiência e eficácia estão baseadas nas abordagens do movimento do TQM (HODGE et al, 2002, p. 74). A mais difundida atualmente é, provavelmente, o Balanced Scorecard de Kaplan e Norton (1996) cujo objetivo é o de transformar decisões estratégicas em ações eficientes e eficazes. As idéias do movimento de TQM, no entanto, permeiam diversas outras metodologias e técnicas, entre elas os PSGs propostos pela International Organization for Standardization - ISO (ABNT, 2000a e 2004; ISO, 2002) e pela Fundação Nacional da Qualidade (FNQ, 2008).

O quarto aspecto das organizações ressaltado por March e Simon é o de que elas são compostas por pessoas e grupos. A escola que mais se dedicou ao estudo das pessoas nas organizações foi chamada de Relações Humanas, cujo início é representado pelos estudos de Mayo sobre o Hawthorne Effect (JONES, 1992), ainda das décadas de 1920 e 1930. A questão central é a motivação das pessoas para o trabalho, fator reconhecido como condicionante da quantidade e da qualidade de sua produção.

Nesse contexto ganham importância a moral do grupo, a atuação das lideranças e as influências mútuas entre todos os atores. Katz e Khan (1978) estão entre os principais autores dessa escola de pensamento e agregaram a visão da organização como sistema aberto com os 
conceitos da psicologia social. O uso que fazem dos conceitos de F. H. Allport (1937) explica essa abordagem e antecipa idéias das abordagens evolucionárias e da Teoria da Complexidade na administração:

\begin{abstract}
Causalidade, na visão estrutural, não é histórica, nem linear, mas contínua, dependente do tempo e reciprocamente cíclica [...] Um não procura por ela na sociedade e nem no indivíduo, tradicionalmente vistos como níveis separados de agência, mas nos padrões compostos de estruturação que são a realidade essencial embasando ambos. ${ }^{9}$ (KATZ; KHAN, 1978, p. 7-8).
\end{abstract}

As atitudes e ações das pessoas emergem de um processo de mútua causalidade no qual, ao mesmo tempo em que são influenciadas pelos comportamentos dos grupos e da organização, também influenciam esses mesmos comportamentos.

O quinto e último aspecto levantado pela definição de March e Simon se refere à diferença entre preferências, informação, interesses e conhecimento das pessoas e grupos que compõe a organização. Esse aspecto, além de envolver os conceitos da escola de Relações Humanas, introduz o que Perrow (1993, p. 119 e 219) chama de modelo neo-weberiano e de teorias econômicas das organizações. Os neo-weberianos reuniriam nomes como o de March, Simon, Cyert e suas propostas seriam uma evolução do modelo burocrático de Weber. Mas, além dessa evolução, os neo-weberianos oferecem também avanços na compreensão do comportamento organizacional oferecida anteriormente pela economia e administração.

Em “Organizations” (MARCH; SIMON, 1993) e “Administrative Behavior” (SIMON, 1997), os autores operacionalizam diversos conceitos e proposições da administração, aprimoram as definições de organização esclarecendo o campo de estudo da teoria das organizações, focam o processo decisório e introduzem conceitos como racionalidade limitada, satisficing e organizational slack.

Ainda segundo Perrow, as teorias econômicas das organizações englobam os conceitos ligados à economia dos neo-weberianos e, também, conceitos como teoria da agência, seleção adversa, risco moral, direitos de propriedade, economia dos custos de transação e toda uma série de idéias que compõem o que, entre outras definições, pode ser chamada de Nova Economia Institucional (NIE - New Institutional Economics) e reúne pesquisadores como

\footnotetext{
${ }^{9}$ Causation, in the structural view, is not historical, nor linear, but continuous, time independent and reciprocally cyclical [...] One looks for it neither in society nor in the individual, as traditionally seen as separate levels of agencies, but in the compounded patterns of structuring which are the essential reality underlying both.
} 
Douglas North, Ronald Coase e Oliver Williamson (MENARD; SHIRLEY, 2005). Essa linha de pensamento é uma das mestras desta tese.

Outras definições de organização também são úteis para desenvolver os argumentos desta revisão da bibliografia. A que segue ressalta a importância das regras da organização para seu funcionamento e a formação de sua identidade:

Organizações são coleções de papéis e identidades, conjuntos de regras pelas quais um comportamento apropriado é pareado com situações reconhecidas. Alguns desses conjuntos são importados para dentro da organização empregando profissionais; contadores fazem o que contadores são treinados para fazer. Outros conjuntos são desenvolvidos em uma organização através experiência coletiva e guardados na organização como procedimentos padrão [...] Organizações transformam suas próprias experiências, como também conhecimento de outros, em regras que são mantidas e implementadas apesar da rotatividade de pessoal e sem necessária compreensão das suas bases. Como resultado, os processos de geração, mudança, evocação, e esquecimento de regras se tornam essenciais em analisar e entender organizações. ${ }^{10}$ (MARCH; SIMON, 1993, p. 12).

Essa definição é talvez a mais importante desta seção, pois contem diversas proposições que fundamentam a análise desta tese:

a) Organizações são coleções de regras: a idéia tem paralelo com o conceito de que a empresa seria um conjunto de contratos, ou “nexus of contracts” (MILGROM; ROBERTS, 1992, p. 20, ALCHIAN; DEMSETZ, 1972, p. 794). Independente de sua forma - contratos, procedimentos formais ou acordos informais - as regras que regem as organizações determinam seu comportamento e, também, são reflexo de sua história.

b) Regras acoplam comportamentos a situações: regras definem qual dos comportamentos, que fazem parte de um repertório pré-definido, deve ser adotado em função de uma determinada situação, também pré-definida. Situações não previstas também são um tipo de situação pré-definida e um tipo pré-determinado de comportamento deve estar ligado a ela.

c) Regras podem ser criadas internamente ou importadas: regras podem ser construídas internamente, geralmente com base no aprendizado organizacional, ou introduzidas

\footnotetext{
${ }^{10}$ Organizations are collections of roles and identities, assemblages of rules by which appropriate behavior is paired with recognized situations. Some of these assemblages are imported into an organization by employing professional; accountants do what accountants are trained to do. Other assemblages are developed in an organization through collective experience and stored in the organization as standard procedures [...] Organizations turn their own experiences, as well experience and knowledge of others, into rules that are maintained and implemented despite turnover of personnel and without necessary comprehension of their bases. As a result, the processes for generating, changing, evoking, and forgetting rules become essential in analyzing and understanding organizations
} 
por pessoas novas que chegam à organização trazendo suas experiências, ou pela adoção de regras desenvolvidas por terceiros (consultores, ERPs, ONGs).

d) Regras são guardadas pela organização na forma de procedimentos padrão: a consolidação de regras na organização ocorre quando as mesmas se tornam procedimentos padronizados. Como exemplo podem-se citar declarações de valores e princípios, de visão e missão, manuais de qualidade, procedimentos formais e informais, instruções de trabalho, rotinas contidas em softwares de gestão e automação, etc.

e) Regras se mantêm apesar da troca das pessoas da organização: como passam a fazer parte da própria estrutura organizacional, regras que realmente se tornam procedimentos padronizados passam a ter uma vida independente da troca rotineira de pessoas.

f) Processos para gerar, mudar, requerer e esquecer regras são essenciais para analisar e entender organizações: a capacidade das organizações de gerar, mudar, requerer e esquecer regras define a capacidade de adaptação das organizações ao contexto onde atual e, portanto, define sua eficiência, eficácia e chances de sobrevivência.

Regras, em uma perspectiva ampla, são normas, regulamentos e expectativas, explícitas ou implícitas, que regulam o comportamento de indivíduos e as interações entre eles (MARCH et al, 2000).

Além do comportamento organizacional, o comportamento individual também é baseado em regras através de uma lógica que March (1994) chama de appropriateness refletida em uma estrutura de regras e definições de identidades: indivíduos agiriam através da combinação de identidades com situações. Nesses casos, um indivíduo se perguntaria: Que tipo de pessoa eu sou? Que tipo de situação é essa? Como uma pessoa como eu age em uma situação como essa? Se aceitarmos essa abordagem, fica clara a importância do conjunto de regras da organização - vista como uma comunidade de pessoas - para o processo decisório individual e o sucesso da organização.

Por outro lado, a importância das regras é questionada por conceitos de "ação baseada em escolhas.” ${ }^{11}$ (MARCH et al, 2000, p. 6 e 7). Essa interpretação relaciona as ações dos

\footnotetext{
11 "choice based action"
} 
indivíduos à antecipação das conseqüências dessas ações, e das ações alternativas, comparadas com um conjunto de preferências. Presume-se que as pessoas avaliam as conseqüências de seus atos e agem de acordo com seus melhores interesses. Nesse caso, as regras são instrumentos usados de acordo com sua utilidade momentânea e são trocadas ou descartadas de acordo com a conveniência dos indivíduos. Podem, por exemplo, ser ferramentas heurísticas para lidar com os problemas de racionalidade limitada levantados por Simon (1961, 1997, 2000, 2001).

Entretanto, como se verá mais à frente, interpretações recentes colocam cada vez mais importância nas regras e instituições (que pode ser vistas como conjuntos coerentes de regras) na definição dos limites nos quais as escolhas racionais dos indivíduos ocorrem. Essas interpretações questionam se as pessoas efetivamente conseguem (a) antecipar as conseqüências de suas ações, (b) avaliar as alternativas e suas conseqüências e (c) comparálas a um conjunto de preferências. Caso não consigam (o que é provável) suas ações não seriam exatamente "baseadas em escolhas", mas baseadas em conjuntos limitados regras que criaram com base em um modelo simplificado a realidade.

Regras também são um elemento muito citado quando se define o que é estrutura organizacional. Repetindo a citação apresentada na introdução:

Estrutura organizacional consiste simplesmente daqueles aspectos do padrão de comportamento na organização que são relativamente estáveis que mudam somente devagar.

[...] para que uma organização se comporte de forma adaptativa, ela precisa de alguns regulamentos e procedimentos estáveis que pode empregar ao desempenhar suas práticas de adaptação. Assim, a todo o momento, os programas da organização para desempenhar suas tarefas são parte de sua estrutura, mas a parte menos estável. Pouco mais estáveis são as regras de troca que determinam quando aplicar um programa, e quando outro. Ainda mais estáveis são os procedimentos que usa para desenvolver, elaborar, instituir e revisar programas." ${ }^{\text {"2 }}$ (MARCH; SIMON, 1993, p.191-192).

Como será apresentado em mais detalhe à frente, esses procedimentos mais estáveis a que se referem os autores são uma definição bastante precisa dos PSGs. A definição é relevante, pois explica porque os PSGs, se corretamente utilizados, não necessariamente limitam a inovação

\footnotetext{
${ }^{12}$ Organization structure consists simply of those aspects of the pattern of behavior in the organization that are relatively stable and that change only slowly.

...in order for an organization to behave adaptively, it needs some stable regulations and procedures that it can employ in carrying out its adaptive practices. Thus, at any given time an organization's programs for performing its tasks are part of its structure, but the least stable part. Slightly more stable are the switching rules that determine when it will apply one program, and when another. Still more stable are the procedures it uses for developing, elaborating, instituting, and revising programs
} 
na organização. Ao contrário, na medida em que disciplinam e estimulam o “desenvolvimento, elaboração, instituição e revisão de programas”, os PSGs podem ser uma importante ferramenta para favorecer a inovação, especialmente nos processos administrativos. Para que a inovação aconteça, decisões e ações precisam ser tomadas em meio a incertezas, conflitos e escassez de recursos. Mais uma vez, uma definição de March e Simon (1993, p. 2) esclarece:

Teorias organizacionais descrevem a delicada conversão de conflito em cooperação, a mobilização de recursos, e a coordenação de esforço que facilita a sobrevivência conjunta da organização e seus membros. $^{13}$

Nesse sentido, este estudo foca nos aspectos de teoria que procuram definir um:

[...] quadro que reconhece que o conjunto de atividades a ser desempenhada não é dado com antecedência, exceto de uma maneira mais geral - que um dos processos muito importantes nas organizações é a elaboração desse conjunto de atividades, e a determinação de quais precisas atividades devem ser desempenhadas em quais precisos tempos e lugares. ${ }^{14}$ (MARCH; SIMON, 1993, p. 45).

O foco aqui são exatamente esses "processos muito importantes": como são definidos, selecionados, iniciados, dirigidos e executados.

\subsubsection{A relação da estrutura organizacional com o desempenho da empresa}

Como o efeito das regras pode chegar ao desempenho da empresa? Nesse sentido, como o administrador pode intervir?

Como já foi comentado, há uma relação de mútua causalidade entre as regras da organização e sua estrutura organizacional. A ilustração 1 mostrada na introdução coloca as regras dentro da estrutura organizacional, como uma parte da mesma.

Por outro lado, Galbraith (1977, p.30-31) propõe uma subdivisão da organização para fins de desenho organizacional (organization design) que coloca as regras organizacionais e a estrutura em uma posição diferente. Ele as considera como duas das cinco variáveis

\footnotetext{
${ }^{13}$ Organization theories describe the delicate conversion of conflict into cooperation, the mobilization of resources, and the coordination of effort that facilitate the joint survival of the organization and its members.

${ }^{14}[. .$.$] framework that recognizes that the set of activities to be performed is not given in advance, except in a$ most general way - that one of the very important processes in organizations is the elaboration of this set of activities, and the determination of which precise activities are to be performed at which precise time and places."
} 
organizacionais sobre as quais um designer organizacional atua. A ilustração 2 abaixo mostra quais são essas 5 variáveis e, através das linhas que as conectam, explicita a influência mútua que todas têm entre si.

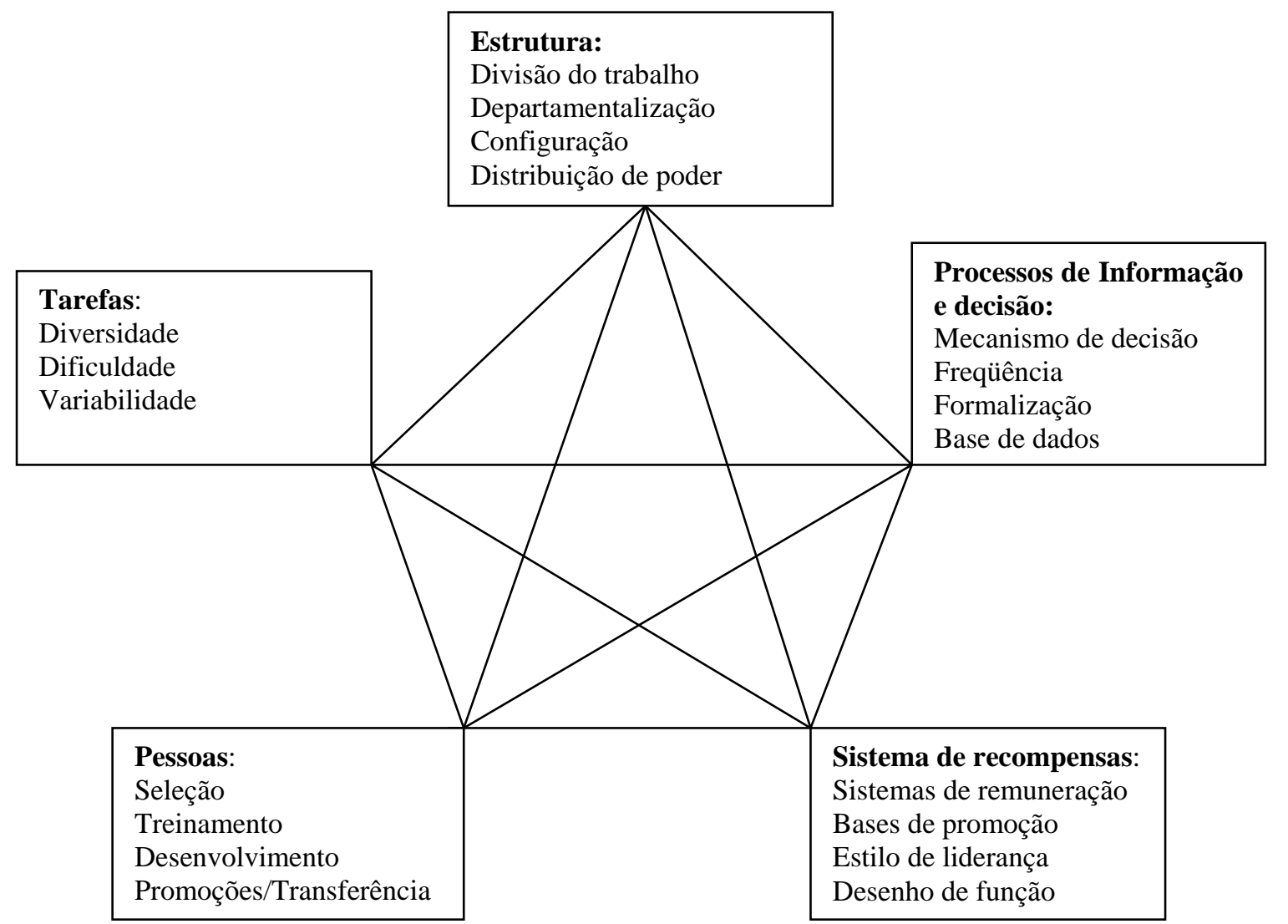

Ilustração 2: Variáveis de desenho organizacional FONTE: adaptado de GALBRAITH (1977)

No modelo conceitual de Galbraith, as regras - chamadas por ele de Processos de Informação e Decisão - estão fora da estrutura organizacional, mas influenciam toda a organização. Mesmo assim, a descrição das regras organizacionais que Galbraith faz em seu modelo está perfeitamente alinhada com a descrição dos sistemas de regras que os PSGs promovem e, portanto, com a proposição da tese de que os PSGs influenciam a estrutura organizacional e a organização.

De acordo com a proposta de Galbraith, o designer organizacional precisa decidir, entre outras coisas, qual o tipo de sistema de regras quer implantar e como irá fazê-lo. Os PSGs têm como finalidade ajudar a encontrar a resposta para ambas as questões. Os PSGs são como sementes que contêm as instruções básicas para a construção de um organismo completo que é o sistema de regras organizacionais. 
Para explicar como se dá esse processo, a ilustração 3 vai um passo atrás na relação causal e procura mostrar onde e como os PSGs podem ser usados pelos administradores para atuar sobre a estrutura organizacional e, conseqüentemente sobre a organização (as linhas pontilhadas representam fronteiras permeáveis à influência do ambiente):

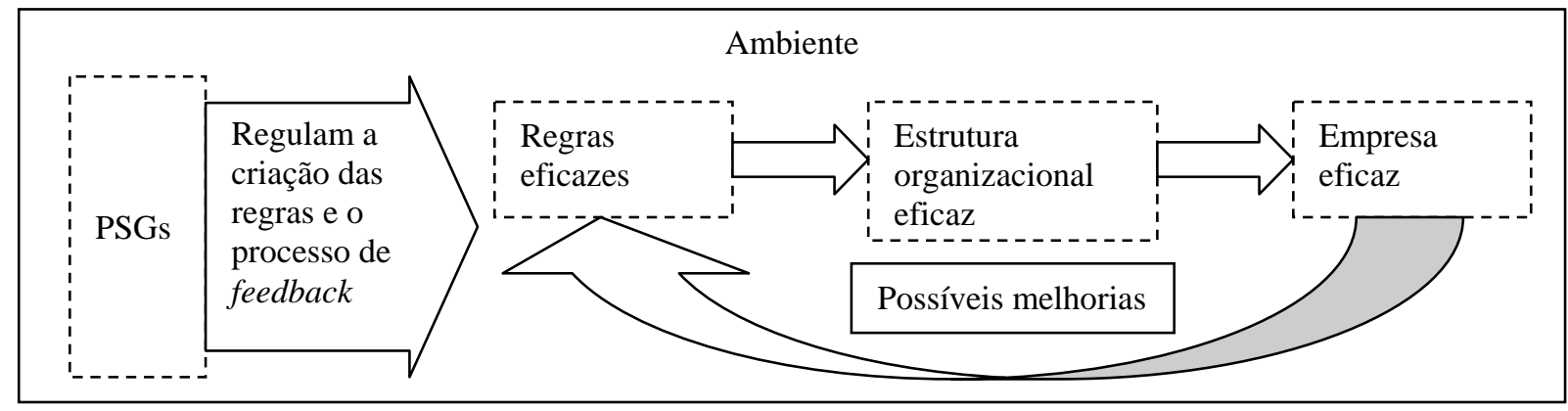

Ilustração 3: A influência dos PSGs na eficácia organizacional

Nesse ponto, para não perder de vista que as organizações são compostas por pessoas, cabe citar o próprio Galbraith:

Em suma, assume-se que uma estrutura conscientemente desenhada baseada nas teorias de organização correntes pode melhorar a eficácia das organizações porque não é provável que a melhor estrutura se desenvolva espontaneamente das interações humanas em um espaço de tempo razoável. Entretanto, uma organização não pode ser desenhada sem as pessoas que irão operar nela. A participação dos membros é necessária não só para a aceitação do novo desenho, as também para gerar o novo design que deve ter em conta as muitas características únicas de cada organização específica. ${ }^{15}$ (GALBRAITH, 1977, p. 9).

Na mesma linha da importância da participação dos membros da organização em seu desenho, March e Simon (1993) sugerem uma forma de dividir as proposições para se alcançar a eficácia nas organizações. Essa divisão assume que o comportamento das organizações é condicionado pelo comportamento de seus membros e, portanto, as proposições sobre comportamento organizacional podem ser divididas da mesma forma como se distinguem os comportamentos possíveis dos membros das organizações:

a) Membros da organização são instrumentos passivos capazes de executar trabalhos e aceitar comandos, mas não iniciar ações ou exercer influência de modo significativo;

\footnotetext{
${ }^{15}$ In summary, it is assumed that a consciously designed structure based on the current theories of organization can improve the effectiveness of organizations because the best structure is not likely to evolve spontaneously out of human interactions over a reasonable time span. However, an organization cannot be designed without the people who are to operate within it. Participation of members is needed not only for acceptance of the new design but also to generate the new design which must take account of the many unique features of any specific organization.
} 
b) Membros das organizações trazem consigo atitudes, valores e objetivos e precisam ser motivados e induzidos para participar no sistema de comportamento organizacional já que esses fatores não estão completamente alinhados com os da organização;

c) Membros da organização são tomadores de decisões e solucionadores de problemas e os processos de percepção e raciocínio são centrais na explicação do comportamento organizacional.

Os grupos acima refletem aproximadamente as proposições das escolas de administração científica, relações humanas e análise de decisão, respectivamente, mas a divisão proposta reflete melhor o conceito de que as escolas são explicações complementares de todo o espectro do comportamento humano nas organizações. Assim, reforçam a importância de se considerar o processo decisório dos membros da organização com fator crucial na construção de sistemas de regras organizacionais. Esse é um dos conceitos que embasam essa tese.

Como o administrador pode atuar neste contexto? Que tipo de contribuição se espera de um administrador, no papel de designer de uma organização, se ele depende, para desempenhá-lo, da cooperação dos outros membros? March e Simon (1993, p.2) ajudam a esclarecer:

Essas contribuições para a sobrevivência [da organização] são alcançadas primariamente através do controle sobre a informação, identidades, estórias e incentivos. Organizações processam e canalizam informação. Elas dão forma a metas e lealdades dos seus participantes. Elas criam estórias compartilhadas - e ethos organizacionais que incluem crenças comuns e práticas padrão. Elas oferecem incentivos para comportamentos apropriados.

O controle eficaz sobre processos organizacionais é limitado, entretanto, pelas incertezas e ambigüidades da vida, pelas limitadas capacidades cognitivas e afetivas dos atores humanos, pelas complexidades de balancear trade-offs através de tempo e espaço, e pelas ameaças da competição. $^{16}$

Na medida em que atores organizacionais negociam entre si, buscando vantagens cooperativas e competitivas, eles lidam com essas limitações através de cálculos, planejamento e análise, aprendendo da sua experiência e da experiência e conhecimento de outros, e criando e usando sistemas de regras, procedimentos e interpretações que conservam entendimentos em formas

\footnotetext{
${ }^{16}$ These contributions to survival are accomplished primarily through control over information, identities, stories, and incentives. Organizations processes and channel information. They shape the goals and loyalties of their participants. They create shared stories - and organizational ethos that includes common beliefs and standard practices. They offer incentives for appropriate behaviors.

Effective control over organizational processes is limited, however, by the uncertainties and ambiguities of life, by the limited cognitive and affective capabilities of human actors, by the complexities of balancing trade-offs across time and space, and by threats of competition.
} 
facilmente recuperáveis. Eles costuram culturas, acordos, estruturas e crenças de suporte em torno de suas atividades. ${ }^{17}$

A relação da administração com a organização é condicionada, também, pelos limites cognitivos dos membros da organização - e, supostamente, dos administradores:

[...] as características básicas da estrutura e função organizacional deriva das características dos processos humanos de solução de problemas e escolha racional. Devido aos limites das capacidades intelectivas humanas em comparação com as complexidades dos problemas que os indivíduos e organizações encaram comportamento racional clama por modelos simplificados que capturam as principais características de um problema sem capturar todas suas complexidades. ${ }^{18}$ (MARCH; SIMON, 1993, p.190).

Segundo os autores, os modelos simplificados necessários para o "comportamento racional” deveriam possuir algumas características:

a) Otimização é substituída por "satisficing” - isto é, que níveis satisfatórios das variáveis em questão são alcançados;

b) Alternativas de ação e conseqüências de ação são descobertas seqüencialmente através de um processo de busca;

c) Repertórios de programas de ação são desenvolvidos por organizações e indivíduos, e estes servem como alternativas de escolha em situações recorrentes;

d) Cada programa de ação específica trata com uma amplitude restrita de situações e uma amplitude restrita de conseqüências;

e) Cada programa de ação é capaz de ser executado semi-independentemente dos outros - eles estão acoplados, mas com folgas entre si.

Como se verá mais adiante, os PSGs procuram criar estruturas com essas características. O conceito contido nos PSGs é novamente apresentado quando se procura definir as condições para que as organizações sejam realmente sistemas adaptativos:

Se uma organização possui um repertório de programas, então ela é adaptativa no curto prazo na medida em que ela tem procedimentos para selecionar desse repertório um programa apropriado para cada situação específica que surgir. O processo usado para selecionar um programa

\footnotetext{
17 As organizational actors deal with each other, seeking cooperative and competitive advantage, they cope with these limitations by calculation, planning and analysis, by learning from their experience and the experience and knowledge of others, and by creating and using systems of rules, procedures, and interpretations that stores understandings in easily retrievable form. They weave supportive cultures, agreements, structures, and beliefs around their activities.

${ }^{18}$ [...] the basic features of organization structure and function derive from the characteristics of human problem-solving processes and rational human choice. Because of the limits of human intellective capacities in comparison with the complexities of the problems that individuals and organizations face, rational behavior calls for simplified models that capture the main features of a problem without capturing all its complexities
} 
apropriado é o fulcro no qual repousa a adaptabilidade de curto prazo. Se, agora, a organização possui processos para somar ao seu repertório de programas ou para modificar programas em seu repertório, esses processos se tornam fulcro ainda mais básico para alcançar adaptabilidade de longo prazo. Adaptabilidade de curto prazo corresponde ao que comumente chamamos de solução de problemas, adaptabilidade de longo prazo a aprendizado. ${ }^{19}$ (MARCH; SIMON, 1993, p. 192).

Os PSGs são as regras que definem exatamente os processos de criação e modificação de programas do repertório da organização. PSGs também exigem a criação e manutenção de processos para o registro do desempenho das organizações e sua comparação com as expectativas dos stakeholders. Ocorrendo uma, assim definida, “não-conformidade” e, na análise de causas, ficar caracterizada a inadequação de determinado procedimento (programa) e a inexistência de outro adequado, os PSGs demandam que seja desenvolvido novo procedimento que garanta a conformidade das ações. Além disso, como também se exige o registro formal e divulgação interna de todo esse processo, garante-se o aprendizado organizacional. Bons PSGs são exatamente aqueles mais eficientes e eficazes para essa função.

Dessa forma, os PSGs poderiam ser os modelos simplificados necessários para os administradores darem racionalidade aos processos de solução de problemas, adaptabilidade de longo prazo e aprendizado.

\subsubsection{Os Padrões para Sistemas de Gestão (PSGs)}

O que são PSGs? Como são criados e como funcionam?

Os PSGs são conjuntos de regras voltados à criação e manutenção de regras para processos de gestão para diversas áreas da organização. Alguns, como o MEG (FNQ, 2008), abrangem praticamente toda a administração de uma empresa. Outros se limitam a processos de gestão restritos a determinadas áreas. Esses conjuntos de regras são chamados por Brunsson e Jacobsson (2005) de Standards. Neste trabalho os termos Standards, padrões e normas são usados com o mesmo significado dado pelos autores para Standards.

\footnotetext{
${ }^{19}$ If an organization has a repertory of programs, then it is adaptive in the short run insofar as it has procedures for selecting from this repertory a program appropriate to each specific situation that arises. The process used to select an appropriate program is the "fulcrum" on which short-run adaptiveness rests. If, now, the organization has processes for adding to its repertory of programs or for modifying programs in the repertory, these processes become still more basic fulcra for accomplishing longer-run adaptiveness. Short run adaptiveness corresponds to what we ordinarily call problem-solving, long-run adaptiveness to learning.
} 
Os PSGs são a expressão, na administração de organizações, de um movimento de padronização que cresce continuamente. Apesar da pouca atenção que tem recebido da literatura acadêmica, os padrões permeiam nossas vidas com cada vez maior intensidade. Hoje há padrões para o desenho e qualidade de telefones, para como empresas devem relatar seus resultados financeiros, como contratos devem ser escritos, quais as políticas ambientais os estados devem perseguir, como crianças devem ser criadas e educadas e como o tênis deve ser jogado (BRUNSSON; JACOBSSON, 2005).

Os autores citados compuseram a única obra acadêmica relevante que se dedica à analise ampla dos efeitos e da importância dos padrões em vários aspectos da vida econômica e organizacional. Esse fato, se de um lado, mostra a pouca atenção dedicada ao assunto, também ressalta a abundância de oportunidades de pesquisa já que é inegável, como demonstram os autores, que os padrões são um elemento indispensável para o entendimento das atuais organizações e de sua dinâmica.

Padrões facilitam a coordenação e a cooperação em um ambiente complexo e de escala global. Ajudam a criar uma ordem no mundo moderno que não seria possível sem eles. Padrões são formas de regulação e controle que podem ser consideradas, hoje, quase tão cruciais como hierarquias e mercados. Padrões também recebem as mesmas críticas desses últimos no sentido em que, de um lado, podem ser responsáveis por excessos de regras ou, por outro lado, podem ser insuficientes para desempenhar o que deles se espera.

Mas quem é, hoje, responsável por criar padrões (ou Standards, ou normas)? Os governos são, obviamente, os maiores criadores de padrões, na forma de leis que valem para dentro de suas fronteiras. Países também se reúnem em organizações supranacionais para criar normas: OCDE, UNESCO, Nações Unidas e União Européia criam um grande número de normas.

Mas não é por esses padrões que se interessa este estudo. Há inúmeras organizações não governamentais que criam e disseminam padrões dentro de países e pelo mundo. A Associação Brasileira de Normas Técnicas (ABNT), a Fundação Nacional de Qualidade (FNQ), a American National Standards Institute (ANSI), a Britsh Standards Institution (BSI) e a Deutches Institut für Normung (DIN) recebem, muitas vezes do governo, a incumbência de criar e manter normas. Essas instituições também colaboram, em instituições internacionais normatizadoras criadas após a segunda guerra mundial, como o Comité Européen de 
Normatisation (CEN) e a International Organization for Standardization (ISO), para a criação de normas de maior abrangência. Todas são instituições privadas e que são financiadas em sua maior parte por empresas que fazem parte dos comitês de normas e que tem interesse no desenvolvimento de normas para seus setores. Por exemplo, a ABNT e a FNQ são financiadas por empresas associadas e a ABNT, por sua vez, participa dos comitês da ISO.

Há também exemplos de normas restritas a determinados setores, criadas por associações setoriais para regulamentar certos aspectos dos negócios. A “Atuação Responsável” da ABIQUIM (2008) é um exemplo desse tipo de norma.

Por serem privadas e não possuírem a força coercitiva do estado, essas organizações precisam persuadir as empresas e outras organizações a adotarem suas normas. A adoção é geralmente voluntária e, portanto, as normas precisam oferecer alguma vantagem para ser adotadas. Dessa forma, as forças de mercado acabam definindo qual norma possui uma relação custobenefício positiva e qual não.

É importante ressaltar esse aspecto dada a controvérsia que freqüentemente ronda a introdução de PSGs. No setor de autopeças, por exemplo, quando se iniciou com mais força a adoção da norma ISO 9000 na década de 1990, a maioria das adoções era motivada pela exigência dos clientes e, nesses casos, houve protestos contra o suposto aumento de custos que a norma provocava e contra a ingerência dos clientes na gestão da qualidade das empresas. Como se verá adiante, os resultados alcançados pelo setor e a ampla adoção voluntária dessa norma por empresas deste e de outros setores indica que essas preocupações eram infundadas.

Como já foi dito, há diversos PSGs sendo propostos por diferentes organizações. Atualmente, os mais difundidos PSGs relacionados com à área de manufatura no Brasil são:

a) ISO 9000:2000: “descreve os fundamento de sistemas de gestão da qualidade e estabelece a terminologia para estes sistemas” (ABNT, 2000, p. 1). Foi o primeiro PSG a ter ampla difusão no setor industrial; 
b) ISO/TS 16.949: TS significa Especificação Técnica ${ }^{20}$. A ISO/TS foi elaborada por um comitê técnico da ISO formado pela International Automotive Task Force (IATF) e a Japan Manufacturers Association, Inc. (JAMA). Ela adiciona ao texto da ISO 9000:2000 uma série de elementos que tem como objetivo “o desenvolvimento de um sistema de gestão da qualidade que provê melhoria contínua, dando ênfase à prevenção de defeitos e à redução de variação e desperdício na cadeia produtiva” ${ }^{21}$ (ISO, 2002, p. xii). Além disso, há acoplados requisitos específicos de clientes do setor automotivo. É um PSG exclusivo para a indústria de autopeças.

c) ISO 14.001:2004: essa norma "especifica os requisitos para que um sistema de gestão ambiental capacite uma organização a desenvolver e implementar política e objetivos que levem em consideração requisitos legais e informações sobre aspectos ambientais significativos” (ABNT, 2004, p. v). É o segundo mais difundido PSG no Brasil e é adotado por mais de 34\% das indústrias de autopeças brasileiras.

d) OHSAS 18.000: essa norma "fornece requisitos para um sistema de gestão de segurança e saúde ocupacional (SSO), de modo a capacitar a organização a controlar seus riscos e melhorar seu desempenho.” (UFPR, 2008, p. 4). Apesar de somente 5\% das indústrias de autopeças (em 2006) estarem certificadas nesse PSG, dada a alta complexidade e riscos da legislação trabalhista brasileira, um número cada vez maior de empresas está buscando essa certificação.

e) SA 8.000: essa norma "especifica requisitos de responsabilidade social para possibilitar a uma empresa [...] desenvolver, manter e executar políticas e procedimentos com o objetivo de gerenciar aqueles temas os quais ela possa controla ou influenciar” (SAI, 2008, p. 3). Apesar de ainda pouco adotada, dada a importância cada vez maior das questões sociais para as empresas, essa norma tem atraído a atenção de um número cada vez maior de organizações, especialmente as de grande porte com maior exposição pública.

f) MEG: o Modelo de Excelência de Gestão da Fundação Nacional da Qualidade propõe um modelo sistêmico de gestão que "estabelece uma orientação integrada e interdependente, na qual os vários elementos da organização e as partes

\footnotetext{
${ }^{20}$ Technical Specification

21 " [...] the development of a quality management system that provides for continual improvement, emphasizing defect prevention and the reduction of variation and waste in the supply chain."
} 
interessadas interagem de forma harmônica e balanceada em função de estratégias e resultados mutuamente definidos” (FNQ, 2006, p. 4). O MEG é também o padrão de avaliação para o Prêmio Nacional da Qualidade, o mais prestigiado do Brasil. Sua proposta é apoiar a criação de um sistema de gestão que integra todas as áreas de uma organização e as partes interessadas sendo, portanto, mais amplo que os PSGs acima. Entretanto, dada sua complexidade, ainda são poucas as empresas que conseguiram implantá-lo em um grau elevado, mas tem servido como referência para organizações que buscam a integração de seus sistemas de gestão.

A leitura de todos os PSGs citados mostra fortes evidências, quando não citações diretas (FNQ, 2006, P. 5-6), que a sua origem é o movimento do TQM. Esse movimento se baseia em cinco princípios que foram difundidos inicialmente por Deming e Juran:

a) Foco no cliente e em sua satisfação total através da avaliação precisa de suas necessidades e do alinhamento de toda a empresa no sentido de satisfazê-las;

b) Empowerment através de gestão participativa, delegação e garantia de poder para as pessoas no nível da produção tomarem decisões e agirem para garantir a qualidade;

c) Administração baseada em equipes para garantir o envolvimento e alinhamento de todos os responsáveis pela qualidade dos produtos;

d) Medição de desempenho e melhoria contínua, pois para se tomar decisões baseadas em fatos e para melhorar continuamente produtos e processos é essencial criar e manter indicadores de desempenho confiáveis;

e) Comunicação aberta e feedback através de sistemas de comunicação, registro e acompanhamento que garantam ações rápidas e eficazes.

Adicionalmente a esses princípios, vem sendo introduzido, nos PSGs, o princípio de que as organizações atuam como coleções de processos interligados entre si e com o ambiente externo. Os PSGs definem, portanto, que esses processos devem ser o foco de monitoramento, avaliação, decisão e ação dos sistemas de gestão. A ISO 9004:2000 (ABNT, 2000b, p3), parte da norma dedicada a orientar a sua implantação, por exemplo, apresenta esta figura para definir o que entende por gestão por processos: 


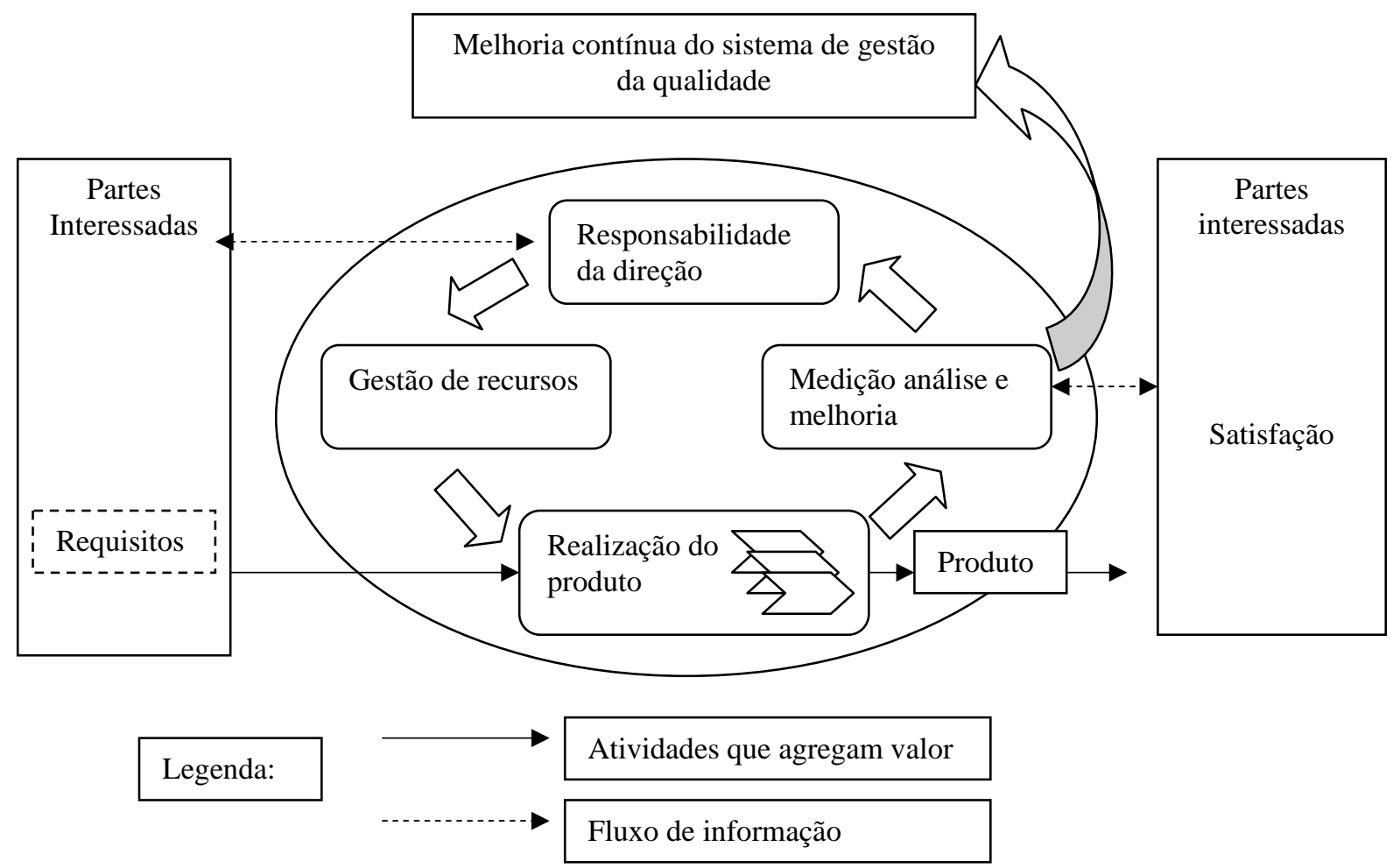

Ilustração 4: Modelo de um sistema de gestão da qualidade baseado em processos FONTE: adaptado de ABNT, 2000b, p.3

Deve-se mencionar também, o princípio do uso da técnica chamada PDCA - Plan, Do, Check, Act - como base dos ciclos de feedback. Essa técnica simples define que se deve planejar antes de agir, fazer o que foi planejado, monitorar os resultados e avaliá-los frente ao planejado e, no caso de desvios, agir, baseando-se em fatos, no sentido de corrigir as ações ou o plano.

A norma ISO 9.000:2000, por exemplo, estabelece oito princípios de gestão da qualidade, "os quais podem ser usados pela Alta Direção para conduzir a organização à melhoria de seu desempenho" (ABNT, 2000b, p. 6). É evidente a relação deles com os princípios de Deming e Juran descritos acima:

a) Foco no cliente: organizações dependem de seus clientes e, portanto, convêm que entendam suas necessidades atuais e futuras do cliente, atendam aos requisitos e procurem exceder as suas expectativas;

b) Liderança: líderes estabelecem unidade de propósitos e o rumo da organização. Convém que eles criem e mantenham um ambiente interno no qual as pessoas possam estar totalmente envolvidas no propósito de atingir os objetivos da 
organização;

c) Envolvimento de pessoas: pessoas de todos os níveis são a essência de uma organização e seu total envolvimento possibilita que as suas habilidades sejam usadas para o benefício da organização;

d) Abordagem de processo: um resultado desejado é alcançado mais eficientemente quando as atividades e os recursos relacionados são gerenciados como um processo;

e) Abordagem sistêmica para gestão: identificar, entender e gerenciar processos interrelacionados, como um sistema, contribui para a eficácia e eficiência da organização no sentido desta atingir seus objetivos;

f) Melhoria contínua: convém que a melhoria contínua no desempenho global da organização seja seu objetivo permanente;

g) Abordagem factual para tomada de decisão: decisões eficazes são baseadas na análise de dados e informações;

h) Benefícios mútuos nas relações com fornecedores: uma organização e seus fornecedores são interdependentes e uma relação de benefícios mútuos aumenta a habilidade de ambos em agregar valor.

Outra característica relevante dos PSGs é a preocupação com a terminologia. Das 26 páginas da norma ISO 9000:2000 (ABNT, 2000, p. 7-22), 16 são dedicadas a padronizar o significado de termos e conceitos. Essa padronização é necessária para que sejam usados por todas as partes de forma eficiente e eficaz. Claramente procura-se estabelecer um "domínio lingüístico" comum (MATURANA; VARELA, 1995) sobre o qual construir um sistema entendido e compartilhado por todos seus agentes. Para que haja interações eficientes e eficazes entre os agentes de um sistema, estes precisam compartilhar um mesmo domínio lingüístico. É o que se costuma chamar de "falar a mesma língua". March e Simon também ressaltam a importância do domínio lingüístico comum (1993, p. 183 e 184):

A capacidade de uma organização de manter um complexo, altamente independente padrão de atividade é limitada em parte pela sua capacidade de lidar com a comunicação requerida para coordenação, quanto maior a eficiência da comunicação dentro da organização, maior a tolerância para interdependência. $^{22}$

Os autores sugerem o uso de mecanismos de feedback "automático" sempre que possível e o

\footnotetext{
${ }^{22}$ The capacity of an organization to maintain a complex, highly interdependent pattern of activity is limited in part by it capacity to handle the communication required for coordination, the greater the efficiency of communication within the organization, the greater the tolerance for interdependence.
} 
desenvolvimento de códigos para a transmissão eficiente da maior quantidade possível de informação de forma não ambígua. Esses códigos, propostos pelos PSGs, como se verá em mais profundidade adiante, acabam sendo eficientes e eficazes também para a comunicação com os clientes e todos os outros stakeholders.

É relevante citar novamente March e Simon (1993, p. 171 e 172) sobre a importância da padronização para a eficiência e eficácia da estrutura organizacional:

\begin{abstract}
Um importante objetivo da standardização é ampliar o quanto possível o alcance de situações que podem ser lidadas pela organização pela combinação e recombinação de um relativamente pequeno número de programas elementares. A limitação da ação de alto nível à recombinação de programas ao invés da construção detalhada de novos programas a partir de pequenos elementos, é extremamente importante de um ponto de vista cognitivo. Nosso tratamento de comportamento racional repousa na proposição que a situação "real” e quase sempre complexa demais para ser lidada detalhadamente. ${ }^{23}$
\end{abstract}

Os programas a que se referem os autores são equivalentes aos procedimentos criados com base nas regras dos PSGs e a combinação e recombinação desses programas são feitas também de acordo com essas regras. Os procedimentos criados dessa forma são "programas" relativamente genéricos que definem ações para determinadas situações, rotineiras ou não.

Com já foi dito, mesmo em casos de situações inéditas, há um procedimento específico que determina a análise do caso, as técnicas de análise e solução de problemas a serem usadas, ações a serem tomadas ao final da análise de acordo com o resultado e o procedimento de verificação da eficácia das ações tomadas. Elementos de um procedimento desse tipo já são, em geral, procedimentos genéricos aos quais basta fazer referência. Por exemplo, as técnicas de análise e solução de problemas são praticamente as mesmas em inúmeras situações e, em geral, estão definidas em um procedimento específico. March e Simon (1993, p. 185) novamente esclarecem:

[...] o problema normativo ou adaptativo do desenho organizacional é um de balanço. Se o seu modelo de realidade não é para ser tão complexo que a paralise, a organização precisa desenvolver simplificações radicais de suas reações. Uma dessas simplificações é ter (a) um repertório de reações padronizadas, (b) uma classificação de situações de evocação de programas, (c) um conjunto de regras para determinar qual é a reação apropriada para cada classe de situações. O balanço de economias e eficiências aqui é exatamente a mesma em que é em todos os casos de

\footnotetext{
${ }^{23}$ An important objective of standardization is to widen as far as possible the range of situations that can be handled by combination and recombination of a relatively small number of elementary programs. Limitation of high-level action to the recombination of programs rather than the detailed construction of new programs out of small elements, is extremely important from a cognitive standpoint. Our treatment of rational behavior rests on the proposition that the "real" situation is almost always far too complex to be handled in detail
} 
standardização. ${ }^{24}$

É interessante notar o total alinhamento dessa explicação com as vantagens da standardização citadas no início desta seção, inclusive a idéia de simplificação para viabilizar decisões e ações em um ambiente complexo através de agentes cuja racionalidade é limitada.

Neste momento é útil esclarecer em que nível da hierarquia de regras se encontram os PSGs. A escolha de se adotar um PSG é uma decisão estratégica, no nível do que se pode chamar de Plano de Negócios. Assim, o PSG está em segundo lugar na hierarquia de regras como descrita na ilustração 5 abaixo:

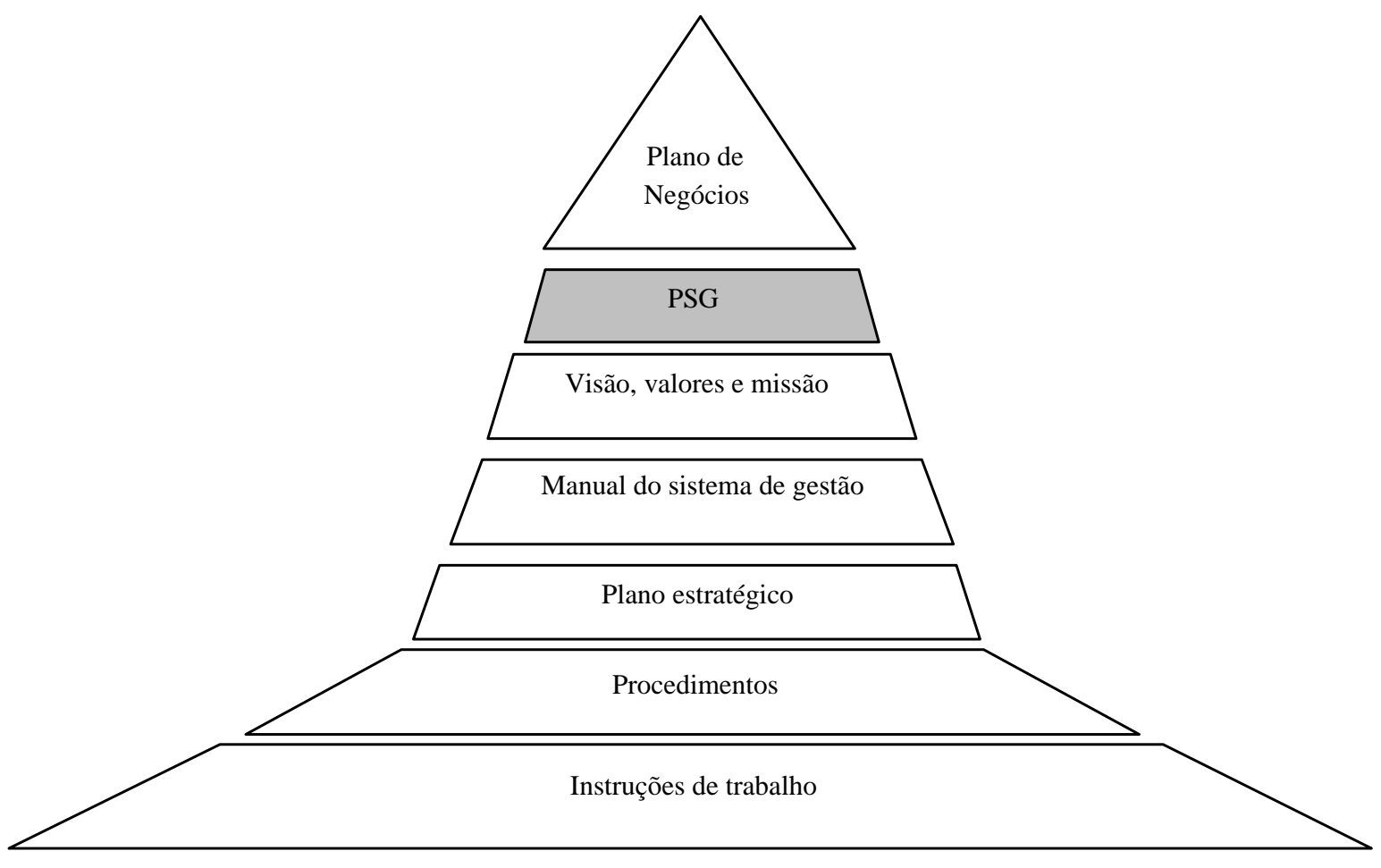

Ilustração 5: Hierarquia de regras

FONTE: adaptado de GIOVANNINI e KRUGLIANSKAS, 2004

Logo abaixo do PSG aparecem a Visão, Valores e Missão. Os PSGs exigem que sejam definidas e amplamente divulgadas políticas expressamente voltadas ao atendimento das necessidades dos stakeholders para as quais foram criadas, sejam eles acionistas, clientes, sociedade, funcionários e fornecedores. Assim, mesmo que a decisão de implantar um PSG

\footnotetext{
${ }^{24}[\ldots]$ the normative or adaptative problem of organization design is one of balance. If its model of reality is not to be so complex as to paralyze it, the organization must develop radical simplifications of its responses. One such simplification is to have (a) a repertory of standard responses, (b) a classification of program-evoking situations, (c) a set of rules to determine what is the appropriate response for each class of situations. The balance of economies and efficiencies here is exactly the same as it is in all cases of standardization.
} 
reflita visão, valores e missão de uma empresa, em geral sua formalização e divulgação só ocorre após a adoção do PSG.

Segue, na hierarquia, o Manual do Sistema de Gestão que é uma simples cópia das regras do PSG ajustada para o uso interno da empresa. É através do Manual que as regras do PSG se tornam as Metaregras da empresa.

No nível seguinte da hierarquia de regras criada pelos PSGs se encontra o Plano Estratégico. Esse pode se apresentar de várias formas, mas deve seguir o exigido no Manual e conter, no mínimo, o que é chamado de “análise crítica pela administração” dos resultados do período, uma comparação com as necessidades dos clientes e com as melhores práticas (bechmarking) e decisões estratégicas, e eventualmente táticas, sobre como sanar resultados insatisfatórios e alcançar níveis superiores de desempenho. É um processo típico de feedback voltado à melhoria contínua.

A seguir estão os Procedimentos. Baseados no manual, os Procedimentos são regras para orientar os processos e sub-processos chave da empresa. Eles definem o que deve ser feito em função de determinadas situações rotineiras ou não. É o que March e Simon (1993) chamam de repertório de ações a ser usado em determinadas situações pré-definidas. Novos procedimentos, entretanto, podem ser criados em função de novas necessidades derivadas do aumento de complexidade das operações da empresa.

O nível mais baixo da hierarquia de regras é ocupado por Instruções de Trabalho. Essas são regras, baseadas nos Procedimentos, para atividades executadas no nível mais básico da operação e que, mesmo sendo processos, possuem inputs e outputs rotineiros e específicos, onde não se espera atividades de análise e decisão freqüentes.

Cada nível da hierarquia depende do nível anterior. Dessa forma, as Instruções de Trabalho dependem, indiretamente, do próprio PSG e refletem, assim, sua orientação. O objetivo é obter coerência e integridade em toda a estrutura de regras. 


\subsubsection{Breve histórico dos PSGs no setor de Autopeças}

A adoção dos PSGs na indústria de autopeças vem ocorrendo de forma contínua. Os primeiros PSGs a serem adotados foram aqueles voltados para os sistemas de gestão da qualidade, pois na década de 1990 ganhou força um amplo movimento, incentivado pelas montadoras de veículos, para que as empresas do setor se certificassem sob a norma ISO 9.000. O objetivo das montadoras era melhorar a confiabilidade de sua base de fornecedores, especialmente no que se referia à qualidade.

Uma empresa é chamada de Certificada quando, além de adotar as normas, ela se submeteu a uma auditoria por um órgão habilitado pela ISO - ou por outra entidade autorizada por ela - e recebeu um Certificado (sujeito a renovação periódica) atestando que implantou e utiliza de forma adequada as normas.

No final de década de 1990, com o avanço das preocupações com o meio ambiente, começou crescer o interesse na norma ISO 14.001. As montadoras mais voltadas a uma atuação ambientalmente responsável começaram a exigir a certificação nessa norma a seus fornecedores. Entretanto, dadas as dificuldades que muitos deles enfrentam para obter tal certificação, as exigências foram relaxadas pela maioria das montadoras. De qualquer modo há um número crescente de indústrias de autopeças que adotam a ISO 14.001 voluntariamente. A tendência de valorização da atuação socialmente responsável está levando algumas empresas de autopeças a adotar voluntariamente também a OHSAS 18.001 e a SA 8000. O gráfico 1 abaixo mostra a tendência: 
Gráfico 1: Número de empresas certificadas por tipo de norma

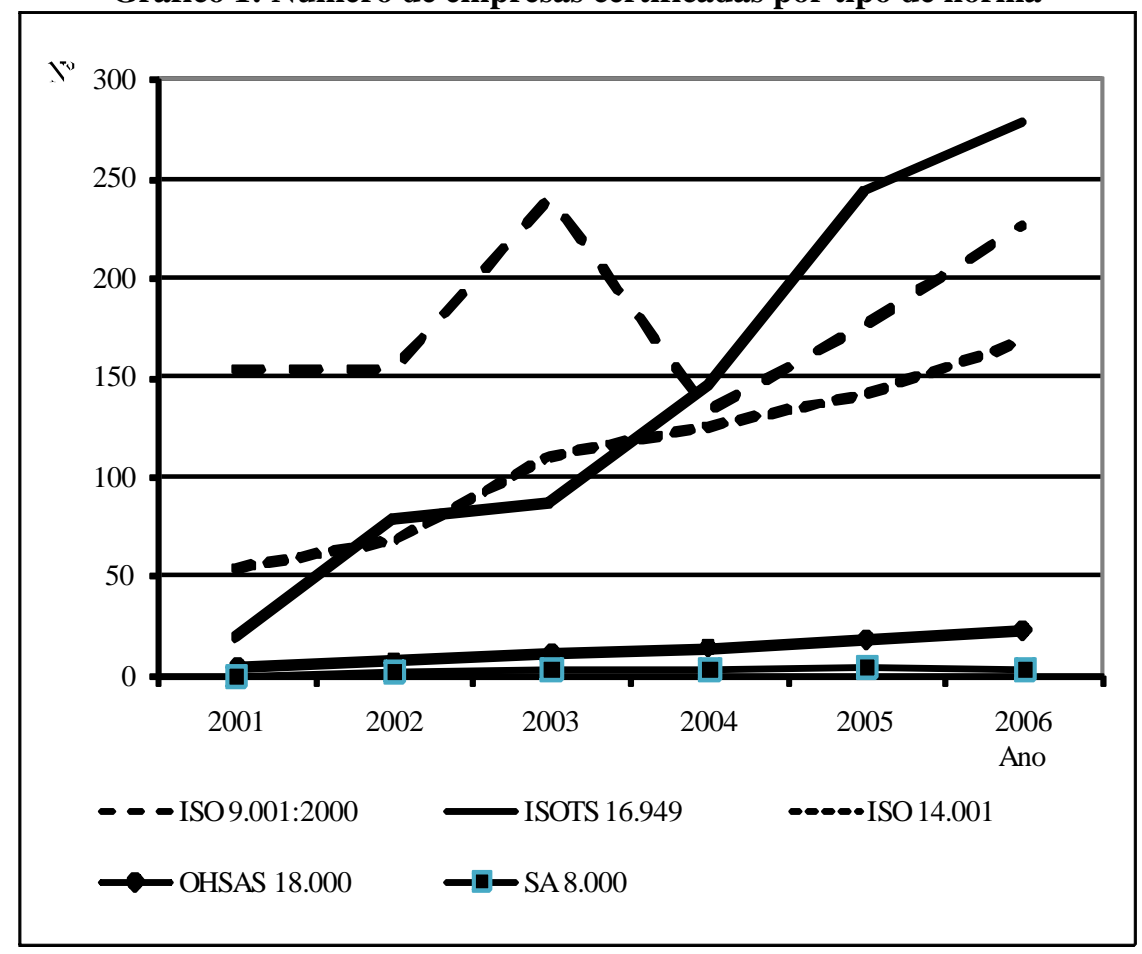

FONTE: SINDIPEÇAS

Nota-se a troca de ISO 9001 por ISO/TS 16.949 após 2003 e uma retomada na adoção da primeira norma já em 2005. A ISO/TS 16.949 é muito complexa já que inclui as normas da ISO 9.001 e exigências específicas de montadoras em diversas questões operacionais. Tende a ser adotada somente nos casos em que é exigida por um cliente importante.

Já a ISO 9001 tem sido adotada de forma mais voluntária e conta com aceitação mais ampla pelas indústrias de autopeças, seus sub-fornecedores e por todos os clientes. O resultado líquido dessas trocas de normas, somado com as novas implantações, pode ser visto no gráfico 2. É importante observar que em 2001 mal havia 0,5 PSGs certificados em vigor por empresa e, cinco anos depois, já havia quase 1,5 PSGs certificados por empresa. Dadas as mudanças organizacionais necessárias para a implantação de um PSG, um aumento de três vezes na densidade de certificados em cinco anos é muito relevante.

É de se notar também o aumento na diversidade dos PSGs implantados. Como as empresas seguem uma ordem de certificação conhecida - qualidade, meio-ambiente, saúde e segurança, responsabilidade social - pode-se supor que esse aumento da diversidade é estimulado por bons resultados com PSGs implantados previamente pelas empresas. 
Gráfico 2: Total de certificados de PSGs vigentes no setor de autopeças

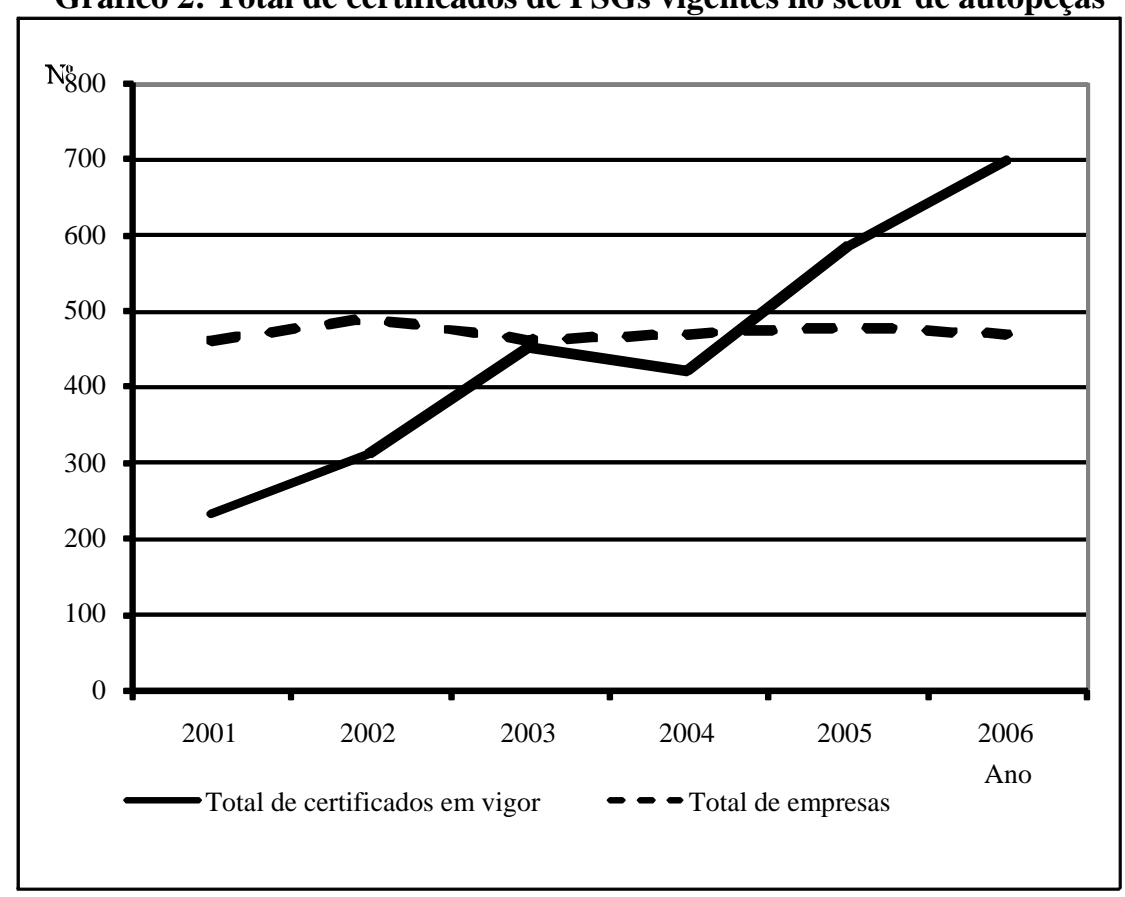

FONTE: SINDIPEÇAS

Atualmente as montadoras consideram as certificações adicionais características que valem pontos em seus sistemas de avaliação de fornecedores. Esses pontos os qualificam a participar em novos projetos e, principalmente, exportar para países com maiores exigências de responsabilidade social. Mas as regras ainda são pouco transparentes e fatores como qualidade, entrega pontual e preço ainda predominam nas negociações.

Assim, as certificações de sistemas de gestão ambiental, saúde e segurança do trabalho e responsabilidade social devem ser interpretadas como iniciativas motivadas principalmente per questões estratégicas visando a sustentabilidade do negócio no longo prazo, como também a resultados concretos no curto prazo.

\subsection{Os Padrões para Sistemas de Gestão e o desempenho das organizações}

No centro das preocupações da teoria das organizações, no que se refere ao desempenho das mesmas, estão os mecanismos de controle, de coordenação e de cooperação. Através da análise desses mecanismos a teoria procura responder a perguntas como: 
a) Por quem as organizações são conscientemente (se for possível) construídas e com que objetivo(s)?

b) É possível alguém desenhar organizações eficazes conscientemente? Como?

c) Quais são os mecanismos de controle, coordenação e cooperação das pessoas dentro e fora da organização?

d) Como as organizações se ajustam às mudanças externas e das pessoas que nelas trabalham?

e) Como as organizações alcançam eficiência e eficácia?

Respostas a elas, mesmo que condicionais e baseadas em teorias, são necessárias para desenvolver o presente estudo. Há outras perguntas relacionas à teoria das organizações que, não sendo diretamente relacionadas com essa tese, não são seu foco. As respostas são procuradas indistintamente em abordagens descritivas e prescritivas ligadas à teoria das organizações.

A teoria das organizações é multidisciplinar. Entretanto, a economia das organizações, por sua forte ligação com o conceito de regras, fornecerá a linha mestra da argumentação que segue e, ao longo desta linha, serão adicionadas contribuições da administração, da psicologia e da sociologia. O objetivo desta seção é mostrar, ao longo dessa linha mestra, como os PSGs podem auxiliar no sentido de melhorar o desempenho das organizações.

\subsubsection{As diferentes abordagens no estudo das organizações}

\subsubsection{A abordagem da economia no estudo das organizações}

A divisão do trabalho, e a especialização que esta possibilita, apesar de melhorarem a eficiência dos processos produtivos, podem criar problemas de controle, coordenação e cooperação. Soluções para esses problemas permitem explorar melhor as vantagens da divisão do trabalho e da especialização. Em geral, essas soluções precisam ser encontradas em um ambiente de escassez de recursos, característica dos sistemas econômicos livres no quais as organizações disputam recursos humanos, intelectuais, financeiros e físicos (materiais, espaço, tempo). Este é um dos principais motivos do envolvimento da economia na teoria das organizações no que concerne sua administração. 
Ao longo das próximas seções seguintes serão exploradas oito vertentes da economia das organizações. As primeiras seis são listadas por Ménard e Shirley (2005) e Douma e Schreuder (2002) e a última é a abordagem mais recente:

a) Teoria da Agência: voltada a explicar os incentivos, isto é, as maneiras pelas quais os principais (proprietários e chefes) podem induzir os agentes (executivos e subordinados) a se comportarem conforme seus interesses (JENSEN; MECKLING, 1976; MILLER, 2005);

b) Economia dos Custos de Transação (TCE): voltada a explicar o motivo da existência e as características de modos alternativos de organização e os tradeoffs entre eles (WILLIAMSON, 1996);

c) Direitos de Propriedade: voltada a explicar os direitos de decisão derivados da propriedade como determinantes para investimentos específicos em relacionamentos (DEMSETZ, 1967);

d) Teoria dos Jogos e Teoria de Cooperação (AXELROD, 1984 e 1997): voltadas a explicar, no que concerne este trabalho, como a coordenação e a cooperação entre pessoas, grupos e organizações são construídas com base nos resultados de interações contínuas (jogos) podendo surgir sem uma autoridade central;

e) Teoria Comportamental da Firma ${ }^{25}$ (CYERT; MARCH, 1992): voltada a explicar como as organizações - entendidas como coalizões de grupos de participantes, cada um com seus próprios objetivos - tomam decisões econômicas como preço, volume de produção, investimentos, níveis de qualidade, etc.;

f) Abordagens Evolucionárias das Organizações: voltadas a explicar, sob uma perspectiva dinâmica, o desenvolvimento das organizações usando como base conceitos de adaptação a mudanças e seleção natural, principalmente para as regras internas das organizações, que são consideradas como o DNA das organizações (NELSON e WINTER, 1982);

g) Economia e Complexidade: voltada a explicar as dificuldades - provocadas pela incerteza - de controle e coordenação em estruturas centralizadas; e como estruturas e comportamentos organizacionais eficazes emergem através de um processo de auto-organização baseado em comportamentos individuais guiados por regras

\footnotetext{
${ }^{25}$ Behavioral Theory of the Firm
} 
relativamente simples (SCHELLING, 1978; AXELROD, 1986; ARTHUR, e 1994 e 2005; GIOVANNINI; KRUGLIANSKAS, 2004).

\subsubsection{A abordagem da administração no estudo das organizações}

Desde Taylor e Fayol, a administração desenvolveu diversas abordagens para o estudo das organizações. Boa parte delas contém elementos presentes na relação acima. Apesar de estarem classificadas como abordagens econômicas, a maioria se desenvolveu baseada nas necessidades dos administradores, dadas as limitações da teoria econômica clássica para explicar as organizações. Podem ser, portanto, consideradas abordagens econômicas com um viés administrativo.

Há, entretanto, abordagens para a questão do controle, coordenação e cooperação nas organizações que não estão contidas claramente nas abordagens econômicas acima. Apesar de se sobreporem, inclusive com aspectos de Psicologia e Sociologia, são consideradas aqui separadamente devido à sua relevância para a administração e à importância com relação ao outro foco deste trabalho, isto é, o efeito das regras nas organizações:

a) Teoria de Sistemas: voltada a explicar a organização de forma holística, como um conjunto de processos interdependentes, abertos a influências do ambiente externo, e cujo resultado pode ser maior que a soma das contribuições individuais (BERTALLANFY, 1998; FORRESTER, 1999a e 1999b; STERMAN, 2000);

b) Análise de decisão: voltada a explicar as dificuldades para a tomada de decisão em situações de incerteza e prescrever técnicas para melhorar a qualidade dessas decisões (MARCH, 1994; CLEMEN, 1996; SIMON, 1997);

c) Escola de Ralações Humanas: voltada a explicar como estruturas informais, relações de poder, comportamento político e cultura organizacional afetam a eficiência e a eficácia organizacional (HODGE et al, 2003);

d) Escola da Administração Total da Qualidade - TQM: voltada à recomendação de técnicas administrativas para a criação de compromissos e comportamentos alinhados com as expectativas das partes interessadas (stakeholders) (EASTON; JARREL, 1998; DE FEO; BARNARD, 2004; FNQ 2007). 


\subsubsection{A abordagem da psicologia no estudo das organizações}

Psicólogos, quando analisam o comportamento organizacional, no que concerne o foco deste estudo, procuram responder a seguintes questões:

a) Como as características organizacionais (sistemas de controle e coordenação) afetam o comportamento individual e de grupos dentro da organização (ABELL, 2006);

b) Se há objetivos organizacionais que não são puramente econômicos, quais são eles, e como o comportamento das pessoas e grupos contribui para seu alcance;

c) Como as pessoas absorvem as informações e como tomam decisões (PLOUS, 1993).

Mais uma vez, há sobreposições com questões anteriores de economia e administração. Como se verá adiante, entretanto, há contribuições específicas da psicologia para sua resposta. De qualquer forma, como a preocupação principal aqui é explicar as diferenças de desempenho entre empresas, e não entre pessoas e grupos, serão usados para análise modelos simplificados de comportamento individual.

\subsubsection{A abordagem da sociologia no estudo das organizações}

A abordagem dos sociólogos, no que se refere a este trabalho, procura responder às mesmas perguntas dos psicólogos, mas com um foco mais amplo (ABELL, 2006):

Como sistemas de crenças e valores (cultura) e a distribuição de poder na sociedade influenciam os modos nos quais as organizações são estruturadas, controladas e coordenadas?

A abordagem sociológica das organizações é também profundamente influenciada por Max Weber e seu modelo de burocracia. Dada a forte relação que tem com o tema deste trabalho, segue abaixo a descrição de burocracia do próprio Weber:

A oficialidade moderna funciona da seguinte maneira:

I. Há o princípio de áreas jurisdicionais fixas e oficiais, as quais são geralmente ordenadas por regras, isto é, por leis ou regulamentos administrativos [...]

II. Os princípios de hierarquia de cargos e de níveis de autoridade graduada significam um sistema firmemente ordenado de super- e subordinação no qual há supervisão dos cargos mais baixos pelos mais altos [...] 
III. A administração do escritório moderno é baseada em documentos escritos ("os arquivos”), que são preservados em sua forma original ou rascunho [...]

IV. Administração de escritório, pelo menos toda administração especializada de escritório e tal administração é distintamente moderna - normalmente pressupõe treinamento extenso e competente [...]

V. $[\ldots]$

VI. A administração do escritório segue regras gerais, as quais são mais ou menos estáveis, mais ou menos exaustivas, e que podem ser aprendidas [...]

A redução da moderna administração de escritório a regras é profundamente enraizada em sua própria natureza. ${ }^{26}$ (GERTH; MILLS, 1961, p.196).

Pode-se perceber a importância dada por Weber às regras organizacionais como base da burocracia. Talvez, a partir de interpretações dessa proposta, desenvolveu-se um preconceito que liga regras a estruturas burocráticas tradicionais - pesadas, lentas e inflexíveis. Isso tem, provavelmente, obstaculizado o estudo mais amplo do uso das regras como ferramentas eficientes e eficazes para a administração.

Mas a burocracia de Weber inclui conceitos mais amplos. Uma maneira de se entender a burocracia é a de considerá-la como um algoritmo especificando os padrões de atividades apropriadas para cada membro da organização. Se cada membro seguir as regras apropriadas para cada situação, o controle, a coordenação e a cooperação são atingidos automaticamente. As regras de Weber se equiparam, dessa forma, aos contratos da abordagem econômica e aos PSGs.

A abordagem sociológica também inclui outras perspectivas que interessam aqui:

a) Normas sociais: voltada a explicar como normas sociais, de origem externa às organizações, podem contribuir ou prejudicar os esforços de controle, coordenação e cooperação;

\footnotetext{
${ }^{26}$ Modern officialdom functions in the following manner:

I. There is the principle of fixed and official jurisdictional areas, which are generally ordered by rules, that is, by laws or administrative regulations...

II. The principles of office hierarchy and of levels of graded authority mean a firmly ordered system of super- and subordination in which there is supervision of the lowest offices by the higher ones...

III. The management of the modern office is based upon written documents ('the files'), which are preserved in their original or draught form...

IV. Office management, at least all specialized office management - and such management is distinctly modern - usually presupposes thorough and expert training...

V. ...

VI. The management of the office follows general rules, which are more or less stable, more or less exhaustive, and which can be learned...

The reduction of modern office management to rules is deeply embedded in its very nature.
} 
b) Impacto das instituições: voltada a explicar como instituições - conjuntos de regras como, por exemplo, leis e Standards - externas à organização influenciam a forma da organização;

c) Mudança organizacional: voltada a explicar a dinâmica de adaptação das organizações a mudanças na sociedade e, quando essa adaptação não ocorre, a morte e o nascimento de organizações;

d) Administração participativa: voltada a explicar como estruturas de participação dos membros nas decisões organizacionais podem ser usadas como mecanismos de controle, coordenação e cooperação.

\subsubsection{Os Padrões para Sistemas de Gestão e suas soluções}

Partindo-se dessas abordagens, nas próximas páginas, elaborem-se diversas proposições sobre como os PSGs podem contribuir para melhorar o desempenho das organizações. O foco são sempre os aspectos de controle, coordenação, cooperação e inovação.

Para enquadrar as análises, são resumidas abaixo algumas características básicas dos PSGs (ABNT, 2000 (a) e 2004; ISO, 2002; UFPR, 2008; SAI, 2008; FNQ, 2008) que tem uma relação estreita com os itens que seguem mais à frente:

a) PSGs são Metaregras cujo objetivo é a criação e manutenção de regras eficientes e eficazes para a organização;

b) Os Principais (proprietários e gestores) têm como uma de suas principais funções, no que concerne os PSGs, garantir que as regras sejam conhecidas por todos e que haja punições e incentivos para que as regras sejam seguidas. Os PSGs possuem um forte caráter disciplinador que se reflete na importância dada às auditorias sistêmicas internas e de terceiros;

c) Os PSGs são conjuntos de regras suficientemente simples para que sejam compreendidas em seu conjunto pelos gestores e, ao mesmo tempo, abrangem todos os aspectos do processo administrativo ao qual são destinadas;

d) Os PSGs contam com ciclos de feedback para garantir a eficácia do sistema. O ciclo mais recomendado é o PDCA: Planejar, Executar (Do), Controlar e Agir sobre eventuais desvios do planejado; 
e) Os PSGs dão grande ênfase à conscientização de todas as pessoas sobre as políticas organizacionais relativas ao sistema de gestão;

f) Os PSGs ressaltam a necessidade de constante treinamento das pessoas sobre as regras que as afetam;

g) Os PSGs recomendam o empowerment das pessoas para que sejam agentes ativos na promoção da eficiência e eficácia do sistema de gestão.

\subsubsection{Informação e conhecimento}

Sob a perspectiva econômica, as organizações enfrentam o problema da assimetria de informação. As pessoas na organização não dispõem das mesmas informações e essa situação pode promover e premiar comportamentos oportunistas. Há dois conceitos que representam esse tipo de comportamento.

O conceito de seleção adversa representa o que ocorre quando as características do agente não podem ser observadas ex ante com precisão pelo principal e o primeiro procura obter uma vantagem em detrimento do segundo (SALANIÉ, 1997, MILGROM; ROBERTS, 1992). Por exemplo, quando diversos fornecedores de serviços (agentes) participam de uma concorrência na qual o cliente (principal) não consegue especificar todas as características que o agente precisa possuir para prestar o serviço, o vencedor tende a ser aquele com as piores características, mesmo atendendo estritamente, mas somente, as especificações do cliente.

Essa situação, de contratos incompletos, é muito comum dentro e entre organizações. Contratos de trabalho entre empregado e empregados são sujeitos à mesma seleção adversa. Os PSGs tendem a atenuar a seleção adversa, pois recomendam a mais completa possível especificação de contratos, a auditoria de fornecedores para sua qualificação, e a posterior checagem se o que é entregue atende às necessidades da organização independentemente do atendimento das especificações contratuais. Os PSGs especificam que, caso os contratos e regras de contratação não garantam o atendimento das necessidades da organização, esses contratos e regras devem ser modificados. Para fim de monitoramento desse atendimento, os PSGs demandam que haja indicadores de desempenho. Os contratos tendem, assim, a ficar cada vez mais completos e os agentes a serem selecionados. O mesmo vale para o risco moral. 
O conceito de risco moral represente o que ocorre quando as ações do agente não podem ser observadas ex post com precisão pelo principal e o primeiro procura obter uma vantagem em detrimento do segundo (SALANIÉ, 1997, MILGROM; ROBERTS, 1992). Por exemplo, se não há como verificar a eficácia do trabalho de cada equipe em uma estação de tratamento de efluentes que trabalha 24 horas por dia, e nem há uma clara responsabilização das pessoas, uma das equipes, ou todas elas, eventualmente, podem sem negligentes em seu trabalho e, eventualmente, permitirem o lançamento de efluentes no ambiente.

Todos os PSGs têm regras específicas que obrigam a adoção de formas de monitoramento da qualidade do trabalho e exigem a separação das funções de produção e monitoramento para evitar conflitos de interesses. Há regras, por exemplo, para o planejamento da qualidade, isto é, o estudo de possíveis fontes de falhas e a definição de medidas preventivas nos casos de combinações de riscos/impactos graves, técnica chamada de FMEA (análise de modos e efeitos de falhas) ${ }^{27}$ (DE FEO; BARNARD, 2004). Isso permite a elaboração de “contratos” cada vez mais eficientes e eficazes. Há também regras para o planejamento dos processos, isto é, o estudo antecipado de melhorias de eficiência e eficácia dos processos produtivos e de gestão para garantir melhores resultados para a organização.

Na maioria dos PSGs há também regras específicas para a administração dos documentos e dos registros do sistema. Documentos são o Manual do Sistema, os Procedimentos, as Instruções de Trabalho, as Especificações de Clientes, Standards, Normas, Leis aplicáveis e Formulários. Os registros são todas as informações geradas, coletadas e arquivadas pelo sistema de gestão. Os PSGs especificam que deve haver regras para o arquivamento seguro, rápida disponibilidade e disposição adequada no caso de obsolescência. Também se exige regras para impedir a circulação e uso de versões desatualizadas de documentos.

Agregando à discussão aspectos da psicologia e da sociologia há outras formas de se encarar a questão da informação e do conhecimento.

Sob o aspecto de poder e autoridade, disputas de poder podem incentivar a sonegação de informações e conhecimento. Os PSGs, com suas regras exigindo conscientização, treinamento e empowerment, tendem a reduzir as possibilidades de sonegação a amortecem as

27 "failure mode and effect analysis" 
disputas de poder baseadas no domínio da informação e do conhecimento. Empresas com administração mais transparente tendem a adotar com mais facilidade os PSGs.

Sob o aspecto da cultura da sociedade, um baixo nível de confiança entre pessoas pode exacerbar a questão do oportunismo. Vista sob o prisma econômico, a desconfiança de que uma das partes assumirá uma postura oportunística aumenta os custos de transação, pois as partes precisam criar e usar mecanismos custosos para obrigar a outra parte a cumprir o combinado. A partir do momento em que regras claras (PSGs) de comportamento são adotadas, e a longo do tempo são respeitadas pelos membros do sistema, a cooperação tende a emergir. Na seção 2.3.2.4, quando se fala de motivação em grupos e equipes, a possibilidade da cooperação emergente é mais bem explorada através da teoria dos jogos.

A participação das pessoas na gestão é outro aspecto abordado pela psicologia e pela sociologia relevante para essa discussão. As pessoas tendem a aceitar poderes desiguais em estruturas hierárquicas se, além de apoiados em competência, eles também forem baseados em algum princípio democrático de escolha (uma pessoa, um voto). Formas de controle, coordenação e cooperação baseadas em procedimentos democráticos podem ser muito eficientes e eficazes.

Os “círculos de controle de qualidade” (CCQs) (MAXIMIANO, 1997, p. 135) são um exemplo típico desse conceito aplicado a pequenos grupos. As abordagens de administração participativa e de empowerment também consideram que um melhor desempenho pode ser alcançado com mecanismos democráticos de participação nas decisões organizacionais. Para isso, o livre fluxo de informações para as pessoas da organização é uma condição necessária.

As regras demandadas pelos PSGs impõem essa condição e também exigem autonomia para as pessoas agirem no sentido de garantir a aderência dos processos às regras. Um exemplo típico é a autonomia de trabalhadores para interromper uma linha de montagem caso detectem “não conformidades” no produto ou processo. Nos PSGs há também recomendações para a implementação de planos de sugestões, envolvimento de equipes para a solução de problemas e uso de planos de participação nos lucros como forma de estimular e garantir a participação das pessoas na organização. 


\subsubsection{Monitoramento}

As estruturas organizacionais podem ser analisadas como complexos mecanismos de monitoramento. Uma das funções da burocracia é garantir o monitoramento das atividades dos subordinados pelos superiores.

Sob a perspectiva econômica, há duas formas de o Principal monitorar o trabalho de um Agente: observando o output (ou o produto do trabalho do agente), e observando o input (ou o esforço dedicado pelo agente ao trabalho). A dificuldade está em definir a forma mais eficiente, isto é, de menor custo de monitoramento. Caso o output dependa somente do input (esforço) do agente, basta monitorar o output para verificar se o nível de esforço do agente é a esperada (ou, em outras palavras, a contratada). Verificar o output é, geralmente, a opção de menor custo. Essa situação, entretanto, é raramente encontrada. O output de um agente depende quase sempre, em algum grau, também de inputs de outros agentes da organização. Além disso, o output pode ser coletivo, de um grupo de agentes, e a contribuição de cada um não pode ser medida facilmente. Nesses casos, os custos de monitoramento, representados pelo tempo e esforço do Principal, crescem. Na medida em que esse tempo e esforço crescem, o Principal perde capacidade de supervisionar um maior número de pessoas. Assim, além de um aumento dos custos de monitoramento, temos também um aumento do número de níveis hierárquicos que, por sua vez, prejudica a coordenação.

O monitoramento é, portanto, necessário para reduzir o risco moral ligado a problemas de oportunismo ex post, isto é, de alguém na organização perseguir seus interesses, em detrimento dos interesses da organização, dada a dificuldade (custo) em se verificar suas ações (MILGROM; ROBERTS, 1992). Uma forma de reduzir este risco são os incentivos, assunto ao qual se dedica aproxima seção. Outra alternativa á a adoção de PSGs.

Os PSGs contribuem para reduzir os risco moral e os custos de monitoramento. Na medida em que as regras dos PSGs exigem uma análise e elaboração disciplinada de todos os contratos, internos e externos, reduzem-se as possibilidades de oportunismo dos agentes. Por exemplo: em todo o contrato de fornecimento deve haver uma exaustiva verificação (por parte do fornecedor) de todas as normas, regulamentos, leis e exigências específicas do cliente. Caso alguma condição não possa ser atendida, a empresa fornecedora é obrigada a exigir de 
seu cliente uma “derroga” ${ }^{28}$ (ISO, 2002, p. 30) formal, isto é, uma liberação de cumprir tal exigência. Caso essa “derroga” não seja dada, a empresa não pode atender ao pedido. Isso evita oportunismo ex post das duas partes: a empresa fornecedora não pode declarar que ignorava alguma exigência que não cumpriu, para justificar qualidade fora do especificado ou incapacidade produtiva. Dificulta-se assim que o fornecedor seja oportunista e torne o cliente seu refém em caso de dificuldade para desenvolver outro fornecedor em projetos em andamento. Essa “análise crítica de contrato” (ABNT, 200 (a), p. 14) também protege a empresa fornecedora de assumir compromissos que podem se revelar mais custosos do que o previsto no caso do cliente exigir o cumprimento de condições ignoradas no momento da cotação, mas que podem lhe interessar impor a posteriori.

A “análise crítica de contrato” também reduz riscos de Seleção Adversa, pois inibe o oportunismo ex ante de fornecedores sem condições de atender as necessidades do cliente, mas que, dadas as dificuldades de monitoramento, poderiam se apresentar na concorrência baseados em uma simulada ignorância das condições contratuais.

Sob a perspectiva da administração, da sociologia e da psicologia, há um debate sobre as conseqüências da adoção das técnicas da administração científica e da linha de montagem (Fordismo). Essas técnicas são formas de reduzir custos de monitoramento através da divisão do trabalho em tarefas muito simples cujo ritmo é determinado pela linha de produção (não só de fábricas, mas também de serviços). Poucos supervisores podem monitorar, assim, o trabalho de muitas pessoas. Apesar dos bons resultados que apresentaram, e de ainda estarem sendo amplamente usadas em diversos setores e países, essas técnicas enfrentam algumas dificuldades em função de certos desenvolvimentos sócio-econômicos (adaptado de ABELL, 2006):

a) Países com baixos salários adotam as linhas de produção e concorrem com países de altos salários;

b) Mercados de massa, ideais para produtos de linhas de montagem, começam a se dividir em mercados menores e nichos, com ênfase em qualidade e exclusividade;

c) Tecnologias de produção flexível e eficiente se desenvolvem;

d) Resistências ao de-skilling provocado pela linha de montagem (AMSDEM, 1983).

28 "waiver" 
Os PSGs, por outro lado, com sua ênfase em conscientização para a qualidade, empowerment e participação, tendem a promovem a criação de sistemas de gestão que permitem uma produção mais flexível, preservando padrões eficientes e eficazes de trabalho (mesmo sem o uso de linhas de montagem), e enriquecem o trabalho individual reduzindo os efeitos do deskilling através de:
a) Redução da fragmentação do trabalho;
b) Aumento da autonomia e discricionariedade;
c) Aumento da responsabilidade e autoridade;
d) Participação em grupos de trabalho autônomos (CCQs, Grupos Auto-Geridos);
e) Transparência das decisões que afetam o trabalho.

A necessidade de monitoramento também se baseia na suposição de que as relações entre Principal e Agente são como contratos incompletos - dada a miríade de situações impossíveis de prever contratualmente - e que, portanto, contêm oportunidades de exploração de uma parte pela outra. A redução dos custos envolvidos no monitoramento pode se alcançada com formas eficientes e eficazes de melhorar a qualidade dos contratos e as condições de monitoramento para as quais, os PSGs contribuem. A seguir se discute outra forma de redução dos custos de monitoramento: os incentivos.

\subsubsection{Incentivos e Motivação individual}

O monitoramento direto pode ser caro e ineficaz. Por esse motivo, pesquisadores se dedicam a estudar formas de criar incentivos para o cumprimento dos contratos que dispensem ou reduzam a necessidade de monitoramento.

Sob a perspectiva econômica, o problema de monitoramento também existe na relação entre a propriedade e a alta administração. A propriedade (Principal) delega a administradores profissionais (Agentes) a tarefa de administra seu negócio devido, principalmente, às vantagens que tem os administradores em termos de competência ou informação. Essa vantagem de informação, ou situação de assimetria de informação, faz com que os Principais tenham poucas condições de saber se os Agentes estão realmente defendendo seus interesses 
na condução da organização. Nesse caso, presume-se que a melhor solução seja a criação de incentivos para que os interesses de Principal e Agente estejam alinhados. A pergunta a ser respondida, nesse caso é:

Pode um contrato se escrito definindo incentivos de tal maneira que o Principal pode ser assegurado que o Agente está tomando exatamente a ação que ele [Principal] tomaria, tendo ele as informações disponíveis ao Agente? ${ }^{29}$ (MILLER, 2005, p. 349).

Em economias abertas, o desalinhamento entre as ações dos administradores e os interesses dos proprietários, se não resolvido através de incentivos adequados, pode ser corrigido através de mecanismos de mercado (adaptado de MILGROM; ROBERTS, 1992 e DOUMA; SCHREUDER, 2002):

a) Mercado competitivo para controle corporativo: uma empresa cujo desempenho é considerado ruim pelo mercado e cuja propriedade é condescendente com administradores ruins pode ter seu controle adquirido por terceiros que, posteriormente, trocam a administração e promovem as correções necessárias para que a mesma trabalhe conforme os interesses da empresa. Dessa forma, os novos proprietários realizam, à custa dos proprietários anteriores, um lucro derivado do aumento do valor da empresa.

b) Mercado competitivo para talento administrativo: administradores cujo desempenho é considerado ruim pelo mercado, têm suas perspectivas profissionais e de remuneração reduzidas. Assim, quanto mais intensa é a competição entre administradores profissionais, menos possibilidade tem um Agente de perseguir seus próprios interesses em detrimento dos interesses do Principal.

c) Mercado competitivo para os produtos da organização: quanto mais intensa é a competição no mercado dos produtos da empresa, menor é a possibilidade do Agente perseguir seus próprios interesses em detrimento dos interesses do Principal. O mercado rapidamente reage a custos altos ou qualidade inferior expondo o Agente.

Mesmo com esses mecanismos de mercado, os Principais procuram criar incentivos aos Agentes, pois alguns destes esses mecanismos podem, ao funcionar, transferir custos aos proprietários na forma de redução nos lucros e no valor da empresa. Um incentivo muito

\footnotetext{
${ }^{29}$ Can a contract be written defining incentives in such a way that the Principal can be assured that the Agent is taking just the action that she would take, had she the information available to the Agent?
} 
usado é oferecer participações societárias aos Agentes. Aqui também surgem problemas conforme demonstram e detalham Jensen e Meckling (1976). Por mais que os Principais transfiram participação a um Agente, no limite em que esse não passe ele a ser o Principal, ações inadequadas do Agente serão sempre suportadas com maior intensidade pelos Principais. Uma exceção existe no caso de certos tipos de passivos em sociedades anônimas abertas, onde o Agente acaba sendo responsabilizado no caso de não pagamento e os Principais têm sua perda limitada ao valor das ações. Jensen e Meckling (1976) e Demsetz (1967) citam isso como um dos possíveis fatores para a persistência do modelo de Principal e Agente apesar dos custos envolvidos.

Os PSGs podem ser formas eficazes de se criar incentivos alinhados com os objetivos dos Principais, reduzindo também os riscos dos Agentes. Por exemplo, alguns dos PSGs em análise exigem explicitamente o cumprimento das leis e normas em vigor, inclusive com a criação de mecanismos de atualização constante de informações sobre as mesmas, muito importantes em ambientes institucionalmente voláteis como o brasileiro. Monitoramento e atendimento constante de leis e normas ambientais, fiscais e de saúde e segurança do trabalho estão entre as exigidas mais claramente. Dessa forma, PSGs certificados dão uma razoável segurança aos Principais de que os Agentes não estão sendo negligentes com relação a passivos ambientais, fiscais e trabalhistas. Por outro lado, os Agentes também trabalham sem a pressão para assumir riscos desse tipo (por exemplo, economizando em medidas de segurança no trabalho, controle de efluentes, sonegando impostos) para melhorar os resultados dos Principais no curto e médio prazo.

As questões levantadas conduzem à discussão dos motivos que levam as pessoas a se organizar na forma de empresas para perseguir objetivos, em geral econômicos. Estão envolvidos aspectos de comportamento humano (de acordo com a visão econômica) e de características das transações envolvidas. O comportamento humano, de acordo com a TCE, está condicionado por dois fatores: as pessoas estão sujeitas à racionalidade limitada (bouded rationality), e as pessoas são oportunistas. Em comparação, a Teoria Comportamental da Firma assume a racionalidade limitada, mas não o oportunismo. A Teoria de Principal e Agente, por outro lado, considera a possibilidade de pessoas oportunistas e agindo de forma totalmente racional (DOUMA; SCHREUDER, 2002). 
Para se entender melhor o problema, Williamson (1985) propões focar as seguintes características das transações:

a) Especificidade de ativos: são os valores investidos que seriam perdidos em qualquer outro uso alternativo. Ativos altamente específicos (como uma fábrica construída ao lado de um cliente importante com o fim exclusivo de fornecer a ele) criam dependência mútua e abrem a possibilidade de uma das partes se tornar refém da outra, isto é, uma parte obtém um ganho extraordinário ameaçando a outra de perda do seu investimento específico (MENAD; SHIRLEY, 2005; KLEIN et al, 1978);

b) Incerteza nas transações: quer seja pelo comportamento dos envolvidos na transação, pelas deficiências de organização, pelas instituições inadequadas (leis e normas), ou por “estados da natureza”, as transações estão cercadas de incerteza;

c) Freqüência das transações: quanto maior a freqüência das transações, mais se diluem os custos fixos incorridos em estabelecer uma organização (empresa) para realizar essas transações (MENARD; SHIRLEY, 2005). Também se podem incluir aqui os riscos de oportunismo de não cumprimento de contratos no caso de transações únicas onde a formação de uma reputação pouco importa.

Partindo-se da premissa que todas as pessoas têm algum grau de aversão ao risco, as hipóteses de comportamento humano e as características das transações expostas acima implicam na busca de formas de alocação dos riscos presentes. As empresas podem ser vistas como conjuntos de contratos de distribuição de riscos de acordo com as preferências dos envolvidos. Agentes (funcionários, administradores) aceitam ou preferem ser remunerados de forma fixa, pois tem uma aversão a risco maior do que, por exemplo, os acionistas. Organizações aparentam ser, nesse caso, mecanismos de segurança (ABEL, 2006) não só porque alocam melhor os riscos, mas porque também podem mitigá-los.

Os riscos derivados da racionalidade limitada podem ser mitigados através a criação de um número de procedimentos a serem usados em determinadas situações de acordo com um conjunto de regras. Como sugerem March e Simon (1993, p. 173): “Comportamento racional envolve substituir a realidade complexa por um modelo de realidade suficientemente simples para ser lidado por processos de solução de problemas” ${ }^{30}$. Desse modo consegue-se atenuar a

\footnotetext{
30 "Rational behavior involves substituting for the complex reality a model of reality that is sufficiently simple to be handled by problem-solving processes."
} 
indecisão provocada pela racionalidade limitada frente à complexidade da maioria das situações organizacionais relevantes e agir de forma pelo menos consistente com uma estratégia pré-definida.

A criação dessas regras é uma das características fundamentais das organizações e um dos motivos de sua existência. Os PSGs são conjuntos de Metaregras que, para a grande maioria das organizações, podem ser uma solução eficiente e eficaz para essa necessidade de mitigação dos riscos inerentes à racionalidade limitada. São "modelos suficientemente simples da realidade para serem lidados por processos de solução de problemas” e suficientemente completos para gerar todos os procedimentos e regras para seu uso em todas as possíveis situações que a organização enfrenta na área à qual estão direcionados.

Os riscos derivados do oportunismo podem ser mitigados através de monitoramento e incentivos. Além do que se discutiu acima sobre essas formas de controle de oportunismos, a literatura também mostra que grupos e equipes de trabalho tem um papel importante nessa questão. Esse papel é discutido na próxima seção.

Os riscos derivados da especificidade de ativos são mitigados através da verticalização, isto é, as empresas internalizam mais processos que dependem de investimentos específicos. Essa internalização é uma forma de evitar custos contratuais elevados devidos, ou ao temor de fornecedores de serem vítimas de oportunismo da empresa depois de fazerem os investimentos específicos, ou ao temor da empresa em se tornar refém de um fornecedor que possui algum tipo de monopólio dado o investimento específico que realizou (KLEIN et al, 1978; COASE, 1996). Esse é considerado um dos motivos do surgimento das firmas como as conhecemos em contraposição à possibilidade de se contratar tudo através dos mecanismos de mercado.

Aqui também, os PSGs podem desempenhar um papel importante na medida em que permitem estruturar sistemas de regras para promover o controle, a coordenação e a cooperação de processos internalizados, reduzindo os riscos de ineficiência e ineficácia pela falta de concorrência, um dos aspectos negativos da verticalização.

Mesmo no caso de não ocorrer a verticalização, os PSGs podem reduzir os riscos derivados da especificidade de ativos através da já citada análise crítica de contratos - que disciplina a 
aceitação de pedidos e obriga a análise de investimentos necessários - e através da avaliação e qualificação de fornecedores - que disciplina a admissão de novos fornecedores e obriga a avaliação de sua capacidade e segurança no fornecimento. Um dos principais motivos da disseminação dos PSGs nas cadeias produtivas de autopeças é dar mais segurança contratual a todas as partes, principalmente diante de riscos provocados por elevados investimentos em ativos específicos feitos por todos.

Os riscos derivados da incerteza nas transações surgem de contratos necessariamente incompletos - que não conseguem prever todas as possibilidades de mudança - e das dificuldades (custos) para se fazer valer o que foi combinado. Mais uma vez, isso tem origem na racionalidade limitada, no oportunismo latente dos envolvidos nas transações e no ambiente de constante mudança que caracteriza nossa sociedade há muito tempo:

Se nós podemos concordar que o problema econômico da sociedade é principalmente um de rápida adaptação a mudanças nas particulares circunstâncias de tempo e espaço, pareceria seguir daí que decisões definitivas devem ser deixadas para as pessoas que tem familiaridade com essas circunstâncias, que sabem diretamente das mudanças relevantes e dos recursos imediatamente disponíveis para fazer frente a elas. ${ }^{31}$ (HAYEK, 1945, p. 524).

Os PSGs promovem a criação de regras que responsabilizam e dão autoridade às pessoas familiarizadas com as circunstâncias, com as mudanças relevantes e com os recursos à disposição, disciplinam a elaboração de contratos relativamente completos, e estruturam sistemas de feedback sobre esses contratos para expor eventuais desvios. Dessa forma tendem a reduzir os riscos derivados da incerteza nas transações.

Os riscos da baixa freqüência das transações decorrem da dificuldade de amortizar custos fixos de diversos tipos. Se o problema fosse limitado a custos, porém, uma boa análise crítica de contrato seria suficiente para controlar os riscos da transação, refletindo-os no preço solicitado. Entretanto, esses riscos são amplos e ficam mais pronunciados quando se considera o risco de oportunismo de alguma das partes em situações em que a transação tem pouca chance de ocorrer novamente (ou é a única transação) e onde a reputação, para uma das partes (ou ambas) não é importante.

\footnotetext{
${ }^{31}$ If we can agree that the economic problem of society is mainly one of rapid adaptation to changes in the particular circumstances of time and place, it would seem to follow that the ultimate decisions must be left to the people who are familiar with these circumstances, who know directly of the relevant changes and of the resources immediately available to meet them
} 
A importância da reputação para as partes de uma transação depende de vários fatores: como a sociedade ou o grupo avaliam certas formas de oportunismo, qual a possibilidade de uma atitude oportunista ser comunicada à sociedade ou ao grupo, o poder da parte que se beneficia, as condições de se poder comprovar que houve um comportamento oportunista.

De novo, no caso de transações no mercado, uma boa “análise crítica de contrato” pode incluir a avaliação de risco moral na transação para reduzi-los. Em outros casos, a alternativa é internalizar a transação na organização e submetê-la a uma relação de hierarquia onde um gestor avalia os fatos e decide o que deve ser feito. É o caso de uma relação entre empregado e empregador. O empregado concorda em seguir as orientações do empregador, dentro de certos limites comumente aceitos, em troca de um salário. Mesmo assim, em grandes organizações, pode não se trivial definir o que é comumente aceito. É necessário construir um sistema de reputação dentro do grupo baseado em “[...] um conjunto de princípios e rotinas viáveis que criam expectativas partilhadas pelos membros do grupo.” 32 (MILGROM; ROBERTS, 1992, p. 265). Essa é uma definição precisa do que os PSGs se propõem a criar. Eles ajudam os administradores a criar sistemas de gestão para tomar decisões coerentes ao longo do tempo e sinalizam às pessoas o que é esperado de cada um.

Há outra forma estudada em economia para incentivar o cumprimento dos contratos. O contratante pode demonstrar, através algum tipo de ato, que tem interesse concreto em levar a cabo todas as ações necessárias para fazer valer o contrato, tanto no sentido positivo (atender o combinado) como no sentido negativo (punir a parte que não cumpre o combinado). Um general, por exemplo, pode destruir as pontes em sua retaguarda para demonstrar, ao inimigo e a seus soldados, que fará tudo ao seu alcance para vencer a batalha e avançar, já que eliminou a opção de recuar. É o que se chama de compromisso crível (credible commitment). Para criar esses compromissos críveis, na organização e entre organizações, há três mecanismos descritos por Williamson (1996).

O primeiro é a tomada de "reféns”. No setor de autopeças, nos casos em que o fornecedor precisa fazer investimentos específicos para atender a demanda de um determinado pedido da montadora além de sua atual capacidade, o cliente pode oferecer um “refém” para mostrar que não vai tentar expropriar o fornecedor depois que fez o investimento. Um tipo de “refém” é a

32 “[...] set or workable principles and routines that create shared expectations for group members” 
nomeação do fornecedor como único fornecedor do produto em questão (que é componente para toda uma linha de produtos do cliente) cujo desenvolvimento de outra fonte envolve meses de trabalho e altos investimentos por parte do cliente.

Dentro da uma cadeia de fornecimento fortemente organizada em torno de fornecedores certificados nos mesmos PSGs, que exigem rígidos procedimentos organizacionais padronizados para o desenvolvimento de novos produtos (devido às questões de qualidade, meio-ambiente e segurança), o oferecimento de “reféns” desse tipo ganha maior credibilidade.

Dentro da organização, um exemplo de “refém” oferecido pela organização para mostrar um compromisso crível para as pessoas é a certificação sob algum PSG. Para manter a certificação é necessário, obviamente, seguir as regras contidas no PSG e todos os outros níveis de regras criados por ele. A perda da certificação, além de impedir o fornecimento a determinados clientes, envia um sinal muito negativo ao mercado, prejudicando a reputação da empresa. Na medida em que todas as pessoas da organização sabem e compreendem facilmente a gravidade de tais conseqüências, sabem e compreendem que há um compromisso crível da alta administração em fazer valer o contrato de trabalho no que concerne o PSG, isto é, punir quem não segue as regras e premiar quem o faz.

Outro mecanismo é o da especificidade de ativos. Há certa similaridade com a idéia de “refém”, mas o investimento em ativos específicos pode sinalizar um compromisso crível com algo mais genérico que um contrato específico. Dentro do tema, pode-se citar como exemplo a própria opção por adotar um PSG. Sua adoção requer investimentos de vários tipos (instalações, equipamentos, treinamento, contratações e demissões, consultorias) que são altamente específicos, pois só gerarão retorno se mantidos no longo prazo e a empresa se dedicar a mercados que valorizam seus resultados. É um compromisso crível para investidores, clientes, fornecedores, funcionários e outros parceiros, como bancos e governos.

O terceiro mecanismo é a micro-análise de contratos. Devido à importância do formato dos contratos (formais e informais) para garantir seu enforcement eficiente (a custos adequados à transação), deve-se considerar a relação custo-benefício de se fazer uma micro-análise dos incentivos neles contidos e de sua credibilidade. Os PSGs, com sua ênfase em planejamento de processos e análise das causas raiz de problemas, também englobam esse mecanismo. 
Sob a perspectiva da psicologia e sociologia, indo além da hierarquia de necessidades de Maslow, a definição de motivação que segue, se diferencia do que até o momento foi discutido, indo além do simples oportunismo e da racionalidade limitada:

Motivação também pode ser definida como o processo cognitivo, de tomada de decisão através do qual o indivíduo escolhe resultados desejados, e coloca em movimento as ações apropriadas para seu alcance. ${ }^{33}$ (BUCHANAN; HUCZINSKI, 1997, p. 78).

Esse processo de decisão, porém, ocorre em indivíduos que, conforme Perrow (1993, p, 257), se caracterizam por "espontaneidade, imprevisibilidade, egoísmo, pluralidade de valores, influência recíproca, e ressentimento por dominação.” ${ }^{34}$ Perrow critica a visão da Teoria de Principal e Agente como enviesada a favor dos Principais:

[...] o problema de espoliação, ou mesmo negligência, pelo Principal é raramente considerado pelos teóricos da agência [...] as coisas estariam bem se os teóricos considerassem violações de contratos pelos Principais tão freqüentemente quanto os Agentes? Ajudaria, mas complicaria desesperadamente o modelo porque destacaria os recursos superiores do Principal no ambiente organizacional, atraindo a atenção a essa assimetria no contrato. Forçaria a questão que essas são relações de autoridade ao invés de contratuais [... ${ }^{35}$ (PERROW, 1993, p. 227-228).

Se considerarmos as características dos indivíduos e as relações de autoridade citadas pelo autor, o modelo de análise pode ser tornar realmente “desesperadamente complicado”. Apesar de essa situação criar enormes barreiras para a operacionalização de pesquisas, teóricos de organização não podem simplesmente ignorar essas questões. Psicólogos e sociólogos propõem enfrentar tal situação melhorando a dimensão humana do trabalho através de empowerment, job enrichment e job enlargement. Seriam maneiras de ampliar o domínio das pessoas sobre o seu trabalho e ampliar as alternativas para alcançar satisfação através dele.

Os PSGs, como já comentado, contam com o empowerment para garantir a eficácia do sistema de gestão. Job enrichment e job enlargement são, também, conseqüências esperadas da disseminação da informação e conhecimento e do desenvolvimento de habilidades para a ação eficiente e eficaz de todas as pessoas envolvidas nos processos submetidos às regras dos PSGs. Há, por exemplo, regras explícitas para a definição de funções que incluem

\footnotetext{
${ }^{33}$ Motivation can also be defined as the cognitive, decision-making process trough which the individual chooses desired outcomes, and sets in motion the actions appropriate to their achievement"

34 "spontaneity, unpredictability, selflessness, plurality of values, reciprocal influence, and resentment of domination"

${ }^{35}[. .$.$] the problem of exploitation or even shirking, by the principal is rarely considered by agency theorists$ [...] would things be fine if the theorists considered contract violations by the principals as often as the agents? It would help, but it would hopelessly complicate the model because it would highlight the superior resources of the principal in organizational settings, drawing attention to this asymmetry in the contract. It would force the issue that these are authority rather than contractual relationships...
} 
qualificação das pessoas para que tenham condições de se desenvolver ao longo do tempo, para a definição das necessidades de treinamento com o mesmo objetivo e para a verificação da eficácia de tais treinamentos. Pesquisas de satisfação das pessoas da organização, planos de participação nos lucros e resultados e planos de sugestões também são exigidos e contribuem para atender às recomendações acima.

\subsubsection{Incentivos e Motivação em Grupos e Equipes}

Sob a perspectiva da economia, as interações estratégicas entre pessoas dentro de grupos são freqüentemente analisadas através da Teoria dos Jogos. Os indivíduos são caracterizados como “jogadores” que precisam fazer escolhas racionais (dentro de um determinado número de possibilidades) levando em consideração o que os outros “jogadores” irão escolher já que as escolhas desses últimos influenciam o resultado da escolha do primeiro. Além disso, o “jogador” precisa levar em consideração que os outros “jogadores” podem estar fazendo cálculos semelhantes aos seus e procurando antecipar a decisão dele para obter os melhores resultados. Em geral, a Teoria dos Jogos retrata situações de dilema de prisioneiro com dois jogadores, onde a cooperação entre os “jogadores” traz o maior ganho coletivo, mas a recompensa para defecções individuais é maior que a parcela que cabe a cada um em uma situação cooperativa. Entretanto, a recompensa individual, caso todos os indivíduos recorrerem à defecção, é menor que em ambas as situações anteriores. Assim, recorrer à defecção só vale a pena se o “jogador” esperar que os outros não façam o mesmo.

Um jogo de dilema de prisioneiro com várias pessoas pode ser comparado à dinâmica de uma equipe de trabalho se for considerada a propensão natural das pessoas de shirking (evitar o esforço, negligenciar uma tarefa) se aproveitando do esforço dos outros (free-riding). Esse tipo de jogo - chamado de “dilema do prisioneiro repetido para muitos jogadores” 36 (DOUMA; SCHREUDER, 2002, p. 87), ou de “dilema do prisioneiro multi-pessoas” 37 (MPD) (SCHELLING, 1978) - é adequado para descrever a situação de equipes que trabalham juntas continuamente, e dentro de organizações, já que considera várias interações (e não só uma) e vários jogadores (mais de dois). Se não houver mecanismos de controle, coordenação e/ou cooperação, a tendência é que os esforços das pessoas da equipe encontrem um equilíbrio abaixo de seu real potencial.

\footnotetext{
36 “iterated prisoners dilemma for many players"

${ }^{37}$ multi-person prisoners' dilemma
} 
Essa situação é também classificada como “equilíbrio de Nash” ${ }^{38}$ (WEISSTEIN, 2003, p. 1987): nenhuma pessoa pode melhorar sua situação alterando sua estratégia sozinha, isto é, nenhum trabalhador consegue melhorar seu retorno se esforçando mais, pois seu esforço, além de ter seu resultado aproveitado por todos, também é anulado pelos colegas que, percebendo seu esforço adicional optam por ampliar seu shirking. Para a organização o problema que essa situação não alcança um ótimo de Pareto (PINDYCK e RUBINFELD, 1998) e, portanto, há perdas de eficiência.

Por outro lado, Axelrod (1984) demonstra que a cooperação, em um ambiente de MPD, havendo a possibilidade de seguidas interações, pode surgir desde que haja um pequeno grupo que adote a estratégia chamada de “TIT for TAT" (WEISSTEIN, 2003, p. 2987). Essa estratégia é muito simples: na primeira rodada coopera-se e nas rodadas seguintes escolhe-se a mesma ação que o outro jogador escolheu. Se houver cooperação, responde-se com cooperação. Se houver não-cooperação responde-se retaliando com não-cooperação.

Os PSGs possuem regras que demandam “ações corretivas” sempre que há uma "não conformidade” relevante (ANBT, 2000a, p. 11-12). “Não conformidades” são ações, voluntárias ou não, que resultam em perdas para a organização e seus stakeholders. Chamar as “ações corretivas" dos PSGs de retaliação pode parecer muito forte, mas as regras dos PSGs exigem que se verifique a eficácia dessas ações corretivas a posteriori e, caso essa não seja alcançada, a “ação corretiva” deve ser intensificada ou alterada para que gere os efeitos pretendidos. Caso a "não conformidade” seja resultado de um comportamento oportunístico (por exemplo, negligência e relaxamento de um operador de máquina sem supervisão) ele é exposto e desestimulado pelas reações da organização.

Essa é uma das formas que os economistas desenvolveram para operacionalizar um dos desafios da produção em grupo para alcançar melhor eficiência. Com base nessas idéias, os autores abaixo resumem de forma clara uma interpretação econômica da função do administrador e da estrutura de contratos da firma para premiar e induzir os trabalhadores a trabalhar eficientemente (sem shirking) e eficazmente:

\footnotetext{
38 "Nash equilibrium”
} 
Monitorar e mensurar as produtividades para equiparar produtividades marginais a custos de inputs a, dessa forma, reduzir shirking, pode ser alcançado de forma mais econômica (que através de negociações bilaterais de mercado entre inputs) em uma empresa.

[...] Nenhum controle autoritário é envolvido; o arranjo é simplesmente uma estrutura contratual sujeita a contínuas negociações com o agente central (dono ou empregador). A estrutura contratual surge como um meio de reforçar a organização eficiente da produção em equipe. Em particular, a habilidade de detectar shirking, entre donos de inputs usados em conjunto na produção, é reforçada (custos de detecção são reduzidos) por esse arranjo e a disciplina (pela revisão de contratos) dos donos dos inputs é tornada mais econômica ${ }^{39}$. (ALCHIAN; DEMSETZ, 1972, p. 794).

Os autores propõem em seu artigo que a vantagem das firmas sobre o mercado, para coordenar trabalhos de grupos, está na redução dos custos de detecção e de renegociação de contratos entre as partes. Os PSGs são guias para se construir uma estrutura contratual com custos de detecção e de revisão de contratos mais econômica. São instrumentos nas mãos dos “agentes centrais” para a melhoria dos contratos e de sua contínua renegociação.

Alchian e Demsetz descartam a viabilidade de esquemas de auto-gestão dados os custos mais elevados para detectar e renegociar esses tipos de contratos para evitar shirking. Um "agente central”, para exercer essa função de “policial” e renegociador de contratos, recebe como remuneração um valor residual resultante da maior eficiência do trabalho do grupo. A relação custo-benefício dessa remuneração residual tende a ser melhor que a de uma auto-gestão.

Outra abordagem econômica relevante neste contexto é a Teoria Comportamental da Firma Behavioral Theory of the Firm (CYERT e MARCH, 1992). A proposta dos autores, que avançam a partir das bases colocadas por March e Simon (1993), tem três pontos principais.

O primeiro é que as firmas devem ser vistas como coalizões de participantes ao invés de um conjunto de indivíduos ou um todo homogêneo. Essas coalizões são formadas de acordo com diversas condições internas e externas à organização, mas podem ser basicamente identificadas com os chamados stakeholders: acionistas, funcionários, clientes, fornecedores e sociedade.

\footnotetext{
${ }^{39}$ Monitoring and metering the productivities to match marginal productivities to costs of inputs and thereby reduce shirking can be achieved more economically (that across market bilateral negotiations among inputs) in a firm.

[...]No authoritarian control is involved; the arrangement is simply a contractual structure subject to continuous negotiation with the central agent [owner and employer]. The contractual structure arises as a mean of enhancing efficient organization of team production. In particular, the ability to detect shirking among owners of jointly used inputs in production is enhanced (detection costs are reduced) by this arrangement and the discipline (by revision of contracts) of input owners is made more economic.
} 
O segundo é que as firmas não possuem um objetivo único, mas sim objetivos múltiplos gerados através de processos de barganha entre as coalizões de participantes. Devido a esse processo, os autores argumentam que conflitos nunca estão completamente resolvidos. "Com respeito à firma contemporânea - e preço, output, e decisões estratégicas de vendas - nós temos argumentado que podemos identificar cinco metas principais: produção, estoques, vendas, fatia de mercado, e lucro.” ${ }^{40}$ (CYERT; MARCH, 1992, p. 50).

O terceiro é que as firmas procuram se adaptar ao meio ambiente, mas, devido a problemas de racionalidade limitada, fluxo de informação, inércia organizacional e conflitos permanentes entre coalizões, sempre estão em uma “combinação ambiental imperfeita” ${ }^{41}$ (CYERT; MARCH, 1992, p. 215), isto é, a forma que assumem não é a ideal frente ao ambiente em que atuam. Decorre daí também a presença simultânea de diferentes formas organizacionais dentro de setores e ambientes similares. A Teoria Comportamental da Firma enfatiza que "as maneiras nas quais a combinação entre um ambiente e as regras seguidas pela organização podem ser lentas em evoluir ou indeterminadas, daí a importância de especificar os processos de adaptação organizacional” 42 (CYERT; MARCH, 1992, p. 215)

Dadas essas condições os autores propõem uma "teoria de escolha e controle organizacional" 43 (CYERT e MARCH, 1992, p. 134) que enfatiza a importância das regras organizacionais para o processo de adaptação organizacional, especialmente no longo prazo. Essa teoria reforça, mais uma vez, a importância de sistemas de regras eficientes e eficazes para o desempenho das organizações.

Mais uma vez, sistemas de regras são vistos, não como limitadores da inovação, aprendizado e adaptação, mas, ao contrário, como condição necessária para que esses processos ocorram de forma eficiente e eficaz. Os autores explicam essa dinâmica:

Nós assumimos:

1) Meta múltipla, mutável, de nível-aceitável. O critério de escolha é aquele que alternativas selecionadas atendem todas as demandas (metas) da coalizão.

\footnotetext{
40 "With respect to the contemporary firm - and price, output, and sales strategy decisions - we have argued that we can identify five major goals: production, inventory, sales, market share, and profit."

41 "Imperfect environmental matching”

42 "...the ways in which the match between an environment and the rules followed by the organizations may be slow to evolve or indeterminate, thus the importance of specifying the process of organization adaptation."

43 "Theory of organizational choice and control"
} 
2) Uma consideração de alternativas aproximadamente seqüencial. A primeira alternativa satisfatória evocada é aceita. Onde uma política existente satisfaz as metas, há pequeno interesse em procurar por alternativas. Quando uma falha ocorre, a procura é intensificada.

3) A organização procura evitar incerteza seguindo procedimentos regulares e a política de reagir a feedback ao invés de prever o ambiente.

4) A organização usa procedimentos operacionais padronizados e aproximações para fazer e implementar escolhas. No curto prazo esses procedimentos dominam as decisões feitas. ${ }^{44}$ (CYERT; MARCH, 1992, p. 134).

Nesse contexto predomina o critério de satisficing (já apresentado anteriormente) como explica o item 2: se a alternativa evocada é suficiente para atingir o objetivo, a busca por alternativas é encerrada. Dada a racionalidade limitada, devida à limitação humana para a obtenção de informações e o seu processamento, satisficing é uma alternativa mais eficiente e eficaz que optimizing - porque não se consegue definir os parâmetros de otimização.

Para ajudar a explicar o funcionamento da organização em um ambiente de satisficing, de ajustes não imediatos às mudanças e de objetivos diferentes entre coalizões, os autores introduzem o conceito de "folgas organizacionais" 45 (CYERT; MARCH, 1992, p. 44): como há atritos nos processos de barganha entre coalizões, uma organização que está operando nunca está no equilíbrio imaginado pela teoria econômica convencional, que considera que a única folga é a remuneração dos proprietários. Por exemplo: os salários pagos estão acima do mínimo que poderia ser pago para manter os empregados na organização, os preços estão em média abaixo do que os clientes aceitariam, a qualidade está acima do que seria o mínimo aceitável, executivos recebem benefícios maiores do que seriam necessários para mantê-los na empresa, etc. Essas folgas são importantes pois, se não existissem, as flutuações do ambiente provocariam fortes instabilidades na organização. "Folga opera para estabilizar o sistema de duas formas: (1) absorvendo excesso de recursos, ela retarda o ajuste de aspirações durante momentos relativamente bons; (2) provendo uma fonte de recursos de emergência, ela permite

\footnotetext{
${ }^{44}$ We assume:

1. Multiple, changing, acceptable-level goal. The criterion of choice is that the alternatives selected meet all of the demands (goals) of the coalition.

2. An approximate sequential consideration of alternatives. The first satisfactory alternative evoked is accepted. Where an existing policy satisfies the goals, there is little search for alternatives. When failure occurs, search is intensified.

3. The organization seeks to avoid uncertainty by following regular procedures and a policy of reacting to feedback rather than forecasting the environment.

4. The organization uses standard operating procedures and rules of thumb to make and implement choices. In the short run these procedures dominate the decisions made.

45 "organizational slack"
} 
que as aspirações sejam mantidas (e alcançadas) durantes momentos relativamente ruins” 46 (CYERT; MARCH, 1992, p. 44).

Os PSGs, promovendo a criação de regras eficientes e eficazes, auxiliam a reduzir as folgas operacionais ao mesmo tempo em que mantêm as coalizões satisfeitas. Dessa forma, preservam a estabilidade organizacional e, simultaneamente, liberam mais recursos para o desenvolvimento do negócio ou como lucro para os proprietários. Por exemplo, pesquisas de satisfação interna e pesquisas de satisfação de clientes (exigidas pelos PSGs) ajudam a monitorar eventuais folgas nessas coalizões e melhor direcionar o uso dos recursos escassos da organização.

Sob a perspectiva da psicologia e da sociologia, uma abordagem relevante é a dos papéis: “Papel é um padrão de comportamento esperado, pelos outros, de uma pessoa ocupando certa posição em uma organização hierárquica” ${ }^{47}$ (BUCHANAN; HUCZYNKI, 1997, p. 374). Essa é uma das alternativas às teorias de escolha racional. As pessoas, sob a influência do grupo em que estão inseridas, adotariam comportamentos - e tomam decisões e ações - com base no que acham que se espera de um ocupante do seu cargo (ou papel). É como uma profecia que se auto-realiza, isto é, se todos esperam que a pessoa haja como um chefe, ele acabará agindo. Uma experiência dando papéis de prisioneiros e guardas em um estudo controlado (ZIMBARDO et al, 1973) mostrou que as pessoas rapidamente (em poucas horas) assumem o papel a que foram alocados mudando completamente seu comportamento habitual, mesmo que isso as coloque em uma situação desconfortável. A experiência de Zimbardo mostrou que a força do papel pode ser maior que o controle e a capacidade de racionalização, mesmo quando as pessoas sabem que a situação é meramente uma simulação.

Outros estudos sobre papéis (ASCH, 1952) mostram que decisões em grupo tendem a ser ineficazes, pois membros do grupo tendem a mudar suas opiniões e atitudes no sentido de se alinhar com a visão da maioria ou de alguma liderança, mesmo que percebam, inicialmente, que o grupo está equivocado. Esse comportamento estaria ligado à tendência das pessoas de seguir normas (regras) sociais. Existiria um acordo tácito entre as pessoas de que é necessário

\footnotetext{
46 "Slack operates to stabilize the system in two ways: (1) by absorbing excess resources, it retards adjustment of aspirations during relative good times; (2) by providing a pool of emergency resources, it permits aspirations to be maintained (and achieved) during relatively bad times."

47 "Role is a pattern of behavior expected by others from a person occupying a certain position in na organization hierarchy.”
} 
seguir regras para que a vida possa transcorrer se problemas e decisões a serem tomadas a todo o momento. A conformidade a essas regras aconteceria através de três mecanismos.

O primeiro seria ceder às pressões do grupo em função de três fatores:

a) Distorção de percepção: uma pessoa pouco segura de si passa a acreditar em fatos que o grupo acredita, mesmo que, inicialmente, saiba que esses fatos nunca existiram;

b) Distorção de julgamento: nesse caso, partindo-se de fatos conhecidos por todos, o julgamento da pessoa muda completamente diante do julgamento do grupo;

c) Distorção de ação: mesmo pessoas que sabem que o que sabem está correto e seu julgamento também - e oposição ao que o grupo considera correto - cedem e agem conforme a maioria para não parecerem diferentes ou não tolerarem a aparência de “traidor” frente ao grupo.

O segundo mecanismo seria baseado na necessidade das pessoas de dar ordem e sentido a suas vidas. Incerteza gera desconforto e as pessoas preferem criar modelos da realidade incompletos (modelos são sempre incompletos) e até mesmo incorretos, para não precisar fazer análises extensas a cada momento para tomar decisões e agir. Um importante elemento nesses modelos são as regras: diante de determinado tipo de situação há uma decisão/ação pré-definida a ser tomada.

O terceiro mecanismo seria baseado na necessidade de conformidade e aceitação pelos outros. Para a formação de uma identidade as pessoas precisariam se comparar com os outros e receber aceitação por parte desses de seu comportamento. As regras seriam o padrão de medida e comparação.

Todas essas idéias reforçam a importância das regras para a organização. Os PSGs são manuais de instruções para elaborar um modelo de realidade para as organizações. Os PSGs definem quais parâmetros devem ser pesquisados e incluídos no modelo (satisfação de clientes, preservação do meio ambiente, relação com fornecedores, respeito às leis, busca de eficiência e eficácia, etc.) e de que forma o modelo deve ser representado (manuais, procedimentos, instruções de trabalho, registros, documentos, etc.). Os PSGs também definem como o modelo deve ser implantado (declarações de políticas, participação das pessoas, 
treinamento, disponibilidade física) e usado (regras para manutenção do sistema, incentivos e punições para não atendimento das regras).

Se as pessoas precisam de modelos de realidade para poder tomar decisões e agir de forma eficiente e eficaz, eles tenderão a criar esses modelos na falta de um. A adoção de PSGs pode ser uma forma de melhorar a qualidade desses modelos no que se refere ao atendimento dos interesses dos stakeholders da organização.

\subsubsection{Poder e autoridade}

Sob a perspectiva da economia, poder e autoridade em organizações são conceitos controversos já que, se considerarmos sociedades onde as pessoas são livres, a entrada e permanência em uma organização são voluntárias e, portanto, seguir suas regras é um ato de livre arbítrio e não de sujeição ao poder de alguém. Uma visão talvez simplista é que, se de um lado o empregador pode ordenar ao empregado fazer qualquer coisa que a lei não proíba, do outro lado o empregado pode simplesmente pedir demissão se não concordar.

Simon (1951) sugere que o empregador assina um cheque em branco no momento em que contrata um empregado na esperança que este desempenhe a função para a qual foi contratado. É o contrário do que ocorre com um contrato no mercado - como exemplifica Simon, uma empreitada para a construção de uma calçada - onde o vendedor recebe em função da entrega de um combinado facilmente verificável, uma relação de emprego (isto é, dentro de uma organização) envolve um contrato onde o comprador paga antecipadamente (sem poder exigir devolução) pelo direito de exigir do vendedor que faça algo (sempre especificado de forma incompleta), mas sem nenhuma garantia de que o mesmo irá empenhar seus melhores esforços para cumpri a tarefa. Essa relação envolve uma constante barganha. “O contrato de trabalho usual é muito mais um contrato relacional: ele enquadra a relação, especificando seus termos e objetivos amplos e definindo alguns mecanismos de decisão quando eventos imprevistos ocorrem” ${ }^{48}$ (MILGROM; ROBERTS, 1992, p. 330).

\footnotetext{
48 "The usual employment contract instead is much more a relational contract: it frames the relationship, specifying broad terms and objectives and putting in place some mechanisms for decision making when unforeseen events occur."
} 
O processo de barganha e o uso dos mecanismos de decisão podem ser custosos. Assim é necessário explicar porque se recorre a esse tipo de relação. Uma explicação muito citada na literatura é a de que é mais eficiente (menos custoso) dar a alguém o poder de decidir a respeito das situações não previstas completamente no contrato, isto é, dar as ordens de que tipo de trabalho deve ser realizado, controlar se está sendo realizado dentro de padrões aceitáveis e tomar providências caso não esteja. Caso esse poder não seja dado a alguém, os custos e o tempo envolvidos em barganhas constantes entre empregador e empregado inviabilizariam a organização. Mesmo em uma administração participativa, pode ser impossível chegar a algum consenso e minorias podem prejudicar todos os outros. A solução é delegar a alguém o poder de fazer valer a decisão da maioria.

Também se sugere que o poder deve ficar nas mãos de quem corre o maior risco na organização. Como, em geral, o empregador garante o pagamento dos salários do empregados independentemente dos resultados da empresa (desde que fique solvente) à custa do capital empenhado na empresa, é ele que exerce o poder na organização. Em organizações onde o capital empregado é de outra natureza - por exemplo, em escritórios de advocacia, engenharia, arquitetura e consultoria - o poder de decisão usualmente fica nas mãos dos que detêm o capital intelectual.

Outra proposição coloca as organizações (firmas) como detentoras de reputação, principal fator que as permite atuar no mercado e garantir a sobrevivência em longo prazo. Como a vida da organização usualmente supera o tempo de permanência das pessoas nela, são os proprietários da organização que devem deter o poder necessário para garantir a preservação de sua reputação. Os proprietários teriam incentivos mais fortes que qualquer outra parte para tomar decisões boas para a organização como um todo, isto é, para todos os seus stakeholders, já que da satisfação deles depende a reputação da organização e o valor dela no mercado.

Sob qualquer ponto de vista, há sempre um processo de barganha na relação de poder. Os PSGs reduzem os custos desse processo de barganha já que complementam, com um alto grau de detalhe, os contratos de emprego. Como exemplo desse grau de detalhe podem-se citar as regras de PSGs que demandam a definição clara de: políticas e valores da organização, relações de autoridade e responsabilidade, descrição de processos, descrição de funções, procedimentos no caso de não-conformidades, instruções de trabalho e definição de indicadores de desempenho. Adicionalmente, os PSGs exigem que todas essas regras estejam 
acessíveis a qualquer pessoa da organização desde o primeiro dia de trabalho tornando, assim, muito mais transparente o processo de barganha.

Antes de se passar para as perspectivas da psicologia e da sociologia, que tendem a dar muita relevância ao poder, vale a pena citar uma no extremo oposto:

É comum ver a firma caracterizada pelo poder de resolver questões por direito, autoridade, ou por ação disciplinadora superior daquela disponível no mercado convencional. Essa é uma ilusão. A firma não é proprietária de todos seus inputs. Ela não tem qualquer poder legal, nem autoridade, nem ação disciplinadora diferente, no menor grau, do que contratações em mercados comuns entre duas pessoas quaisquer. Eu posso "punir" você somente suspendendo negócios futuros ou buscando compensação nas cortes por qualquer falha em honrar nosso acordo de troca. Isso é exatamente tudo o que um empregador pode fazer. Ele pode demitir ou processar, assim como eu posso demitir o dono da mercearia onde compro parando de comprar dele ou processando-o por entregar produtos com falhas [...] Falar de administração, direção, ou de designar trabalhadores a várias tarefas é uma maneira enganosa de registrar que o empregador está continuamente envolvido na renegociação de contratos em termos que precisam ser aceitáveis para ambas as partes. ${ }^{49}$ (ALCHIAN; DEMSETZ, 1978, p. 777).

Os PSGs tornam essas “negociações de contratos” mais eficientes e eficazes já que detalham os contratos com relativa precisão e prevêem mecanismos de renegociação - através da revisão de manuais, procedimentos, instruções de trabalho, mapas de processos, etc. - que envolvem todos os stakeholders da organização.

Sob a perspectiva da psicologia e sociologia, há outras maneiras de se encarar poder e autoridade nas organizações. Katz e Kahn (1978) resumem a visão de Weber sobre o poder nas organizações em três formas. A primeira é a autoridade tradicional, decorrente de direitos herdados. A segunda forma é a autoridade carismática, que não está ligada a nenhum tipo de regra, mas a características pessoais de um líder. Essa é considerada temporária e idiossincrática e, portanto, de pouca importância para a análise ampla das organizações. A terceira forma, mais relevante aqui, é a que chamam de "autoridade legal-racional” ${ }^{50}$ (KATZ; KAHN, 1978, p. 299). Suas características seriam a seguintes:

\footnotetext{
${ }^{49}$ It is common to see the firm characterized by the poser to settle issues by fiat, by authority, or by disciplinary action superior to that available in the conventional market. This is a delusion. The firm does not own all of its inputs. It has no power of fiat, no authority, no disciplinary action any different in the slightest degree from ordinary market contracting between any two people. I can "punish" you only by withholding future businesses or by seeking redress in the courts for any failure to honor our exchange agreement. That is exactly all that any employer can do. He can fire or sue, just as I can fire my grocer by stopping purchases from him or sue him for delivery of faulty products [...] To speak of managing, directing or assigning workers to various tasks is a deceptive way of noting that the employer continually is involved in renegotiation of contracts on terms that must be acceptable to both parts

50 "rational-legal authority"
} 
1. Uma contínua organização de funções oficiais limitadas por regras.

2. Uma esfera específica de competência baseada na divisão do trabalho, com autoridade e sanções para assegurar o adequado desempenho dos papéis.

3. Um arranjo hierárquico de funções em termos de supervisão e controle.

4. O governo da conduta de uma função por regras técnicas ou por normas e a exigência de treinamento especializado para os responsáveis por essas funções.

5. Completa separação da propriedade pertencente à organização e a propriedade pertencente ao funcionário...

6. A ausência de direitos do responsável sobre a função. O detentor da função não deve se apropriar da posição oficial para interesses pessoais ou privados.

7. Atos administrativos, decisões, e regras são formulados e registrados por escrito...A combinação de documentos escritos e a contínua organização de funções oficiais constituem o "office" que é o foco central de todos os tipos de ações corporativas modernas. ${ }^{51}$ (KATZ; KAHN, 1978, p. 299).

Apesar de datada e alvo de críticas constantes, a visão de burocracia e poder de Weber ainda é a base de comparação para alternativas que surgiram após. Os próprios Katz e Kahn (1978, p. 299) aceitam isso fazendo referência à burocracia de Weber: "Para a utilização máxima das fontes de energia no ambiente, incluindo fontes humanas, e sua transformação em produtos sociais, a organização social formal pode ser a maior invenção social da história.” ${ }^{52}$ Os autores contribuem para essa abordagem do poder nas organizações propondo as condições que levam as pessoas a obedecer às regras da organização. A tabela abaixo resume a proposta:

${ }^{51}$ 1. A continuous organization of official functions bound to rules.

2. A specified sphere of competence based on a division of labor with authority and sanctions to ensure proper role performance.

3. A hierarchical arrangement of offices in terms of supervision and control.

4. The governing of the conduct of an office by technical rules or by norms and the requiring of specialized training for the incumbents of these offices.

5. Complete separation of the property belonging to the organization and the property belonging to the official...

6. The lack of rights to the office by the incumbent The office-holder must not appropriate the official position for personal or private interests.

7. Administrative acts, decisions, and rules are formulated and recorded in writing...The combination of written documents and the continuous organization of official functions constitute the "office" which is the central focus of all types of modern corporate action.

52 "For maximum utilization of the energy sources in the environment, including human sources, and their transformation into social products, the formal social organization may be the greatest social invention in history." 
Tabela 1 - Condições e métodos para usar o modelo de autoridade legal-racional

\begin{tabular}{l} 
Condição Objetiva \\
\hline Práticas normativas de socialização das instituições \\
sociais \\
Uso de símbolos de autoridade apropriados \\
Clareza de normas legais e exigências \\
Uso de penalidades específicas e disponibilidade de \\
força física \\
Expulsão de não conformes
\end{tabular}
Variáveis psicológicas mediadoras

Internalização de normas de conformidade

Reconhecimento e aceitação de símbolos

Ausência de subjetividade ambígua que permita

interpretações desejadas (preferidas)

Expectativa individual de ser pego

Desejo de ficar dentro do sistema: dependência do sistema para seu estilo de vida

FONTE: adaptado de KATZ; KAHN, 1978, p. 306

Os autores admitem o excesso de foco no uso de incentivos negativos (punições) nesse modelo e reconhecem a tendência ao uso de modelos que combinam o uso de incentivos positivos, no que se usa chamar de "cenoura e bastão" ${ }^{53}$. Outro problema que admitem existir nesse modelo - e que é uma crítica comum à burocracia - é o seu custo. Organizações que dependem excessivamente em estruturas burocráticas de poder para conseguir controlar, coordenar e obter cooperação das pessoas, podem acabar tendo excesso de níveis hierárquicos e, portanto, custos administrativos excessivos.

A opção seriam organizações que utilizem mecanismos de empowerment e participação para obter o controle, a coordenação e a cooperação necessários para competir. Haveria, então, condições ideais para o uso de estruturas fortemente hierárquicas e outras ideais para estruturas participativas. As condições ideais para estruturas hierárquicas seriam:

a) Tarefas com exigências mínimas de criatividade, e o envolvimento com os objetivos organizacionais dispensável;

b) As exigências do ambiente sobre a organização são claras, suas implicações óbvias e, portanto, a informação que chega à organização em vários pontos é redundante, não sendo necessária sua coleta em vários pontos da organização;

c) Quando a velocidade de decisão é importante e o envolvimento de muitas pessoas no processo gera custos, riscos e atrasos;

d) Quando os processos da organização são similares a sistemas fechados, com pouca interação com o ambiente.

\footnotetext{
53 “carrot and stick”
} 
Pode-se perceber que, com exceção do item (c), são cada vez mais raras as organizações que operam nessas condições. Daí deriva a constante procura por formas de organização que combinem as qualidades da burocracia Weberiana com a agilidade de organizações com maior participação das pessoas nas decisões.

O dilema parece estar no equilíbrio entre um modelo suficientemente estável de organização e um modelo que distribui suficientemente poder e informação. Os PSGs podem ser considerados uma contribuição para a solução a esse dilema. Ironicamente, as maiores evidências dessa possibilidade talvez venham das críticas que os PSGs recebem. De um lado são considerados formas de engessamento das organizações com seus manuais, procedimentos, instruções de trabalho e outras regras que permeiam todos os processos. De outro lado, são temidos por alguns gestores pela perspectiva de dividirem poder com toda a estrutura dada a disseminação de informação, conhecimento e poder de decisão sobre uma ampla gama de questões. Como se vê, uma combinação bem sucedida dessas características iria na direção de um modelo de organização estável, mas também flexível diante das mudanças do ambiente.

Perrow (1993) apresenta de outra forma o dilema organizacional que envolve poder e a burocracia Weberiana. Para o autor, estruturas fortemente hierárquicas - com o poder claramente concentrado no topo - incentivam a geração de "poder de soma-zero" 54 (PERROW, 1993, p. 259), isto é, o poder é disputado para a divisão de um volume de recursos definido e, portanto, para que alguém ganhe, outro precisa perder. Por exemplo, se o proprietário quer aumentar seus lucros, tenta usar o poder que tem - através de demissões para reduzir salários.

De forma oposta, se os trabalhadores querem aumentar seus salários, tentam usam o poder que têm - através de sindicatos, greves - para se apropriar de uma parcela maior dos lucros que ajudam a gerar. Qualquer que seja o resultado da disputa de poder, porém, o valor total de recursos gerados é o mesmo ou, eventualmente, menor, dados os custos do conflito. Perrow (1993, p. 258-259) propõe que:

\footnotetext{
"Uma organização que permite a seus empregados autonomia e um escopo para ação amplo terá recursos mais amplos para explorar do que uma que não o faz. Uma organização que convence seus empregados que seus objetivos são compatíveis com aqueles dos líderes gera mais capacidade
}

\footnotetext{
54 “zero-sum power"
} 
de ação e, nesse sentido, mais poder...A maioria dos recursos nas organizações e na sociedade podem ser expandidos; muito esforço é desperdiçado em conflitos improdutivos e até mesmo em negligência, que freqüentemente requer esforço.” 55

Os PSGs são formas de dar a sugerida "autonomia e escopo de ação amplo”, ajudam a “convencer os empregados que seus objetivos são compatíveis com os da organização” qualidade de produtos e processos, preservação do meio-ambiente, saúde e segurança no trabalho, responsabilidade social - e reduzem o desperdício de recursos em conflitos e negligência já que definem regras claras e processos decisórios participativos.

\subsubsection{Cultura Organizacional}

O que se deve perguntar aqui é como a cultura organizacional ajuda no controle, na coordenação e na cooperação entre as pessoas de uma organização. Sob a perspectiva da economia, a cultura organizacional pode ser representada pelo conjunto de expectativas que as pessoas têm sobre como as outras irão se comportar diante de determinadas situações. Esse conjunto de expectativas pode ser chamado de sistema de reputações (MILGROM; ROBERTS, 1992).

A pesquisa econômica mostra que o sistema de reputações existente em uma organização, ou entre organizações, é uma importante fundação para diversos tipos de transação. Entretanto, as pesquisas também mostram que as reputações de confiança podem ser destruídas mais facilmente do que construídas já que diversos fatores - altos incentivos, diferenças de personalidade, diferenças culturais externas, experiências pessoais - podem levar pessoas a trair a confiança que recebem dos outros. Dessa forma, uma cultura que dissemina confiança entre as partes reduz os custos de se obter controle, coordenação e cooperação, mas não elimina o risco de oportunismo (DOUMA; SCHREUDER, 2002).

Sistemas de regras são citados explicitamente como formas de melhorar a eficácia do sistema de reputação e, assim, criar uma cultura organizacional também mais eficaz:

\footnotetext{
${ }^{55}$ An organization that allows its employees autonomy and broad scope for action will have resources to drawn on than one that doesn't. An organization that convinces its employees that their goals are compatible with those of the leaders will generate more capacity for action and in this sense more power...Most resources in organizations and society can be expanded; much effort is wasted in unproductive conflict and even shirking, which often requires effort.
} 
Uma maneira de aprimorar a eficácia de um sistema de reputações dentro de um grupo é construir ou fazer evoluir um conjunto de princípios e rotinas trabalháveis que criam expectativas compartilhadas para os membros do grupo. Em grandes organizações, os princípios ajudariam a guiar os administradores a tomar decisões como também a prover um conjunto claro de expectativas para todos na organização. Às vezes, rotinas evoluem sem propósitos de longo alcance em mente, mas simplesmente representam padrões de ação que funcionaram bem no passado. Em outros exemplos, os princípios tomam a forma de regras explícitas promulgadas com um claro propósito em mente [...] Dessa perspectiva, cultura corporativa é o conjunto de rotinas para tomada de decisão e expectativas compartilhadas ensinado aos empregados e as estórias e relativos dispositivos usados para expressar aquelas expectativas. ${ }^{56}$ (MILGROM; ROBERTS, 1992, p. 265).

Nota-se a semelhança da descrição de cultura feita acima com os PSGs. Eles englobam tanto as "rotinas que evoluem sem um propósito de longo alcance" - sob a forma de mudanças em procedimentos e instruções de trabalho derivadas de "ações corretivas" - como "as regras explícitas promulgadas com um claro propósito” - sob a forma de visão, missão, valores, manuais e procedimentos elaborados no momento da implantação dos PSGs ou alterados com base nas auditorias do sistema de gestão.

Sob a perspectiva da administração, cultura organizacional recebe definições diferentes, mas que mantêm ligações com as outras propostas. Um exemplo relevante é o de Mintzberg (1989) em que chega a propor outra nomenclatura para cultura organizacional: ideologia. O autor considera a ideologia como a sexta e última “parte” da organização, aquela que “[...] engloba as tradições, e crenças de uma organização e que a distingue de outras organizações e injeta certa vida no esqueleto da sua estrutura” ${ }^{57}$ (MINTZBERG, 1989, p. 98). O esqueleto da estrutura seria composto pelo núcleo operacional, o apex estratégico, a linha média, a estrutura técnica e a equipe de suporte - essas duas últimas servindo como apoio, fora da linha hierárquica principal.

É interessante notar que Minzberg considerava a organização como tendo cinco partes sendo a ideologia uma parte que surgiria apenas depois da definição das cinco primeiras e que seria difícil de perceber. A exceção seriam as organizações que chama de "missionárias” que seriam:

\footnotetext{
${ }^{56}$ One way to enhance the effectiveness of a system of reputations within a group is to construct or evolve a set of workable principles and routines that create shared expectations for group members. In a large organization, the principles would help guide the managers in making decisions, as well as providing a set of clear expectations for everyone in the organization. Sometimes, routines evolve with no far-reaching purpose in mind, but simply represent patterns of action that have worked well in the past. In other instances, the principles take the form of explicit rules promulgated with clear purpose in mind...From this perspective, corporate culture is the set of routines for decision making and shared expectations that employees are taught and the stories and related devices used to convey those expectations.

57 "[...] encompasses the traditions and beliefs of na organization and infuses a certain life into the skeleton of its structure."
} 
[...] construídas em torno de uma missão inspiradora [...] e de um conjunto de crenças e normas que a acompanha. Em relação a isso, a Missionária é uma forma de burocracia, já que se coordena baseada na standardização das normas. Nesse sentido, ela é também inflexível e não-adaptativa [...] Em outra relação, entretanto, a Missionária é muito diferente de nossas outras formas de burocracia. Acima de tudo, ela é muito solta estruturalmente. Uma vez que seus novos membros são devidamente socializados e doutrinados, estabelecendo sua lealdade não dividida, pode-se confiar que farão seu trabalho livre de todos os controles da burocracia convencional. Em outras palavras, controle "normativo" é mais que suficiente para atingir a maior parte da necessária coordenação. De fato, tal lealdade pode ser mantida somente confiando igualitariamente em todos os membros, o que exige dispensá-los desses controles. Isso também requer uma missão simples e um sistema técnico simples, ambos livres da necessidade de habilidades especiais e todas as diferenças de status que as acompanham. ${ }^{58}$ (MINTZBERG, 1993, p. 294-295).

Essa descrição de Mintzberg é, como o próprio autor admite (MINTZBERG, 1989), muito influenciada pela administração das empresas japonesas. Em uma época (décadas de 1980 e início de 1990) em que o modelo japonês de gestão, favorecido pela cultura do país, era estudado e copiado, por ser considerado melhor que os modelos “ocidentais”, é natural que se buscassem explicações como a proposta pelo autor acima.

Entretanto, essa influência criou algumas confusões, como pode ser percebido na exposição acima de Mintzberg. O autor responsabiliza a "standardização das normas” por uma suposta “inflexibilidade e não-adaptabilidade”. Por outro lado, diz que organização é "muito solta estruturalmente" e que se pode confiar que os membros farão o "seu trabalho livres de todos os controles da burocracia”, isto é, livres dos controles supostamente definidos pela “normas”. A seguir, afirma que o “controle 'normativo' é mais que suficiente para atingir a maior parte da coordenação". Nesse caso, aparentemente, as "normas” seriam boas o suficiente para atingir seus objetivos - de controle, coordenação e cooperação - sem a necessidade da maioria dos controles burocráticos.

É difícil entender como regras desse tipo seriam responsáveis por falta de flexibilidade e adaptabilidade. Além disso, é quase uma unanimidade que o modelo japonês de gestão representado por técnicas como Just-in-Time, TQM, Lean Manufacturing, etc. - proporciona

\footnotetext{
${ }^{58}$ [...] built around an inspiring mission [...] and an accompanying set of beliefs and norms. In this later respect, the Missionary is a form of bureaucracy, since it coordinates based on the standardization of norms. In that sense, it too is inflexible and nonadaptive [...] In other respects, however, the Missionary is very different from our other forms of bureaucracy. Above all, it is very loosely structured. Once its new members are duly socialized and indoctrinated, establishing their undivided loyalty, they can be trusted to perform their work free of all the controls of conventional bureaucracy. In other words, "normative" control is more than sufficient to achieve most of the needed coordination. Indeed, such loyalty can be maintained only by trusting all the members equally, which necessitates dispensing with these controls. This also requires a simple mission and a simple technical system, both free of the need for expert skills and all the status differences that accompany them.
} 
flexibilidade e adaptabilidade eficientes e eficazes, principalmente para processos de manufatura.

É possível que Mintzberg estivesse se referindo a coisas diferentes quando falava de "normas” em momentos diferentes do texto. As “normas” de organizações “missionárias” responsáveis pela falta de flexibilidade e adaptabilidade seriam normas sociais tipicamente orientais: submissão à autoridade, respeito à hierarquia, evitar o conflito e a confrontação, busca do consenso. Essas normas sociais são consideradas ineficazes quando aplicadas em ambientes com mudanças muito rápidas, que exigem criatividade e mudanças de paradigma na forma de criar e produzir.

Por outro lado, há organizações “missionárias” que tem “normas” sociais que estimulam a confrontação de idéias, o empreendedorismo intraorganizacional e que procuram eliminar os rituais e símbolos de hierarquia e autoridade. Esse tipo de organização é tido como estimulador da autonomia criativa.

Já as “normas standardizadas” seriam as normas burocráticas no sentido mais estrito. Nesse caso, como se viu ao longo das seções anteriores, o desempenho dessas normas para a organização depende de sua qualidade para cada aplicação específica. Parece excessivo generalizar que qualquer conjunto de "normas standardizadas” leva à falta de flexibilidade e adaptabilidade como faz o autor. Sua eficiência e eficácia dependem de diversos fatores que foram analisados ao longo desta revisão bibliográfica.

É necessário, inclusive, quando se trata de eficácia e cultura organizacionais, avaliar o processo de mútua causalidade entre as normas sociais e as regras formais da organização. A implementação de PSGs tem como premissa que é possível influenciar, em algum grau, a criação e a evolução da cultura organizacional através de um sistema de regras formais. É nessa direção da relação causal que se concentra este trabalho sem, entretanto, deixar de registrar as teses sobre o circuito de feedback que alimenta a mudança das Metaregras que, em geral, é estudado sob perspectivas da psicologia e sociologia que tratam de participação e democracia nas organizações, das abordagens evolucionárias (NELSON; WINTER, 1982) e da Complexidade (GIOVANNINI; KRUGLIANSAS, 2004). 


\subsubsection{Abordagens evolucionárias}

A abordagem evolucionária de Nelson e Winter (1982) traz como um dos pontos de principal interesse a proposição que as regras não restringem a capacidade de inovação das empresas. Ao contrário, as regras seriam uma importante base sobre a qual a inovação pode surgir e se desenvolver de forma eficiente e eficaz. Os autores partem dos trabalhos de Simon, Williamson, Perrow, Schumpeter e outros e procuram dar um passo além ressaltando a importância da regras - que chamam de rotinas - no funcionamento da organização e nos processos de inovação. Tratam as regras como o DNA da organização que, através de recombinações dessa regras, leva à evolução da mesma. Nesse sentido, os autores destacam diversos pontos dentro de sua “Teoria Evolucionária da Mudança Econômica” ${ }^{59}$, em especial o conceito de rotinas.

As rotinas organizacionais são um conceito chave no quadro teórico e representam todas as atividades executadas pela organização e pelas pessoas individualmente (no contexto da organização) com base em “programas” similares a programas de computador. Esses “programas”, termo emprestado de March e Simon (1993), são as mesmas regras a que se faz referência ao longo dessa revisão bibliográfica.

As rotinas são consideradas também como a memória da organização, no sentido em que consolidam e sedimentam o resultado das experiências da organização na solução de problemas e as informações necessárias à coordenação. Além disso, as rotinas ajudam a preservar e transmitir essa memória através da prática constante das mesmas, onde a memória é “relembrada fazendo” ${ }^{60}$ (NELSON e WINTER, 1982, p. 131).

As rotinas representam "tréguas" no sentido em que reconhecem e equacionam os diferentes interesses dos membros da organização. Se refletirem os compromissos alcançados entre esses membros, e esses compromissos tiverem sido bem negociados, as rotinas podem motivar os membros da organização a buscar objetivos individuais que favorecem a busca dos objetivos organizacionais.

\footnotetext{
59 "Evolutionary Theory of Economic Change"

60 "Remembered by doing"
} 
Para os autores, a operação através de rotinas, viabiliza o controle diretivo, a capacidade de replicar rotinas eficientes e eficazmente, e a possibilidade de imitar rotinas de outras organizações.

As organizações, diferentemente de algumas abordagens econômicas ortodoxas, não “otimizam consistentemente" ${ }^{61}$ (NELSON e WINTER, 1982, p. 126). Diante das incertezas que enfrentam constantemente, as organizações não são capazes e nem podem pretender otimizar sempre. Através de rotinas, escolhidas de acordo com a situação, a organizações resolvem situações de alguma forma não necessariamente otimizadora. Isso é devido ao fato que as organizações não possuem um menu ilimitado de opções e, normalmente, escolhem a solução dentro de um conjunto relativamente limitado de rotinas disponíveis.

As rotinas podem ser a base para a inovação acontecer na empresa de forma eficiente e eficaz. A inovação bem sucedida surge, muitas vezes, de perguntas corretas que emergem de anomalias e dificuldades durante atividades rotineiras. Dessa forma, esforços de solução de problemas iniciados dentro de atividades rotineiras podem levar à inovação.

Rotinas são componentes que, quando recombinados, podem levar à inovação. Pode haver eventualmente também a introdução de uma nova rotina no centro de um processo que continua adotando rotinas antigas para as atividades de suporte. Nelson e Winter (1982) ressaltam que, para isso, as rotinas em uso precisam ser confiáveis - no sentido que eventuais problemas de eficiência e eficácia são detectados e resolvidos - e precisam ser o mais livres possíveis de ambigüidades operacionais e semânticas. Resumem esta posição claramente da seguinte forma:

\footnotetext{
"Rotinas confiáveis de escopo bem compreendido fornecem os melhores componentes para novas combinações. Nesse sentido, sucesso na fronteira da inovação pode depender da qualidade e do suporte pelas regiões "civilizadas" das rotinas estabelecidas." ${ }^{62}$ (NELSON; WINTER, 1982, p.131).
}

A inovação pode ser obtida através de atividades que são rotinas em si. Cada vez mais as organizações confiam em processos estruturados para suportar e dirigir a inovação. Mesmo que os resultados desses processos sejam incertos, devido à própria natureza da busca pela

\footnotetext{
61 "consistently optimize"

${ }^{62}$ Reliable routines of well-understanded scope provide the best components for new combinations. In this sense, success at the innovative frontier may depend on the quality of the support from the "civilized" regions of established routines.
} 
inovação, as rotinas usadas não precisam sê-lo. Podem, eventualmente, utilizar processos de busca heurísticos para fazer frente à incerteza do processo.

Como fica bastante claro, os pontos acima colocam os PSGs em posição destacada no que concerne o funcionamento das organizações. Na condição de Metaregras, os PSGs zelam pela coerência das regras com a estratégia da empresa e pela sua criação e manutenção. Em todos os pontos listados, as rotinas - que nada mais são que regras em ação - desempenham funções diversas, amplas e essenciais na organização.

\subsubsection{Complexidade}

A utilização da Teoria da Complexidade para a compreensão da dinâmica das organizações vem gradativamente encontrando espaço no currículo das escolas de economia. Um número cada vez maior de artigos e livros acadêmicos vem sendo publicado com essa abordagem (SHEINKMAN; LEBARON, 1989; SAMUELSON, 1996; KRUGMAN, 1996; KIEL; ELLIOTT, 1997; COLANDER, 2000a e 2000b; ARTHUR, 2005). Esses trabalhos têm em comum olhar para a organização como um sistema dinâmico não-linear adaptativo complexo que possui propriedades de auto-organização. Essa auto-organização surge da interação entre agentes que seguem regras de comportamento próprias, sem um comando centralizado. Comportamentos organizados, mas imprevisíveis e, muitas vezes, contra intuitivos, emergem dessas interações (ARTHUR, 1994; ARTHUR et al, 1997; SCHELLING, 1978; AXELROD, 1984 e 1997).

Até mesmo a evolução das normas foi estudada sob a abordagem da complexidade (AXELROD, 1986). Apesar da capacidade de auto-organização dos sistemas adaptativos complexos, há uma imprevisibilidade incontornável dada a sensibilidade desses sistemas às condições iniciais. Uma definição precisa do que é “sensibilidade às condições iniciais” vem da física quando explica como pode surgir o caos determinístico, uma condição comum a sistemas complexos, mas que não pode ser confundida com aleatoriedade:

O caos determinístico é essencialmente devido à dependência sensitiva ás condições iniciais. Esta dependência, quando existe, resulta das não-linearidades presentes no sistema, as quais amplificam exponencialmente pequenas diferenças nas condições iniciais. Assim sendo, leis de evolução determinísticas podem levar a comportamentos caóticos, inclusive na ausência de ruído ou flutuações externas. (FIEDLER-FERRARA; PRADO, 1994). 
Essa sensibilidade se deve ao efeito multiplicador que as rápidas interações que ocorrem nas atuais organizações têm sobre as pequenas diferenças nas condições iniciais. Um gestor que pretende dar uma direção definida ao sistema organizacional precisaria conhecer com precisão muito elevada (eventualmente infinita) as condições em que se encontra a organização no momento que implementa as decisões que imagina serem as corretas. Infelizmente, nenhum gestor tem ou terá essa condição e, dada a velocidade com que ocorrem as interações, a previsibilidade de suas ações é impossível para horizontes de tempo estrategicamente significativos.

Uma importante diferença dessa abordagem em relação a outras abordagens "contingenciais" é que a incerteza é gerada internamente: para que ela exista não é necessária a influência do ambiente externo, que é meramente uma fonte adicional de incerteza dada a sua própria Complexidade.

Por outro lado, essa incerteza generalizada não é só um problema, mas é também fonte de ruído que impede a acomodação do sistema e, portanto, fomenta a inovação. Assim, a melhor solução pode ser deixar que a organização se auto-regule (ou se auto-organize).

Esse raciocínio está por trás da idéia da “mão invisível” de Adam Smith (1979), da doutrina econômica de Hayek (2007), dos estudos de Schelling (1978), Axelrod (1984, 1986, 1997), Krugman (1996) e Beinhocker (2006), entre outros. A solução, proposta por alguns desses autores e apoiada pela Teoria da Complexidade, é a adoção de regras básicas, relativamente simples e, sempre que possível, auto-aplicáveis, que reconheçam as motivações e interesses que movem os agentes do sistema e as canalizem no sentido de permitir que a autoorganização emirja.

São também necessários mecanismos que permitam a evolução das regras para acompanhar as mudanças nas motivações e interesses desses agentes provocadas por mudanças culturais ou tecnológicas. É por esse motivo que os autores que seguem essa linha de pensamento defendem estados mínimos e democráticos.

Os principais conceitos da Economia da Complexidade (BEINHOCKER, 2006) - alguns tomados da Teoria Comportamental da Firma, da Teoria Evolucionária da Firma e da Teoria dos Jogos - que a diferenciam da economia tradicional são os seguintes: 
a) Dinâmica: considera os sistemas como abertos e operando dinamicamente fora do equilíbrio e de forma não linear não-linear. "Dinamicamente fora do equilíbrio" significa que o sistema nunca encontra uma posição fixa, independente das condições externas. Essa condição também é chamada de estabilidade dinâmica já que surge da não-linearidade das interações. Isso, por sua vez, significa que dentro do sistema há circuitos de feedback com auto-referência (para exemplo ver GIOVANNINI, 2002);

b) Agentes: os agentes são modelados individualmente, usam regras heurísticas para decidir, possuem informações incompletas, são sujeitos a erros e vieses e aprendem e se adaptam ao longo do tempo;

c) Redes: modelos explicitam as interações entre agentes individuais; as redes de relacionamento mudam ao longo do tempo;

d) Emergence: Não há distinção entre micro e macroeconomia já que padrões macroeconômicos são resultados emergentes de comportamentos e interações no nível microeconômico.

e) Evolução: o processo evolucionário de diferenciação, seleção e amplificação introduz no sistema a inovação (mudança) e é responsável pelo seu crescimento em termos de ordem e complexidade (adaptado de BEINHOCKER, 2006).

A eficácia das regras implementadas sob PSGs se baseia nesses conceitos. Os agentes dos sistemas organizacionais agem sob regras simples, que reconhecem a impossibilidade de planejamento e controle centralizado. Como se comentou anteriormente, sob os PSGs os agentes criam programas básicos de ação, com base em sua experiência e aprendizado, que são evocados de acordo com situações relativamente genéricas. Se funcionarem suficientemente bem, serão mantidos. Se falharem, serão alterados ou trocados pelos próprios agentes. Da aplicação dessas rotinas relativamente simples, emergem organizações eficazes.

Na administração ainda pouco se usa a Teoria da Complexidade, principalmente pela dificuldade que muitos pesquisadores das ciências sociais têm com os conceitos matemáticos por trás dessa teoria. Apesar de relativamente simples, eles podem ser contra-intuitivos e exigem um esforço de adaptação. É freqüente encontrar os conceitos de Complexidade e Caos citados incorretamente para representar certos fenômenos relacionados com incerteza, e isso tem prejudicado a reputação da teoria no meio. 
Entre as tentativas de uso da Teoria da Complexidade para a administração, as mais bem estruturadas são as da Sterman (2000) e Stacey (1991, 1996, 2000 e 2001). Sterman, aluno de Forrester, segue a tradição da dinâmica de sistemas que desemboca naturalmente na Teoria da Complexidade quando chega aos sistemas dinâmicos não-lineares. Stacey adota uma abordagem de administração geral e usa os conceitos da Complexidade para explicar e propor soluções para os problemas de planejamento e organização. Ambos procuram mostrar as origens da incerteza nas organizações e no mercado e, desta forma, recomendam maneiras de conviver com essa condição e explorar as possibilidades oferecidas por ela.

Giovannini e Kruglianskas (2004) após pesquisarem, usando como base os conceitos da Complexidade, empresas que implantaram PSGs para a qualidade, resumiram os conceitos dessa Teoria que se aplicam às organizações:

a) As organizações estão à mercê da Dependência Sensitiva às Condições Iniciais e, portanto, sujeitos à incerteza a partir de um determinado número de ciclos de interação, quer sejam internos ao sistema organizacional, quer sejam com o ambiente externo;

b) As organizações estão sujeitas a operar sob Caos Determinístico gerando internamente a força em direção à mudança;

c) As organizações que sobrevivem operam em estabilidade dinâmica;

d) Se possuírem as regras fundamentais para operar em estabilidade dinâmica, as organizações podem evoluir autonomamente, isto é, inovar, sem necessidade de um estímulo externo, através de processos de geração de alternativas que, apesar de não eficientes, são eficazes;

e) As organizações podem emergir de processo de auto-organização baseados no acúmulo e renovação de experiências na forma de regras.

Baseados nesses conceitos e nas pesquisas de campo, Giovannini e Kruglianskas (2004) levantaram indícios de que PSGs implantados de forma participativa e como Metaregras no topo de uma hierarquia de regras, podem melhorar a eficácia das organizações.

O principal motivo dessa possível melhora de eficácia é o alinhamento das ações e atitudes das pessoas com a estratégia da empresa através de regras coerentes com essa última e adotadas de forma consciente pelas pessoas responsáveis por sua aplicação. 
Essas conclusões estimularam a continuidade das pesquisas sobre a influência dos PSGs que desembocaram na presente tese.

\subsection{Pesquisas empíricas sobre Padrões para Sistemas de Gestão}

Incrivelmente, há relativamente poucos trabalhos acadêmicos dedicados ao estudo da influência dos PSGs sobre o desempenho empresarial. O único livro publicado com esse perfil é o de Brunsson e Jacobsson (2005) que, entretanto, apesar de conter muitas informações relevantes sobre as tendências de standardização no mundo, não apresenta nenhuma pesquisa quantitativa sobre a eficácia do que os autores chamam de standards de sistemas administrativos. Mesmo entre os diversos trabalhos citados no livro, não há nenhum nessa linha. Há, sim, muitos manuais genéricos que orientam sobre a implantação de PSGs em diferentes áreas de negócios e que comentam sobre suas supostas vantagens.

Entre os trabalhos encontrados nas bases de dados científicas que se aproximam de uma pesquisa quantitativa sobre a eficácia de PSGs, a maioria se concentra na adoção do TQM que não é exatamente um PSG. TQM é um conjunto amplo de recomendações sem a formalização profunda característica dos PSGs.

Zairi et al (1994) resumem os resultados de dois estudos. Um americano, realizado através de questionários com escalas tipo Likert com apenas três níveis, inclusive para avaliar resultados financeiros. De 20 empresas, apenas 9 responderam consistentemente. Os dados mostram certa influência do grau de adoção do TQM sobre o desempenho da empresa percebido pelos respondentes. Entretanto, os autores ressaltam as extremas limitações do estudo.

O outro estudo, europeu, foi realizado com relativamente poucas empresas (29) de setores diferentes, mas usando como indicador de resultados a variação do valor das empresas na bolsa de valores ao longo de cinco anos. As conclusões sobre a relação do TQM com resultados financeiros positivos foram: 
“Apesar de não ser possível provar causalidade direta, já que outros fatores podem estar presentes, a consistência dos resultados aponta na direção de uma forte associação.” ${ }^{3}$ (ZAIRI et al, 1994, p. 42-43).

Maani et al (1994), analisam a melhoria de desempenho de 184 empresas de manufatura da Nova Zelândia usando SEM (Modelagem de equações estruturantes) como metodologia estatística. Esse estudo é um dos pioneiros na área a usar o SEM. O modelo conceitual usado pelos autores é reproduzido abaixo na ilustração 6.

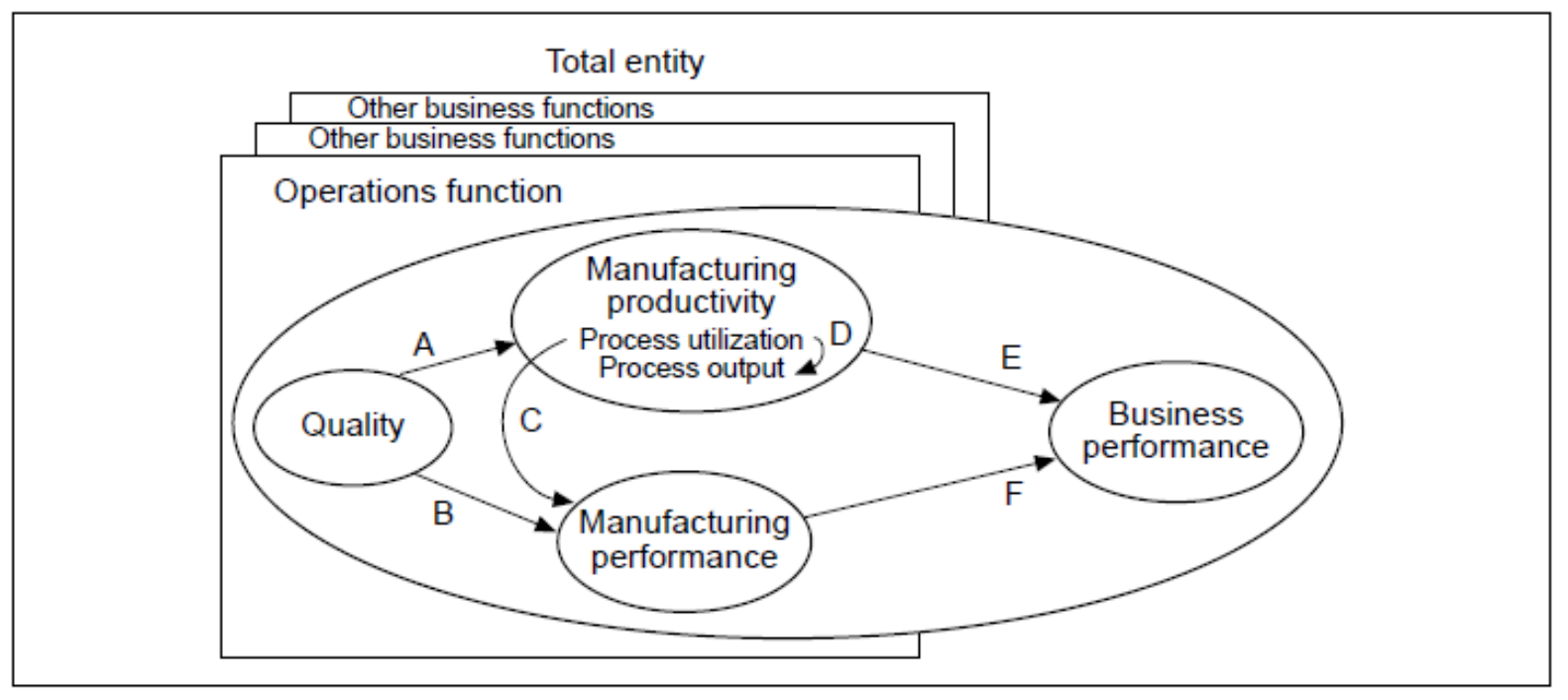

Ilustração 6: Modelo ligando melhorias de qualidade com desempenho do negócio FONTE: MAANI et al (1994)

A dimensão qualidade foi medida pelas rejeições internas, retrabalho interno e rejeição externa (pelos clientes). O desempenho do negócio foi medido pela margem sobre vendas, margem sobre ativos, crescimento de vendas e crescimento de participação de mercado. Há também medidas de desempenho em pontos intermediários do processo, como produtividade e estoques. As conclusões podem ser resumidas nas seguintes frases:

Os estudo foi capaz de mostrar empiricamente que em companhias manufatureiras, melhorar a qualidade melhora positivamente a performance operacional e a produtividade e determinados indicadores de desempenho do negócio. A associação é mais pronunciada entre qualidade e processo de utilização, com o segundo maior impacto da qualidade sendo sobre custos de manufatura. ${ }^{64}$ (MAANI et al, 1994, p. 34).

\footnotetext{
63 "Although it is not possible to prove direct causation, since other factors may be present, the consistency of the results does point towards a strong association."

${ }^{64}$ The study has been able to show empirically that in manufacturing companies, improving quality positively enhances operational performance and productivity, and certain indicators of business performance. The
} 
Esta conclusão indica a possível existência de relação entre o desempenho de parte da estrutura organizacional (garantia da qualidade e operação de manufatura) e o desempenho da empresa. Mostra que melhor qualidade tende a levar a melhores resultados, conceito hoje praticamente aceito, mas visto de outra forma até os anos 80. Esse estudo, entretanto, escolhe como variáveis independentes os resultados da dimensão qualidade do processo produtivo não explorando os motivos que causam um melhor desempenho dessas variáveis. Além disso, o estudo avalia empresas de diversos dificultando o controle das variáveis ambientais.

O trabalho de Feldman et al (1996) examinou o desempenho de 300 empresas abertas dos Estados Unidos e os comparara com as respectivas gestões e performances ambientais. O modelo conceitual desse trabalho (ilustração 7) é, em sua essência, similar ao de Maani et al (1994) e ao desta tese:

\section{Conceptual Model Linking Corporate Environmental Management and Performance with Firm Value}

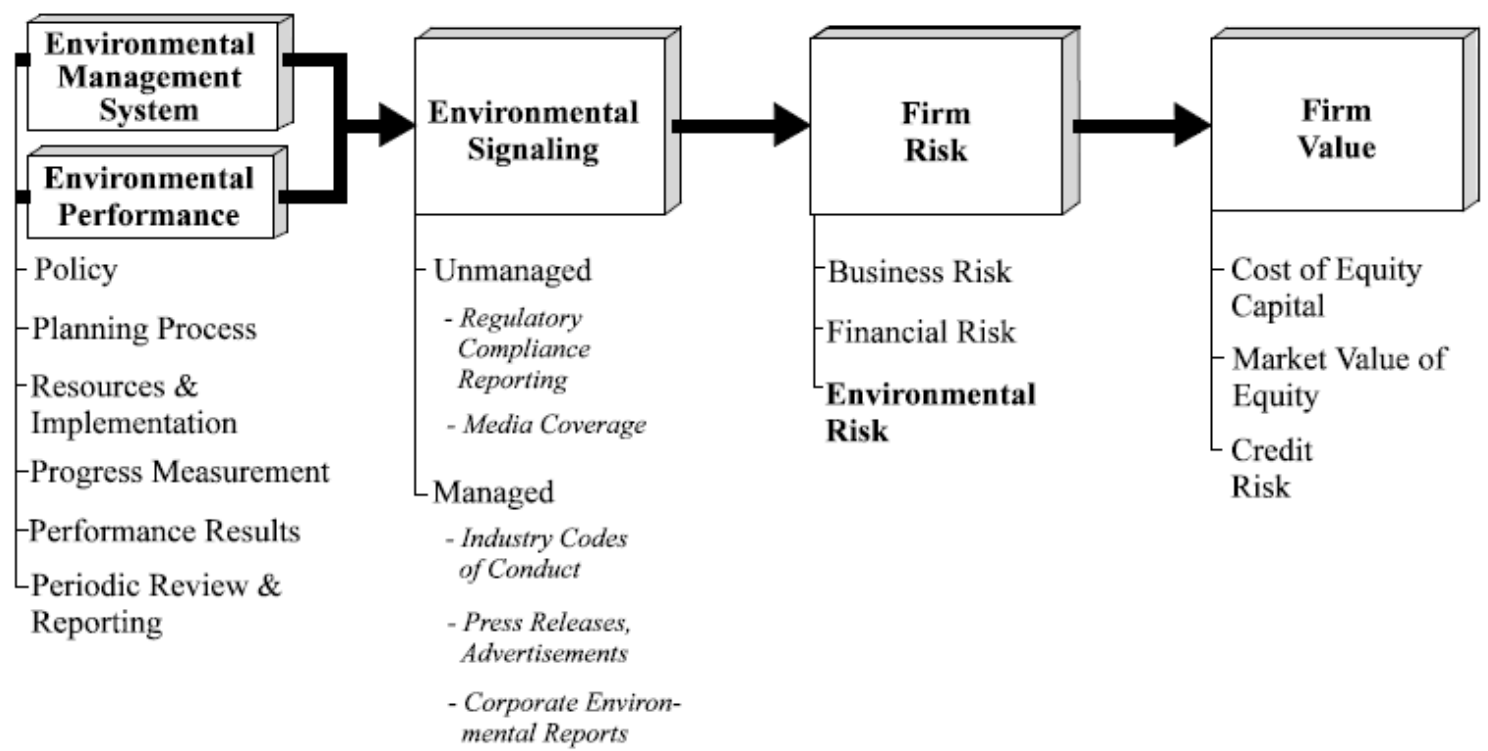

Ilustração 7: Modelo conceitual ligando gestão e performance ambiental com valor da empresa FONTE: FELDMAN et al (1997)

Feldman et al entendem que os resultados de um bom sistema de gestão de um determinado processo (preservação do meio ambiente) podem gerar, de forma indireta como mostra a ilustração 7, resultados positivos no valor da empresa. Eles alertam também para a 
importância da qualidade e dos resultados desse sistema - e da comunicação desses resultados - para a redução do risco percebido pelo mercado e, portanto, para o aumento do valor de suas ações de forma robusta, isto é, permanente ao longo do tempo. A qualidade e resultados do sistema de gestão ambiental foram medidos através de um sistema de pontuação desenvolvido pelos autores. As conclusões indicam que uma melhora de 50\% na gestão ambiental, somada a uma melhora de 50\% no desempenho ambiental dois anos depois, leva a um aumento de aproximadamente 5\% no valor das empresas no final do período analisado.

Chapman et al (1997) ressaltam, em sua pesquisa, a importância de integrar os esforços de TQM com a estratégia organizacional para se obter um melhor desempenho financeiro nas empresas. De 150 empresas australianas convidadas a participar da pesquisa, 75 acabaram entregando alguns questionários completos e utilizáveis, mas somente 41 entregaram informações razoavelmente completas sobre os resultados financeiros solicitados. Esses indicadores são retorno sobre o valor das ações, retorno sobre os ativos e vendas por empregado. Este último indicador não parece fazer sentido e não está justificado no artigo o motivo do seu uso.

As dificuldades metodológicas aumentam quando se considera que as empresas respondentes são de oito setores totalmente diferentes. O estudo conclui que há “confirmação que iniciativas seletivas de QSA/TQM [Quality and Strategic Advantage/Total Quality Management] podem ser ligadas a desempenho financeiro expresso em relações de produtividade do trabalho” (CHAPMAN et al, 1997, p. 445). Não há ligação com retorno sobre o valor das ações e retorno sobre ativos. Entretanto, dadas as limitações da metodologia e da amostra de empresas esses dados devem ser considerados com cautela.

Chenhall (1997) elaborou um estudo que compara a lucratividade de empresas que implantaram TQM sem definir medidas de desempenho no processo de manufatura, com empresas que o fizeram. Sua contribuição para a presente tese é mostrar que formalizar o sistema com indicadores de desempenho e seus respectivos meios de enforcement pode ser positivo para a lucratividade das empresas.

As conclusões mostram uma clara associação entre maior lucratividade e a adoção de indicadores de desempenho no processo de manufatura. Infelizmente há algumas limitações no estudo. A principal é que não foi possível conseguir dados objetivos de lucratividade. Essa 
foi obtida de forma relativa, perguntando-se aos executivos como consideravam a lucratividade de sua empresa comparada com a concorrência. Há outras limitações tal como poucas empresas respondentes e falta de controle das variáveis ambientais.

Easton Jarrel, (1998) publicaram um artigo sobre os resultados da implantação do TQM em 108 empresas americanas. As empresas se auto-avaliaram em relação ao grau de adoção do TQM e as informações de lucratividade, por serem empresas abertas, foram obtidas através dos relatórios anuais publicados por elas. Resumidamente, as conclusões dos autores foram as seguintes:

A maior descoberta desse estudo é clara evidência que o desempenho de longo prazo das empresas que implementaram TQM melhorou. Nós acreditamos que a evidência de melhora é particularmente forte quando a análise ampla é considerada. ${ }^{65}$ (EASTON; JARREL, 1998, p. 298).

Esse estudo sofre dos mesmos problemas de alguns dos anteriormente citados, isto é, o de amostra composta por empresas de setores diferentes, falta de controle das variáveis ambientais e auto-avaliação do grau de implantação de técnicas de TQM.

Gavin et al (2008) fazem uma revisão bastante completa de toda a literatura de revistas científicas (peer review) de 1990 a 2006 e concluem que somente 26 artigos trazem pesquisas que procuram verificar a influência da certificação ISO 9.001 sobre resultados organizacionais. Entretanto, o objetivo específico da pesquisa de Gavin et al é verificar a direção da relação causal da certificação ISO 9.001 e os resultados da organização. Os autores colocam em dúvida a direção da causalidade, isto é, se a certificação causa melhores resultados ou se melhores resultados criam as condições para as empresas buscarem a certificação.

A ilustração 8 abaixo resume o modelo conceitual - que reflete o primeiro tipo citado de direção de causalidade - no qual se encaixam todos os artigos pesquisados pelos autores:

\footnotetext{
${ }^{65}$ The major finding of this study is clear evidence that the long-term performance of firms that implemented $T Q M$ is improved. We believe the evidence of improvement is particulary strong when the overall analysis is considered.
} 


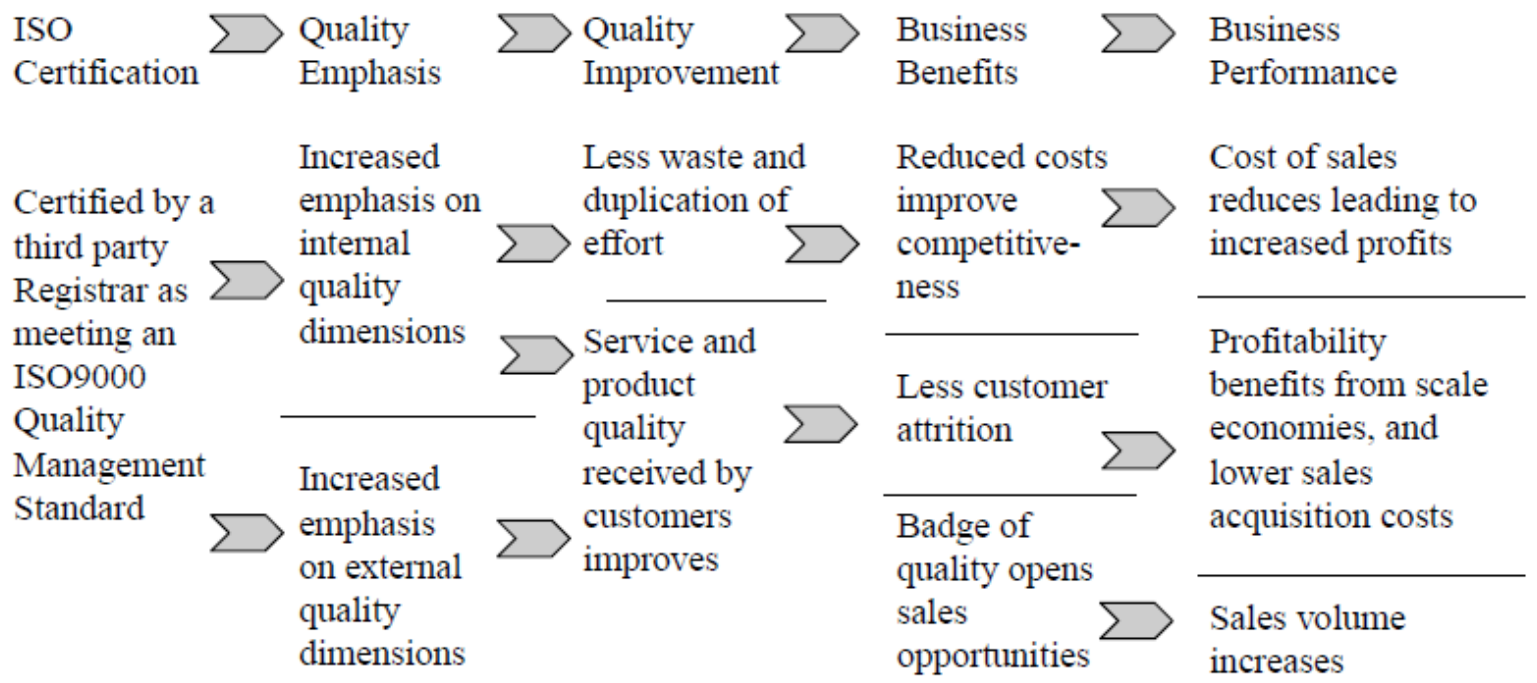

Ilustração 8: Relação esperada entre certificação ISO 9.000 e desempenho do negócio FONTE: GAVIN et al, 2008

Mais uma vez encontra-se a proposição de que haveria uma relação indireta entre o desempenho na gestão de um processo específico (gestão da qualidade) e o desempenho final da organização. Dos 26 estudos, apenas dez pesquisaram a influência da certificação sobre os lucros. Destes, quatro estudos encontraram indícios de melhores lucros para as empresas certificadas. Onze estudos pesquisaram a influência sobre o volume de vendas e quatro deles encontraram uma influência positiva da certificação. Segundo os autores:

Em geral, a avaliação das ligações entre certificação de sistemas de qualidade e melhoria de desempenho, revela que há evidências nas pesquisas empíricas feitas no campo que sugerem que o amplo leque de benefícios mostrados na figura 1 [ilustração 8] é possível mas incerto a não ser que a motivação para perseguir a certificação seja por razões internas ou de desenvolvimento. ${ }^{66}$ (GAVIN et al, 2008, p. 690).

Essa conclusão está perfeitamente alinhada com outros trabalhos recentes (GIOVANNINI, 2002; GIOVANNINI e KRUGLIANSKAS, 2004) que mostraram indícios que a implantação de sistemas de qualidade tem maiores chances de sucesso se feita de forma alinhada com a estratégia da empresa e com o apoio das pessoas da organização através de maior participação nas decisões e ações de implantação.

Entretanto, outra conclusão de Gavin et al levanta uma questão que deve ser abordada neste estudo. Nos estudos que mostravam um melhor desempenho externo, isto é, aumento de

\footnotetext{
${ }^{66}$ Overall, the evaluation of the links between QCert and improved performance reveals that ther is evidence in the field's empirical research to suggest that the broad range of benefits shown in figure 1 are possible but uncertain unless motivation for pursuing QCert for internal or developmental reasons.
} 
vendas e de lucratividade, os autores encontraram evidências de que essa condição antecedia a certificação ISO 9.001. As hipóteses para esse fenômeno vão desde a disponibilidade de recursos para se investir na certificação - que seria dispendiosa de acordo com os autores até a maior exposição de empresas lucrativas ao comércio internacional que exige a certificação. Apesar de intrigantes, os achados deste estudo, como reconhecem os próprios autores, estão limitados a uma amostra de apenas cinco empresas, que foram as únicas com resultados positivos e que foram pesquisadas em detalhe ao longo do tempo, antes e depois da certificação. De qualquer forma, fica claro que a direção da causalidade deve ser tratada com atenção nas pesquisas sobre a influência dos PSGs sobre os resultados organizacionais.

Entre os 26 artigos levantados por Gavin et al (2008) há um de autores brasileiros. Lima et al (2000) compararam o desempenho de 129 empresas brasileiras de diversos setores certificadas ISO 9.001 e 9.002 com empresas não certificadas. A pesquisa limita-se, portanto a PPG de qualidade. Os indicadores de desempenho escolhidos foram o lucro operacional sobre ativos e sobre vendas e lucro líquido sobre ativos e sobre vendas. Os autores obtiveram os dados contábeis a partir de uma base de dados das mil maiores empresas do Brasil, mantida pela Fundação Getúlio Vargas. Os autores não encontraram evidências de diferente desempenho entre empresas certificadas e não.

Infelizmente, os dados contábeis se referem ao período de 1986 a 1996, anos de alta inflação que levavam à elaboração de demonstrações contábeis com pouco significado. Além disso, o setor industrial, que compõe mais de 90 \% da amostra do estudo, passou por profundas crises e transformações devido à abertura comercial e valorização da moeda brasileira no período.

A Serasa, em parceria com a Fundação Nacional da Qualidade (FNQ, 2008), realizou um levantamento que pode indicar que PSGs contribuem para o desempenho organizacional. Nele, a Serasa compara o desempenho de 130 empresas associadas à FNQ que implantaram, em diferentes graus, o Modelo de Excelência de Gestão (MEG) criado pela fundação (FNQ, 2008). Em todas as dimensões avaliadas (evolução do faturamento, lucro sobre faturamento e LAJIDA sobre faturamento), as empresas que adotaram o MEG, tiveram desempenho melhor que empresas dos mesmos setores (comércio, indústria, serviços e bancos). A comparação foi feita com os resultados de 43.574 empresas ao longo de sete anos. Não há, entretanto, tratamento estatístico aprofundado e controle adequado de variáveis ambientais. 


\subsection{Conclusões da fundamentação teórica}

Ao longo da revisão da bibliografia foram delineadas algumas das questões enfrentadas pelos administradores para melhorar o desempenho das empresas através da atuação sobre as regras e a estrutura organizacional. Destacaram-se problemas de coordenação, cooperação, burocracia (regras como um fim em si mesmo), conflitos de interesses entre os membros da organização, limitações à racionalidade nas decisões, não-linearidade e não-coordenação temporal de causa e efeito, entre outros.

Analisando-se as propostas de diversas linhas do pensamento administrativo e da economia de empresas, passando pelas abordagens da sociologia e psicologia aplicadas à administração, não se pode deixar de ressaltar que sistemas de regras, em especial aqueles com característica na linha dos PPGs, são constantemente citados como tendo o potencial de mitigar ou solucionar diversos problemas organizacionais.

Os PSGs demandam a construção de sistemas de gestão que atendem as principais recomendações da literatura pesquisada. Entre essas recomendações estão a promoção do alinhamento das regras com a estratégia da empresa, a existência de mecanismos de enforcement das próprias regras, a coordenação de circuitos de feedback para a melhoria contínua, a garantia de mecanismos de ação corretiva, e a participação consciente e qualificada de todos os membro da organização.

Para mostrar de forma mais clara como os PSGs podem melhorar o desempenho das empresas, algumas proposições que emergem da revisão da bibliografia devem ser destacadas.

Em primeiro lugar, os sistemas estruturados conforme PSGs exigem a participação intensa das pessoas nas decisões e ações, promovendo, dessa forma, uma cultura organizacional mais alinhada com a estratégia da empresa. Além disso, juntamente com a produção de informações corretas e transparentes, o sistema tende a reduzir conflitos, atenuar os custos de barganha ligados às relações de poder, melhorar a percepção das pessoas e fazê-las assumir papéis baseados em modelos de realidade mais racionais.

Além disso, graças ao destaque que os sistemas estruturados conforme PSGs dão à análise, ao registro e ao controle de atividade e documentos, eles atenuam as dificuldades de decisão e 
protegem contra más decisões relacionadas à seleção adversa (de pedidos, clientes, fornecedores, funcionários, etc.), risco de agência, risco moral, oportunismo, criação de "reféns" e investimento em ativos específicos. Dessa maneira reduzem riscos e liberam recursos que, de outra forma, estariam comprometidos.

Graças também ao foco em análise, registro e controle, que se reflete em maior clareza de compromissos e responsabilidades de todas as partes, os potenciais conflitos de interesses são expostos reduzindo os custos de monitoramento. Dessa forma também se cria um sistema de reputação dentro do grupo de trabalho e melhores estruturas de incentivo.

Em função do empenho e dos investimentos dedicados à implantação de PSGs - que são amplamente conhecidos no mercado - as empresas que os adotam sinalizam, aos stakeholders, compromissos críveis que reduzem os riscos derivados das incertezas nas transações e, conseqüentemente, reduzem os custos envolvidos.

Os PSGs criam sistemas com processos estruturados para a solução de problemas, para a melhoria contínua e para a avaliação constante de desempenho dos produtos e processos Esses processos são rotinas que promovem a inovação. Os resultados da inovação são consolidados dentro da organização também pelo sistema de gestão, que é o responsável pelo registro das novas especificações, parâmetros, etc.

Graças à base robusta criada pelos sistemas certificados por PSGs, a organização pode deixar os seus circuitos de feedback funcionarem com riscos controlados. Os riscos de circuitos de feedback excessivamente negativos, que levam à estagnação, ou excessivamente positivos, que levam ao crescimento descontrolado são reduzidos pelo monitoramento constante e por ações corretivas sistêmicas.

Há, portanto, diversas indicações de que pode haver uma influência positiva dos PSGs sobre os resultados das empresas. Essas influências não se limitariam a aspectos pontuais como qualidade ou preservação do meio ambiente. É possível, assim, propor a hipótese de que os efeitos dos PSGs podem chegar ao desempenho financeiro das empresas. Evidências dessa influência seriam importantes para dar suporte a várias proposições aqui apresentadas. 
Entretanto, há poucas pesquisas que testam a validade destas proposições. A grande maioria esbarra na dificuldade de operacionalizar indicadores e obter dados confiáveis. Os indicadores do grau de adoção de PSGs e de desempenho organizacional exigem, muitas vezes, acesso a dados que as empresas ou não possuem, ou levantam de formas diferentes, ou não querem divulgar por questões estratégicas.

Isso leva a um problema maior que é o baixo controle das variáveis ambientais e o pequeno tamanho das amostras. Com poucas opções disponíveis os pesquisadores recorrem a dados de empresas que se dispõem a respondem questionários, mas que não necessariamente formam um conjunto, ou amostra, que favorece a análise estatística.

Outra restrição é que as pesquisas existentes se limitam a estudar a influência de um único PSG, quase sempre voltado para sistemas de gestão da qualidade. Foi encontrado somente um estudo que avaliou a influência de um PSG voltado à gestão do meio ambiente. Apesar das limitações, serve de estímulo o fato de que a maioria das pesquisas avaliadas mostra indícios de que há influências positivas do PSGs sobre o desempenho das empresas. 


\section{METODOLOGIA DE PESQUISA}

\subsection{Pergunta da pesquisa e hipótese}

Como colocado na introdução, a pergunta da pesquisa é:

Há alguma influência da adoção de Padrões para Sistemas de Gestão sobre o desempenho das empresas?

A pergunta de pesquisa pode ser traduzida na seguinte forma de hipótese nula:

$H_{0:}$ Não há diferença entre o desempenho de empresas com e sem PSGs.

A hipótese alternativa e, portanto:

$H_{1}$ : Há diferença entre o desempenho de empresas com e sem PSGs.

A hipótese nula acima representa a hipótese principal. Os dados serão explorados com o intuito de ser verificar também a influência da adoção de múltiplos PSGs no desempenho das empresas.

A hipótese nula será testada com os dados coletados conforme o modelo conceitual abaixo. Vale esclarecer, também, que as empresas a que se refere à hipótese são as indústrias de autopeças brasileiras e o desempenho refere-se ao período compreendido entre os anos de 2002 e 2005.

\subsection{Modelo Conceitual}

O modelo conceitual exposto na ilustração 9 abaixo propõe a existência de uma influência indireta das variáveis independentes sobre as dependentes que usa como elemento de 
transmissão dessa influência a organização. Essa situação exige que se inclua, nas variáveis intervenientes, características da organização que podem influenciar seu desempenho de forma significativa no contexto deste estudo.

A direção da relação de causalidade, como foi já comentado, pode ser questionada, mas esse é um problema de difícil solução em qualquer modelo conceitual. Entretanto, as idéias e proposições avaliadas na revisão da bibliografia indicam que a direção escolhida é a correta.

É claro que há uma relação de mútua causalidade entre as variáveis independentes e dependentes, já que os próprios PSGs promovem a existência de circuitos de feedback para melhorarem o desempenho do sistema e esses podem estimular a adoção de PSGs adicionais. Mas é exatamente a existência dos PSGs e dos sistemas de feedback que eles promovem que esta tese propõe como influência positiva para o desempenho das organizações.

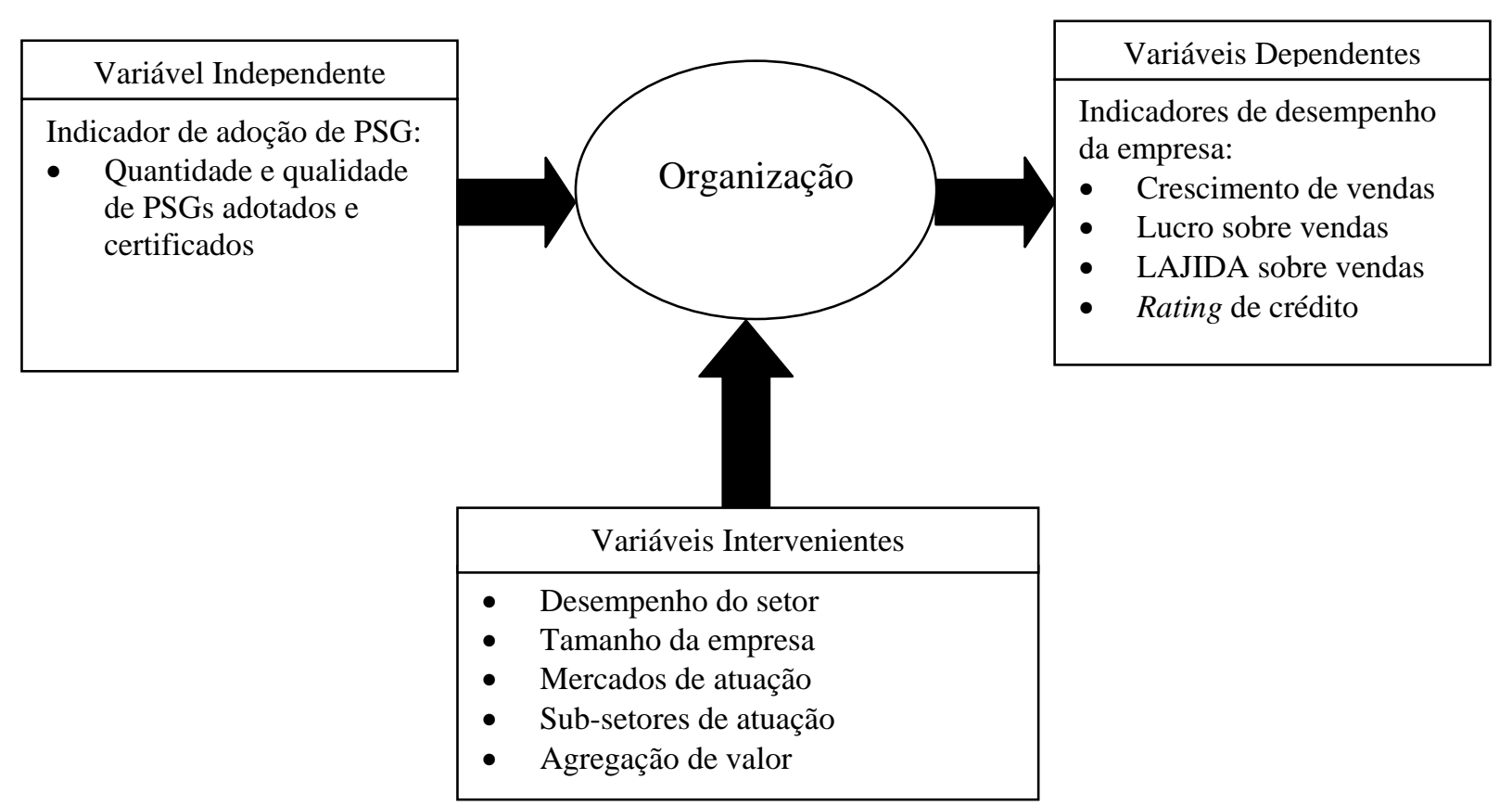

Ilustração 9: Modelo conceitual de pesquisa 


\subsection{Operacionalização das Variáveis}

\subsubsection{Variáveis independentes}

As empresas que adotam PSGs de forma ativa e deliberada geralmente submetem-se a um processo de certificação como motivação para a equipe e para obterem uma confirmação que o padrão foi adequadamente implantado. Essas certificações são feitas por empresas especializadas, chamadas de Certificadoras, que são licenciadas pelos criadores dos PSGs para tal tarefa. O processo de certificação é uma auditoria de sistema de gestão e o resultado, se for positivo, é a emissão de um certificado sujeito a acompanhamentos anuais e renovações a cada três anos. É uma forte evidência - bem documentada - de que o PSGs foi realmente adotado e que permanece funcionando.

O conflito de interesse que pode haver no processo, já que o órgão certificador é contratado e pago pela empresa auditada, é mitigado pela forma como todo o processo é documentado e por como toda essa documentação e o próprio órgão certificador é auditado pelas organizações que lhes dão a licença para atuar. De qualquer forma, esse conflito de interesse existe e, portanto, a certificação tem suas limitações como evidência da adoção de PSGs.

Apesar dessa limitação, considera-se, neste estudo, que a quantidade de PSGs que a empresa possui demonstra o grau de adoção e o compromisso da mesma com essa forma de desenvolvimento organizacional. Já que a adoção é quase sempre gradual, isto é, um PPGs de cada vez, supõe-se que, na medida em que a experiência com um PSG é positiva, criam-se as condições para a adoção do seguinte. Esse processo faz com que porções cada vez maiores da estrutura organizacional sejam submetidas aos PSGs.

O indicador de adoção de PSGs é, portanto, a posse, ou não dos seguintes certificados: ISO 9.001, ISO/TS 16.949, ISO 14.001, OHSAS 18.001 e SA 8.000. A posse de cada um é representada como uma variável nominal, isto é, zero (0) equivale à não posse e um (1) equivale à posse de certificado.

Devido à impossibilidade de se obter, de forma confiável, a data da certificação original das empresas em cada PPG, o critério escolhido é a posse ou não em 31 de dezembro de 2005. A data, que coincide com o fim do período no qual é avaliado o desempenho das empresas (ver 
a seguir), reflete razoavelmente o nível de adoção do PSG devido à longa preparação para se conseguir a certificação e ao aumento progressivo das exigências dos órgãos certificadores. Além disso, empresas que possuíam certificados de PPGs mais antigos (ISO 9.000:1994 e ISO 14.000:2000) tiveram de renová-los no período da pesquisa. Assim, as empresas que possuíam sistemas antigos implementados de forma precária e que não conseguiram a renovação, aparecem na pesquisa classificadas com não possuidoras.

\subsubsection{Variáveis dependentes}

Como a questão de pesquisa trata da influência indireta das regras da organização sobre o seu desempenho ela exige, portanto, que se escolham indicadores para medir esse desempenho. $\mathrm{O}$ primeiro problema para escolhê-los é definir sob qual ótica, ou para quem, está-se medindo esse desempenho. Os diferentes stakeholders da empresa possuem, em geral, formas diferentes de avaliar o desempenho dela como, por exemplo, critérios sociais, ambientais e financeiros.

Uma opção é medir o desempenho vis-à-vis os objetivos estratégicos da empresa (STEERS, 1975). Essa alternativa, já utilizada por este autor (GIOVANNINI, 2002), depende, porém, do acesso do pesquisador a estes objetivos e aos respectivos indicadores. Isso geralmente exige um estudo de caso já que é inviável obter essas informações de muitas empresas simultaneamente e na profundidade necessária para serem confiáveis.

Nessa mesma linha, há propostas para se utilizar indicadores focados na sobrevivência e desempenho de longo prazo como, por exemplo, indicadores de qualidade interna e externa, satisfação de clientes, satisfação de funcionários, satisfação de outros stakeholders (GRI, 2006) e "retorno sobre gerenciamento” 67 - ROM (SIMONS; DÁVILA, 2000, p. 73). Entretanto, medir esses indicadores através de questionários - geralmente com baixo índice de resposta e confiabilidade questionável - ou relatórios de empresas - elaborados geralmente com critérios diferentes uns dos outros - é, provavelmente, uma maneira pouco confiável e eficaz para os objetivo deste estudo (ZAIRI et al, 1994).

\footnotetext{
${ }^{67}$ “ Return over management”
} 
Trabalhos estrangeiros utilizam, muitas vezes, a evolução dos valores de ações em bolsa e os resultados publicados pelas empresas abertas como indicadores de desempenho (CHAPMAN et al, 1997; FELDMAN et al, 1996). Apesar da influência de fatores externos nas cotações, a avaliação que o mercado faz da empresa pode ser um excelente indicador de desempenho. Nesse caso, dado que as informações de empresas listadas em bolsa são públicas, consegue-se também acesso a indicadores como, por exemplo, retorno sobre ativos, retorno sobre valor da empresa no mercado, retorno sobre patrimônio líquido, etc. No Brasil, infelizmente, essa fonte de informação é, ainda, muito limitada. É pequeno o número de empresas abertas no setor: apesar de estar crescendo, ao final do segundo semestre de 2008 havia apenas treze fabricantes de autopeças listadas na bolsa de valores de São Paulo, a principal do país (BM\&FBOVESPA, 2008).

A forma escolhida de se reduzir a influência das variáveis intervenientes sobre os resultados da pesquisa foi restringir as empresas a um único setor. Além disso, o ideal é incluir o maior número possível de empresas evitando algum tipo de critério de escolha que introduza um viés nos dados. Dessa forma, tornou-se necessário verificar o que está disponível e, posteriormente, avaliar sua adequação para uma análise estatisticamente robusta e adequada.

Entre todas as possíveis fontes de informação, a escolha recaiu sobre a Serasa S.A. Com a devida negociação de um termo de cooperação e compromisso de confidencialidade, essa empresa de informações comerciais concordou em fornecer determinadas informações de todas as empresas do setor de autopeças. Entretanto, mesmo com essa ampla base, as opções de dados para a pesquisa são limitadas pelo que as empresas informam voluntariamente à Serasa, pelas limitações impostas pela confidencialidade dos dados, e, no caso de dados contábeis, pelas deformações sobre valores de ativos e patrimônio líquido provocadas por anos de inflação elevada e pela regulamentação contábil brasileira.

Para se obter uma visão melhor dos resultados das empresas, optou-se por avaliar o período dos cinco anos mais recentes disponíveis, isto é, de 2001 a 2005. Infelizmente, como se verá mais adiante, foi necessário abrir mão do ano de 2001 devido à falta desses dados em mais de 50\% das empresas. Os indicadores de desempenho da organização são os seguintes:

a) Crescimento de faturamento líquido: é uma meta perseguida por quase todas as empresas para obterem, por exemplo, maiores economias de escala, maior controle 
sobre o mercado, maiores margens absolutas, maior capacidade de investimento, busca de melhor reputação e maior poder por parte de acionistas e principais gestores.

b) Margem de lucro sobre faturamento líquido: maiores margens são também perseguidas por praticamente todas as empresas, pois influenciam o retorno sobre o capital investido e, portanto, o resultado para os acionistas. As margens de lucro sobre faturamento refletem a capacidade da empresa de competir no mercado praticando preços adequados aos seus custos. Margens de lucro melhores que os concorrentes refletem maior capacidade de competição, quer seja com menores custos, quer seja com capacidade de extrair melhores preços dos clientes devido a um melhor desempenho em algum atributo valorizado pelo mercado (qualidade, atendimento, assistência técnica, capacidade de inovação, etc.).

c) Margem de Lucro Antes de Juros, Impostos, Depreciação e Amortizações (LAJIDA) sobre faturamento líquido: o valor absoluto do LAJIDA, representando a capacidade de geração de caixa, têm sido o principal indicador usado na avaliação de empresas. É comum o uso de multiplicadores sobre o LAJIDA para definir o valor de mercado de uma empresa. Um maior LAJIDA sobre faturamento representa a capacidade da empresa de remunerar adequadamente os ativos aplicados ao negócio. Da mesma forma que o lucro sobre faturamento, representa a capacidade de competir no mercado, principalmente quando comparado com os concorrentes.

d) Risk Scoring: a Serasa calcula um indicador de risco para estimar a possibilidade de inadimplência de uma empresa. Obviamente, o algoritmo utilizado não é divulgado, mas pode-se supor que esse indicador de alguma forma procura representar o desempenho futuro provável da empresa já que a inadimplência é, normalmente, provocada pela incapacidade de gerar recursos para pagar seus compromissos. Indícios de possível inadimplência, coletados em fornecedores, bancos e clientes, e análise das demonstrações financeiras, reduzem o Risk Scoring.

Como se pode constatar, os indicadores de desempenho são eminentemente financeiros e, nesse sentido, a ilustração 10 abaixo suporta essa escolha, colocando os indicadores desse tipo como o núcleo da eficácia organizacional. Como demonstram os autores citados, em seu amplo levantamento sobre indicadores de eficácia organizacional na literatura, os indicadores financeiros predominam nos construtos para operacionalizá-los (VENKATRAMAN e VASUDEVAN, 1986). 

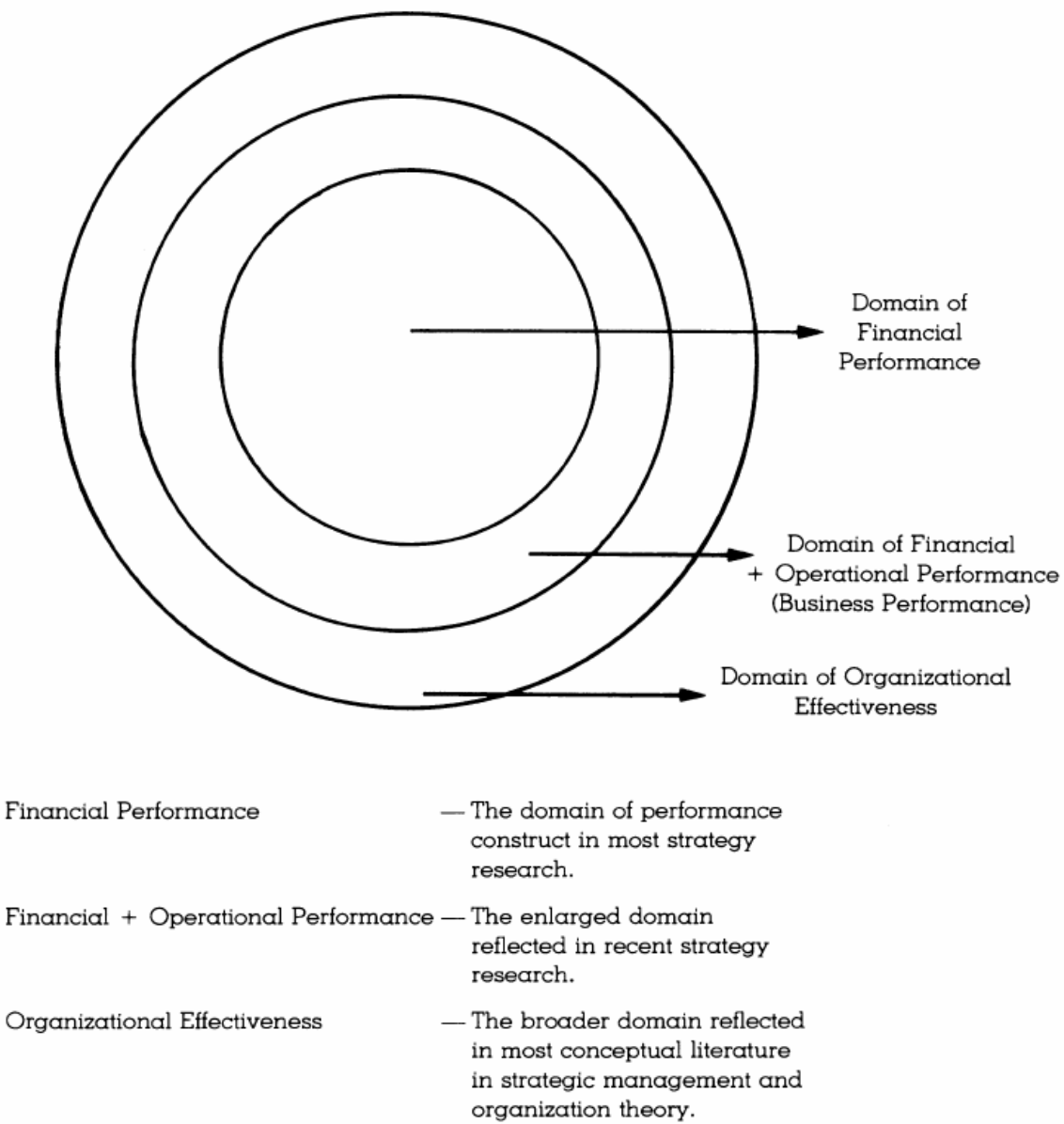

Ilustração 10: Definindo os domínios da performance da empresa FONTE: VENKATRAMAN e VASUDEVAN, 1986

Com a óbvia exceção do Risk Scoring, os outros três indicadores adotados nesta tese encontram suporte, para sua condição de representantes do desempenho organizacional, em uma ampla literatura, desde naquela voltada à atuação socialmente responsável (GRI, 2006) até no padrão contábil internacional (IASB, 2008), passando pelas abordagens estratégicas (KAPLAN e NORTON, 1996; VENKATRAMAN e VASUDEVAN, 1986).

Outra qualidade dos indicadores escolhidos é a de que são variáveis quantitativas contínuas. Dessa forma, os valores obtidos por cada empresa podem ser comparados com os outros e com médias gerais ou de sub-grupos. Assim, mesmo que em termos absolutos não se possa avaliar a qualidade do desempenho da empresa - já que é difícil, por exemplo, definir o que é um bom lucro - é possível fazê-lo comparando seu desempenho com as outras do setor. Atende-se, assim, plenamente o objetivo deste estudo que é o de comparar o desempenho de empresas de acordo com o grau de adoção de PSGs. 
Essa condição é possível também pelo fato do setor de autopeças ser relativamente homogêneo, no qual as empresas têm acesso a um mercado no qual podem atuar em praticamente todos os sub-setores. Por exemplo, um fabricante de pneus pode atuar nos subsetores de motocicletas, automóveis, caminhões, ônibus, máquinas agrícolas e de construção. Mesmo que nem todos os sub-setores ofereçam oportunidades de crescimento e margens similares, as indústrias de autopeças podem buscar seus resultados em todos eles já que consomem produtos similares.

\subsubsection{Variáveis intervenientes}

O controle das variáveis intervenientes está ligado principalmente às empresas (e seu ambiente), pois é através delas que a influência dos PSGs se transforma em algum tipo de resultado. Apesar terem sido considerados para a escolha do setor de autopeças para a pesquisa, os dados ambientais mais amplos, como variação do PIB, produção de veículos, balança comercial do setor, e outros, não foram considerados como variáveis. Como a comparação acontece entre empresas dentro de um mesmo setor relativamente homogêneo, adota-se o pressuposto de que são afetadas uniformemente por essas variáveis.

Mais uma vez a escolha das variáveis é condicionada não só pelas necessidades metodológicas e da pesquisa em si, mas também pela disponibilidade de informações confiáveis. As variáveis escolhidas são as seguintes:

a) Desempenho do setor: esse indicador serve como padrão de referência e comparação para os resultados das empresas individualmente ou agrupadas e, também, para avaliar eventuais influências do ambiente de negócios sobre as empresas. Ambientes mais estáveis podem introduzir menos incerteza nos dados das empresas. Mede-se esse indicador através dos dados agregados dos mesmos indicadores das variáveis dependentes.

b) Tamanho da empresa: o tamanho da empresa pode afetar o seu desempenho e a propensão em adotar PSGs. Mediu-se essa variável através do número de funcionários em 31 de dezembro de 2005 e do faturamento total da empresa (de 2005 e do acumulado de 2002 a 2005). 
c) Mercados de atuação: diferentes mercados de atuação podem afetar as variáveis independentes em função de diferentes condições ambientais e exigências específicas de cada mercado. Foram coletados dados sobre a atuação em 4 mercados no ano de 2005: montadoras, reposição, exportação e intersetorial.

d) Sub-setores de atuação: diferentes sub-setores de atuação dentro do setor automotivo também podem afetar as variáveis independentes em função de desempenhos diferentes de cada um e em função de diferentes exigências das empresas clientes. Foram coletados dados sobre a atuação em 4 sub-setores no ano de 2005: automóveis, caminhões e ônibus, máquinas agrícolas e motocicletas.

e) Faturamento por pessoa: entre empresas de um mesmo setor, avaliar o faturamento por pessoa pode ser uma forma de medir quanto de valor é agregado pelos processos da empresa e, portanto, o grau de sofisticação de seus produtos e processos.

\subsection{Fontes e métodos de coleta dos dados}

O motivo da escolha do setor de autopeças como fonte dos dados para a pesquisa já foi abordado preliminarmente em seções anteriores. Segue abaixo uma descrição mais detalhada das razões:

a) Familiaridade do autor com o setor, no qual atua como empresário a 25 anos;

b) Grau de formalização de grande parcela das empresas: todas as empresas que vendem para montadoras precisam demonstrar a seus clientes, com diferentes graus de rigor, que estão regulares com suas obrigações trabalhistas, tributárias, legais e ambientais. Esta formalização favorece a confiabilidade dos balanços.

c) Grau de estruturação da entidade que agrega as empresas do setor, SINDIPEÇAS, e o volume de informações que disponibiliza: esse sindicato mantém estatísticas com relativa qualidade há décadas (SINDIPEÇAS 2008) e se dispôs a colaborar com a pesquisa.

d) Número de empresas relativamente limitado, aproximadamente 480: o que permite viabilizar pesquisas englobando grande parcela do setor.

e) Distribuição equilibrada de empresas não certificadas e certificadas em um ou mais PSGs: o que permite estudar quantidades expressivas de empresas em cada situação. 
f) Desempenho recente de estável crescimento do setor: com um mercado favorável e em constante crescimento no período analisado, se reduzem as chances de diferenças de desempenho provocadas por fatores idiossincráticos.

g) Disponibilidade de dados: sendo o setor de autopeças um setor estruturado, relativamente pequeno em termos de número de empresas e com um longo histórico no país, há muitos dados disponíveis para quem se dispõe a procurar por eles. Além disso, há uma boa disponibilidade de dados das variáveis de controle como, por exemplo, vendas de cada sub-setor e de mercados específicos.

O SINDIPEÇAS, dado o interesse em promover os negócios de seus associados, possui um banco de dados bastante completo sobre eles que inclui mercados e setores de atuação bem como certificações possuídas. Os métodos de coleta foram o acesso aos dados disponíveis no site da entidade para o levantamento preliminar e, posteriormente, a aquisição das informações detalhadas das empresas associadas que o sindicato possui em seu banco de dados. Essas últimas foram entregues em um CD ROM.

Os dados do SINDIPEÇAS estavam, porém, incompletos ou desatualizados. Assim, foi necessário consultar diretamente as empresas através de seus sites e buscas na Internet, por correio eletrônico (e-mail) e pelo telefone. Além da confirmação de alguns dados, o contato foi necessário para a obtenção de seus respectivos números de CNPJs (Cadastro Nacional de Pessoa Jurídica), pois somente através desse número a Serasa pode levantar as informações das empresas.

A coleta se iniciou com as 488 empresas registradas no SINDIPEÇAS. Dessas, doze empresas foram eliminadas do conjunto por serem simples atacadistas ou prestadores de serviços de transporte ou logística, e não indústrias. Outras quatro foram eliminadas por serem filiais e duas por terem encerrado atividades. Restaram assim 460 empresas.

Como já foi comentado, a Serasa S.A. se dispôs a colaborar com a pesquisa. A empresa possui um setor para se relacionar com pesquisadores e que contribui com informações para trabalhos acadêmicos e de interesse social. É necessário, porém, apresentar um projeto de pesquisa dentro de determinados padrões, além de assumir o compromisso de utilizar os dados de forma agregada e com objetivos estritamente acadêmicos, sob pena de multa. 
A elaboração da matriz de dados exigiu, portanto, um trabalho meticuloso, já que não haveria, depois da entrega dos dados à Serasa, oportunidade de complementar, revisar ou corrigir as informações. Isso se deve à exigência da Serasa de não identificação das empresas nos dados que ela fornece por questões de sigilo e política comercial (já que esses dados são exatamente o produto que ela vende). A solução encontrada foi a eliminação, pela Serasa, do nome e do CNPJ das empresas na matriz de dados que foram substituídos por um número aleatório.

A Serasa possui um banco de dados de centenas de milhares de empresas do Brasil que inclui informações societárias, referências comerciais, demonstrações de resultados e balanços. O grau de confiabilidade dessas informações cresceu muito nos últimos anos em função das novas responsabilidades legais que recaem sobre os contadores - que são inclusive fiscalizados pelos CRCs (Conselhos Regionais de Contabilidade) - e graças à verificação dos próprios clientes e usuários dos dados da Serasa. A própria Serasa possui rotinas para verificar a consistência dos dados. As empresas fornecem voluntariamente seus dados para obterem crédito em bancos e fornecedores e demonstrarem a potenciais clientes sua situação financeira.

Após algumas reuniões para ajustes da matriz de dados e algumas semanas de trabalho do setor de modelagem da Serasa, as informações de 460 empresas foram entregues contidas em uma matriz de 460 linhas por 42 colunas, gravada em um CD de dados.

Os dados entregues pela Serasa não estavam completos. A Serasa depende das empresas para completar seu banco de dados e nem todas as empresas fornecem os dados solicitados. Há faltas, por exemplo, de vendas de algum ano, lucro ou LAJIDA de outro ou número de empregados atual. O tratamento dos casos com dados faltantes está descrito na próxima seção.

Também foram coletados dados sobre mercado - vendas de sub-setores e de mercados específicos - na ANFAVEA (Associação Nacional dos Fabricantes de Veículos Automotores) e na ABRACICLO (Associação Brasileira de Fabricantes de Motocicletas) para auxiliar na análise das variáveis de controle. Esses dados estão disponíveis mediante solicitação por telefone e são fornecidos por e-mail. 
Falta de dados de diversas empresas e dados com confiabilidade questionável são as principais limitações das fontes e do método de coleta. Existem, porém, algumas condições que restringem a extensão dessas limitações e de seus efeitos.

No caso dos dados fornecidos pelo SINDIPEÇAS, a entidade não tem nenhum processo de checagem sobre a veracidade de certificados de PSGs declarados ou dos sub-setores e mercados de atuação. As empresas poderiam ter interesse em informar um número maior de certificados ou um maior número de sub-setores e mercados de atuação para conquistar clientes. Esse problema é mitigado pelo controle feito pelas outras empresas do setor e pelos clientes que poderiam denunciar informações falsas. Além disso, o mercado de autopeças, por ser relativamente restrito, faz com que a reputação seja um ativo importante demais para ser colocado em risco desta forma.

No caso dos dados fornecidos pela Serasa, informações sobre o número de empregados podem estar incorretas e as demonstrações contábeis podem ter sido manipuladas. O primeiro problema é de difícil controle, mas pode ser verificado comparando-se o valor de faturamento por empregado com o de outras empresas no momento da análise dos dados. De qualquer forma, não afeta demasiadamente os resultados do estudo, pois é uma variável de controle. O problema das demonstrações contábeis existe efetivamente, mas é hoje bem menor do que no passado, devido à responsabilização criminal de contadores (PENASSO, 2004) e pelo trabalho de checagem de consistência feito pela Serasa e pelos próprios usuários dos seus dados. Por um lado, as empresas poderiam estar tentadas a declarar lucros artificialmente baixos para pagar menos impostos. Por outro lado, porém, dada a grande interdependência entre clientes e fornecedores na cadeia de autopeças, há uma crescente preocupação com a saúde financeira das empresas, o que incentiva a exibição de lucros saudáveis. Some-se a isso, a necessidade de exibir boas informações para a obtenção de crédito em bancos e subfornecedores. Além disso, se comparado com opções como, por exemplo, questionários, as demonstrações contábeis no banco de dados da Serasa são, provavelmente, uma fonte bem mais confiável.

\subsection{Tratamento dos dados e Métodos Estatísticos}


Antes de se passar para a análise estatística propriamente dita, é necessário preparar os dados. Apesar da boa quantidade de casos e da qualidade das informações, havia problemas de falta de dados em algumas variáveis de alguns casos e havia indícios de dados extremos que poderiam contaminar a amostra. Estas primeiras informações foram extraídas através de análises executadas no software Microsoft Excel 2007.

Conforme Rubin (1976) e Little e Rubin (2002), quando há dados faltantes em uma pesquisa similar à presente, antes de se proceder é necessário analisar o processo que causou a falta. Os autores explicam as razões:

\begin{abstract}
Análise de casos completos restringe a análise a casos em que todas as variáveis estão presentes. Vantagens desta abordagem são (1) simplicidade, já que análise estatística padrão de dados completos pode ser aplicada sem modificações, e (2) comparabilidade da estatística univariada, já que essa é calculada em uma base amostral comum de casos. Desvantagens surgem da potencial perda de informação no descarte de casos incompletos. Essa perda de informação possui dois aspectos: perda de precisão, e viés quando o mecanismo de [que causa] dados faltantes não é MCAR [faltante de forma completamente aleatória], e os casos completos não são uma amostra aleatória de todos os casos. Análise de casos completos pode ser justificada em termos de simplicidade quando a perda de precisão e viés são mínimos, de forma que o pay-off de utilizar a informação nos casos incompletos será mínimo. ${ }^{68}$ (LITTLE; RUBIN, 2002, p. 41-42).
\end{abstract}

O motivo da exclusão de empresas é a falta de algum dado de faturamento, lucro ou LAJIDA nos anos de 2002 a 2005. As tabelas dois e três, exibidas na seção resultados, mais à frente, mostram que não há diferenças significativas entre os indicadores chave de empresas com informações parciais e empresas com informações completas. Assim, procedeu-se na análise estatística somente dos casos completos (com exceção da variável Risk Scoring) por não haver razões para supor que os dados faltantes não são MCAR.

Além disso, se de um lado as 460 empresas pesquisadas representam um censo do setor, de outro lado o número de empresas com dados completos - 220 como se verá adiante - ainda é razoavelmente elevado. Assim se pode considerar, também, que o nível de precisão perdido com a não consideração dos casos incompletos é limitado.

\footnotetext{
${ }^{68}$ Complete-case analysis confines attention to cases where all the variables are present. Advantages of this approach are (1) simplicity, since standard complete data statistical analyses can be applied without modifications, and (2) comparability of univariate statistics, since these are all calculated on a common sample base of cases. This loss of information has two aspects: loss of precision, and bias when the missing-data mechanism is not MCAR, and the complete cases are not a random sample of all the cases. Complete-case analysis may be justified in terms of simplicity when the loss of precision and the bias is minimal, so that the pay-off of exploiting the information in the incomplete cases will be minimal
} 
Outra questão a ser enfrentada é a possível existência de dados extremos que poderiam comprometer os resultados da pesquisa. Por exemplo, empresas que erraram na informação dos dados à Serasa ou empresas que reportam resultados anormais devidos a eventos extremos como falências, concordatas, encerramento de atividades ou acidentes. Esses e outros tipos de dados que podem contaminar amostras recebem o nome de outliers. Barnet e Lewis (1998, p. 7) definem o conceito:

Nós definimos um outlier em um conjunto de dados sendo uma observação (ou subconjunto de observações) que aparenta ser inconsistente com o remanescente desse conjunto de dados.

A frase “aparenta ser inconsistente” é crucial. É uma questão de julgamento subjetivo da parte do observador se alguma observação (ou subconjunto de observações) é escolhida para escrutínio ou não. O que realmente importa é se algumas observações são membros genuínos da população principal ou não. Se eles não são, mas são contaminantes (surgindo de alguma outra distribuição), eles podem frustrar tentativas de tirar inferências sobre a população (basicamente) original. ${ }^{69}$

Para reduzir a citada subjetividade da procura por outliers, um dos softwares estatísticos utilizados, o AMOS, calcula a distância de Mahalanobis (LATTIN et al, 2008) para cada caso (empresa) da matriz de dados. A distância de Mahalanobis no AMOS leva em conta todas as variáveis e é “a medida de quão longe a observação de x está do centro das distribuições de todos os valores, levando em conta todas as variáveis sendo consideradas em suas covariâncias” (MANLY, 2008, p. 76). O resultado é uma lista de valores crescentes que pode ser vista no apêndice três. Há um salto de valores para os dez maiores em relação aos outros. Além disso, nos gráficos de distribuição mostrados no apêndice um, as mesmas empresas podem ser vistas como extremos em muitos deles. Foram então selecionadas nove empresas como valores extremos: as de números 86, 181, 284, 337, 16, 164, 210, 343, 433.

Dada a subjetividade ainda presente na seleção, foi criada uma matriz sem estas nove empresas - que foi chamada de Matriz sem Extremos - que foi comparada com os dados originais - Matriz Original - e com a matriz que inclui todas as empresas com dados completos - Matriz Revisada. Na próxima seção descrevem-se os resultados dessa comparação.

\footnotetext{
${ }^{69}$ We shall define an outlier in a set of data to be an observation (or subset of observations) which appears to be inconsistent with the remainder of that set of data.

The phrase 'appears to be inconsistent' is crucial. It is a matter of subjective judgment on the part of the observer whether or not some observation (or set of observations) is picked out for scrutiny. What really matters is whether or not some observations are genuine members of the main population. If they are not, but are contaminants (arising from some other distribution), they may frustrate attempts to draw inferences about the original (basic) population.
} 
Os primeiros métodos estatísticos utilizados foram comparações de médias e variâncias, regressão múltipla, além de análises descritivas para auxiliar a visualização dos dados. Os resultados estão na próxima seção e foram calculados através do software Microsoft Excel e SPSS 15.0. Os diversos indícios de relações que essas análises expõem, permitiram algumas conclusões prévias e serviram de base para análises de regressão e para a elaboração de modelos a serem testados através da técnica multivariada descrita mais abaixo.

Para se extrair o máximo de informações dos dados, foi escolhida a técnica de análise multivariada Modelagem de Equações Estruturais com Variáveis Latentes ou, abreviadamente em inglês, SEM ${ }^{70}$. Essa técnica, viabilizada graças ao uso de softwares específicos, utiliza múltiplas medidas diretas (os indicadores) para obter construtos não observáveis diretamente (as variáveis latentes) e modela relações de dependência entre esses construtos (as equações estruturais) ao invés de entre as medidas diretas em si (LATTIN et al, 2008). As variáveis latentes podem representar variáveis independentes e dependentes, como também as variáveis de controle e mediadoras. As variáveis mediadoras são aquelas que sofrem efeitos de outras variáveis e provocam efeitos sobre outras variáveis mediadoras ou dependentes. São também chamadas de variáveis endógenas. Variáveis exógenas, por outro lado, são variáveis independentes que não possuem variável causal antecedente.

A técnica SEM possui vantagens quando comparada com a alternativa mais simples de regressão múltipla. Em regressão, somente as relações entre variáveis observadas (indicadores) são modeladas e somente à variável dependente é atribuído um coeficiente de erro - não às variáveis independentes e de controle. Os softwares de SEM, além de possibilitar a modelagem com variáveis latentes, inerentes à técnica, também possuem interfaces gráficas para uma modelagem eficiente e calculam medidas de ajustamento (fitness) do modelo e índices de modificação que sugerem melhorias ao pesquisador (GARSON, 2008, p. 2).

A técnica SEM tem natureza confirmatória permitindo testar hipóteses. O pesquisador elabora um modelo que representa sua hipótese e o testa. Se o modelo for aceitável, significativo e obter boas medida de fitness ele pode ser usado para aceitar ou rejeitar hipóteses. Há diversos

\footnotetext{
${ }^{70}$ Structural Equation Modeling with latent variables
} 
critérios de aceitabilidade, significância e fitness que, por praticidade, serão expostos na análise dos próprios dados da tese na seção 4.2.

O software utilizado para a SEM foi o AMOS 16.0, distribuído pela SPSS Inc. 


\section{RESULTADOS}

\subsection{Análise preliminar}

Os dados obtidos no SINDIPEÇAS estavam na forma de fichas individuais por empresa. A primeira tarefa foi elaborar uma matriz de dados em que cada linha representa uma empresa e cada coluna uma variável. Essa matriz foi feita através do software Microsoft Excel. As etapas abaixo descrevem resumidamente esse processo:

a) Estudo 0: levantados os dados básicos de 468 empresas que representam 100\% das empresas associadas ao SINDIPEÇAS.

b) Estudo 1: através de contatos diretos com as empresas a lista foi completada com diversas informações faltantes na base de dados do SINDIPEÇAS. A obtenção do número do CNPJ (Cadastro Nacional de Pessoas Jurídicas) exigiu a consulta a 100\% da empresas, pois não constava na base de dados do SINDIPEÇAS. Foram eliminadas as empresas identificadas como não industriais. Restaram 460 empresas.

c) Estudo 2: a lista (matriz de dados) foi enviada à Serasa e devolvida com as informações solicitadas, mas sem a identificação das empresas - nome e CNPJ, que foram eliminados - por questões de confidencialidade. Para isso a Serasa desenvolveu um conjunto especial de algoritmos para a coleta dos dados solicitados em sua base.

d) Estudo 3: foi introduzido na planilha o cálculo de faturamento por funcionário e da idade das empresas. Foi eliminada a empresa número 98 por ter características não industriais restando, assim, 459 empresas.

Os dados das 459 empresas foram ordenados e divididos em grupos de acordo com diferentes critérios - por tipo de cerificação, por número de funcionários, por sub-setores, etc. - para se tentar intuir algum padrão e, eventualmente, já encontrar diferenças nos indicadores de desempenho entre empresas com níveis diferentes de adoção de PSGs. Um dos primeiros frutos dessa análise foi a separação das empresas em cinco grupos de acordo com as suas certificações em PSGs: 
a) Grupo 0 (G0): empresas sem sistemas de gestão certificados formando um grupo de 99 empresas.

b) Grupo 1 (G1): empresas com sistemas certificados em gestão da qualidade somente sob a norma ISO 9.001 formando um grupo de 80 empresas.

c) Grupo 2 (G2): empresas com sistemas certificados em gestão da qualidade sob as normas ISO 9.001 e ISO/TS 16.949 formando um grupo de 126 empresas.

d) Grupo 3 (G3): empresas com sistemas certificados em gestão da qualidade - ISO 9.001 e ISO/TS 16.949 - e meio-ambiente sob a norma ISO 14.001. Neste grupo há três empresas, em um total de 132, que não possuem certificação em ISO/TS 16.949, mas que foram incluídas dadas características comuns com o grupo e para evitar a criação de um grupo adicional.

e) Grupo 4 (G4): empresas com sistemas certificados em gestão da qualidade - ISO 9.000 e ISO/TS 16.949 - meio-ambiente - ISO 14.001 - e saúde e segurança do trabalho - OHSAS 18.001. Nesse grupo se encontram empresas também certificadas em responsabilidade social - SA 8.000 - mas, como são apenas três em um total 23, não foi criado um grupo específico para elas.

Feita essa divisão, passou-se para a avaliação dos dados faltantes e outliers, e a conseqüente definição dos critérios de seleção para a elaboração das matrizes de dados para a análise estatística propriamente dita. As etapas abaixo resumem esse processo feito com o uso dos softwares Microsoft Excel, SPSS e AMOS:

a) Estudo 4: empresas foram divididas em 5 grupos em função de suas certificações conforme critério descrito acima.

b) Estudo 5: foram eliminadas as empresas que não informaram faturamento, LAJIDA e Lucro de 2002 a 2005, pelo menos. Restaram 225 empresas.

c) Estudo 6: foram eliminadas as empresas que restaram do G4 por serem poucas (5) em relação à população original (23). Nos outros grupos restaram $47,5 \%$ ou mais das empresas da população original. Restaram 220 empresas nessa matriz - que chamamos de Matriz Revisada - que se tornou a base de dados principal desse estudo.

d) Estudo 7: foram eliminadas do estudo 3 acima as empresas do grupo G4 para poder se comparar os dados com o estudo 6 - Matriz Revisada. Restaram 436 empresas na 
matriz de dados - que chamamos de Original - para ser comparada com a Matriz Revisada para a verificação de similaridade.

e) Estudo 8: após a análise multivariada de vários modelos (ver seção 4.3), apenas um modelo, o Modelo C, passou pelos testes. Uma análise de distâncias de Mahalanobis, executada pelo software AMOS nesse modelo, destacou 16 empresas com índices de $\mathrm{d}^{2}$ de Mahalanobis superiores a 10. Os dados dessas empresas foram checados nos gráficos de distribuição para verificar seu afastamento das curvas normais. Nove empresas foram consideradas outliers. Essas empresas foram então excluídas tanto da Matriz Original como da Matriz Revisada criando, assim, a Matriz Original sem Extremos e a Matriz sem Extremos.

As tabelas 2 e 3 abaixo mostram que não se pode rejeitar a hipótese de que a Matriz Revisada e a Matriz sem Extremos são similares à Matriz Original e que, portanto, não devem ter sido introduzidos desvios significativos para a análise. As proporções, médias e desvios padrão são bastante similares e os valores de Z calc estão próximos a zero. Esse foi um resultado animador, pois na Matriz Revisada e na Matriz sem Extremos todas as variáveis estão com os dados completos, e isso permite um estudo amplo e mais robusto, especialmente com a SEM.

Devido ao resultado da SEM exposto na seção 4.3, onde somente os dados da Matriz Revisada confirmaram o modelo proposto, os dados dessa matriz receberão maior atenção. Os dados da Matriz sem Extremos servirão como forma de verificar se um pequeno número de casos está influenciando sobremaneira os resultados. Esse critério segue a orientação geral da literatura de se eliminar da análise principal os outliers somente diante de evidências muito fortes de que os casos não são representativos da amostra ou população estudados (BARNETT; LEWIS, 1998; LATTIN et al, 2003). 
Tabela 2: Comparação da matriz Original com a Revisada.

\begin{tabular}{|c|c|c|c|c|c|}
\hline \multirow[t]{2}{*}{ Característica } & \multicolumn{2}{|c|}{ Matriz Original } & \multicolumn{2}{|c|}{ Matriz Revisada } & \\
\hline & Quantidade & $\%$ & Quantidade & $\%$ & \\
\hline Total de Empresas & 436 & & 220 & & \\
\hline Empresas Certificadas & 338 & $78 \%$ & 175 & $80 \%$ & \\
\hline G3: Cert. em Qualidade, M.A. & 132 & $30 \%$ & 65 & $30 \%$ & \\
\hline G2: Dois certificados ou só ISO/TS & 126 & $29 \%$ & 72 & $33 \%$ & \\
\hline G1: Somente ISO 9000 & 80 & $18 \%$ & 38 & $17 \%$ & \\
\hline G0: Sem certificação & 98 & $22 \%$ & 45 & $20 \%$ & \\
\hline Mercados de atuação: & & & & & \\
\hline Montadoras & 350 & $80 \%$ & 179 & $81 \%$ & \\
\hline Reposição & 316 & $72 \%$ & 165 & $75 \%$ & \\
\hline Exportação & 303 & $69 \%$ & 163 & $74 \%$ & \\
\hline Inter-setorial & 97 & $22 \%$ & 44 & $20 \%$ & \\
\hline Sub-setores de atuação: & & & & & \\
\hline Automóveis & 396 & $91 \%$ & 202 & $92 \%$ & \\
\hline Caminhões e ônibus & 334 & $77 \%$ & 178 & $81 \%$ & \\
\hline Máquinas agrícolas & 204 & $47 \%$ & 111 & $50 \%$ & \\
\hline Motocicletas & 101 & $23 \%$ & 53 & $24 \%$ & \\
\hline & Médias* & Desvio padrão* & Médias & Desvio padrão & Zcalc \\
\hline Número de Empregados em 2006 & 378 & 764 & 476 & 903 & $-1,382$ \\
\hline Média de volume de vendas em 2005 & $\mathrm{R} \$ 111.875 .088$ & $\mathrm{R} \$ 307.762 .618$ & $\mathrm{R} \$ 119.261 .801$ & $\mathrm{R} \$ 329.024 .483$ & $-0,277$ \\
\hline Média de lucro sobre vendas em 2005 & $1,45 \%$ & $17,50 \%$ & $1,39 \%$ & $8,06 \%$ & 0,058 \\
\hline Média de LAJIDA sobre vendas em 2005 & $9,54 \%$ & $13,87 \%$ & $9,61 \%$ & $10,37 \%$ & $-0,064$ \\
\hline Média de risk scoring em setembro $2007 * *$ & 338 & 144 & 329 & 151 & 0,749 \\
\hline *das empresa que informaram ${ }^{* *}$ nos casos & ERAS & & & & \\
\hline
\end{tabular}

Tabela 3: Comparação da Matriz Original sem Extremos com a Matriz sem Extremos.

\begin{tabular}{|c|c|c|c|c|c|}
\hline \multirow[t]{2}{*}{ Característica } & \multicolumn{2}{|c|}{ Matriz Original } & \multicolumn{2}{|c|}{ Matriz sem Extremos } & \\
\hline & \begin{tabular}{|l|l|} 
Quantidade & \\
\end{tabular} & $\%$ & Quantidade & $\%$ & \\
\hline Total de Empresas & 427 & & 211 & & \\
\hline Empresas Certificadas & 331 & $78 \%$ & 168 & $80 \%$ & \\
\hline G3: Cert. em Qualidade, M.A. & 129 & $30 \%$ & 62 & $29 \%$ & \\
\hline G2: Dois certificados ou só ISO/TS & 123 & $29 \%$ & 69 & $33 \%$ & \\
\hline G1: Somente ISO 9000 & 79 & $19 \%$ & 37 & $18 \%$ & \\
\hline G0: Sem certificação & 96 & $22 \%$ & 43 & $20 \%$ & \\
\hline \multicolumn{5}{|l|}{ Mercados de atuação: } & \\
\hline Montadoras & 342 & $80 \%$ & 171 & $81 \%$ & \\
\hline Reposição & 310 & $73 \%$ & 159 & $75 \%$ & \\
\hline Exportação & 297 & $70 \%$ & 157 & $74 \%$ & \\
\hline Inter-setorial & 95 & $22 \%$ & 42 & $20 \%$ & \\
\hline \multicolumn{5}{|l|}{ Sub-setores de atuação: } & \\
\hline Caminhões e ônibus & 328 & $77 \%$ & 172 & $82 \%$ & \\
\hline Máquinas agrícolas & 200 & $47 \%$ & 107 & $51 \%$ & \\
\hline \multirow[t]{2}{*}{ Motocicletas } & 98 & $23 \%$ & 50 & $24 \%$ & \\
\hline & Médias* & Desvio padrão* & Médias & \begin{tabular}{|l|} 
Desvio padrão \\
\end{tabular} & Zcalc \\
\hline Número de Empregados em 2006 & 380 & 771 & 484 & 921 & $-1,415$ \\
\hline Média de volume de vendas em 2005 & $\mathrm{R} \$ 111.781 .725$ & $\mathrm{R} \$ 311.268 .757$ & $\mathrm{R} \$ 119.465 .813$ & $\mathrm{R} \$ 333.797 .042$ & $-0,280$ \\
\hline Média de lucro sobre vendas em 2005 & $1,92 \%$ & $16,16 \%$ & $1,86 \%$ & $6,54 \%$ & 0,070 \\
\hline Média de LAJIDA sobre vendas em 2005 & $9,80 \%$ & $13,21 \%$ & $9,95 \%$ & $8,35 \%$ & $-0,178$ \\
\hline Média de risk scoring em setembro $2007^{* *}$ & 339 & 145 & 331 & 152 & 0,652 \\
\hline
\end{tabular}

Nas tabelas 4 e 5 a seguir se fazem as primeiras comparações entre o desempenho das empresas agrupadas de acordo com se nível de certificação. Nessa primeira avaliação dos dados, a principal técnica estatística utilizadas foi o teste $\mathrm{t}$ de igualdade de médias. O software SPSS 15.0 foi utilizado com esse intuito em muitos casos. O SPSS executa simultaneamente o teste de Lavene para a igualdade de variâncias. Os relatórios desses testes estão nos apêndices 
1 e 2. Em alguns casos optou-se por fazer o teste t através de fórmulas em planilhas do software Microsoft Excel.

Tabela 4: Análise de variáveis dependentes por grupos de certificações na Matriz Revisada

\begin{tabular}{|c|c|c|c|c|c|c|c|c|c|}
\hline \multirow{3}{*}{\begin{tabular}{|l|} 
Grupos \\
de Cert.
\end{tabular}} & \multicolumn{9}{|c|}{ Variáveis dependentes na Matriz Revisada } \\
\hline & $\mathrm{N}^{\mathrm{o}}$ & $\begin{array}{r}\text { Variação } \\
2002\end{array}$ & $\begin{array}{l}\text { de vendas } \\
-2005\end{array}$ & $\begin{array}{r}\text { Lucro sobre v } \\
200\end{array}$ & $\begin{array}{l}\text { endas 2002- } \\
5\end{array}$ & $\begin{array}{r}\text { LAJIDA sobre } \\
20\end{array}$ & $\begin{array}{l}\text { e vendas } 2002 \\
05\end{array}$ & Risk scorin & ng set. 2007 \\
\hline & & Média & $\begin{array}{l}\text { Desvio } \\
\text { padrão }\end{array}$ & Média & $\begin{array}{l}\text { Desvio } \\
\text { padrão }\end{array}$ & Média & $\begin{array}{l}\text { Desvio } \\
\text { padrão }\end{array}$ & Média & $\begin{array}{l}\text { Desvio } \\
\text { padrão }\end{array}$ \\
\hline G3 & 65 & $150 \%$ & $204 \%$ & $2,33 \%$ & $6,77 \%$ & $10,59 \%$ & $8,35 \%$ & 343 & 134 \\
\hline G2 & 72 & $133 \%$ & $94 \%$ & $0,30 \%$ & $9,45 \%$ & $9,67 \%$ & $8,79 \%$ & 315 & 172 \\
\hline G1 & 38 & $91 \%$ & $110 \%$ & $2,51 \%$ & $6,96 \%$ & $12,10 \%$ & $9,15 \%$ & 306 & 140 \\
\hline G0 & 45 & $91 \%$ & $100 \%$ & $0,85 \%$ & $8,21 \%$ & $5,98 \%$ & $14,80 \%$ & 359 & 141 \\
\hline Médias & 220 & $122 \%$ & $140 \%$ & $\overline{11,39 \%}$ & $8,06 \%$ & $9,61 \%$ & $10,37 \%$ & 329 & 151 \\
\hline
\end{tabular}

Tabela 5: Análise de variáveis dependentes por grupo de certificações na Matriz sem Extremos

\begin{tabular}{|c|c|c|c|c|c|c|c|c|c|}
\hline \multirow{3}{*}{$\begin{array}{l}\text { Grupos } \\
\text { de Cert. }\end{array}$} & \multicolumn{9}{|c|}{ Variáveis dependentes na Matriz sem Extremos } \\
\hline & $\mathrm{N}^{\mathrm{o}}$ & $\begin{array}{r}\text { Variação } \\
2002 \\
\end{array}$ & $\begin{array}{l}\text { de vendas } \\
-2005\end{array}$ & $\begin{array}{r}\text { Lucro sobre ve } \\
200\end{array}$ & $\begin{array}{l}\text { endas 2002- } \\
5\end{array}$ & $\begin{array}{r}\text { LAJIDA sobre } \\
20\end{array}$ & $\begin{array}{l}\text { e vendas } 2002 \\
05\end{array}$ & Risk scorin & ig set. 2007 \\
\hline & & Média & $\begin{array}{l}\text { Desvio } \\
\text { padrão }\end{array}$ & Média & $\begin{array}{l}\text { Desvio } \\
\text { padrão }\end{array}$ & Média & $\begin{array}{l}\text { Desvio } \\
\text { padrão }\end{array}$ & Média & $\begin{array}{l}\text { Desvio } \\
\text { padrão }\end{array}$ \\
\hline G3 & 62 & $152 \%$ & $207 \%$ & $1,94 \%$ & $5,67 \%$ & $10,19 \%$ & $7,51 \%$ & 342 & 138 \\
\hline G2 & 69 & $135 \%$ & $92 \%$ & $1,62 \%$ & $7,08 \%$ & $10,08 \%$ & $8,73 \%$ & 319 & 172 \\
\hline G1 & 37 & $92 \%$ & $111 \%$ & $2,36 \%$ & $6,99 \%$ & $11,69 \%$ & $8,91 \%$ & 309 & 142 \\
\hline G0 & 43 & $90 \%$ & $102 \%$ & $1,68 \%$ & $6,64 \%$ & $7,93 \%$ & $8,28 \%$ & 359 & 141 \\
\hline Médias & 211 & $\overline{123 \%}$ & $142 \%$ & $\overline{1,86 \%}$ & $\overline{~ 6,54 \%}$ & 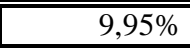 & $8,35 \%$ & 331 & 152 \\
\hline
\end{tabular}

As tabelas acima, combinadas com os testes estatísticos, permitem tirar as seguintes conclusões sobre os grupos:

a) Em ambas as matrizes a variação de faturamento de 2002 a 2005 dos grupos G2 e G3 é significativamente superior ao dos grupos G1 e G0. Empresas com mais PSGs certificados tiveram um maior crescimento de faturamento quando comparadas com empresas sem PSGs certificados ou com apenas um.

b) Na Matriz Revisada, os lucros sobre faturamento de 2002 a 2005 de G1 e G3 são significativamente superiores aos de G0 e G2. O baixo lucro sobre faturamento de G2, inferior inclusive ao de G0, é o ponto mais discrepante de todo o quadro.

c) Na Matriz sem Extremos, os lucros sobre faturamento de G1 e G3 são maiores, mas só os de G1 o são de forma significativa.

d) Nas duas matrizes revela-se também o fato que, depois de se possuir uma certificação, um maior número de certificações não se traduz em maior lucro sobre faturamento como mostra a proximidade de resultados entre G1 e G3; 
e) Em ambas as matrizes, o LAJIDA sobre faturamento de 2002 a 2005 de G1, G2 e G3 é significativamente superior. Empresas certificadas geraram mais caixa sobre faturamento que empresas sem certificação.

f) Em ambas as matrizes, o LAJIDA sobre faturamento entre G1, G2 e G3 não apresentam diferenças significativas, apesar de haver uma média menor para G2 alinhada com o também menor lucro sobre faturamento desse grupo. A partir de uma certificação, um maior número de certificações também não se reflete em maior geração de caixa sobre faturamento.

g) Não há diferenças significativas entre os grupos no que se refere a Risk Scoring.

É importante observar que a última linha das tabelas 3 e 4 acima resumem os resultados médios do setor (e os respectivos desvios padrão) para o período analisado. Estes números podem ser usados para comparar o desempenho de cada grupo e subgrupo com o setor como um todo.

As tabelas 6 e 7 abaixo analisam o efeito dos PSGs por empresas agrupadas também de acordo com o número de empregados. As empresas foram divididas em três grupos pequenas (até 200 empregados), médias (de 201 a 500 empregados) e grandes (acima de 500 empregados) - e, dentro de cada grupo, foram divididas de acordo com seus PSGs certificados. 
Tabela 6: Análise de variáveis de controle por tamanho de empresa (empregados) e grupos de certificações na Matriz Revisada

\begin{tabular}{|c|c|c|c|c|c|c|c|c|c|}
\hline & \multicolumn{9}{|c|}{ Variáveis dependentes na Matriz Revisada } \\
\hline \multirow[t]{2}{*}{$\begin{array}{l}\text { Grupos } \\
\text { de Cert. }\end{array}$} & $\mathrm{N}^{\mathrm{o}}$ & $\begin{array}{r}\text { Variação } \\
2002\end{array}$ & $\begin{array}{l}\text { de vendas } \\
-2005\end{array}$ & $\begin{array}{r}\text { Lucro sobre ve } \\
2005\end{array}$ & $\begin{array}{l}\text { endas 2002- } \\
5\end{array}$ & $\begin{array}{r}\text { LAJIDA sobre } \\
200\end{array}$ & $\begin{array}{l}\text { e vendas } 2002 \\
05\end{array}$ & Risk scorin & ng set. 2007 \\
\hline & & Média & $\begin{array}{l}\text { Desvio } \\
\text { padrão }\end{array}$ & Média & $\begin{array}{l}\text { Desvio } \\
\text { padrão }\end{array}$ & Média & $\begin{array}{l}\text { Desvio } \\
\text { padrão }\end{array}$ & Média & $\begin{array}{l}\text { Desvio } \\
\text { padrão }\end{array}$ \\
\hline \multicolumn{10}{|c|}{ Empresas Grandes (acima de 500 empregados) } \\
\hline G3 & 30 & $137 \%$ & $185 \%$ & $1,3 \%$ & $5,2 \%$ & $9,8 \%$ & $6,4 \%$ & N.D. & N.D. \\
\hline G2 & 10 & $160 \%$ & $146 \%$ & $-0,1 \%$ & $11,3 \%$ & $11,8 \%$ & $10,9 \%$ & 434 & 13 \\
\hline G1 & 2 & $84 \%$ & $13 \%$ & $3,0 \%$ & $3,5 \%$ & $11,2 \%$ & $2,4 \%$ & N.D. & N.D. \\
\hline G0 & 5 & $104 \%$ & $26 \%$ & $-5,3 \%$ & $14,9 \%$ & $-4,0 \%$ & $39,8 \%$ & N.D. & N.D. \\
\hline Médias & (47) & $134 \%$ & $153 \%$ & $0,8 \%$ & $\overline{77,8 \%}$ & $8,8 \%$ & $13,6 \%$ & N.D. & N.D. \\
\hline \multicolumn{10}{|c|}{ Empresas Médias (acima de 200 empregados) } \\
\hline G3 & 24 & $115 \%$ & $64 \%$ & $3,3 \%$ & $8,2 \%$ & $11,3 \%$ & $9,2 \%$ & 313 & 163 \\
\hline G2 & 33 & $133 \%$ & $69 \%$ & $0,1 \%$ & $6,9 \%$ & $9,7 \%$ & $6,2 \%$ & 226 & 171 \\
\hline G1 & 12 & $92 \%$ & $65 \%$ & $1,7 \%$ & $3,6 \%$ & $9,8 \%$ & $5,6 \%$ & 233 & 134 \\
\hline G0 & 11 & $241 \%$ & $391 \%$ & $1,3 \%$ & $4,1 \%$ & $8,1 \%$ & $4,4 \%$ & 342 & 130 \\
\hline Médias & 80 & $\overline{136 \%}$ & $158 \%$ & $1,5 \%$ & 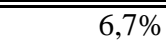 & $10,0 \%$ & 6,9\% & 265 & 159 \\
\hline \multicolumn{10}{|c|}{ Empresas pequenas (abaixo de 200 empregados) } \\
\hline G3 & 9 & $156 \%$ & $83 \%$ & $4,0 \%$ & $7,5 \%$ & $12,1 \%$ & $12,6 \%$ & 390 & 52 \\
\hline G2 & 27 & $129 \%$ & $101 \%$ & $0,8 \%$ & $11,9 \%$ & $8,8 \%$ & $10,9 \%$ & 383 & 146 \\
\hline G1 & 26 & $88 \%$ & $127 \%$ & $2,6 \%$ & $8,1 \%$ & $13,0 \%$ & $10,4 \%$ & 320 & 141 \\
\hline G0 & 31 & $78 \%$ & $97 \%$ & $1,5 \%$ & $7,6 \%$ & $6,9 \%$ & $9,2 \%$ & 369 & 142 \\
\hline Médias & (93 & $104 \%$ & $105 \%$ & $2,1 \%$ & 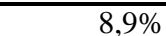 & 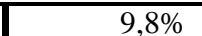 & $\mid 10,2 \%$ & 351 & $\overline{141}$ \\
\hline
\end{tabular}

Tabela 7: Análise de variáveis de controle por tamanho de empresa (empregados) e grupos de certificações na Matriz sem Extremos

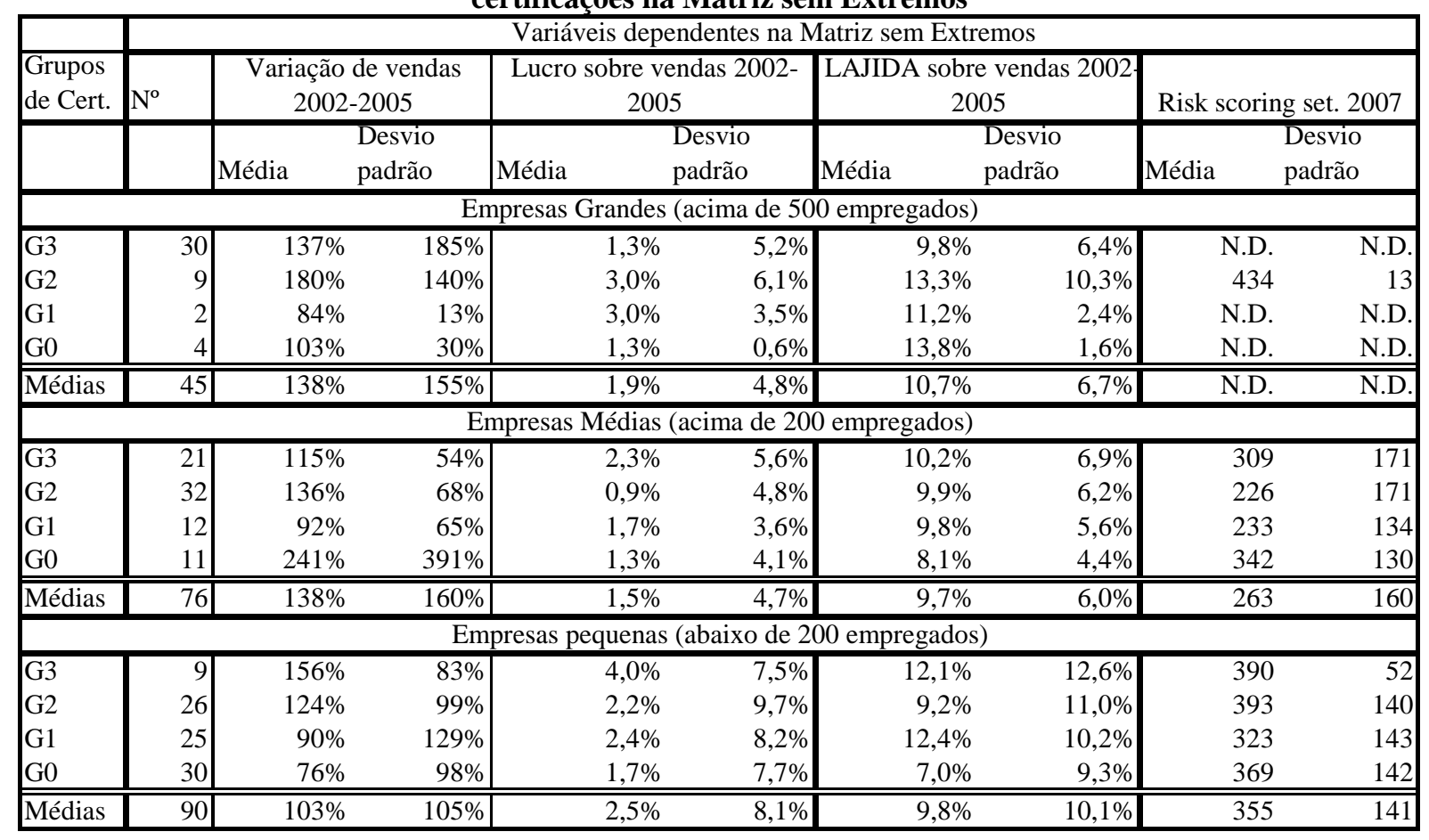


As tabelas 6 e 7 expõem alguns outros fatos sobre os dados:

a) Apesar de algumas exceções, as certificações influenciam positivamente o faturamento, especialmente em empresas pequenas. $\mathrm{O}$ comportamento do faturamento no G0 das empresas média é o dado mais discrepante, mas o elevado desvio padrão reduz sua significância.

b) Em ambas as matrizes, para todos os tamanhos de empresa, com a única exceção para empresas grandes na Matriz sem Extremos, as que implantaram o primeiro PSG para a qualidade (G1) tiveram resultados de lucro sobre faturamento e LAJIDA sobre faturamento melhores que os obtidos por empresas sem PSGs certificados (G0), a maioria de forma estatisticamente significativa.

c) Analisando-se as duas matrizes simultaneamente, a implantação de ISO/TS 16.949 (G2) aparentemente prejudica o lucro sobre faturamento e o LAJIDA sobre faturamento, especialmente para empresas médias e pequenas.

d) Empresas com PSGs de qualidade e ambientais (G3) possuem resultados muito bons e equilibrados em todos os grupos. No grupo das empresas grandes na Matriz Revisada, só as do grupo G1 possuem desempenho nitidamente melhor, mas são apenas duas, contra trinta do grupo G3. Na Matriz sem Extremos os resultados são similares, com exceção das grandes empresas, onde o G3 não mais se destaca com melhor desempenho.

e) Em geral, quanto menor a empresa, maior o efeito positivo dos PSGs em todos os indicadores de desempenho.

As constatações acima devem ser analisadas levando-se em conta outras variáveis de controle além do número de funcionários. As tabelas 8 e 9 abaixo fazem um resumo dessas variáveis por grupo de empresas.

Tabela 8: Análise das variáveis de controle na Matriz Revisada

\begin{tabular}{|c|c|c|c|c|c|c|c|c|c|c|c|c|c|}
\hline & \multicolumn{13}{|c|}{ Variáveis de controle na Matriz Revisada } \\
\hline \multirow[t]{2}{*}{$\begin{array}{l}\text { Grupos } \\
\text { de Cert. }\end{array}$} & $\mathrm{N}^{\mathrm{o}}$ & \multicolumn{4}{|c|}{ Mercados } & \multicolumn{4}{|c|}{ Sub-setores } & \multicolumn{2}{|c|}{\begin{tabular}{|c} 
Empregados em \\
2005
\end{tabular}} & \multicolumn{2}{|c|}{$\begin{array}{c}\text { Vendas totais 2002-2005 } \\
\text { em R } \$ 1.000\end{array}$} \\
\hline & & & & Export. & $\begin{array}{l}\text { Inter- } \\
\text { set. }\end{array}$ & Autos & $\begin{array}{l}\text { Cam. e } \\
\text { Onibus }\end{array}$ & $\begin{array}{l}\text { Maq. } \\
\text { Agric. }\end{array}$ & & Média & $\begin{array}{l}\text { Desvio } \\
\text { padrão }\end{array}$ & Média & \\
\hline G3 & 65 & $98 \%$ & $85 \%$ & $75 \%$ & $11 \%$ & $98 \%$ & $88 \%$ & $51 \%$ & $26 \%$ & 987 & 1.498 & $\mathrm{R} \$ 956.980$ & $\mathrm{R} \$ 1.98$ \\
\hline G2 & 72 & $90 \%$ & $69 \%$ & $65 \%$ & $31 \%$ & $93 \%$ & $77 \%$ & $46 \%$ & $19 \%$ & 307 & 258 & $\mathrm{R} \$ 153.054$ & 4.145 \\
\hline G1 & 38 & $61 \%$ & $74 \%$ & $82 \%$ & $26 \%$ & $82 \%$ & $76 \%$ & $66 \%$ & $29 \%$ & 224 & 270 & R\$ 93.320 & $\mathrm{R} \$ 113.213$ \\
\hline G0 & 45 & $60 \%$ & $71 \%$ & $80 \%$ & $11 \%$ & $89 \%$ & $82 \%$ & $44 \%$ & $24 \%$ & 219 & 274 & $\mathrm{R} \$ 122.461$ & $\mathrm{R} \$ 224.508$ \\
\hline Médias & 220 & $81 \%$ & $75 \%$ & $74 \%$ & $20 \%$ & $92 \%$ & $81 \%$ & $\overline{50 \%}$ & $24 \%$ & $\overline{4776}$ & 903 & R\$374.002 & $\mathrm{R} \$ 1.145 .748$ \\
\hline
\end{tabular}


Tabela 9: Análise das variáveis de controle na Matriz sem Extremos

\begin{tabular}{|c|c|c|c|c|c|c|c|c|c|c|c|c|c|}
\hline & \multicolumn{13}{|c|}{ Variáveis de controle na Matriz sem Extremos } \\
\hline \multirow[t]{2}{*}{$\begin{array}{l}\text { Grupos } \\
\text { de Cert. }\end{array}$} & $\mathrm{N}^{0}$ & \multicolumn{4}{|c|}{ Mercados } & \multicolumn{4}{|c|}{ Sub-setores } & \multicolumn{2}{|c|}{\begin{tabular}{|c} 
Empregados em \\
2005 \\
\end{tabular}} & \multicolumn{2}{|c|}{$\begin{array}{c}\text { Vendas totais } 2002-2005 \\
\text { em R\$ } 1.000\end{array}$} \\
\hline & & Mont. & Repos. & Export. & & Autos & $\begin{array}{l}\text { Cam. e } \\
\text { Onibus }\end{array}$ & $\begin{array}{l}\text { Maq. } \\
\text { Agric. }\end{array}$ & otos & Média & $\begin{array}{l}\text { Desvio } \\
\text { padrão }\end{array}$ & Média & \\
\hline G3 & 62 & $98 \%$ & $85 \%$ & $76 \%$ & $10 \%$ & $98 \%$ & $89 \%$ & $50 \%$ & $26 \%$ & 1.026 & 1.525 & $\mathrm{R} \$ 965.550$ & $\mathrm{R} \$ 2.0$ \\
\hline G2 & 69 & $90 \%$ & $70 \%$ & $65 \%$ & $32 \%$ & $93 \%$ & $78 \%$ & $46 \%$ & $19 \%$ & 303 & 260 & R\$ 148.997 & .486 \\
\hline G1 & 37 & $59 \%$ & $76 \%$ & $84 \%$ & $27 \%$ & $81 \%$ & $78 \%$ & $68 \%$ & $30 \%$ & 230 & 272 & R\$ 94.768 & $\mathrm{R} \$ 1$ \\
\hline G0 & 43 & $60 \%$ & $70 \%$ & $79 \%$ & $9 \%$ & $88 \%$ & $81 \%$ & $44 \%$ & $23 \%$ & 207 & 258 & $\mathrm{R} \$ 122.049$ & $\mathrm{R} \$ 229.597$ \\
\hline Médias & 211 & $81 \%$ & $75 \%$ & $74 \%$ & $20 \%$ & $91 \%$ & $82 \%$ & $51 \%$ & $24 \%$ & 484 & 921 & $\mathrm{R} \$ 373.931$ & $\mathrm{R} \$ 1.164 .093$ \\
\hline
\end{tabular}

Com se pode ver pelas tabelas 8 e 9, há algumas diferenças entre os grupos que poderão ser mais bem exploradas no momento da análise multivariada dos dados. De qualquer forma algumas situações se destacam:

a) Não há diferenças significativas entre a Matriz Revisada e a Matriz sem Extremos;

b) Os grupos G0 e G1 atuam menos em montadoras e mais em exportação quando comparados aos outros grupos. Nota-se, entretanto, que a atuação em montadoras parece não ser a principal motivação para a adoção de PSGs ISO 9000 , pois o percentual de empresas que atuam nesse mercado é praticamente igual (60\% e 61\%) nos dois grupos. Por outro lado, a passagem para ISO/TS 16.949, como era de se esperar, está ligada a um maior percentual de empresas atendendo montadoras (90\% e 98\%). Só montadoras podem exigir a adoção da ISO/TS 16.949 e a norma só permite a certificação de empresas que, direta ou indiretamente, forneçam a montadoras. No grupo que adota a ISO 14.001 (G3) há um percentual maior de empresas que atendem montadoras, mas a diferença em relação ao grupo G2 é pequena (8\%);

c) Empresas com mais empregados e maiores volumes de faturamento tendem a possuir mais certificações, o que pode mostrar uma ligação entre tamanho, profissionalização da administração e adoção de PSGs;

d) Há um salto no número de empregados e no faturamento nas empresas do grupo G3 em relação aos grupos G0, G1 e G2. Aparentemente, a preocupação em ter um sistema de gestão ambiental estruturado é maior em empresas de maior porte.

Grosso modo, a análise de dados feita até aqui mostra que os PSGs e o tamanho da empresa influenciam o desempenho das empresas das seguintes formas:

a) Em geral, os PSGs influenciam positivamente o desempenho das empresas; 
b) Empresas maiores tendem a ter mais PSGs certificados;

c) Entretanto, empresas maiores não mostram ter conseguido ganhos evidentes com a adoção de mais PSGs.

Dessa forma, empresas pequenas com um maior número de PSGs certificados apresentam os melhores resultados. Por outro lado, a maior tamanho das empresas aparenta anular a influência positiva dos PSGs.

Foi feita também uma tentativa de análise com regressão múltipla. O objetivo dela é definir uma fórmula matemática que permita prever o valor de uma variável dependente com base nos valores conhecidos de variáveis independentes (CORRAR et al, 2007). É um passo adiante em relação às técnicas univariadas utilizadas na seção anterior, mas ainda está limitada a uma única variável dependente.

A Matriz Revisada e a Matriz sem Extremos foram analisadas. Primeiro elaborou-se uma matriz de correlações para se identificar os graus de relacionamento entre as variáveis. Depois, com base nos valores encontrados, foram feitos testes com dez diferentes combinações de variáveis independentes com independentes. Através do software SPSS 15.0 é possível, rapidamente, verificar a capacidade de previsão e o ajuste das regressões.

Esses testes estão listados nas últimas páginas dos apêndices 1 e 2 . Como se pode verificar, nenhuma das regressões apresentou bons resultados. As melhores geraram $\mathrm{R}^{2}$ de 0,087 , para dados da Matriz Revisada e de 0,080 para dados da Matriz sem Extremos. Para que uma regressão seja significativa o $\mathrm{R}^{2}$, também denominado de coeficiente de determinação, precisa ser significativamente maior que zero. Esse resultado reflete as baixas correlações individuais encontradas na matriz de correlação.

Esta situação mostra a importância de se considerar simultaneamente as influências das variáveis. É o que procuram fazer as duas técnicas usadas nas próximas seções, seguindo as pistas sugeridas por essa análise preliminar. 


\subsection{Análise multivariada}

Para aplicar a modelagem de equações estruturantes (SEM) aos dados, um modelo preliminar de relações, baseado nos pressupostos teóricos do trabalho, deve ser criado. Uma das principais fontes de informação para a criação desse modelo, além da análise preliminar exposta acima, é a matriz de correlações (apêndices 1 e 2) na qual pode-se visualizar as correlações entre todas as variáveis consideradas. A matriz de correlações gerada pelo SPSS indica também quais correlações são significativas acima determinados níveis.

O uso da SEM também exige que os dados estejam distribuídos de forma próxima à normal. Nos apêndices 1 e 2 é possível verificar graficamente que essa condição está satisfeita. O software AMOS também verifica a normalidade dos dados para validar os modelos propostos.

Após diversas tentativas mal sucedidas de se obter um modelo aceitável com os dados brutos de adoção de PSGs - variáveis nominais de certificação ou não - foi elaborada uma Nota de Sistema através da simples soma de 1 para cada certificado de PSG que a empresa possui. Assim, as empresas receberam notas de zero (para aquelas sem nenhum PSG) a três (para aquelas com três). Somente após a introdução desse indicador, foi possível construir um SEM aceitável. As matrizes de correlação nos apêndices 1 e 2 já possuem essa nota entre as variáveis.

A procura por variáveis latentes também deve ser feita respeitando-se o modelo conceitual da pesquisa. A metodologia SEM exige que o pesquisador construa o Modelo de Medição e o Modelo Estrutural e que esses sejam testados. O Modelo de Medição é o que lida com as variáveis latentes e seus indicadores. O Modelo Estrutural é o que lida com as variáveis endógenas e exógenas e todos os efeitos diretos que as conectam, as suas correlações e eventuais indicadores de erro (refletindo os efeitos de variáveis ausentes do modelo) (GARSON, 2008).

Foram testados diversos Modelo de Medição e Modelos Estruturais antes de se chegar ao Modelo C representado na ilustração 11. As variáveis latentes sempre giraram em torno de construtos que refletiam a adoção de PSGs, a influência das variáveis de controle e o desempenho da empresa. Nessa linha, as variáveis latentes que conseguiram gerar um modelo 
aceitável foram chamadas de Adoção de PSGs, Tamanho da Empresa e Desempenho da Empresa e, como se pode notar no modelo, refletem indicadores coerentes com seus respectivos nomes.

O uso de SEM exige que se construa e se teste o maior número possível de modelos. Isso porque o fato de que um modelo se ajusta aos dados, não quer dizer que seja o melhor. Além disso, os modelos de SME devem refletir os fundamentos teóricos e as perguntas da pesquisa para que seus resultados façam algum sentido. Isso porque, existe o risco de se construir modelos que, apesar de serem estatisticamente aceitáveis, não fazem sentido para a pesquisa e, muitas vezes, não possuem nenhuma lógica interna (UNIVERSITY OF TEXAS, 2008).

O software AMOS fornece, opcionalmente, “indicadores de modificação” que são sugestão de melhoria no modelo. Entretanto, de acordo com recomendação de Lattin et al (2003) esses indicadores não foram usados neste estudo. O motivo é que, se esse recurso é usado, o modelo perde sua natureza confirmatória. Mudanças feitas ad-hoc por recomendação do software podem conter bons ajustes devido a características idiossincráticas dos dados. Tais modelos só podem ser validados com uma nova pesquisa (LATTIN et al, 2003).

Após testar mais de 30 modelos que atendem os critérios acima, o único modelo aceitável foi o modelo chamado de "C" (ilustração 11). A aceitabilidade de um modelo é definida por uma série de indicadores, sugeridos por diversos autores, chamados de medidas de ajuste (fitness). Entretanto, conforme Garson (2008), não há um consenso sobre quais os melhores indicadores utilizar. Uma sugestão dada pelo autor é escolher pelo menos um de cada categoria de indicadores:

a) Baseados em comparação de covariância observada versus prevista;

b) Baseados em comparações entre o modelo proposto e um alternativo;

c) Baseados em comparação de covariância penalizando por falta de parcimônia e;

d) Baseados na teoria de informação.

O software AMOS calcula indicadores em todas estas categorias. A seguir analisamos os resultados de cada indicador para o Modelo C. É importante notar que, ao interpretar as medidas de ajuste do modelo, um bom ajuste não significa que as relações entre as variáveis são fortes. Pode-se ter um ajuste perfeito, mas as variáveis não terem correlação nenhuma. A 
checagem do ajuste é o primeiro passo. Se o modelo tiver um bom ajuste, passa-se à segunda fase que é analisar as relações entre as variáveis com a certeza, dentro das margens de significância, que elas existem. Os valores analisados encontram-se relacionados nas tabelas geradas pelo AMOS no apêndice 3.

Antes de passarmos para a análise é necessário esclarecer que o AMOS, para efetuar algumas comparações de teste de ajuste, gera um modelo paralelo que considera que todas as variáveis são independentes entre si. O software o chama de independence model. Portanto, alguns indicadores são calculados para o modelo testado - o Modelo C nessa análise - e para o independence model e serão comparados em nossa análise.

Na primeira categoria de indicadores de ajuste está o indicador mais comum e considerado como principal pelo AMOS. O modelo apresentou um ótimo valor no teste de probabilidade de Qui-quadrado, ou p-value: 0,801. Valores de p-value acima de 0,05 garantem a aceitação da hipótese que o modelo está correto ao nível de 0,05. Para ocorrer a rejeição do modelo o pvalue precisaria se menor que 0,05 . Um valor de Qui-quadrado $(3,66)$ baixo em relação ao número de graus de liberdade do modelo (6) mostra um bom ajuste do modelo aos dados. (LATTIN et al, 2003; ARBUCKLE, 2007; GARSON, 2008; UNIVERSITY OF TEXAS, 2008).

Outro indicador dessa categoria é o N crítico de Hoelter que mede a adequação do tamanho da amostra. Para que um modelo seja aceitável o valor deve ficar acima de 200 (GARSON, 2008). O Modelo C alcançou 900 (a 0,05 de significância) e 1201 (a 0,01 de significância). Os números são excelentes, ainda mais se comparados com o independence model: 32 e 39 respectivamente.

Na segunda categoria, em que se compara o Modelo C com o independence model, encontrase o CFI, ou índice de ajuste comparativo (Comparative Fit Index) também conhecido como Bentler Comprative Fit Index. Índices próximos de 1,0 indicam bom ajuste (GARSON, 2008; ARBUCKLE, 2007). O Modelo C alcançou o valor CFI de 1,0. Nessa mesma categoria também se encontram os indicadores NFI (Normed Fit Index), RFI (Relative Fit Index), IFI (Incremental Fit Index) e TLI (Tucker- Lewis Index). Em todos, a recomendação é que estejam acima de 0,90 ou 0,95 (GARSON, 2008; ARBUCKLE, 2007). O Modelo 5 superou com folga todas essas marcas. 
A terceira categoria de indicadores penaliza a falta de parcimônia dos modelos, pois modelos mais complexos tendem a melhorar o ajuste, mas prejudicam a força das correlações e a utilidade do modelo. Afinal, um modelo tem por objetivo simplificar uma situação para promover a sua compreensão. O PRATIO (Parsimony Ratio) é a relação entre os graus de liberdade do modelo em teste e o independence model. Quanto menor, melhor (GARSON, 2008; ARBUCKLE, 2007). O resultado de 0,400 igualou os melhores modelos propostos por esta tese, mas que, entretanto, não foram aceitos por outros indicadores.

Outro comum e importante indicador dessa categoria é o RMSEA (Root mean square error of approximation). Por convenção há um bom ajuste do modelo se o RMSEA for menor que 0,05 (GARSON, 2008) ou 0,08 (ARBUCKLE, 2007). Além disso, o indicador PCLOSE, que testa a hipótese nula que o RMSEA não é maior que 0,05 , deve ser maior que 0,05 (GARSON, 2008; ARBUCLE, 2007). O Modelo C alcançou um RMSEA de 0,000 e um PCLOSE de 0,933, ambas marcas que confirmam um excelente ajuste.

A quarta categoria de indicadores de ajuste também penaliza a falta de parcimônia em comparação com o grau de informação fornecido pelo modelo, e só pode ser usada comparando-se os valores encontrados entre modelos alternativos. $\mathrm{O}$ menor valor indica um ajuste melhor. O Modelo C alcançou um AIC (Akaike Information Criterion) de 45,066 e um BCC (Browne-Cudeck Criterion) de 46,453. Para comparação o independence model alcançou respectivamente 199,890 e 200,682. O Modelo B, o segundo melhor (mas não aceitável) alcançou respectivamente 58,645 e 60,093. Mais uma vez se confirma um bom ajuste do Modelo C.

Uma situação não prevista nos indicadores de ajuste, mas que pode tornar um modelo inaceitável é a existência de cálculos no modelo que resultam em variâncias negativas, pois estas são impossíveis. Nesse caso, o AMOS informa que o modelo não é aceitável e em qual variável está sendo calculada a variância negativa. Resta ao pesquisador alterar o modelo a fim de eliminar o problema.

Outra avaliação a ser feita antes de se passar à análise das correlações do modelo é a da normalidade dos dados. O AMOS faz essa avaliação automaticamente antes de aceitar o modelo. Entretanto, essa normalidade pode também ser verificada nos gráficos gerados pelo 
SPSS e que estão no apêndice 1. Pode-se constatar, através deles, que há um bom ajuste dos dados à curva normal.

A estrutura deste Modelo C abaixo (ilustração 11) segue o padrão para SEM. Nos retângulos ficam os indicadores, nas elipses ficam as varáveis latentes e nos círculos ficam os valores residuais dos indicadores ou das variáveis latentes. As setas representam as relações causais entre os elementos do modelo. Em SEM, contrariamente ao senso comum, as setas saem das variáveis latentes em direção aos indicadores como se as primeiras fossam a causa desses últimos. Essa representação, porém, é uma necessidade dos modelos de SEM e não pressupõe uma direção da causalidade.

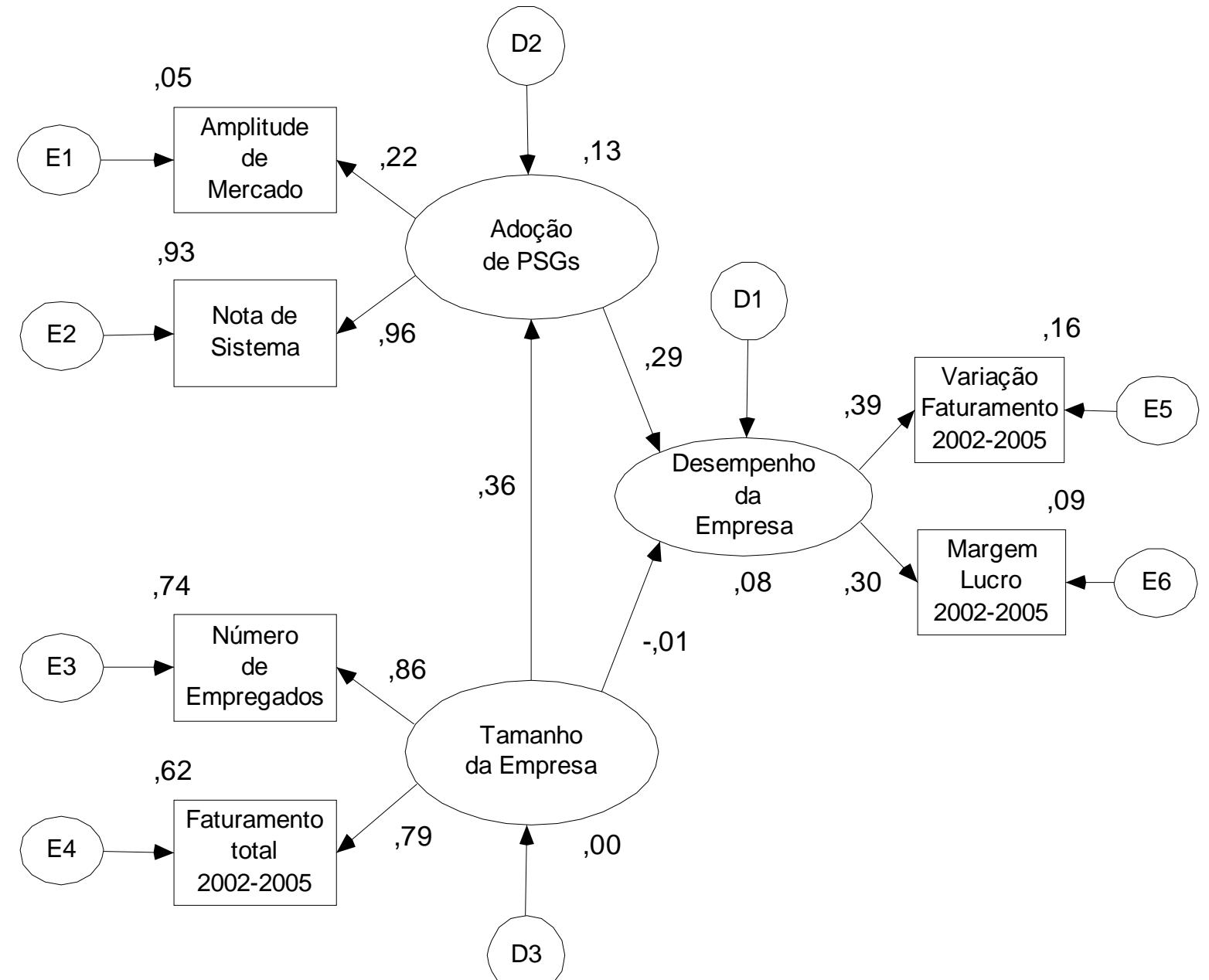

Ilustração 11: Modelo C 
Os valores ao lado das setas são os coeficientes de regressão - padronizados neste modelo que mostram quanto uma mudança equivalente a um desvio padrão no fator de origem da seta provoca de variação no fator de destino. Os valores sobre os retângulos, elipses e círculos são os estimadores da relação entre a variância da variável e a variância de todas as variáveis explicativas juntas (JÖRESKOG, 1999).

Dada a necessidade de mais de um indicador para cada variável latente (GARSON, 2008; LATTIN et al, 2003) foi escolhido, para complementar a Nota de Sistema, após diversos testes, o indicador de Amplitude de Mercado que é o número de mercados em que a empresa atua: montadoras, reposição, exportação e inter-setorial. Sua influência em conjunto com a da Nota de Sistema sobre a variável latente Adoção de PSGs pode ser explicada pela necessidade, das empresas que atuam em diversos mercados, de possuírem sistemas de gestão certificados para fazer frente a exigências de diversos tipos de clientes e para gerir a maior complexidade de suas atividades administrativas, comerciais e de produção. Os coeficientes de regressão padronizados mostram um predomínio da Nota de Sistema $(0,96)$, mas uma influência não desprezível da Amplitude de Mercado $(0,26)$.

A variável latente Tamanho da Empresa possui como indicadores o número de funcionários e o faturamento do período analisado. Esses indicadores foram escolhidos, juntamente com a variável latente, devido à influência sobre a adoção de PSGs e sobre a eficácia da empresa que ficou evidenciada na análise preliminar. Ambos apresentam coeficientes de regressão padronizados expressivos $(0,86$ e 0,79$)$ mostrando uma influencia equivalente sobre a variável latente. Não é um resultado óbvio dadas as diferenças de faturamento por funcionário verificadas nas matrizes de dados.

A variável latente Desempenho da Empresa acabou sendo representada por apenas dois indicadores: Margem de Lucro e Variação de Faturamento. Os outros dois indicadores, Margem LAJIDA e Risk Scoring foram testados em outros modelos, mas sem sucesso. Os coeficientes de regressão padronizados para Margem de Lucro $(0,30)$ e para Variação do Faturamento $(0,39)$ não são elevados, mas dadas as dificuldades envolvidas com a operacionalização de uma variável como Desempenho da Empresa, o resultado pode ser considerado satisfatório. Muito bom se considerado no contexto das ciências sociais aplicadas. 
Os coeficientes de regressão padronizados entre as variáveis latentes são o fulcro da análise do modelo. É interessante constatar que há um evidente alinhamento com o quadro mostrado no modelo C e a análise preliminar da seção anterior. O modelo mostra que uma variação de 1 desvio padrão em Tamanho da Empresa leva a um aumento de 0,36 em Adoção de PSGs. Empresas maiores tendem a adotar mais PSGs que empresas menores, mas com uma diferença de intensidade que não pode ser considerada elevada.

Por outro lado, como se pôde perceber também na análise preliminar, o tamanho da empresa não influencia o desempenho da empresa. No Modelo C o coeficiente de regressão padronizado de Tamanho da Empresa sobre Desempenho da Empresa é praticamente nulo (0,01). Como mostram os dados da análise preliminar, o maior tamanho da empresa tende a conter o seu desempenho. Essa situação é, sob certos aspectos, contra intuitiva, já que o crescimento é um objetivo perseguido por conta das supostas vantagens em termos de desempenho proporcionadas por economias de escala, acesso a capital, controle de mercado, etc. Os dados também mostram que a adoção de PSGs melhora o desempenho das empresas grandes, mas não com a mesma intensidade que o faz nas médias e pequenas.

A influência da variável latente Adoção de PSGs sobre Desempenho da Empresa é a mais importante da pesquisa. O coeficiente de regressão padronizado mostra que para cada variação de um desvio padrão na Adoção de PSGs ocorre uma variação de 0,29 desvios padrão no Desempenho da Empresa. Dada a infinidade de influências que o Desempenho da Empresa recebe do ambiente de negócios, e que está refletida nos indicadores Margem de Lucro e Variação de Faturamento, o coeficiente de regressão de 0,29 é um resultado expressivo.

O Modelo C tem como limitação o uso de apenas dois indicadores para cada variável latente. A literatura, apesar de aceitar dois indicadores, recomenda pelo menos três (LATTIN et al, 2003; GARSON, 2008). A aceitação de apenas dois indicadores, ou até mesmo de somente um, está condicionada à confiança do pesquisador na confiabilidade e representatividade dos mesmos. Esta confiança existe e, portanto, pode-se considerar essa limitação razoavelmente contornada.

Outra limitação do Modelo C é que não satisfaz completamente a recomendação de que os coeficientes de regressão dos indicadores com as variáveis latentes - não entre as variáveis 
latentes - sejam de 0,7 ou maiores (GARSON, 2008). Os que estão mais longe disso são os de Amplitude de Mercado, Variação de Faturamento e Margem de Lucro. Essa situação, já justificada em parágrafos anteriores, pode ser considerada contornável dado o contexto em que ocorre a pesquisa.

\subsection{Conclusões da análise dos resultados}

Com base nas análises desenvolvidas nas seções 4.1 e 4.2 é possível rejeitar a hipótese nula $H_{0}$ conforme o modelo conceitual proposto na seção 3, isto é, rejeita-se a hipótese de que não há diferença entre o desempenho de empresas com e sem PSGs. Os dados indicam uma influência positiva dos PSGs sobre o desempenho das empresas, principalmente na passagem de zero para um PSG.

Entre todos os testes efetuados, a principal evidência para a rejeição da hipótese nula é a aceitação da validade do Modelo C descrita na seção 4.2. Esse modelo mostra que o aumento do número de PSGs adotados melhora o desempenho das empresas.

Há também evidências na análise preliminar (seção 4.1) que indicam um melhor desempenho de empresas que adotam PSGs e que, portanto, reforçam a rejeição da hipótese nula. Nesta análise, também, há evidências de que a adição de PSGs - não só a passagem de zero para um PSG - favorece os resultados das empresas.

Os resultados também mostram que empresas pequenas e médias colhem melhores resultados da adoção de PSGs do que as empresas grandes.

Finalmente, a comparação de médias entre matrizes descrita na seção 4.1, mostra que não se pode rejeitar a hipótese nula de que não há diferença entre a amostra de 220 empresas e o universo de 459 indústrias de autopeças. Isso permitiria a extrapolação dos resultados para todo o setor. Entretanto, a comparação tem suas limitações, pois é feita apenas com os dados disponíveis para o último ano em análise (2005).

Essas conclusões se limitam aos pressupostos do modelo e ao setor pesquisado. 


\section{CONCLUSÕES}

A literatura de administração é abundante em recomendações sobre como organizar uma empresa. Há também diversas recomendações de como e por que utilizar regras nessa tarefa. Não existe, porém, uma unanimidade a respeito do problema, suas possíveis soluções, e nem mesmo uma linha de pensamento aceita pela maioria dos pesquisadores e dos praticantes da administração.

Resta o fato de que, quando se trata de definir regras em uma organização, escolhas precisam ser feitas. Assim que uma organização assume certo tamanho, regras formais são necessárias.

Já há muito tempo existem regras impostas às empresas pelo ambiente institucional, na forma de leis e regulamentos, que condicionam suas alternativas de organização. Mesmo assim, os administradores ainda possuem um amplo grau de liberdade para escolherem as regras de suas organizações.

Os Padrões para Sistemas de Gestão (PSGs) se apresentam como uma ferramenta para a construção de sistemas de regras de gestão. Eles têm sido criados, em sua quase totalidade, por ONGs de abrangência internacional como, por exemplo, ISO, OHSAS, SAI e IASB. Essas organizações reúnem, sob sua coordenação, ONGs de âmbito nacional que representam os interesses de pessoas envolvidas na gestão de sistemas de governança, qualidade, meio ambiente e outros. Constroem, assim, PSGs através de um processo amplamente participativo.

A adoção de PSGs envolve, como grande parte das decisões empresariais, um cálculo comparativo de custos e benefícios. Apesar de haver inúmeras entidades dedicadas à atividade de incentivar, implantar e auditar sistemas de regras baseados em PSGs, a decisão de adotálos ainda é mais baseada na intuição do que em fatos. Muitas vezes é simplesmente motivada pela exigência de algum cliente. Isso se deve, como em muitas outras situações da administração, à incerteza que ronda as relações de causa e efeito. 
Este trabalho, baseado em argumentos da bibliografia e na experiência do autor, propõe a tese de que os PSGs possuem uma boa relação custo-benefício, isto é, de que sua adoção pode influenciar positivamente desempenho das empresas.

Entretanto, essa proposta não encontra unanimidade na literatura da administração. Há questões não resolvidas entre os que defendem um uso intenso e os que defendem um uso restrito de regras formais. Há controvérsias também entre os que defendem sistemas de regras relativamente padronizados e os que postulam a impossibilidade de haver modelos prédefinidos dadas as idiossincrasias inerentes às organizações.

As entidades que coordenam os processos de criação dos PSGs procuram superar essas questões criando Metaregras ao invés de sistemas de regras padronizados. Metaregras são regras para a criação e o enforcement de sistemas de regras. Os PSGs são Metaregras que procuram garantir que conceitos praticamente consolidados da administração - satisfação dos stakeholders, eficiência, eficácia, gestão baseada em fatos, alinhamento das ações com a estratégia, inovação e melhoria contínua, entre outros - estejam no cerne dos sistemas de regras das organizações.

Diante da incerteza provocada pela Complexidade crescente que permeia a atividade dos administradores e das empresas, Metaregras podem ser uma ferramenta para criar organizações que são robustas o suficiente para manter sua integridade quando ameaçadas e flexíveis o suficiente para se adaptar às mudanças.

A Complexidade a que se faz referência aqui é aquela definida pela Teoria da Complexidade: a incerteza de situações Complexas tem origem na extrema sensibilidade dos sistemas organizacionais às condições iniciais que impede qualquer tipo de previsibilidade para as ações dos administradores em horizontes de tempo cada vez menores. Esta tese defende que Metaregras, devido a seus princípios baseados na emergência (emergence), são uma ferramenta para construir organizações eficazes em um contexto Complexo como esse.

A principal forma para alcançar a eficácia preconizada nos PSGs são os circuitos de feedback para a verificação constante da satisfação dos stakeholders e a tomada de providência caso essa satisfação não esteja sendo alcançada. O conceito por trás dessa prioridade é que as organizações existem exclusivamente para satisfazer seus stakeholders e, portanto, a única 
medida de eficácia que importa é sua satisfação. Esses mecanismos de feedback, associados a processos participativos de decisão, promovem a emergência de organizações mais eficazes.

Uma hipótese tão ampla dificilmente poderia ser testada e, portanto, essa tese desenvolveu um modelo de pesquisa que pudesse avaliar, pelo menos, a influência da adoção de PSGs sobre o desempenho financeiro das empresas. O setor escolhido para estudo foi a indústria brasileira de autopeças em função de diversas condições favoráveis para a pesquisa.

Os resultados mostraram fortes evidências de que a adoção de PSGs influencia positivamente o desempenho financeiro das empresas. A influência positiva da adoção de PSGs é mais sentida no desempenho das empresas pequenas e médias. Além disso, uma maior adoção de PSGs tende a ser acompanhada por um melhor desempenho. Essas conclusões se baseiam em testes estatísticos confirmatórios que mostram que quase $30 \%$ do desempenho das organizações está correlacionado com a adoção de PSGs.

Dessa forma, a resposta à pergunta de pesquisa é: sim, há uma influência da adoção de PSGs no desempenho das empresas e essa influência é positiva. Essa resposta se limita ao modelo conceitual proposto e ao conjunto de empresas estudadas. Essa pesquisa também possui outras limitações cuja descrição se encontra nas conclusões das seções anteriores.

Recomenda-se, portanto, que os Padrões para Sistemas de Gestão sejam considerados uma ferramenta potencialmente eficaz, especialmente para empresas industriais.

Os resultados da pesquisa, além de serem indícios que apóiam as proposições teóricas e práticas formuladas nas seções anteriores, também sugerem outras linhas de investigação. Por que, por exemplo, a adoção de PSGs parece favorecer mais os resultados das empresas pequenas e médias? Será que os PSGs favorecem os resultados das grandes empresas com a mesma intensidade, mas há outros fatores específicos amortecendo esse efeito? A investigação também pode ser ampliada para incluir outros setores que não o industrial, mas que, da mesma forma, vêm adotando intensamente PSGs. 


\section{REFERÊNCIAS BIBLIOGRÁFICAS}

ABELL, Peter. Organization theory: an interdisciplinary approach. London: University of London $\quad 2006.2$ Disponível em: $<$ http://www.lse.ac.uk/collections/MES/pdf/peterE8047_Organisation\%20theory.pdf>. Acesso em 15 de janeiro de 2008.

ABIQUIM, Associação Brasileira da Indústria Química. Diretrizes. São Paulo, 2008. Disponível em <http://www.abiquim.org.br/atuacaoresponsavel/praticas_ger.asp>. Acesso em 23 de setembro de 2008.

ABNT, Associação Brasileira de Normas Técnicas. NBR ISO 9001: sistemas de gestão da qualidade - requisitos. Rio de Janeiro: ABNT, 2000.

NBR ISO 9000: sistemas de gestão da qualidade - fundamentos e vocabulário. Rio de Janeiro: ABNT, 2000a.

NBR ISO 9004: sistemas de gestão da qualidade - diretrizes para melhorias de desempenho. Rio de Janeiro: ABNT, 2000b.

. NBR ISO 14001: sistemas de gestão ambiental- requisitos e orientações para uso. $2^{\mathrm{a}}$ ed. Rio de Janeiro: ABNT, 2004.

ALCHIAN, Armen. A.; DEMSETZ, Harold. Production, information costs, and economic organization. The American economic review. American Economic Association: Pittsburg, n. 5, v. 62 , p. 777-795, 12/1972.

ALLPORT, Floyd H. The observation of societal behavior of individuals. Social Forces. Chapel Hill: Univ. of North Carolina Press, n. 4, v. 15, p. 484-487, 05/1937.

AMSDEM, Alice D. De-Skilling, Skilled Commodities, and the NICs' Emerging Competitive Advantage. The American Economic Review: Papers and Proceedings of the Ninety-Fifth Annual Meeting of the American Economic Association. American Economic Association: Pittsburg, n. 2, v. 73, p. 333-337, 05/1983.

ARBUCKLE, James L. AMOS 16.0 users guide. Chicago: AMOS Development Corporation, 2007.

ARROW, Kenneth J. The limits of organization. New York: W.W. Norton \& Company, 1974.

ARTHUR, Brian W. Inductive reasoning and bounded rationality. The American Economic Review: Papers and Proceedings of the Hundred and Sixth Annual Meeting of the American Economic Association. American Economic Association: Pittsburg, n. 2, v. 84, p. 406-411, 05/1994.

. Out of equilibrium economics and agent-based modeling. In: JUDD. Kenneth; TESFATSION, Leith. Handbook of computational economics, v. 2. Amsterdam: Elsevier/North-Holland, 2006. 
ARTHUR, Brian W. et al. Introduction. In: The economy as an evolving complex system II. ARTHUR, Brian W et al. Boulder: Westview Press, 1997.

ASCH, Salomon Eliot. Social Psychology. Englewood Cliffs, NJ: Prentice Hall, 1952.

AXELROD, Robert M. The evolution of cooperation. New York: Basic Books, 1984.

An evolutionary approach to norms. American Political Science Review. American Political Science Association: Washington, DC, n. 4, v. 80, p. 1095-1111, 12/1986.

The complexity of cooperation: agent based models of competition and collaboration (Princeton Studies in Complexity). Princeton, NJ: Princeton Univ. Press, 1997.

AXELROD, Robert; COHEN, Michael. Harnessing Complexity: organizational implications of a scientific frontier. New York: The Free Press, 1999.

BARNARD, Chester I. The functions of the executive: $30^{\text {th }}$ anniversary edition. Cambridge, MA: Harvard Univ. Press, 1968.

BEINHOCKER, Eric D. The origins of wealth: evolution, complexity, and the radical remaking of economics. Boston: Harvard Business School Press, 2006.

BERTALANFFY, Ludwig von. General System Theory. New York: George Braziller, 1998.

BM\&FBOVESPA S.A. - Bolsa de Valores, Mercadorias e Futuros. Classificação Setorial 2008. Disponível em: <http://www.bovespa.com.br/pdf/ClassifSetorial.zip>. Acesso em 28 de setembro de 2008 .

BRUNSSON, Nils, JACOBSSON, Bengt. A word of standards. Oxford, NY: Oxford Univ. Press, 2005.

BHASKAR, Roy. The possibility of naturalism: a philosophical critique of contemporary human science. $2^{\text {nd }}$ ed. Hertfordshire, UK: Harvester Wheatsheaf, 1989.

BUCHANAN, David, HUCZYNSKI, Andrzej. Organization behavior. Hertfordshire, UK: Prentice Hall, 1997.

CHANDLER, Arthur D. Strategy and structure: chapters in the history of American industrial enterprise. Boston: MIT press, 1990.

CHAPMAN, Ross L., et al. Strategic quality management and financial performance indicators. International Journal of Quality \& Reliability Management. Bingley, UK: Emerald, n. 4, v. 14, p. 432-448, 1997.

CHENHALL, Robert H. Reliance on manufacturing performance measures, total quality management and organizational performance. Management Accounting Research. Bingley, UK: Emerald, n.2, v. 8, 06/1997.

CLEMEN, Robert T. Making hard decisions: an introduction to decision analysis. $2^{\text {nd }}$ ed. Duxbury, MA: Duxbury, 1996. 
COLANDER, David. Complexity and the history of economic thought. New York: Routledge, 2000a.

The complexity vision and the teaching of economics. Cheltenham: Edward Elgar Publishing, 2000b.

COASE, Ronald. The Nature of The Firm. In PUTTERMAN, Louis; KROSZNER, Randall. The economic nature of the firm. $2^{\text {nd }}$ ed. Cambridge: Cambridge Univ. Press, 1996.

CORRAR, Luiz J. et al (Coord.). Análise Multivariada: para cursos de administração, ciências contábeis e economia. São Paulo: Atlas, 2007.

CYERT, Richard M.; MARCH, James G. A behavioral theory of the firm. $2^{\text {nd }}$ ed. Cambridge, MA: Blackwell Publishers, 1992.

DE FEO, Joseph A.; BARNARD, William W. Six sigma breakthrough and beyond. New York: McGraw-Hill, 2004.

DEMSETZ, Harold. Toward a theory of property rights. The American economic review. American Economic Association: Pittsburg, n. 2, v. 57, p. 347-359, 05/1967.

DOUMA, Sytse; SCHREUDER, Hein. Economic Approach to Organizations. $3^{\text {rd }}$ ed. Essex, UK: Pearsons Education, 2002.

EASTON, George S., JARREL, Sherry L. The Effects of Total Quality Management on Corporate Performance: An Empirical Investigation. The Journal of Business. Chicago: Univ. of Chicago Press, n.2, v. 71, p. 253-307, 04/1998.

FELDMAN, Staley J. et al. Does improving a firm's environmental management system and environmental performance result in a higher stock price? ICF International (1996). Disponível em: <http://www.icfi.com/Publications/doc_files/resp_pays.pdf>. Acesso em 28 de setembro de 2008.

FERGUSON, Adam. An essay on the history of civil society. Cambridge: Cambridge Univ. Press, 1999.

FIEDLER-FERRARA, Nelson; PRADO, Carmen P. Cintra. Caos: uma introdução. São Paulo: Edgard Blücher, 1995.

FONSECA, Jairo Simon da; MARTINS, Gilberto de Andrade. Curso de Estatística. São Paulo: Atlas, 1996.

FNQ - Fundação Nacional da Qualidade (2007). Estudo FNQ/Serasa 2006. Disponível em: $<$ http://www.fnq.org.br/Portals/_FNQ/Documents/Estudo\%20FNQ\%20Empresas\%20Associa das_11_2006_rev1.pdf $>$. Acesso em 07 de julho de 2007.

FNQ - Fundação Nacional da Qualidade (2008). Modelo de Excelência de Gestão - MEG. Disponível em: <http://www.fnq.org.br/site/376/default.aspx> . Acesso em 28 de setembro de 2008.

FORRESTER, Jay W. Industrial dynamics. Waltham, MA: Pegasus, 1999a. 
Principles of systems. Waltham, MA: Pegasus, 1999b.

FURUSTEN, Staffan. The knowledge base of standards. In BRUNSSON, Nils, JACOBSSON, Bengt. A world of standards. Oxford, NY: Oxford Univ. Press, 2005.

GALBRAITH, Jay R. Organization design. Reading, MA: Addison-Wesley, 1997.

GARSON, David G. Structural Equation Modeling (2008). Disponível em: $<$ http://faculty.chass.ncsu.edu/garson/PA765/structur.htm>. Acesso em 28 de setembro de 2008.

GERTH, Hans H., MILLS C. Wright. From Max Weber: essays in sociology. Nova York: Oxford Univ. Press, 1961.

GIOVANNINI, Fabrizio. As organizações e a Complexidade: um estudo dos sistemas de gestão da qualidade. São Paulo, 2002a. Dissertação (Mestrado em Administração) - Programa de Pós Graduação em Administração, Departamento de Administração, Faculdade de Economia, Administração e Contabilidade da Universidade de São Paulo,.

A Complexidade e o estudo das organizações: explorando possibilidades. RAUSP Revista de Administração da Universidade de São Paulo. São Paulo: Departamento de Administração da Faculdade de Economia, Administração e Contabilidade da Universidade de São Paulo, n. 3, v.37, p. 56-66, julho/setembro 2002b.

GIOVANNINI, Fabrizio; KRUGLIANSKAS, Isak. Organização eficaz: como prosperar em um mundo caótico e complexo usando um modelo racional de gestão. São Paulo: Nobel, 2004.

GRI - Global Reporting Initiative. Reporting Framework Version 3.0 (2006). Disponível em:<http://www.globalreporting.org/ReportingFramework/ReportingFrameworkDownloads/> . Acessado em: 29 de setembro de 2008.

HAYEK, Frederick A. The use of knowledge in society. The American economic review. American Economic Association: Pittsburg, n. 4, v. 35, 09/1945.

HAYEK, F. A. The collected works of F.A. Hayek: the road to serfdom. Chicago: The Univ. of Chicago Press: 2007.

HODGE, B. J. et al. Organization theory: a strategic approach. $6^{\text {th }}$ ed. Upper Saddle River, NJ: Prentice Hall, 2003.

IASB - International Accounting Standards Board. International Financial Reporting Standards (IFRSs) 2008. Londres: IASCF, 2008. CD-ROM.

ISO, International Organization for Standardization. Technical specification ISO/TS 16.949 - Quality management systems - particular requirements for the application of ISO 9001:2000 for automotive production and relevant service part organizations. $2^{\text {nd }}$ ed. Geneve: AIAG, 2002.

JENSEN, Michael C.; MECKLING, William H. Theory of the firm: managerial behavior, agency costs and ownership structure. Journal of Financial Economics. Amsterdam: NorthHolland, n. 4, v. 3, p. 305-360. 10/1976. 
JONES, Stephen R. G. Was there a Hawthorne effect? The American Journal of Sociology. Chicago: The University of Chicago Press, n. 3, v. 98, p. 451-468, 11/1992.

JÖRESKOG, Karl G. What is the interpretation of $\boldsymbol{R}^{2}$ ? (1999). Disponível em: $<$ http://www.ssicentral.com/lisrel/techdocs/WhatistheinterpretationofR2.pdf >. Acessado em: 29 de setembro de 2008.

KAPLAN, Robert S.; NORTON, David P. The balanced scorecard. Boston: Harvard Business School Press, 1996.

KATZ, Daniel; KHAN, Robert. The social psychology of organizations. $2^{\text {nd }}$ ed. New York: Wiley, 1978.

KIEL, Douglas L.; ELLIOTT, Euel. Chaos theory in social sciences: foundations and applications. Ann Arbor: Univ. of Michigan Press, 1997.

KLEIN, Bejamin et al. Vertical integration, appropriable rents, and the competitive contracting process. Journal of Law and Economics, n. 2, v. 21, p. 297-326. 10/1978.

KRUGMAN, Paul. The self-organizing economy (Mitsui lectures in economics). New York: Willey-Blackwell, 1996.

KUHN, Thomas S. A Estrutura da Revoluções Científicas. São Paulo: Perspectiva, 1998.

LAKATOS, Eva Maria; MARCONI, Marina de Andrade. Metodologia Científica. São Paulo: Atlas, 1991.

LATTIN, James M. et al. Analyzing multivariate data. Pacific Grove: Thomson Brooks/Cole, 2003.

LIMA, Marcos A.M. Quality certification and performance of Brazilian firms: an empirical study. International Journal of Production Economics. Amsterdam: Elsevier, n.2, v. 66, p. 133-147, 30/06/2000.

LITTLE, Roderick J.A.; RUBIN, Donald B. Statistical analysis with missing data. Roboken, NJ: Wiley Inter-science, 2002.

MAANI, K. E. Empirical analysis of quality improvement in manufacturing. International Journal of Quality \& Reliability Management. Bingley, UK: Emerald, n. 7, v. 11, p. 19-37, 1994.

MANLY, Bryan J. F. Métodos estatísticos multivariados: uma introdução. $3^{\mathrm{a}}$ ed. Porto Alegre: Bookman, 2008.

MARCH, James G. Bounded rationality, ambiguity, and the engineering of choice. In BELL, D. E. et al. Decision making - descriptive, normative, and prescriptive interactions. Cambridge: Cambridge Univ. Press, 1988.

A primer on decision making: how decision happen. New York: Free Press, 1994. The pursuit of organizational intelligence. Malden, MA: Blackwell, 1999. 
MARCH, James G. et al. The dynamics of rules: change in written organizational codes. Stanford: Stanford Univ. Press, 2000.

MARCH, James G.; SIMON, Herbert. Organizations. $2^{\text {nd }}$ ed. Cambridge, MA: Blackwell, 1993.

MATURANA, Humberto; VARELA, Francisco. A Árvore do Conhecimento. Campinas: Psy, 1995

MAXIMIANO, Antonio C. A. Teoria geral da administração: da escola científica à competitividade em economia globalizada. São Paulo: Atlas, 1997.

MENARD, Claude; SHIRLEY, Mary M. (eds.) Handbook of new institutional economics. Amsterdam: Springer, 2005.

MILGROM, Paul; ROBERTS, John. Economics, organizations, and management. Upper Saddle River, NJ: Prentice Hall, 1992.

MILLER, Gary J. Solutions to principal-agent problems in firms. In MENARD, Claude, SHIRLEY, Mary M. (eds.) Handbook of new institutional economics. Amsterdam: Springer, 2005.

MINTZBERG, Henry. Structures in Fives. Englewood Cliffs, NJ: Prentice Hall, 1993.

Mintzberg on management. New York: The Free Press, 1989.

MOLLONA, Edoardo. Analisi dinamica dei sistemi aziendali. Milano: EGEA-Univ. Bocconi, 2000.

MBC. Movimento Brasil Competitivo. Estatuto (2008). Disponível em: <http://www.mbc.org.br/mbc/portal/uploads/mbc_estatuto/1160168473.0633-F1.pdf>.

Acesso em 23 de setembro de 2008

NELSON, Richard R.; WINTER, Sidney G. An evolutionary theory of economic change. Boston: Harvard Univ. Press, 1982.

PALFREY, Thomas R.; ROSENTHAL, Howard. Repeated Play, Cooperation and Coordination: An Experimental Study. The Review of Economic Studies. Blackwell Publishing: Cambridge, MA, n. 3, v. 61, p. 545-565, 07/1994.

PENASSO, Maria Zamian. O novo código civil e os contabilistas: grandes responsabilidades (2004). Disponível em: < http://www.classecontabil.com.br/trabalhos/uelresponsabilidade.doc $>$. Acesso em 28 de setembro de 2008.

PERROW, Charles. Complex organizations: a critical essay. 3rd ed. New York: McGrawHill, 1993.

PINDYCK, Robert S., RUBINFELD, Daniel L. Microeconomics. New Jersey: Prentice-Hall, 1998.

PLOUS, Scott. The psychology of judgment and decision making. New Yourk: MacGrawHill, 1993. 
POPPER, Karl R. The Logic of Scientific Discovery. New York: Routledge, 2000.

PUTTERMAN, Louis; KROSZNER, Randall S. The Economic Nature of the Firm. $2^{\text {nd }}$ ed. Cambridge: Cambridge Univ. Press, 1997.

RUBIN, Donald B. Inference and missing data. Biometrika. Oxford Journals: Oxford, n. 3, v. 63, p. 581-592, 12/1976.

SAI, Social Accountability International. SA 8000 - Responsabilidade Social 8000 (2008). Disponível em: $<$ http://www.saintl.org/index.cfm?fuseaction=document.showDocumentByID\&nodeID=1\&D ocumentID=141>. Acesso em 7 de abril de 2008.

SALANIÉ, Bernard. The economics of contracts: a primer. Cambridge, MA: MIT Press, 1997.

SAMUELSON, L. Evolutionary games and equilibrium selection. Cambridge, MA: MIT Press, 1996.

SENGE, Petre M. et al. The fifth discipline fieldbook: strategies and tools for building a learning organization. New York: Doubleday, 1994.

SINDIPEÇAS. Sindicato Nacional da Indústria de Componentes para Veículos Automotores. Desempenho do Setor de Autopeças - 2003. São Paulo, 2003. CD-ROM.

. Desempenho do Setor de Autopeças - 2004. São Paulo, 2004. CD-ROM.

Desempenho do Setor de Autopeças - 2005. São Paulo, 2005. CD-ROM.

Desempenho do Setor de Autopeças - 2006. São Paulo, 2006. Disponível em < http://www.sindipecas.org.br/paginas_NETCDM/exibe_documento_saida.asp?ID_TIPODOC =5653\&ID_PUBLICACAO=35750>. Acesso em 15 de abril de 2008 .

Desempenho do Setor de Autopeças - 2007. São Paulo, 2008. Disponível em < http://www.sindipecas.org.br/paginas_NETCDM/exibe_documento_saida.asp?ID_TIPODOC =5652\&ID_PUBLICACAO=35747>. Acesso em 15 de abril de 2008.

SENGE, Peter. A Quinta Disciplina: arte, teoria e prática da organização de aprendizagem. São Paulo: Best Seller, 1990.

SCHELLING, Thonas C. Micromotives and macrobehavior. New York: W.W. Norton e Cia., 1978.

SMITH, Adam. Investigação sobre a natureza e as causas da riqueza das nações. São Paulo: Ed. Abril, 1979.

SIMON, Herbert A. Models of man, social and rational. $2^{\text {nd }}$ ed. New York: John Wiley, 1961.

Administrative behavior: a study of decision-making process in administrative organizations. New York: The Free Press, 1997. 
Scienza economica e comportamento umano. Torino: Edizioni di Comunitá, 2000.

The sciences of the artificial. Cambridge, MA: MIT Press, 2001.

SIMONS, Robert; DÁVILA, Antonio. Qual a magnitude do retorno sobre a gestão?. In Harvard Business Review, Medindo o desempenho empresarial. Rio de Janeiro: Campus, 2000.

STACEY, Ralph D. The Chaos Frontier: creative strategic control for business. Oxford: Butterworth-Heinemann, 1991.

Complexity and Creativity in Organizations. San Francisco: Berret-Koehler, 1996.

Strategic management and organizational dynamics: the challenge of complexity. $3^{\text {rd }}$ ed. Harlow, Essex: Pearson Education, 2000.

Complex responsive processes in organizations: learning and knowledge creation. New York: Routledge, 2001

SCHEINKMAN, José A.; LEBARON, Blake. Non linear dynamics and stock returns. The Journal of Business. Chicago: Univ. of Chicago Press, n. 3, v. 62, 07/1989.

STEERS, Richard M. Problems in measurement of organizational effectiveness. Administrative Science Quarterly. The Johnson School at Cornell University: Ithaca, NY, n. 4, v. 20, 12/1975.

STERMAN, John D. Business Dynamics: systems thinking and modeling for a complex world. New York: McGraw-Hill Higher Education, 2000.

UFPR, Universidade Federal do Paraná. OHSAS 18001 - Sistema de gestão para segurança e saúde ocupacional - especificação (2008). Disponível em: <http://www.ergonomia.ufpr.br/ohsas_18001.pdf>. Acesso em 07 de abril de 2008.

UNIVERSITY OF TEXAS. Structural equation modeling using AMOS: an introduction (2008). Disponível em: < http://ssc.utexas.edu/consulting/tutorials/stat/amos/>. Acesso em: 28 de setembro de 2008.

VASCONCELLOS, Eduardo; HEMSLEY, James. Estrutura das organizações. $3^{\text {a }}$ ed. São Paulo: Pioneira, 1997.

VENKATRAMAN, N.; VASUDEVAN, Ramanujam. Measurement of business performance in strategy research: a comparison of approaches. The Academy of Management Review. Academy of Management: Boston, n. 4, vol. 11, p. 801-814, 10/1986.

WEBER, Max. Economy and society. Los Angeles: Univ. of California Press, 1978.

WEISSTEIN, Eric W. CRC concise encyclopedia of mathematics. Boca Raton: Chapman \& Hall/CRC, 2002.

WILLIAMSON, Oliver E. The economic institutions of capitalism. New York: The Free Press, 1985. 
The mechanisms of governance. New York: Oxford Univ. Press, 1996.

ZAIZIRI, M. et al. Does TQM impact in bottom-line results? The TQM Magazine. Bingley, UK: Emerald, n. 1, v. 6, p. 38-43, 1994.

ZIMBARDO, Philip J. et al (1973). A study of prisoners and guards in a simulated prison(summary). Disponível em: <http://www.holah.karoo.net/zimbardostudy.htm>. Acesso em 28 de setembro de 2008. 
Apêndice 1: Estatísticas da Matriz Revisada

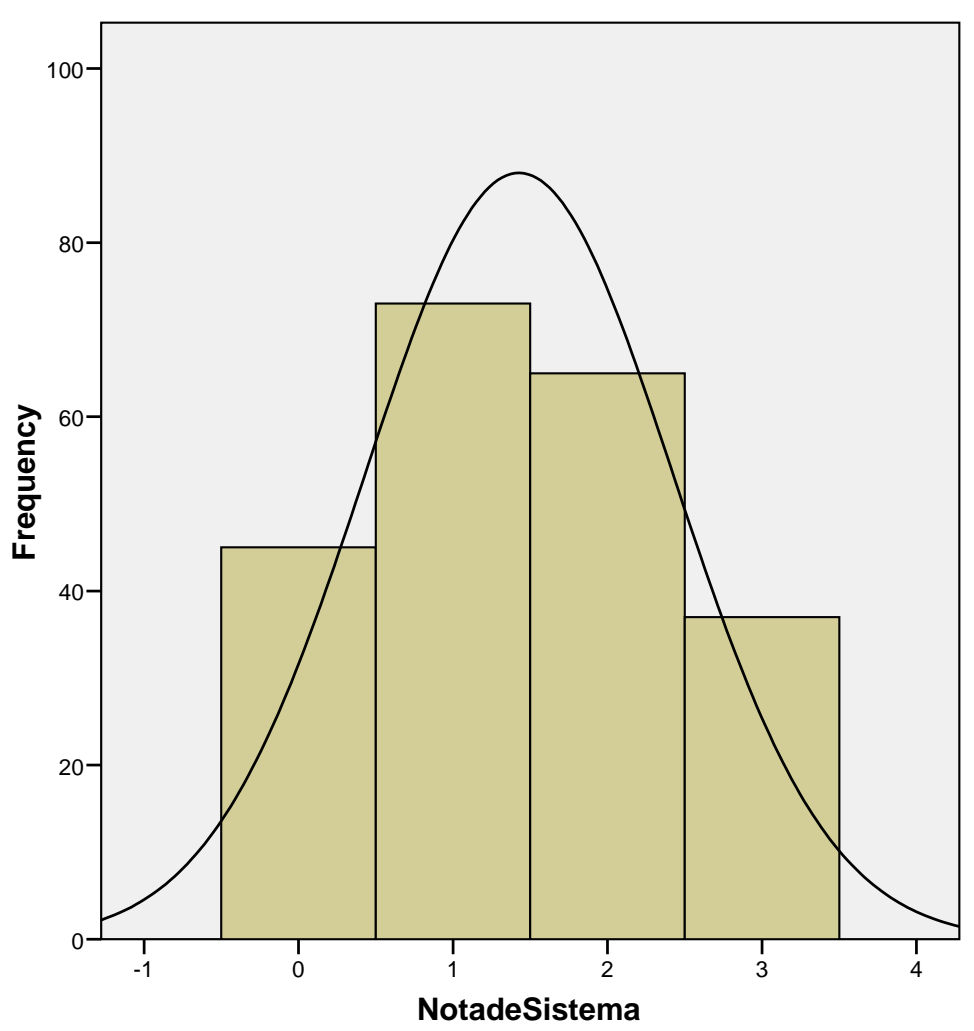
Mean $=1,43$
Std. Dev. $=0,997$
$N=220$

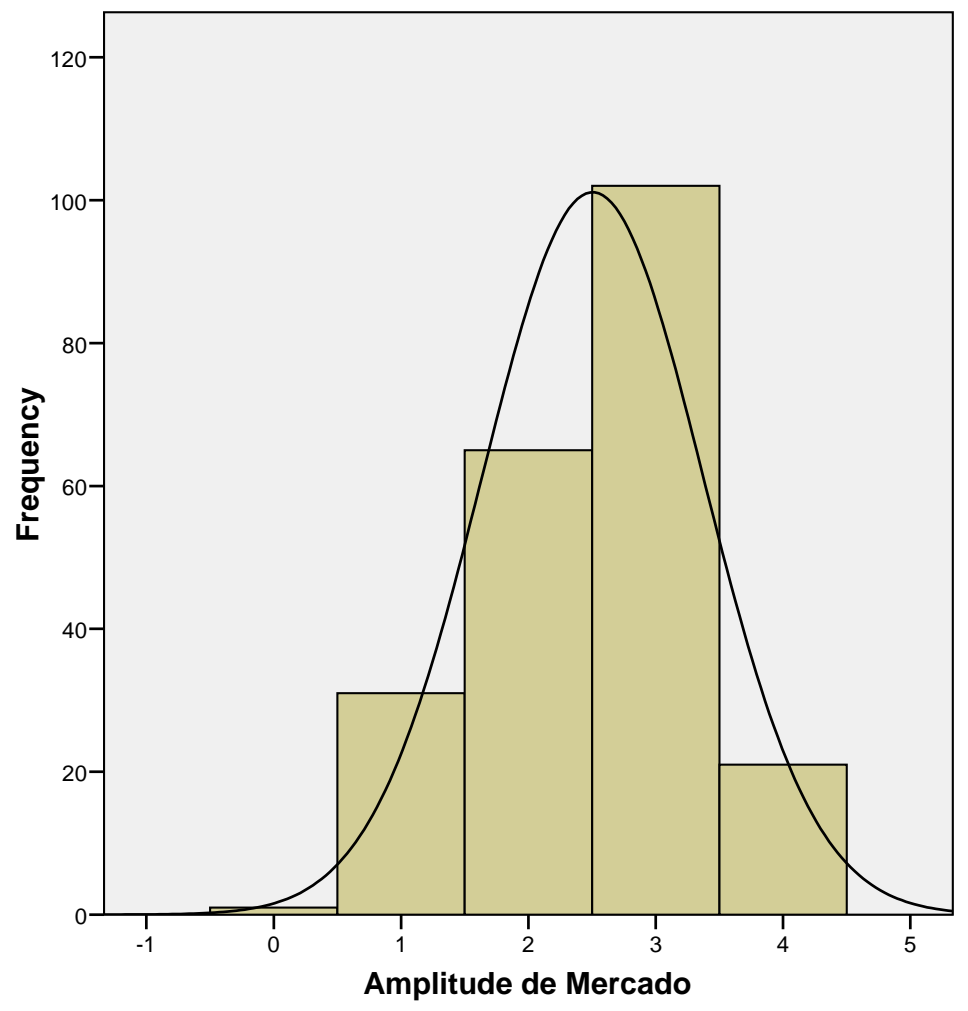
$\begin{aligned} \text { Mean } & =2,5 \\ \text { Std. Dev. } & =0,868\end{aligned}$ $\mathrm{N}=220$ 
Apêndice 1: Estatísticas da Matriz Revisada

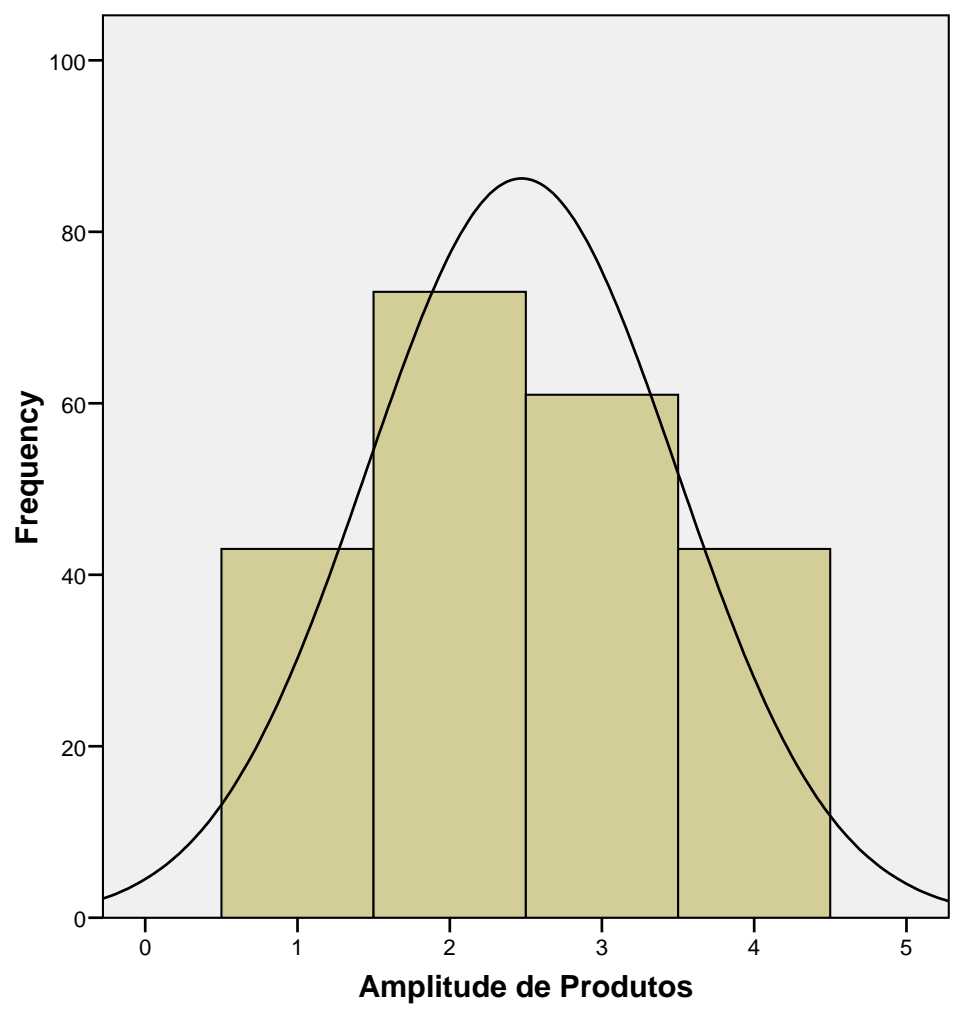

Mean $=2,47$ Std. Dev. $=1,018$
$N=220$

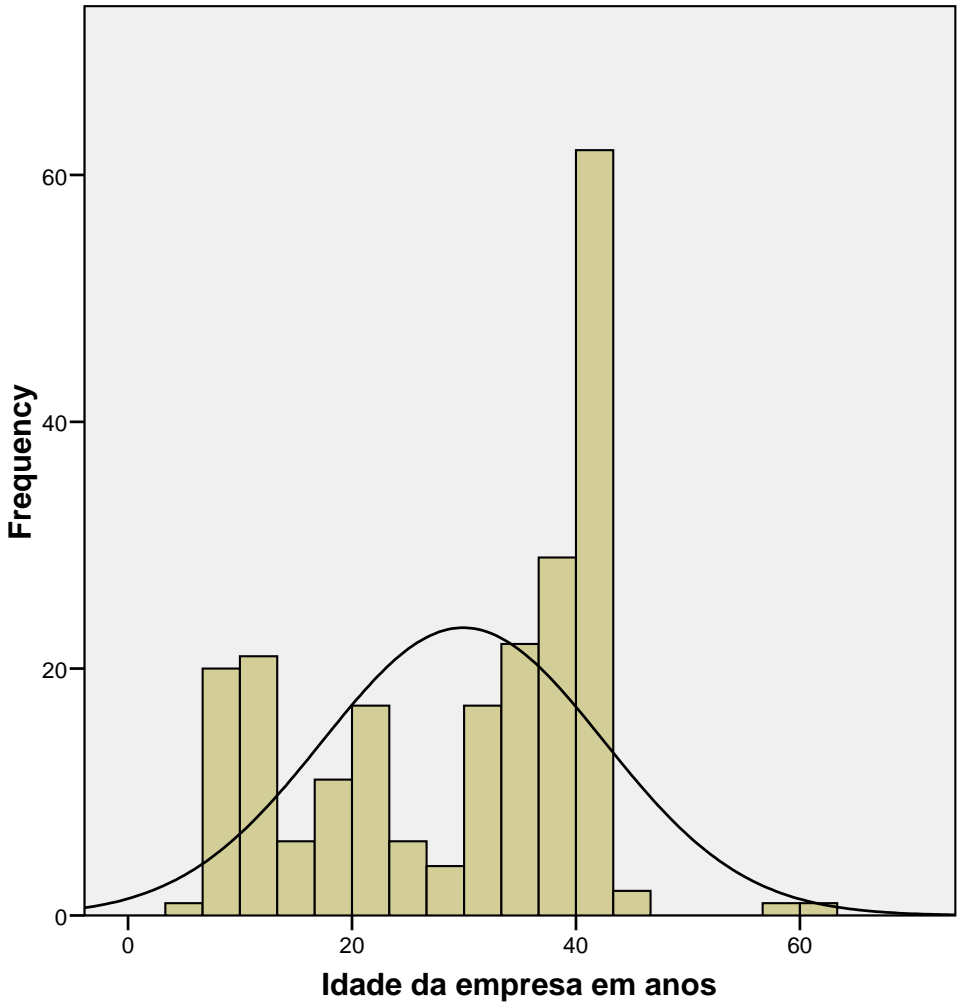

Mean $=29,93$ Std. Dev. $=12,551$ $\mathrm{N}=220$ 
Apêndice 1: Estatísticas da Matriz Revisada

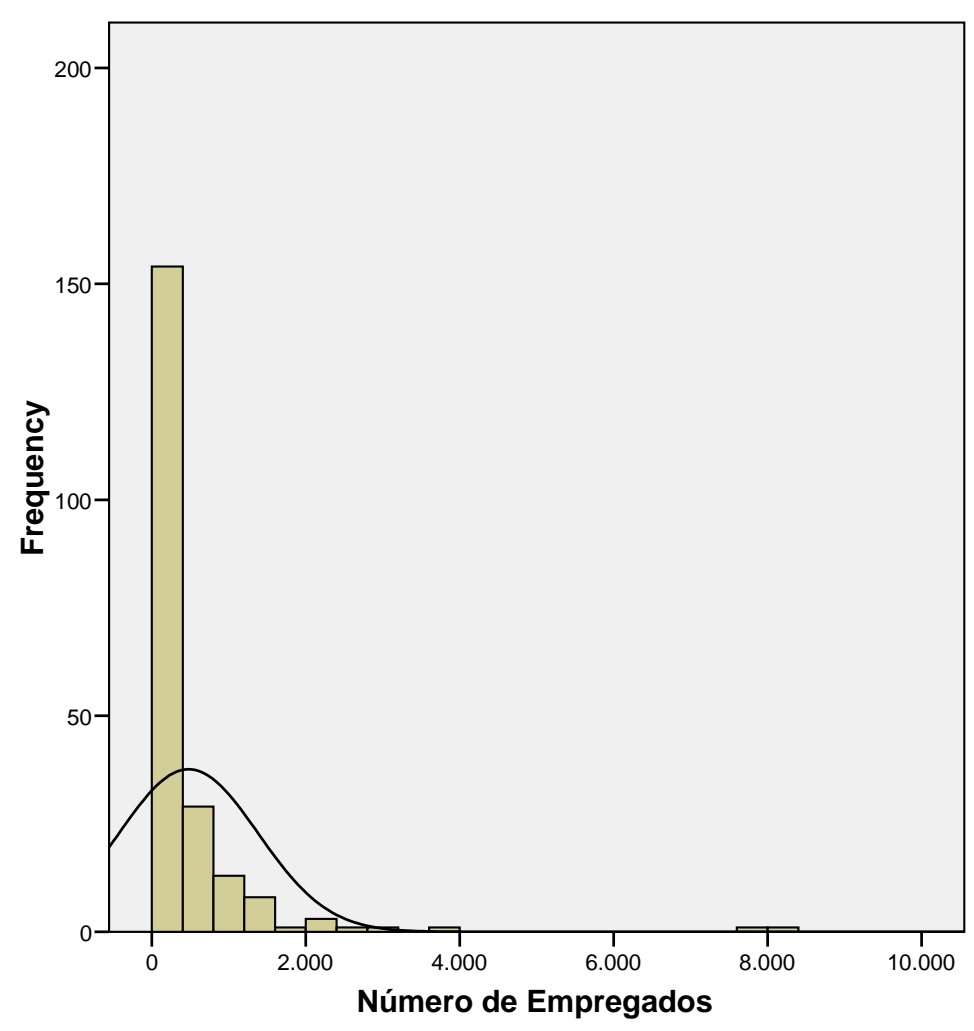

Mean $=476,27$ Std. Dev. $=903,464$ $\mathrm{N}=213$

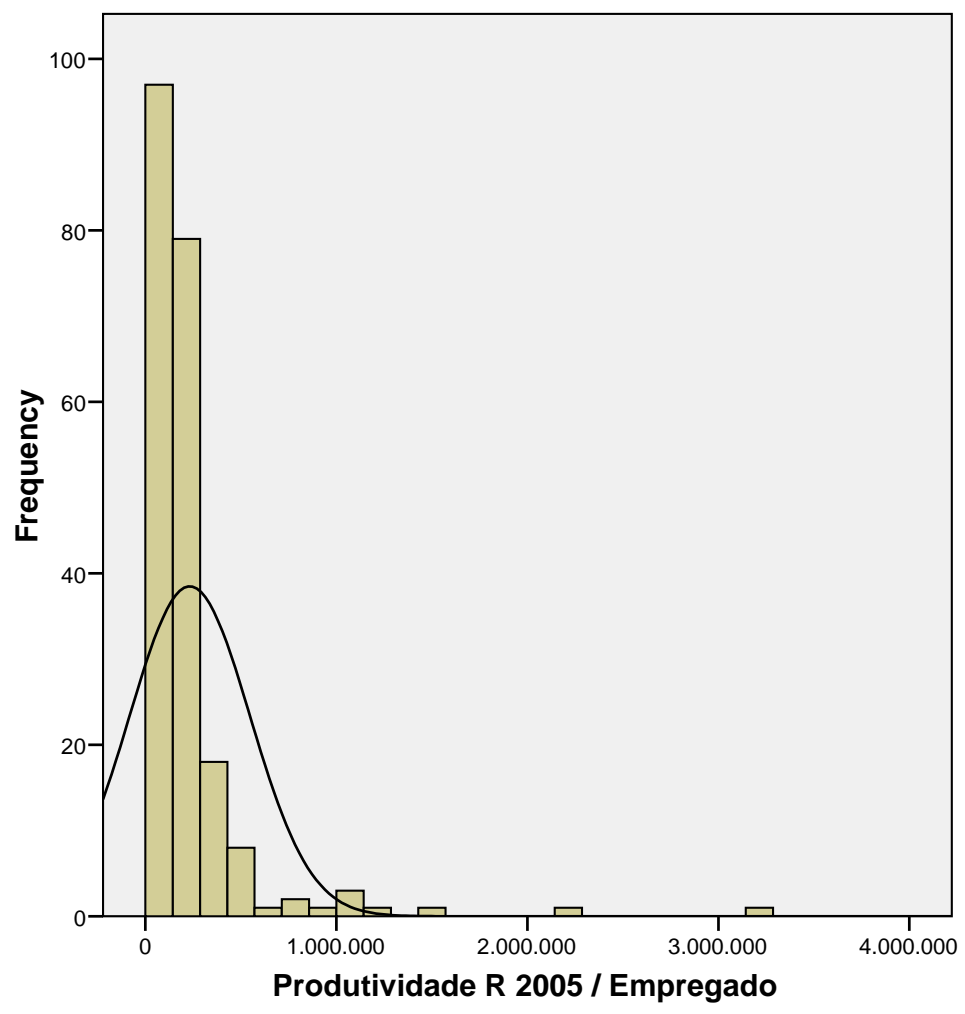

Mean $=232.252,77$ $\begin{aligned} \text { Std. Dev. } & =315.415,13 \\ N & =213\end{aligned}$ 
Apêndice 1: Estatísticas da Matriz Revisada

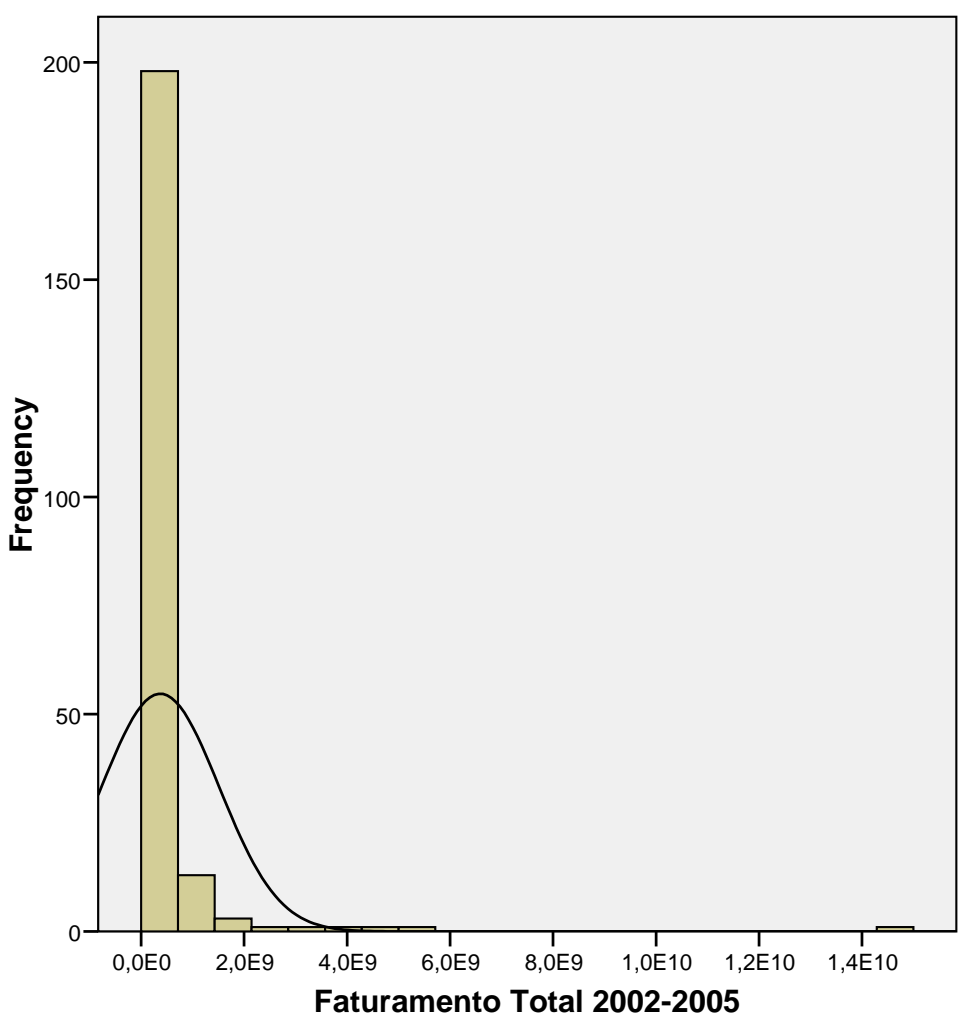

Mean $=3,74 \mathrm{E} 8$ $\mathrm{N}=220$

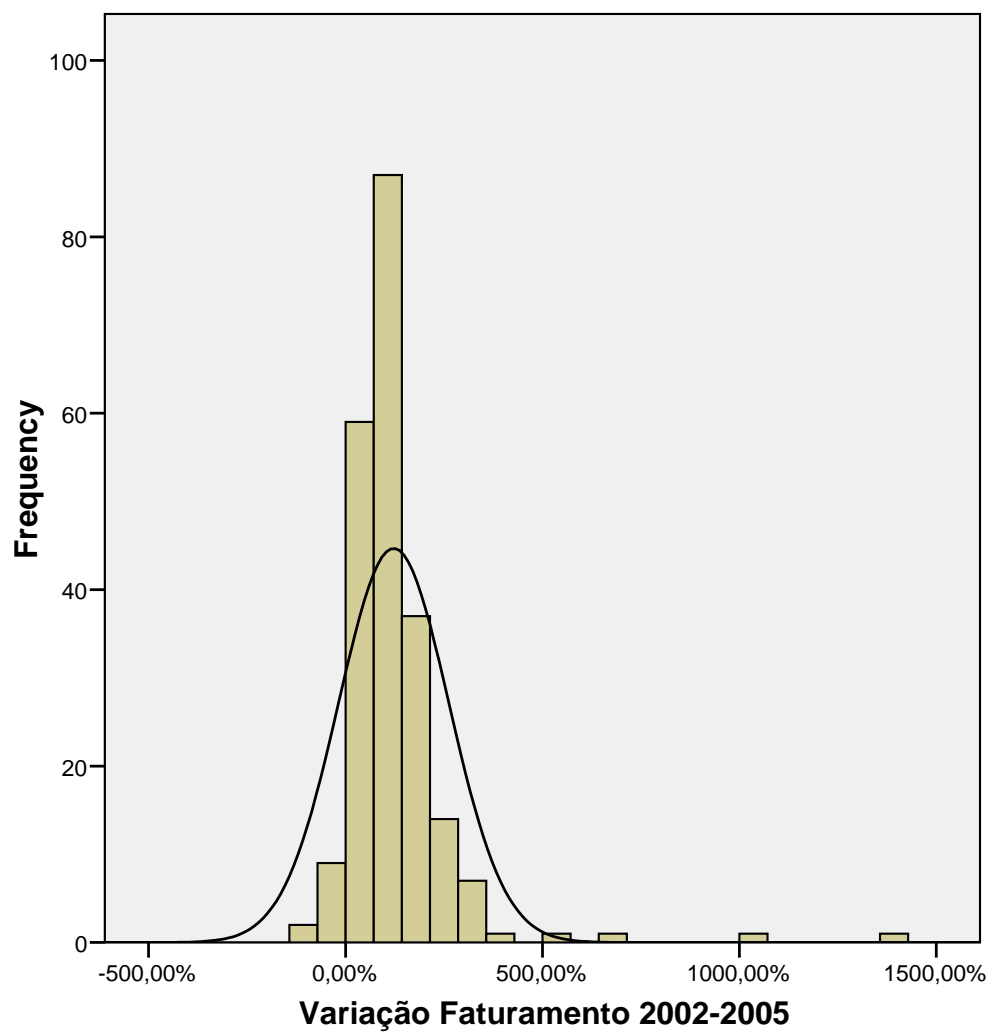
Std. Dev. $=140,327 \%$ $\mathrm{N}=220$ 
Apêndice 1: Estatísticas da Matriz Revisada

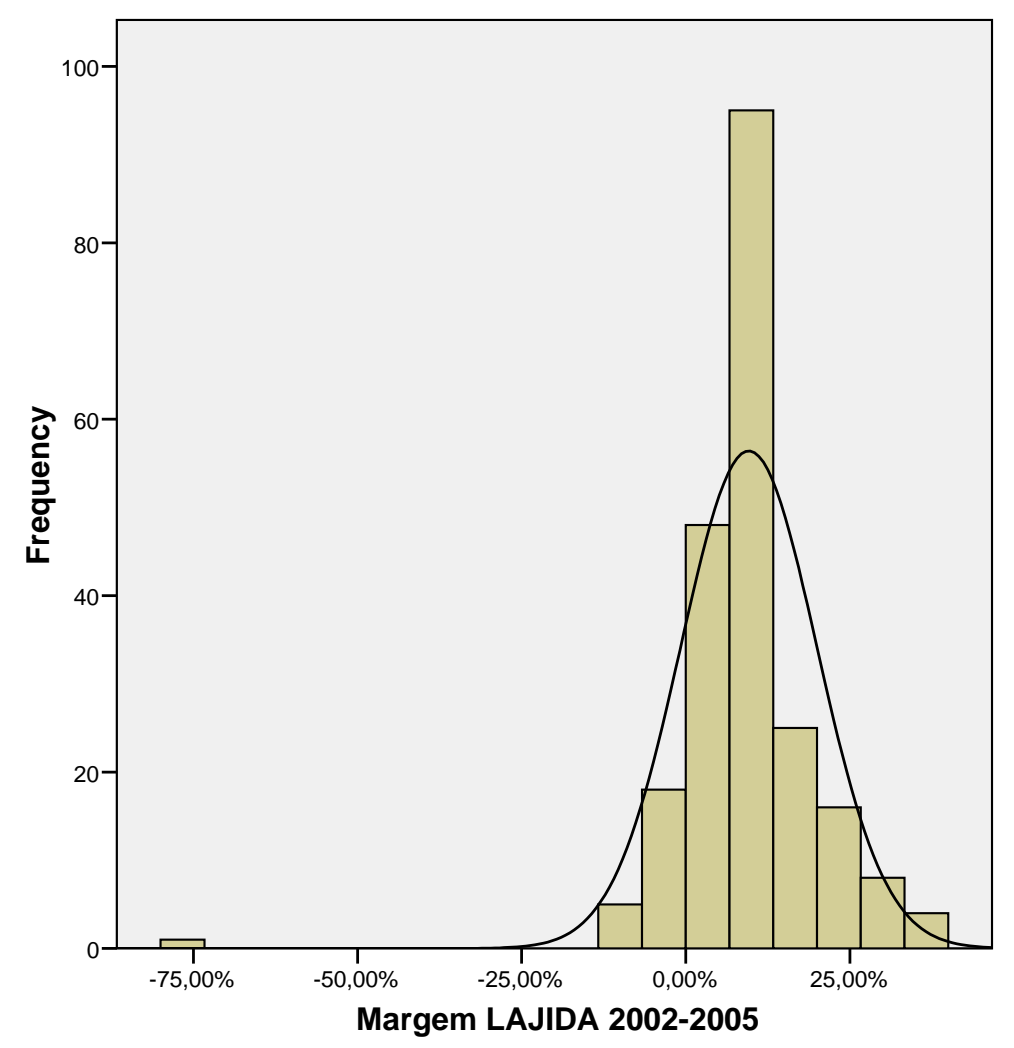

Mean $=9,61 \%$ Std. Dev. $=10,372 \%$ $\mathrm{N}=220$

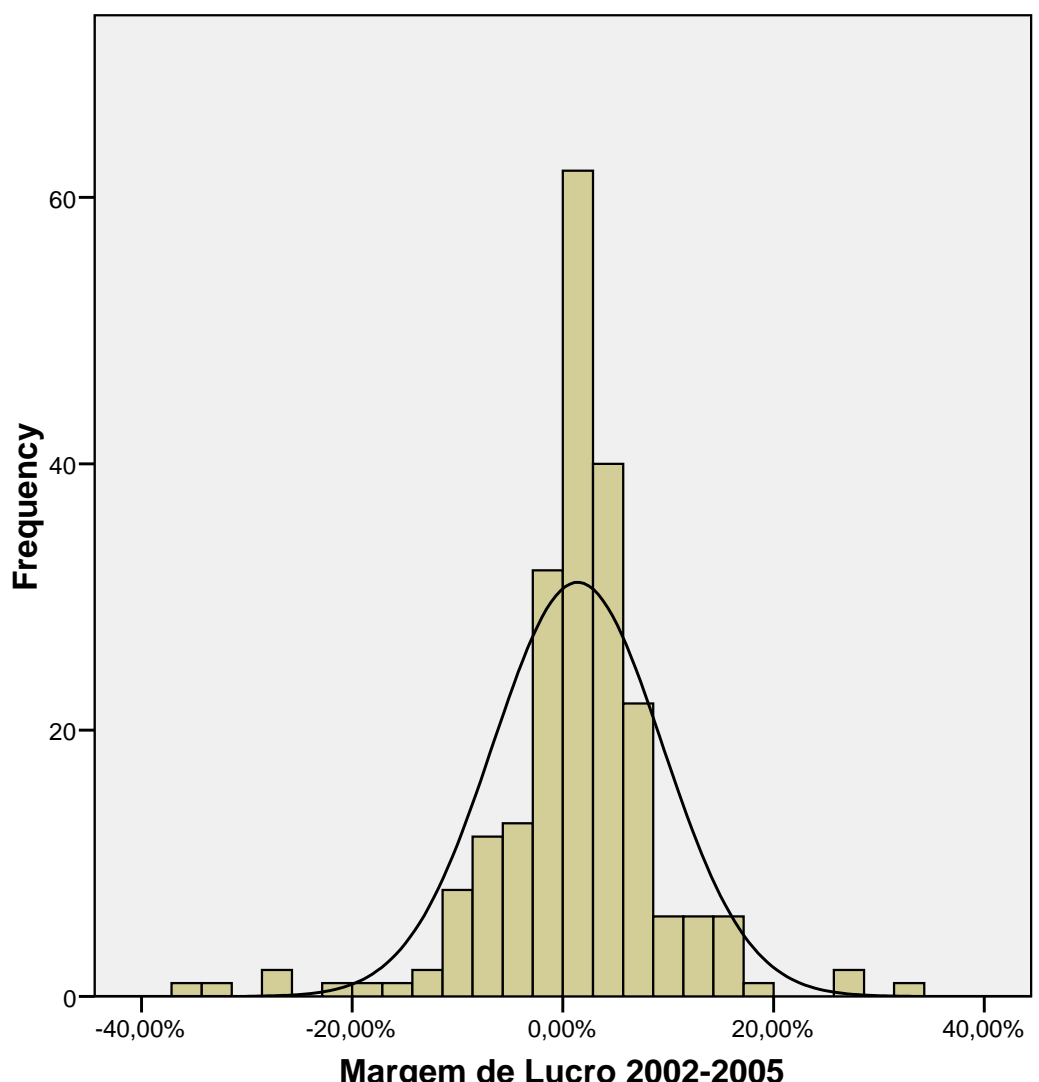

Mean $=1,39 \%$ Std. Dev. $=8,064 \%$ $\mathrm{N}=220$ 
Apêndice 1: Estatísticas da Matriz Revisada

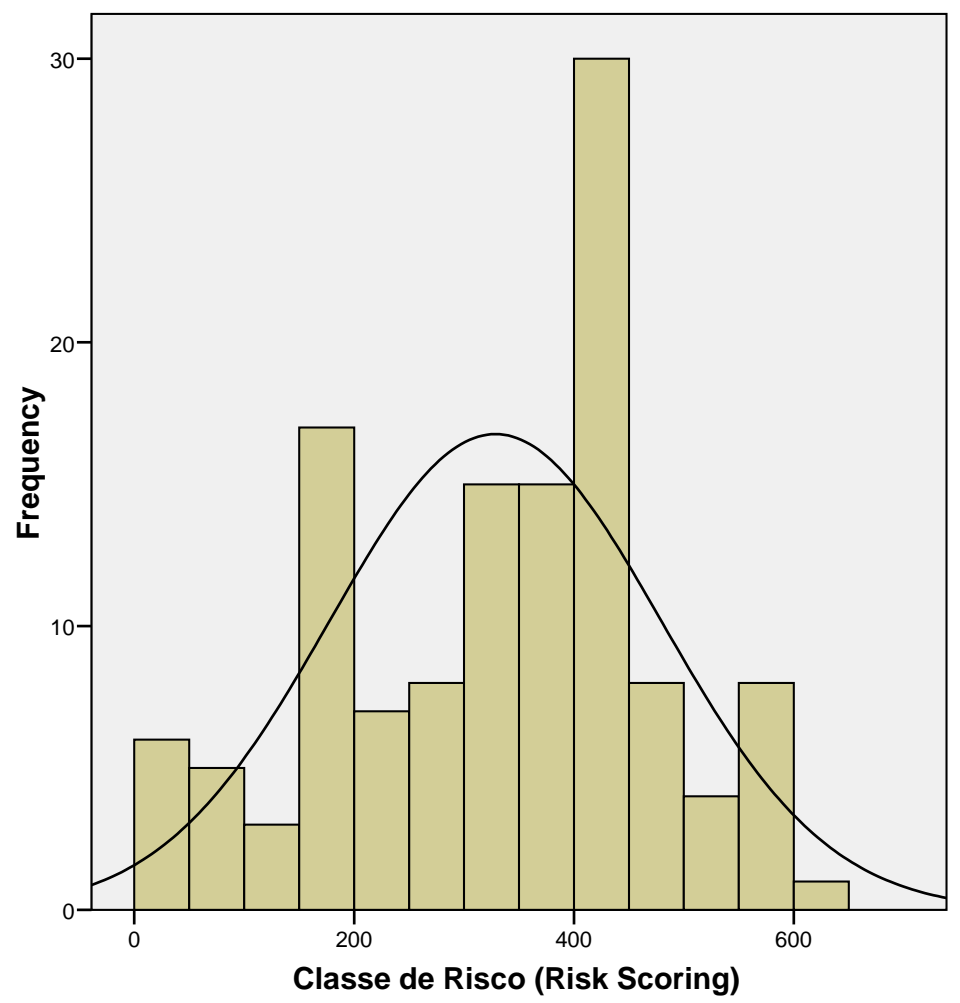

Mean $=328,54$ $\mathrm{N}$. Dev. $=151,082$
$\mathrm{~N}=127$ 
Apêndice 1: Estatísticas da Matriz Revisada
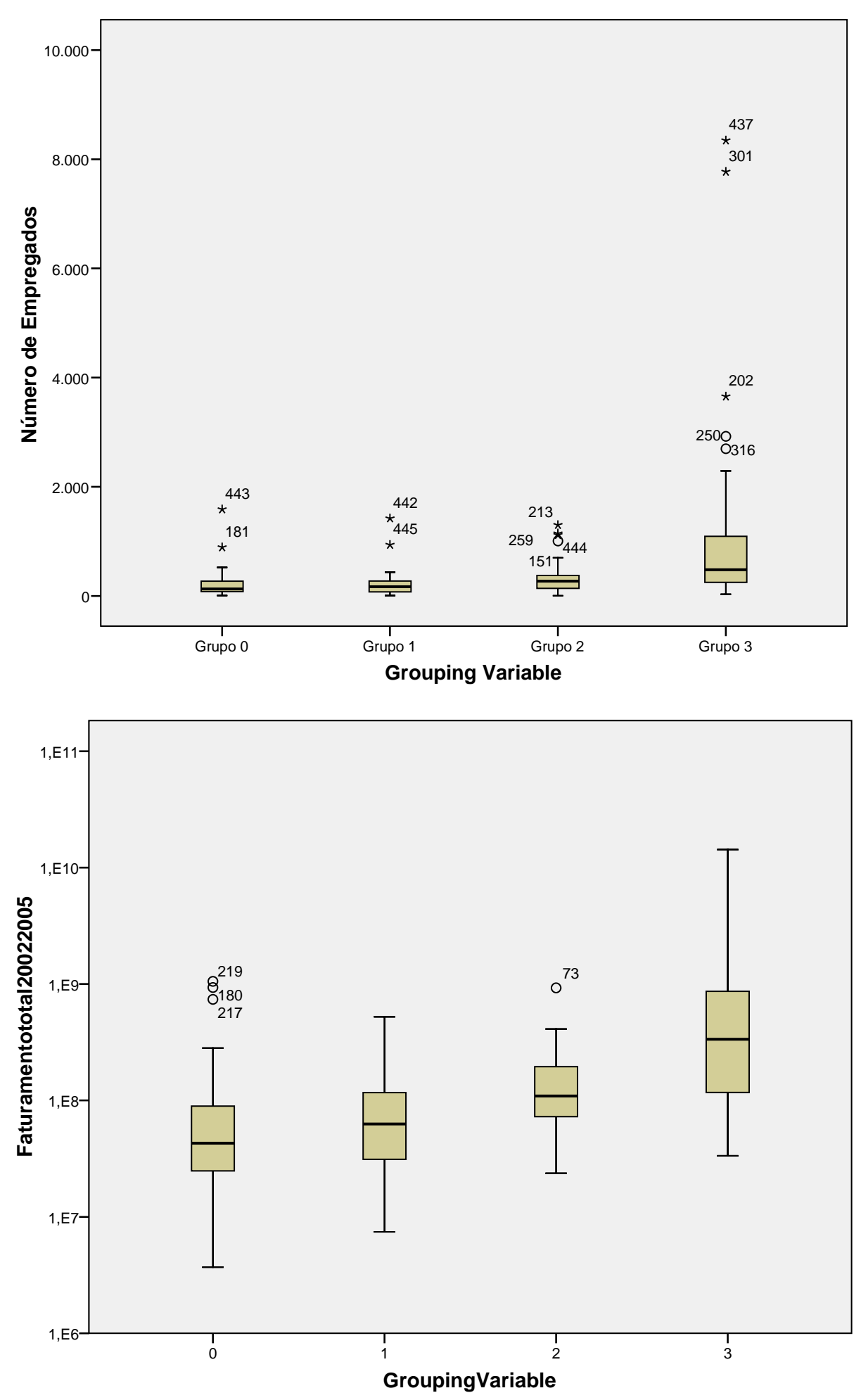
Apêndice 1: Estatísticas da Matriz Revisada
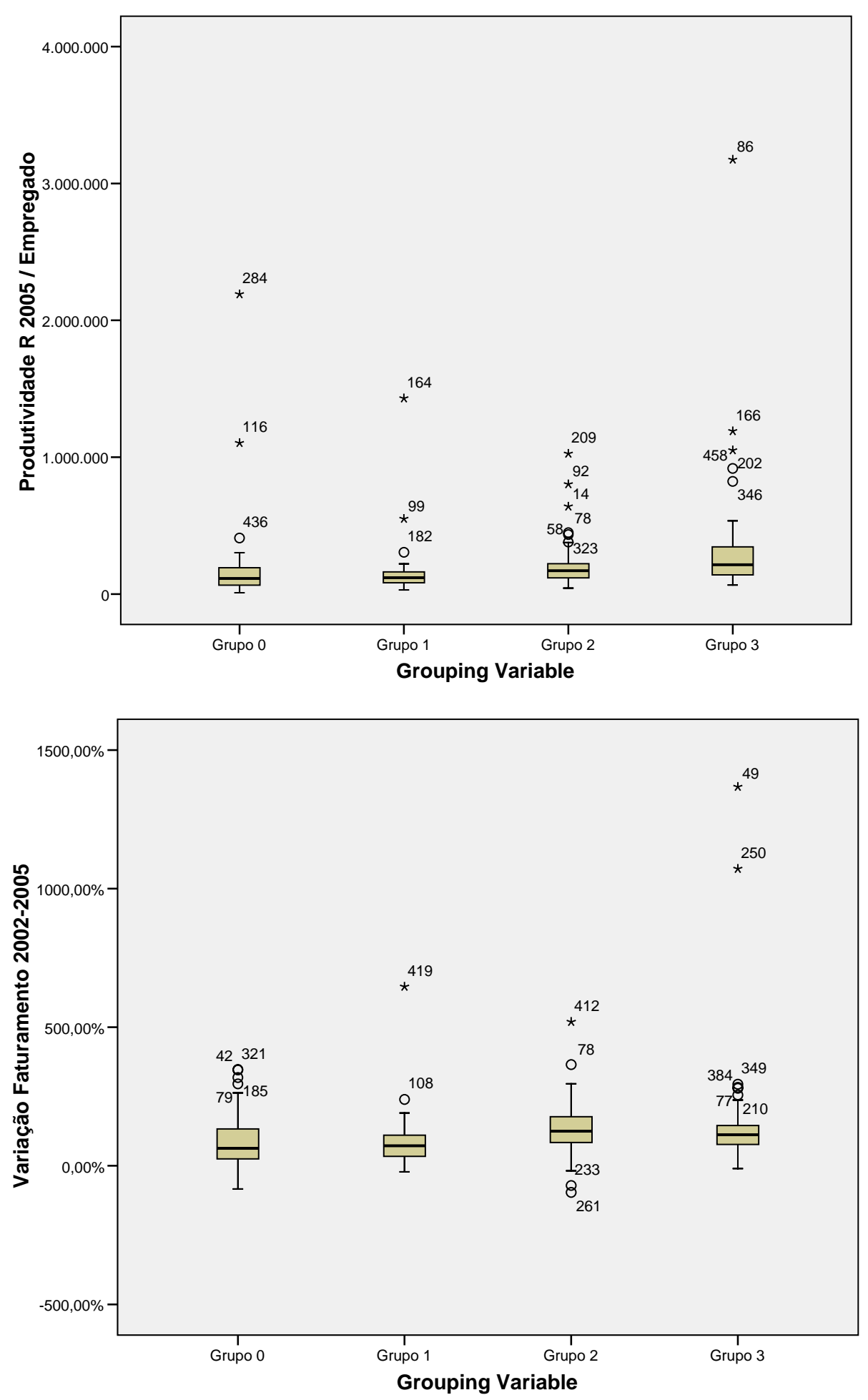
Apêndice 1: Estatísticas da Matriz Revisada
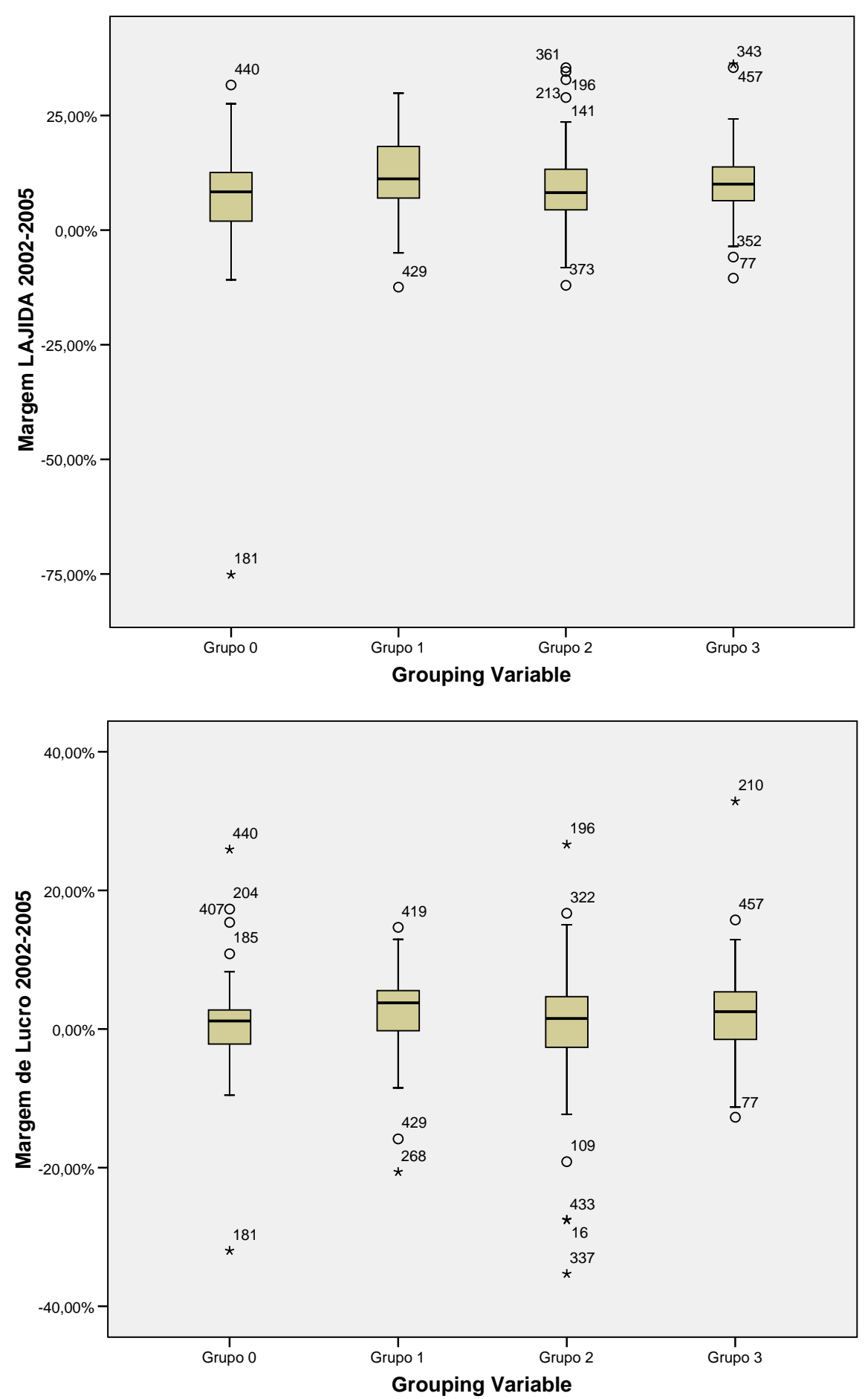
Apêndice 1: Estatísticas da Matriz Revisada

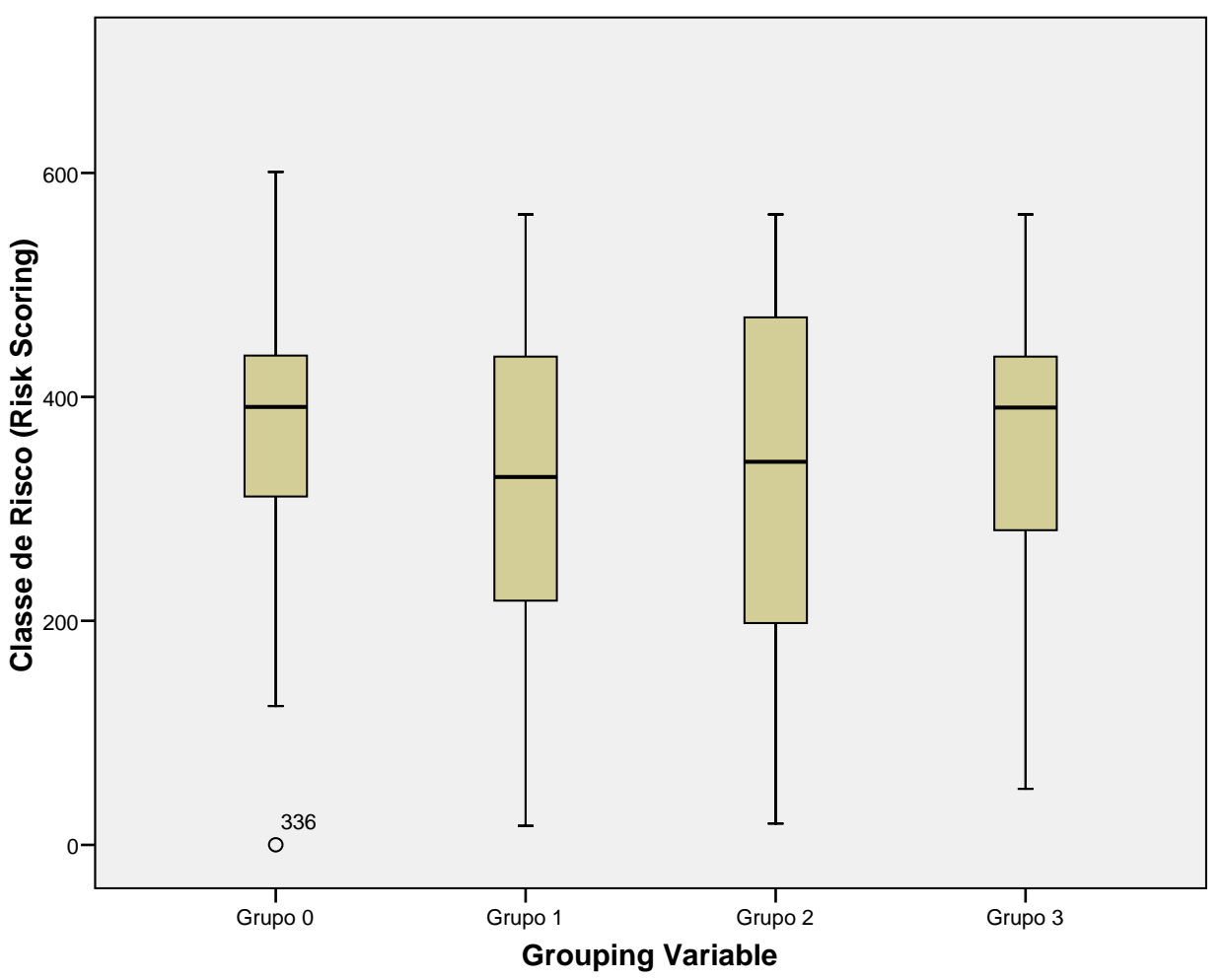


Apêndice 1: Estatísticas da Matriz Revisada

Group Statistics

\begin{tabular}{|c|c|c|c|c|c|}
\hline & Grouping Variable & $\mathrm{N}$ & Mean & Std. Deviation & $\begin{array}{c}\text { Std. Error } \\
\text { Mean }\end{array}$ \\
\hline \multirow[t]{2}{*}{$\begin{array}{l}\text { Variação Faturamento } \\
2002-2005\end{array}$} & Grupo 0 & 45 & $91,3984 \%$ & $99,77590 \%$ & $\begin{array}{r}14,87371 \\
\%\end{array}$ \\
\hline & Grupo 1 & 38 & $90,7999 \%$ & $109,85280 \%$ & $\begin{array}{r}17,82048 \\
\%\end{array}$ \\
\hline \multirow{2}{*}{$\begin{array}{l}\text { Margem LAJIDA 2002- } \\
2005\end{array}$} & Grupo 0 & 45 & $5,9836 \%$ & $14,79547 \%$ & $2,20558 \%$ \\
\hline & Grupo 1 & 38 & $12,1015 \%$ & $9,15128 \%$ & $1,48453 \%$ \\
\hline \multirow{2}{*}{$\begin{array}{l}\text { Margem de Lucro 2002- } \\
2005\end{array}$} & Grupo 0 & 45 & ,8482\% & $8,21199 \%$ & $1,22417 \%$ \\
\hline & Grupo 1 & 38 & $2,5093 \%$ & $6,96405 \%$ & $1,12972 \%$ \\
\hline \multirow{2}{*}{$\begin{array}{l}\text { Classe de Risco (Risk } \\
\text { Scoring) }\end{array}$} & Grupo 0 & 34 & 358,65 & 141,424 & 24,254 \\
\hline & Grupo 1 & 32 & 306,47 & 140,248 & 24,793 \\
\hline
\end{tabular}

Independent Samples Test

\begin{tabular}{|c|c|c|c|c|c|c|c|c|c|c|}
\hline & & \multicolumn{2}{|c|}{$\begin{array}{l}\text { Levene's Test for } \\
\text { Equality of Variances }\end{array}$} & \multicolumn{7}{|c|}{ t-test for Equality of Means } \\
\hline & & \multirow{2}{*}{$\begin{array}{c}\mathrm{F} \\
\text { Lower }\end{array}$} & \multirow{2}{*}{$\begin{array}{l}\text { Sig. } \\
\text { Upper }\end{array}$} & \multirow{2}{*}{$\frac{\mathrm{t}}{\text { Lower }}$} & \multirow{2}{*}{$\begin{array}{c}\text { df } \\
\text { Upper }\end{array}$} & \multirow{2}{*}{$\begin{array}{c}\text { Sig. (2-tailed) } \\
\text { Lower }\end{array}$} & \multirow{2}{*}{$\begin{array}{c}\text { Mean } \\
\text { Difference } \\
\text { Upper }\end{array}$} & \multirow{2}{*}{$\begin{array}{c}\text { Std. Error } \\
\text { Difference } \\
\text { Lower }\end{array}$} & \multicolumn{2}{|c|}{$\begin{array}{l}\text { 95\% Confidence Interval of } \\
\text { the Difference }\end{array}$} \\
\hline & & & & & & & & & Upper & Lower \\
\hline \multirow{2}{*}{$\begin{array}{l}\text { Variação } \\
\text { Faturamento } \\
\text { 2002-2005 }\end{array}$} & $\begin{array}{l}\text { Equal variances } \\
\text { assumed }\end{array}$ &, 566 & 454 & ,026 & 81 & ,979 & ,59850\% & $23,02266 \%$ & $-45,20937 \%$ & $46,40636 \%$ \\
\hline & $\begin{array}{l}\text { Equal variances not } \\
\text { assumed }\end{array}$ & & & ,026 & 75,639 & ,979 & ,59850\% & $23,21200 \%$ & $-45,63577 \%$ & $46,83276 \%$ \\
\hline \multirow[t]{2}{*}{$\begin{array}{l}\text { Margem LAJIDA } \\
\text { 2002-2005 }\end{array}$} & $\begin{array}{l}\text { Equal variances } \\
\text { assumed }\end{array}$ & ,358 &, 551 & $-2,215$ & 81 & ,030 & $-6,11784 \%$ & $2,76198 \%$ & $-11,61332 \%$ &,$- 62237 \%$ \\
\hline & $\begin{array}{l}\text { Equal variances not } \\
\text { assumed }\end{array}$ & & & $-2,301$ & 74,673 & ,024 & $-6,11784 \%$ & $2,65865 \%$ & $-11,41453 \%$ &,$- 82116 \%$ \\
\hline \multirow[t]{2}{*}{$\begin{array}{l}\text { Margem de } \\
\text { Lucro 2002-2005 }\end{array}$} & $\begin{array}{l}\text { Equal variances } \\
\text { assumed }\end{array}$ &, 003 & ,960 &,- 983 & 81 & ,328 & $-1,66106 \%$ & $1,68918 \%$ & $-5,02201 \%$ & $1,69988 \%$ \\
\hline & $\begin{array}{l}\text { Equal variances not } \\
\text { assumed }\end{array}$ & & &,- 997 & 80,997 & ,322 & $-1,66106 \%$ & $1,66579 \%$ & $-4,97547 \%$ & $1,65334 \%$ \\
\hline \multirow[t]{2}{*}{$\begin{array}{l}\text { Classe de Risco } \\
\text { (Risk Scoring) }\end{array}$} & $\begin{array}{l}\text { Equal variances } \\
\text { assumed }\end{array}$ & ,039 & ,844 & 1,504 & 64 & ,137 & 52,178 & 34,692 & $-17,127$ & 121,484 \\
\hline & $\begin{array}{l}\text { Equal variances not } \\
\text { assumed }\end{array}$ & & & 1,504 & 63,819 & ,137 & 52,178 & 34,683 & $-17,113$ & 121,470 \\
\hline
\end{tabular}


Group Statistics

\begin{tabular}{|ll|r|r|r|r|}
\hline & Grouping Variable & $\mathrm{N}$ & \multicolumn{1}{c|}{ Mean } & Std. Deviation & $\begin{array}{c}\text { Std. Error } \\
\text { Mean }\end{array}$ \\
\hline Variação Faturamento & Grupo 0 & 45 & $91,3984 \%$ & $99,77590 \%$ & $14,87371 \%$ \\
2002-2005 & Grupo 2 & 72 & $133,3481 \%$ & $94,21131 \%$ & $11,10291 \%$ \\
Margem LAJIDA 2002- & Grupo 0 & 45 & $5,9836 \%$ & $14,79547 \%$ & $2,20558 \%$ \\
2005 & Grupo 2 & 72 & $9,6660 \%$ & $8,78553 \%$ & $1,03538 \%$ \\
& & 45 &, $8482 \%$ & $8,21199 \%$ & $1,22417 \%$ \\
Margem de Lucro 2002- & Grupo 0 & 72 &, $3011 \%$ & $9,45257 \%$ & $1,11400 \%$ \\
2005 & Grupo 2 & 34 & 358,65 & 141,424 & 24,254 \\
Classe de Risco (Risk & Grupo 0 & 41 & 330,56 & 160,827 & 25,117 \\
Scoring) & Grupo 2 & & & & \\
\hline
\end{tabular}

Independent Samples Test

\begin{tabular}{|c|c|c|c|c|c|c|c|c|c|c|}
\hline & & \multicolumn{2}{|c|}{$\begin{array}{l}\text { Levene's Test for } \\
\text { Equality of Variances }\end{array}$} & \multicolumn{7}{|c|}{ t-test for Equality of Means } \\
\hline & & \multirow[b]{2}{*}{$\mathrm{F}$} & \multirow[b]{2}{*}{ Sig. } & \multirow[b]{2}{*}{$\mathrm{t}$} & \multirow[b]{2}{*}{ df } & \multirow[b]{2}{*}{ Sig. (2-tailed) } & \multirow[b]{2}{*}{$\begin{array}{c}\text { Mean } \\
\text { Difference }\end{array}$} & \multirow[b]{2}{*}{$\begin{array}{l}\text { Std. Error } \\
\text { Difference }\end{array}$} & \multicolumn{2}{|c|}{$\begin{array}{c}95 \% \text { Confidence Interval } \\
\text { of the Difference }\end{array}$} \\
\hline & & & & & & & & & Upper & Lower \\
\hline $\begin{array}{l}\text { Variação Faturamento } \\
\text { 2002-2005 }\end{array}$ & $\begin{array}{l}\text { Equal variances } \\
\text { assumed } \\
\text { Equal variances } \\
\text { not assumed }\end{array}$ & ,358 &, 551 & $-2,290$ & 89,480 &, 024 & $-41,94974 \%$ & $18,31470 \%$ & $\begin{array}{r}- \\
78,22764 \\
\% \\
- \\
78,82686 \\
\%\end{array}$ & $\begin{array}{l}-5,67185 \% \\
-5,07263 \%\end{array}$ \\
\hline \multirow[t]{2}{*}{$\begin{array}{l}\text { Margem LAJIDA 2002- } \\
2005\end{array}$} & $\begin{array}{l}\text { Equal variances } \\
\text { assumed }\end{array}$ & \multirow[t]{2}{*}{1,006} & \multirow[t]{2}{*}{,318 } & $-1,690$ & 115 & ,094 & $-3,68237 \%$ & $2,17838 \%$ & $-7,99731 \%$ &, $63258 \%$ \\
\hline & $\begin{array}{l}\text { Equal variances } \\
\text { not assumed }\end{array}$ & & & $-1,511$ & 63,615 & 136 & $-3,68237 \%$ & $2,43651 \%$ & $-8,55043 \%$ & $1,18570 \%$ \\
\hline \multirow[t]{2}{*}{$\begin{array}{l}\text { Margem de Lucro 2002- } \\
2005\end{array}$} & $\begin{array}{l}\text { Equal variances } \\
\text { assumed }\end{array}$ & \multirow[t]{2}{*}{,933 } & \multirow[t]{2}{*}{,336 } & ,320 & 115 &, 750 & ,54716\% & $1,70991 \%$ & $-2,83984 \%$ & $3,93416 \%$ \\
\hline & $\begin{array}{l}\text { Equal variances } \\
\text { not assumed }\end{array}$ & & & ,331 & 103,192 &, 742 &, $54716 \%$ & $1,65517 \%$ & $-2,73540 \%$ & $3,82973 \%$ \\
\hline \multirow[t]{2}{*}{$\begin{array}{l}\text { Classe de Risco (Risk } \\
\text { Scoring) }\end{array}$} & $\begin{array}{l}\text { Equal variances } \\
\text { assumed }\end{array}$ & \multirow[t]{2}{*}{3,026} & \multirow[t]{2}{*}{,086 } & ,795 & 73 & ,429 & 28,086 & 35,341 & $-42,348$ & 98,520 \\
\hline & $\begin{array}{l}\text { Equal variances } \\
\text { not assumed }\end{array}$ & & & ,804 & 72,727 & ,424 & 28,086 & 34,916 & $-41,506$ & 97,678 \\
\hline
\end{tabular}


Apêndice 1: Estatísticas da Matriz Revisada

Group Statistics

\begin{tabular}{|c|c|c|c|c|c|}
\hline & Grouping Variable & $\mathrm{N}$ & Mean & Std. Deviation & $\begin{array}{l}\text { Std. Error } \\
\text { Mean }\end{array}$ \\
\hline \multirow{2}{*}{$\begin{array}{l}\text { Variação Faturamento } \\
\text { 2002-2005 }\end{array}$} & Grupo 0 & 45 & $91,3984 \%$ & $99,77590 \%$ & $14,87371 \%$ \\
\hline & Grupo 3 & 65 & $149,9929 \%$ & $203,80842 \%$ & $25,27932 \%$ \\
\hline \multirow{2}{*}{$\begin{array}{l}\text { Margem LAJIDA 2002- } \\
2005\end{array}$} & Grupo 0 & 45 & $5,9836 \%$ & $14,79547 \%$ & $2,20558 \%$ \\
\hline & Grupo 3 & 65 & $10,5855 \%$ & $8,34929 \%$ & $1,03560 \%$ \\
\hline \multirow{2}{*}{$\begin{array}{l}\text { Margem de Lucro 2002- } \\
2005\end{array}$} & Grupo 0 & 45 & ,8482\% & $8,21199 \%$ & $1,22417 \%$ \\
\hline & Grupo 3 & 65 & $2,3264 \%$ & $6,76790 \%$ & ,83945\% \\
\hline \multirow{2}{*}{$\begin{array}{l}\text { Classe de Risco (Risk } \\
\text { Scoring) }\end{array}$} & Grupo 0 & 34 & 358,65 & 141,424 & 24,254 \\
\hline & Grupo 3 & 18 & 342,78 & 134,063 & 31,599 \\
\hline
\end{tabular}

Independent Samples Test

\begin{tabular}{|c|c|c|c|c|c|c|c|c|c|c|}
\hline & & \multicolumn{2}{|c|}{$\begin{array}{l}\text { Levene's Test for } \\
\text { Equality of Variances }\end{array}$} & \multicolumn{7}{|c|}{ t-test for Equality of Means } \\
\hline & & \multirow[b]{2}{*}{$\mathrm{F}$} & \multirow[b]{2}{*}{ Sig. } & \multirow[b]{2}{*}{$\mathrm{t}$} & \multirow[b]{2}{*}{ df } & \multirow[b]{2}{*}{ Sig. (2-tailed) } & \multirow[b]{2}{*}{$\begin{array}{c}\text { Mean } \\
\text { Difference }\end{array}$} & \multirow[b]{2}{*}{$\begin{array}{l}\text { Std. Error } \\
\text { Difference }\end{array}$} & \multicolumn{2}{|c|}{$\begin{array}{c}95 \% \text { Confidence Interval } \\
\text { of the Difference }\end{array}$} \\
\hline & & & & & & & & & Upper & Lower \\
\hline $\begin{array}{l}\text { Variação Faturamento } \\
\text { 2002-2005 }\end{array}$ & $\begin{array}{l}\text { Equal variances } \\
\text { assumed } \\
\text { Equal variances } \\
\text { not assumed }\end{array}$ & ,318 &, 574 & $-1,998$ & 98,765 & ,048 & $-58,59451 \%$ & $29,33039 \%$ & $\begin{array}{r}- \\
123,68170 \\
\% \\
- \\
116,79407 \\
\%\end{array}$ &,$- 39495 \%$ \\
\hline \multirow[t]{2}{*}{$\begin{array}{l}\text { Margem LAJIDA 2002- } \\
2005\end{array}$} & $\begin{array}{l}\text { Equal variances } \\
\text { assumed }\end{array}$ & \multirow[t]{2}{*}{1,405} & \multirow[t]{2}{*}{,239 } & $-2,077$ & 108 & ,040 & $-4,60189 \%$ & $2,21528 \%$ & $-8,99296 \%$ &,$- 21082 \%$ \\
\hline & $\begin{array}{l}\text { Equal variances } \\
\text { not assumed }\end{array}$ & & & $-1,889$ & 63,420 &, 064 & $-4,60189 \%$ & $2,43661 \%$ & $-9,47043 \%$ &, $26665 \%$ \\
\hline \multirow[t]{2}{*}{$\begin{array}{l}\text { Margem de Lucro 2002- } \\
2005\end{array}$} & $\begin{array}{l}\text { Equal variances } \\
\text { assumed }\end{array}$ & \multirow[t]{2}{*}{,091 } & \multirow[t]{2}{*}{,764 } & $-1,031$ & 108 & ,305 & $-1,47816 \%$ & $1,43318 \%$ & $-4,31896 \%$ & $1,36265 \%$ \\
\hline & $\begin{array}{l}\text { Equal variances } \\
\text { not assumed }\end{array}$ & & &,- 996 & 82,559 & ,322 & $-1,47816 \%$ & $1,48434 \%$ & $-4,43069 \%$ & $1,47438 \%$ \\
\hline \multirow[t]{2}{*}{$\begin{array}{l}\text { Classe de Risco (Risk } \\
\text { Scoring) }\end{array}$} & $\begin{array}{l}\text { Equal variances } \\
\text { assumed }\end{array}$ & \multirow[t]{2}{*}{, 012} & \multirow[t]{2}{*}{,911 } & ,392 & 50 & ,697 & 15,869 & 40,507 & $-65,492$ & 97,230 \\
\hline & $\begin{array}{l}\text { Equal variances } \\
\text { not assumed }\end{array}$ & & & 398 & 36,420 & ,693 & 15,869 & 39,834 & $-64,885$ & 96,624 \\
\hline
\end{tabular}


Group Statistics

\begin{tabular}{|c|c|c|c|c|c|}
\hline & Grouping Variable & $\mathrm{N}$ & Mean & Std. Deviation & $\begin{array}{l}\text { Std. Error } \\
\text { Mean }\end{array}$ \\
\hline \multirow{2}{*}{$\begin{array}{l}\text { Variação Faturamento } \\
\text { 2002-2005 }\end{array}$} & Grupo 1 & 38 & $90,7999 \%$ & $109,85280 \%$ & $17,82048 \%$ \\
\hline & Grupo 2 & 72 & $133,3481 \%$ & $94,21131 \%$ & $11,10291 \%$ \\
\hline \multirow{2}{*}{$\begin{array}{l}\text { Margem LAJIDA 2002- } \\
2005\end{array}$} & Grupo 1 & 38 & $12,1015 \%$ & $9,15128 \%$ & $1,48453 \%$ \\
\hline & Grupo 2 & 72 & $9,6660 \%$ & $8,78553 \%$ & $1,03538 \%$ \\
\hline \multirow{2}{*}{$\begin{array}{l}\text { Margem de Lucro 2002- } \\
2005\end{array}$} & Grupo 1 & 38 & $2,5093 \%$ & $6,96405 \%$ & $1,12972 \%$ \\
\hline & Grupo 2 & 72 & ,3011\% & $9,45257 \%$ & $1,11400 \%$ \\
\hline \multirow{2}{*}{$\begin{array}{l}\text { Classe de Risco (Risk } \\
\text { Scoring) }\end{array}$} & Grupo 1 & 32 & 306,47 & 140,248 & 24,793 \\
\hline & Grupo 2 & 41 & 330,56 & 160,827 & 25,117 \\
\hline
\end{tabular}

Independent Samples Test

\begin{tabular}{|c|c|c|c|c|c|c|c|c|c|c|}
\hline & & \multicolumn{2}{|c|}{$\begin{array}{l}\text { Levene's Test for } \\
\text { Equality of Variances }\end{array}$} & \multicolumn{7}{|c|}{ t-test for Equality of Means } \\
\hline & & \multirow[b]{2}{*}{$\mathrm{F}$} & \multirow[b]{2}{*}{ Sig. } & \multirow[b]{2}{*}{$\mathrm{t}$} & \multirow[b]{2}{*}{$d f$} & \multirow[b]{2}{*}{ Sig. (2-tailed) } & \multirow[b]{2}{*}{$\begin{array}{c}\text { Mean } \\
\text { Difference }\end{array}$} & \multirow[b]{2}{*}{$\begin{array}{l}\text { Std. Error } \\
\text { Difference }\end{array}$} & \multicolumn{2}{|c|}{$\begin{array}{c}95 \% \text { Confidence Interval } \\
\text { of the Difference }\end{array}$} \\
\hline & & & & & & & & & Upper & Lower \\
\hline $\begin{array}{l}\text { Variação Faturamento } \\
\text { 2002-2005 }\end{array}$ & $\begin{array}{l}\text { Equal variances } \\
\text { assumed } \\
\text { Equal variances } \\
\text { not assumed }\end{array}$ & 132 &, 717 & $-2,125$ & 66,109 & ,036 & $-42,54824 \%$ & $20,02028 \%$ & $\begin{array}{r}- \\
82,23192 \\
\% \\
- \\
84,46738 \\
\%\end{array}$ &,$- 62910 \%$ \\
\hline \multirow[t]{2}{*}{$\begin{array}{l}\text { Margem LAJIDA 2002- } \\
2005\end{array}$} & $\begin{array}{l}\text { Equal variances } \\
\text { assumed }\end{array}$ & \multirow[t]{2}{*}{107} & \multirow[t]{2}{*}{,745 } & 1,363 & 108 & 176 & $2,43548 \%$ & $1,78706 \%$ & $-1,10678 \%$ & $5,97774 \%$ \\
\hline & $\begin{array}{l}\text { Equal variances } \\
\text { not assumed }\end{array}$ & & & 1,346 & 72,777 & 183 & $2,43548 \%$ & $1,80993 \%$ & $-1,17190 \%$ & $6,04286 \%$ \\
\hline \multirow[t]{2}{*}{$\begin{array}{l}\text { Margem de Lucro 2002- } \\
2005\end{array}$} & $\begin{array}{l}\text { Equal variances } \\
\text { assumed }\end{array}$ & \multirow[t]{2}{*}{1,059} & \multirow[t]{2}{*}{,306 } & 1,269 & 108 & ,207 & $2,20823 \%$ & $1,74058 \%$ & $-1,24191 \%$ & $5,65836 \%$ \\
\hline & $\begin{array}{l}\text { Equal variances } \\
\text { not assumed }\end{array}$ & & & 1,392 & 96,427 & 167 & $2,20823 \%$ & $1,58658 \%$ &,$- 94094 \%$ & $5,35739 \%$ \\
\hline \multirow[t]{2}{*}{$\begin{array}{l}\text { Classe de Risco (Risk } \\
\text { Scoring) }\end{array}$} & $\begin{array}{l}\text { Equal variances } \\
\text { assumed }\end{array}$ & \multirow[t]{2}{*}{2,460} & \multirow[t]{2}{*}{121} &,- 671 & 71 &, 504 & $-24,092$ & 35,898 & $-95,670$ & 47,486 \\
\hline & $\begin{array}{l}\text { Equal variances } \\
\text { not assumed }\end{array}$ & & &,- 683 & 70,078 & ,497 & $-24,092$ & 35,292 & $-94,479$ & 46,294 \\
\hline
\end{tabular}


Apêndice 1: Estatísticas da Matriz Revisada

Group Statistics

\begin{tabular}{|c|c|c|c|c|c|}
\hline & Grouping Variable & $\mathrm{N}$ & Mean & Std. Deviation & $\begin{array}{l}\text { Std. Error } \\
\text { Mean }\end{array}$ \\
\hline \multirow{2}{*}{$\begin{array}{l}\text { Variação Faturamento } \\
\text { 2002-2005 }\end{array}$} & Grupo 1 & 38 & $90,7999 \%$ & $109,85280 \%$ & $17,82048 \%$ \\
\hline & Grupo 3 & 65 & $149,9929 \%$ & $203,80842 \%$ & $25,27932 \%$ \\
\hline \multirow{2}{*}{$\begin{array}{l}\text { Margem LAJIDA 2002- } \\
2005\end{array}$} & Grupo 1 & 38 & $12,1015 \%$ & $9,15128 \%$ & $1,48453 \%$ \\
\hline & Grupo 3 & 65 & $10,5855 \%$ & $8,34929 \%$ & $1,03560 \%$ \\
\hline \multirow{2}{*}{$\begin{array}{l}\text { Margem de Lucro 2002- } \\
2005\end{array}$} & Grupo 1 & 38 & $2,5093 \%$ & $6,96405 \%$ & $1,12972 \%$ \\
\hline & Grupo 3 & 65 & $2,3264 \%$ & $6,76790 \%$ & ,83945\% \\
\hline \multirow{2}{*}{$\begin{array}{l}\text { Classe de Risco (Risk } \\
\text { Scoring) }\end{array}$} & Grupo 1 & 32 & 306,47 & 140,248 & 24,793 \\
\hline & Grupo 3 & 18 & 342,78 & 134,063 & 31,599 \\
\hline
\end{tabular}

Independent Samples Test

\begin{tabular}{|c|c|c|c|c|c|c|c|c|c|c|}
\hline & \multicolumn{2}{|c|}{$\begin{array}{l}\text { Levene's Test for } \\
\text { Equality of Variances }\end{array}$} & \multicolumn{7}{|c|}{ t-test for Equality of Means } \\
\hline & & \multirow[b]{2}{*}{$\mathrm{F}$} & \multirow[b]{2}{*}{ Sig. } & \multirow[b]{2}{*}{$\mathrm{t}$} & \multirow[b]{2}{*}{ df } & \multirow[b]{2}{*}{ Sig. (2-tailed) } & \multirow[b]{2}{*}{$\begin{array}{c}\text { Mean } \\
\text { Difference }\end{array}$} & \multirow[b]{2}{*}{$\begin{array}{l}\text { Std. Error } \\
\text { Difference }\end{array}$} & \multicolumn{2}{|c|}{$\begin{array}{l}\text { 95\% Confidence Interval } \\
\text { of the Difference }\end{array}$} \\
\hline & & & & & & & & & Upper & Lower \\
\hline $\begin{array}{l}\text { Variação Faturamento } \\
\text { 2002-2005 }\end{array}$ & $\begin{array}{l}\text { Equal variances } \\
\text { assumed }\end{array}$ & 827 & 365 & $-1,653$ & 101 & 101 & $-59,19301 \%$ & $35,80429 \%$ & 130,21910 & $\begin{array}{r}11,83307 \\
\%\end{array}$ \\
\hline & $\begin{array}{l}\text { Equal variances } \\
\text { not assumed }\end{array}$ & & & $-1,914$ & 100,489 & ,058 & $-59,19301 \%$ & $30,92917 \%$ & $\begin{array}{r}120,55195 \\
\%\end{array}$ & $2,16593 \%$ \\
\hline $\begin{array}{l}\text { Margem LAJIDA 2002- } \\
2005\end{array}$ & $\begin{array}{l}\text { Equal variances } \\
\text { assumed }\end{array}$ & 402 & ,527 & ,858 & 101 & 393 & $1,51595 \%$ & $1,76674 \%$ & $-1,98878 \%$ & $5,02069 \%$ \\
\hline & $\begin{array}{l}\text { Equal variances } \\
\text { not assumed }\end{array}$ & & & ,838 & 71,926 & ,405 & $1,51595 \%$ & $1,81006 \%$ & $-2,09240 \%$ & $5,12430 \%$ \\
\hline $\begin{array}{l}\text { Margem de Lucro 2002- } \\
2005\end{array}$ & $\begin{array}{l}\text { Equal variances } \\
\text { assumed }\end{array}$ & ,068 & 794 & 131 & 101 & 896 & 18291\% & $1,39686 \%$ & $-2,58808 \%$ & $2,95389 \%$ \\
\hline & $\begin{array}{l}\text { Equal variances } \\
\text { not assumed }\end{array}$ & & & 130 & 75,782 & 897 & 18291\% & $1,40746 \%$ & $-2,62043 \%$ & $2,98624 \%$ \\
\hline $\begin{array}{l}\text { Classe de Risco (Risk } \\
\text { Scoring) }\end{array}$ & $\begin{array}{l}\text { Equal variances } \\
\text { assumed }\end{array}$ & 086 & ,770 &,- 892 & 48 & 377 & $-36,309$ & 40,685 & $-118,112$ & 45,494 \\
\hline & $\begin{array}{l}\text { Equal variances } \\
\text { not assumed }\end{array}$ & & &,- 904 & 36,738 & 372 & $-36,309$ & 40,164 & $-117,709$ & 45,091 \\
\hline
\end{tabular}


Group Statistics

\begin{tabular}{|c|c|c|c|c|c|}
\hline & Grouping Variable & $\mathrm{N}$ & Mean & Std. Deviation & $\begin{array}{l}\text { Std. Error } \\
\text { Mean }\end{array}$ \\
\hline \multirow{2}{*}{$\begin{array}{l}\text { Variação Faturamento } \\
2002-2005\end{array}$} & Grupo 2 & 72 & $133,3481 \%$ & $94,21131 \%$ & $11,10291 \%$ \\
\hline & Grupo 3 & 65 & $149,9929 \%$ & $203,80842 \%$ & $25,27932 \%$ \\
\hline \multirow{2}{*}{$\begin{array}{l}\text { Margem LAJIDA 2002- } \\
2005\end{array}$} & Grupo 2 & 72 & $9,6660 \%$ & $8,78553 \%$ & $1,03538 \%$ \\
\hline & Grupo 3 & 65 & $10,5855 \%$ & $8,34929 \%$ & $1,03560 \%$ \\
\hline \multirow{2}{*}{$\begin{array}{l}\text { Margem de Lucro 2002- } \\
2005\end{array}$} & Grupo 2 & 72 & ,3011\% & $9,45257 \%$ & $1,11400 \%$ \\
\hline & Grupo 3 & 65 & $2,3264 \%$ & $6,76790 \%$ & ,83945\% \\
\hline \multirow{2}{*}{$\begin{array}{l}\text { Classe de Risco (Risk } \\
\text { Scoring) }\end{array}$} & Grupo 2 & 41 & 330,56 & 160,827 & 25,117 \\
\hline & Grupo 3 & 18 & 342,78 & 134,063 & 31,599 \\
\hline
\end{tabular}

Independent Samples Test

\begin{tabular}{|c|c|c|c|c|c|c|c|c|c|c|}
\hline & & \multicolumn{2}{|c|}{$\begin{array}{c}\text { Levene's Test for } \\
\text { Equality of Variances }\end{array}$} & \multicolumn{7}{|c|}{ t-test for Equality of Means } \\
\hline & & \multirow[b]{2}{*}{$\mathrm{F}$} & \multirow[b]{2}{*}{ Sig. } & \multirow[b]{2}{*}{$\mathrm{t}$} & \multirow[b]{2}{*}{$\mathrm{df}$} & \multirow[b]{2}{*}{ Sig. (2-tailed) } & \multirow{2}{*}{$\begin{array}{c}\text { Mean } \\
\text { Difference }\end{array}$} & \multirow[b]{2}{*}{$\begin{array}{l}\text { Std. Error } \\
\text { Difference }\end{array}$} & \multicolumn{2}{|c|}{$\begin{array}{l}95 \% \text { Confidence Interval } \\
\text { of the Difference }\end{array}$} \\
\hline & & & & & & & & & Upper & Lower \\
\hline $\begin{array}{l}\text { Variação Faturamento } \\
\text { 2002-2005 }\end{array}$ & $\begin{array}{l}\text { Equal variances } \\
\text { assumed } \\
\text { Equal variances } \\
\text { not assumed }\end{array}$ & 1,037 & ,310 & $\begin{array}{l}-, 623 \\
-, 603\end{array}$ & 88,118 &, 534 & $\begin{array}{l}-16,64477 \% \\
-16,64477 \%\end{array}$ & $26,70399 \%$ & $\begin{array}{r}- \\
69,45705 \\
\% \\
- \\
71,51306 \\
\%\end{array}$ & $\begin{array}{r}36,16751 \\
\% \\
38,22352 \\
\%\end{array}$ \\
\hline \multirow[t]{2}{*}{$\begin{array}{l}\text { Margem LAJIDA 2002- } \\
2005\end{array}$} & $\begin{array}{l}\text { Equal variances } \\
\text { assumed }\end{array}$ & \multirow[t]{2}{*}{132} & \multirow[t]{2}{*}{, 717} &,- 626 & 135 &, 532 &,$- 91952 \%$ & $1,46825 \%$ & $-3,82327 \%$ & $1,98422 \%$ \\
\hline & $\begin{array}{l}\text { Equal variances } \\
\text { not assumed }\end{array}$ & & &,- 628 & 134,634 &, 531 &,$- 91952 \%$ & $1,46441 \%$ & $-3,81575 \%$ & $1,97670 \%$ \\
\hline \multirow[t]{2}{*}{$\begin{array}{l}\text { Margem de Lucro 2002- } \\
2005\end{array}$} & $\begin{array}{l}\text { Equal variances } \\
\text { assumed }\end{array}$ & \multirow[t]{2}{*}{2,276} & \multirow[t]{2}{*}{134} & $-1,428$ & 135 & , 156 & $-2,02532 \%$ & $1,41820 \%$ & $-4,83008 \%$ &, $77944 \%$ \\
\hline & $\begin{array}{l}\text { Equal variances } \\
\text { not assumed }\end{array}$ & & & $-1,452$ & 128,545 & 149 & $-2,02532 \%$ & $1,39487 \%$ & $-4,78520 \%$ &, $73456 \%$ \\
\hline \multirow[t]{2}{*}{$\begin{array}{l}\text { Classe de Risco (Risk } \\
\text { Scoring) }\end{array}$} & $\begin{array}{l}\text { Equal variances } \\
\text { assumed }\end{array}$ & \multirow[t]{2}{*}{2,779} & \multirow[t]{2}{*}{,101 } &,- 282 & 57 &, 779 & $-12,217$ & 43,355 & $-99,033$ & 74,600 \\
\hline & $\begin{array}{l}\text { Equal variances } \\
\text { not assumed }\end{array}$ & & &,- 303 & 38,702 & ,764 & $-12,217$ & 40,365 & $-93,883$ & 69,450 \\
\hline
\end{tabular}




\section{Apêndice 1: Estatísticas da Matriz Revisada}

Correlations

\begin{tabular}{|c|c|c|c|c|c|c|c|c|c|c|c|c|c|c|}
\hline & & ISO90012000 & ISOTS16949 & ISO14000 & $\begin{array}{l}\text { Notade } \\
\text { Sistema }\end{array}$ & $\begin{array}{l}\text { Amplitudede } \\
\text { Mercado }\end{array}$ & $\begin{array}{l}\text { Amplitudede } \\
\text { Produtos }\end{array}$ & $\begin{array}{l}\text { Número } \\
\text { Empregados }\end{array}$ & $\begin{array}{l}\text { Produtivida } \\
\text { deR2005 } \\
\text { Empregado }\end{array}$ & $\begin{array}{l}\text { Faturamentot } \\
\text { otal20022005 }\end{array}$ & $\begin{array}{c}\text { Variação } \\
\text { Faturament } \\
\text { 020022005 }\end{array}$ & $\begin{array}{c}\text { Margem } \\
\text { LAJIDA20 } \\
\text { 022005 } \\
\end{array}$ & $\begin{array}{c}\text { Margem } \\
\text { Lucro200 } \\
22005\end{array}$ & $\begin{array}{c}\text { Classe } \\
\text { RiscoRisk } \\
\text { Scoring }\end{array}$ \\
\hline \multirow[t]{3}{*}{ ISO90012000 } & Pearson Correlation & 1 & , 124 & ,092 & ,587**| & ,142* & , $172^{*}$ & ,060 &,- 040 & ,076 &,- 066 & ,228** & ,161* & $\begin{array}{r}, 002 \\
\end{array}$ \\
\hline & Sig. (2-tailed) & & ,073 & 182 & ,000 & ,040 & ,012 & ,385 &, 567 & ,270 & ,337 & ,001 & ,020 & ,976 \\
\hline & $\mathrm{N}$ & 211 & 211 & 211 & 211 & 211 & 211 & 211 & 211 & 211 & 211 & 211 & 211 & 211 \\
\hline \multirow[t]{3}{*}{ ISOTS16949 } & Pearson Correlation & $\begin{array}{ll}, 124 & \\
,\end{array}$ & 1 & ,488*夫 &, $756^{* *}$ & ,177***t| & ,017 & ,224*x & ,204** & ,184**| & ,177* & ,054 & ,010 & ,003 \\
\hline & Sig. (2-tailed) & ,073 & & ,000 & , 000 & , 010 & 802 & ,001 & ,003 & ,007 & ,010 & 437 & ,887 & ,962 \\
\hline & $\mathrm{N}$ & 211 & 211 & 211 & 211 & 211 & 211 & 211 & 211 & 211 & 211 & 211 & 211 & 211 \\
\hline \multirow[t]{3}{*}{ ISO14000 } & Pearson Correlation & ,092 &, $488^{*}$ & 1 &, $743 * \star x$ & ,135 & ,104 &, $375 * *$ &, $258 * *$ &, $326 * \star$ & ,127 & ,017 & ,010 &,- 012 \\
\hline & Sig. (2-tailed) & ,182 & , 000 & & , 000 & 051 & 132 & , 000 & ,000 & , 000 & ,066 & ,806 & ,887 & ,860 \\
\hline & $\mathrm{N}$ & 211 & 211 & 211 & 211 & 211 & 211 & 211 & 211 & 211 & 211 & 211 & 211 & 211 \\
\hline \multirow[t]{3}{*}{ NotadeSistema } & Pearson Correlation &, $587 * *$ &, $756^{* *}$ &, $743 * \star$ & 1 &, $222 \times+$ & ,135* & $306 * x$ &, $220 * *$ &, $274 * *$ & ,112 & ,135* & ,076 & \begin{tabular}{c|c|c|}
, 016 \\
\end{tabular} \\
\hline & Sig. (2-tailed) & , 000 & , 000 & ,000 & & , 001 & ,049 & , 000 & ,001 & , 000 & 106 & ,050 & ,273 & 819 \\
\hline & $\mathrm{N}$ & 211 & 211 & 211 & 211 & 211 & 211 & 211 & 211 & 211 & 211 & 211 & 211 & 211 \\
\hline \multirow[t]{3}{*}{ AmplitudedeMercado } & Pearson Correlation &, $142^{*}$ &, $177^{* \star}$ & ,135 &, $222^{\star \star *}$ & 1 &, $283 * \star$ & ,075 & ,106 & ,090 &,- 065 & 072 & ,019 & 030 \\
\hline & Sig. (2-tailed) & ,040 & ,010 & ,051 & ,001 & & ,000 & ,278 & ,126 & 191 & ,345 & ,296 & ,789 & ,667 \\
\hline & $\mathrm{N}$ & 211 & 211 & 211 & 211 & 211 & 211 & 211 & 211 & 211 & 211 & 211 & 211 & 211 \\
\hline \multirow[t]{3}{*}{ AmplitudedeProdutos } & Pearson Correlation & ,172* & ,017 & ,104 & ,135* &, $283^{*+4}$ & 1 & ,114 & \begin{tabular}{|c|c|}
-058 \\
\end{tabular} & ,056 & $\begin{array}{l}-, 095 \\
\end{array}$ & 131 & ,076 & ,101 \\
\hline & Sig. (2-tailed) & ,012 & ,802 & 132 & ,049 & ,000 & & 100 & ,402 & ,415 & 169 & ,057 & ,271 & 145 \\
\hline & $\mathrm{N}$ & 211 & 211 & 211 & 211 & 211 & 211 & 211 & 211 & 211 & 211 & 211 & 211 & 211 \\
\hline \multirow[t]{3}{*}{ NúmeroEmpregados } & Pearson Correlation & ,060 & ,224**| & ,375** &, $306^{* *}$ & ,075 & ,114 & 1 & ,130 & ,680** & ,076 & 133 & \begin{tabular}{c|c|}
-021 \\
\end{tabular} & $\begin{array}{c}-, 046 \\
\end{array}$ \\
\hline & Sig. (2-tailed) & ,385 & , 001 & ,000 & , 000 & ,278 & 100 & & ,059 & , 000 & ,270 & ,054 & ,757 &, 507 \\
\hline & $\mathrm{N}$ & 211 & 211 & 211 & 211 & 211 & 211 & 211 & 211 & 211 & 211 & 211 & 211 & 211 \\
\hline \multirow{3}{*}{$\begin{array}{l}\text { ProdutividadeR2005 } \\
\text { Empregado }\end{array}$} & Pearson Correlation &,- 040 & ,204** &, $258 * x$ &, $220 * *$ & ,106 &,- 058 & ,130 & 1 &, $461 * *$ & ,112 & ,039 & ,067 &,- 084 \\
\hline & Sig. (2-tailed) &, 567 & ,003 & ,000 & , 001 & 126 & ,402 & ,059 & & , 000 & 106 & ,568 & ,336 & 224 \\
\hline & $\mathrm{N}$ & 211 & 211 & 211 & 211 & 211 & 211 & 211 & 211 & 211 & 211 & 211 & 211 & 211 \\
\hline \multirow{3}{*}{$\begin{array}{l}\text { Faturamentototal2002200 } \\
5\end{array}$} & Pearson Correlation & ,076 & ,184**| & ,326** & ,274**t & ,090 & ,056 & ,680*+ & ,461**4 & 1 & ,034 & 105 & ,003 &,- 022 \\
\hline & Sig. (2-tailed) & ,270 & ,007 & ,000 & ,000 & 191 & ,415 & ,000 & ,000 & & ,620 & ,128 & ,969 & ,748 \\
\hline & $\mathrm{N}$ & 211 & 211 & 211 & 211 & 211 & 211 & 211 & 211 & 211 & 211 & 211 & 211 & 211 \\
\hline \multirow{3}{*}{$\begin{array}{l}\text { Variação } \\
\text { Faturamento20022005 }\end{array}$} & Pearson Correlation & 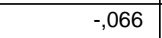 & ,177* & ,127 & ,112 &,- 065 &,- 095 & ,076 & ,112 & ,034 & 1 & ,011 & 123 & ,001 \\
\hline & Sig. (2-tailed) & 337 & ,010 & ,066 & ,106 & ,345 & 169 & ,270 & 106 & ,620 & & ,875 & ,075 & ,991 \\
\hline & $\mathrm{N}$ & 211 & 211 & 211 & 211 & 211 & 211 & 211 & 211 & 211 & 211 & 211 & 211 & 211 \\
\hline \multirow[t]{3}{*}{ MargemLAJIDA20022005 } & Pearson Correlation & ,228**| & 054 & 017 & ,135* & ,072 & ,131 & ,133 & ,039 & ,105 & ,011 & 1 & ,805** & ,159* \\
\hline & Sig. (2-tailed) & ,001 & ,437 & ,806 & ,050 & ,296 & ,057 & ,054 &, 568 & ,128 & 875 & & ,000 & ,020 \\
\hline & $\mathrm{N}$ & 211 & 211 & 211 & 211 & 211 & 211 & 211 & 211 & 211 & 211 & 211 & 211 & 211 \\
\hline \multirow[t]{3}{*}{ MargemLucro20022005 } & Pearson Correlation & ,161* & ,010 & ,010 & ,076 & ,019 & ,076 & $\begin{array}{c}-, 021 \\
\end{array}$ & ,067 & ,003 & ,123 & ,805** & 1 &, $245^{*}$ \\
\hline & Sig. (2-tailed) & ,020 & ,887 & ,887 & ,273 & ,789 & ,271 & ,757 &, 336 & ,969 & 075 & ,000 & & ,000 \\
\hline & $\mathrm{N}$ & 211 & 211 & 211 & 211 & 211 & 211 & 211 & 211 & 211 & 211 & 211 & 211 & 211 \\
\hline \multirow[t]{3}{*}{ ClasseRiscoRiskScoring } & Pearson Correlation & ,002 & ,003 & $-0,012$ & \begin{tabular}{|c|}
-016 \\
\end{tabular} & ,030 & 101 & 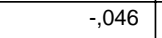 & \begin{tabular}{|c|}
-084 \\
\end{tabular} & $-0,022$ & ,001 & ,159* &, $245^{* *}$ & 1 \\
\hline & Sig. (2-tailed) & 976 & ,962 & 860 & 819 & 667 & 145 & ,507 & ,224 & ,748 & 991 & ,020 & ,000 & \\
\hline & $\mathrm{N}$ & 211 & 211 & 211 & 211 & 211 & 211 & 211 & 211 & 211 & 211 & 211 & 211 & 211 \\
\hline
\end{tabular}

* Correlation is significant at the 0.01 level (2-tald

*. Correlation is significant at the 0.05 level (2-tailed). 


\section{Regression}

\section{Variables Entered/Removed}

\begin{tabular}{|l|l|l|l|}
\hline Model & $\begin{array}{l}\text { Variables } \\
\text { Entered }\end{array}$ & $\begin{array}{c}\text { Variables } \\
\text { Removed }\end{array}$ & Method \\
\hline 1 & $\begin{array}{l}\text { Faturamen } \\
\text { tototal2002 }\end{array}$ & & \\
& 2005, & & \\
& Amplitude & & \\
de & & \\
& Mercado, & & Enter \\
& Notade & & \\
& Sistema, & & \\
& Número & & \\
& Empregad & & \\
& os & & \\
\hline
\end{tabular}

a. All requested variables entered.

b. Dependent Variable: MargemLucro20022005

Model Summary

\begin{tabular}{|l|r|r|r|r|}
\hline Model & \multicolumn{1}{|c|}{$\mathrm{R}$} & R Square & $\begin{array}{c}\text { Adjusted } \\
\text { R Square }\end{array}$ & $\begin{array}{r}\text { Std. Error of } \\
\text { the Estimate }\end{array}$ \\
\hline 1 &, $105^{\mathrm{a}}$ &, 011 &,- 007 &, 08093 \\
\hline
\end{tabular}

a. Predictors: (Constant), Faturamentototal20022005, AmplitudedeMercado, NotadeSistema, NúmeroEmpregados

ANOVA $^{b}$

\begin{tabular}{|ll|r|r|r|r|r|}
\hline \multicolumn{2}{|c|}{} & \multicolumn{1}{c|}{$\begin{array}{c}\text { Sum of } \\
\text { Sodel }\end{array}$} & df & Mean Square & \multicolumn{1}{c|}{$\mathrm{F}$} & \multicolumn{1}{c|}{ Sig. } \\
\hline 1 & Regression &, 016 & 4 &, 004 &, 603 &, $661^{\mathrm{a}}$ \\
& Residual & 1,408 & 215 &, 007 & & \\
& Total & 1,424 & 219 & & & \\
\hline
\end{tabular}

a. Predictors: (Constant), Faturamentototal20022005, AmplitudedeMercado, NotadeSistema, NúmeroEmpregados

b. Dependent Variable: MargemLucro20022005

\section{Coefficients $^{a}$}

\begin{tabular}{|c|c|c|c|c|c|c|}
\hline \multirow[b]{2}{*}{ Mod } & & \multicolumn{2}{|c|}{$\begin{array}{c}\text { Unstandardized } \\
\text { Coefficients }\end{array}$} & \multirow{2}{*}{$\begin{array}{c}\begin{array}{c}\text { Standardized } \\
\text { Coefficients }\end{array} \\
\text { Beta }\end{array}$} & \multirow[b]{2}{*}{$\mathrm{t}$} & \multirow[b]{2}{*}{ Sig. } \\
\hline & & $\mathrm{B}$ & Std. Error & & & \\
\hline \multirow[t]{5}{*}{1} & (Constant) &,- 002 & ,017 & &,- 128 & ,898 \\
\hline & NotadeSistema & ,007 & ,006 & , 089 & 1,223 & ,223 \\
\hline & AmplitudedeMercado &, 003 & ,006 & ,036 &, 512 & ,609 \\
\hline & NúmeroEmpregados & $-6,5 \mathrm{E}-006$ & ,000 &,- 071 &,- 765 & ,445 \\
\hline & $\begin{array}{l}\text { Faturamentototal200 } \\
22005\end{array}$ & 1,77E-012 & ,000 & 025 & ,272 & ,786 \\
\hline
\end{tabular}

a. Dependent Variable: MargemLucro20022005 


\section{Regression}

Variables Entered/Removed

\begin{tabular}{|l|l|l|l|}
\hline Model & $\begin{array}{l}\text { Variables } \\
\text { Entered }\end{array}$ & $\begin{array}{l}\text { Variables } \\
\text { Removed }\end{array}$ & Method \\
\hline 1 & $\begin{array}{l}\text { Amplitude } \\
\text { de } \\
\text { Mercado, } \\
\text { Notade a } \\
\text { Sistema }\end{array}$ & & \\
\hline
\end{tabular}

a. All requested variables entered.

b. Dependent Variable: MargemLucro20022005

Model Summary

\begin{tabular}{|l|r|r|r|r|}
\hline Model & \multicolumn{1}{|c|}{ R } & R Square & $\begin{array}{c}\text { Adjusted } \\
\text { R Square }\end{array}$ & $\begin{array}{r}\text { Std. Error of } \\
\text { the Estimate }\end{array}$ \\
\hline 1 &, $090^{\mathrm{a}}$ &, 008 &,- 001 &, 08068 \\
\hline
\end{tabular}

a. Predictors: (Constant), AmplitudedeMercado, NotadeSistema

ANOVA

\begin{tabular}{|c|c|c|c|c|c|c|}
\hline Model & & $\begin{array}{l}\text { Sum of } \\
\text { Squares }\end{array}$ & df & Mean Square & $\mathrm{F}$ & Sig. \\
\hline \multirow[t]{3}{*}{1} & Regression & ,011 & 2 & ,006 &, 877 &, $418^{\mathrm{a}}$ \\
\hline & Residual & 1,413 & 217 & ,007 & & \\
\hline & Total & 1,424 & 219 & & & \\
\hline
\end{tabular}

a. Predictors: (Constant), AmplitudedeMercado, NotadeSistema

b. Dependent Variable: MargemLucro20022005

Coefficients $^{\mathrm{a}}$

\begin{tabular}{|c|c|c|c|c|c|c|}
\hline \multirow{2}{*}{\multicolumn{2}{|c|}{ Model }} & \multicolumn{2}{|c|}{$\begin{array}{c}\text { Unstandardized } \\
\text { Coefficients }\end{array}$} & \multirow{2}{*}{$\begin{array}{c}\text { Standardized } \\
\text { Coefficients } \\
\text { Beta }\end{array}$} & \multirow[b]{2}{*}{$\mathrm{t}$} & \multirow[b]{2}{*}{ Sig. } \\
\hline & & $\mathrm{B}$ & Std. Error & & & \\
\hline & (Constant) &,- 003 &, 017 & &,- 177 &, 860 \\
\hline & NotadeSistema &, 006 &, 006 &, 075 & 1,078 & ,282 \\
\hline & AmplitudedeMercado & ,003 & ,006 & ,036 &, 520 & ,604 \\
\hline
\end{tabular}

a. Dependent Variable: MargemLucro20022005 


\section{Regression}

\section{Variables Entered/Removed}

\begin{tabular}{|l|l|l|l|}
\hline Model & $\begin{array}{l}\text { Variables } \\
\text { Entered }\end{array}$ & $\begin{array}{c}\text { Variables } \\
\text { Removed }\end{array}$ & Method \\
\hline 1 & $\begin{array}{l}\text { Amplitude } \\
\text { de }\end{array}$ & & \\
& $\begin{array}{l}\text { Mercado, } \\
\text { Notade } \\
\text { Sistema }\end{array}$ & & Enter \\
\hline
\end{tabular}

a. All requested variables entered.

b. Dependent Variable: VariaçãoFaturamento20022005

Model Summary

\begin{tabular}{|l|r|r|r|r|}
\hline Model & R & R Square & $\begin{array}{c}\text { Adjusted } \\
\text { R Square }\end{array}$ & $\begin{array}{r}\text { Std. Error of } \\
\text { the Estimate }\end{array}$ \\
\hline 1 &, $127^{\mathrm{a}}$ &, 016 &, 007 & 1,39823 \\
\hline
\end{tabular}

a. Predictors: (Constant), AmplitudedeMercado, NotadeSistema

ANOVA

\begin{tabular}{|ll|r|r|r|r|c|}
\hline Model & & \multicolumn{1}{|c|}{$\begin{array}{c}\text { Sum of } \\
\text { Squares }\end{array}$} & df & Mean Square & F & \multicolumn{1}{c|}{ Sig. } \\
\hline 1 & Regression & 6,999 & 2 & 3,500 & 1,790 &, $169^{\mathrm{a}}$ \\
& Residual & 424,246 & 217 & 1,955 & & \\
& Total & 431,245 & 219 & & & \\
\hline
\end{tabular}

a. Predictors: (Constant), AmplitudedeMercado, NotadeSistema

b. Dependent Variable: VariaçãoFaturamento20022005

\section{Coefficients $^{\mathrm{a}}$}

\begin{tabular}{|ll|r|r|r|r|r|}
\hline & & \multicolumn{2}{|c|}{$\begin{array}{c}\text { Unstandardized } \\
\text { Coefficients }\end{array}$} & $\begin{array}{c}\text { Standardized } \\
\text { Coefficients }\end{array}$ & & \\
\cline { 3 - 5 } Model & \multicolumn{1}{|c|}{ B } & Std. Error & \multicolumn{1}{c|}{ Beta } & \multicolumn{1}{c|}{ t } & \multicolumn{1}{c|}{ Sig. } \\
\hline 1 & (Constant) & 1,231 &, 299 & & 4,117 &, 000 \\
& NotadeSistema &, 176 &, 097 &, 125 & 1,810 &, 072 \\
& AmplitudedeMercado &,- 103 &, 111 &,- 064 &,- 925 &, 356 \\
\hline
\end{tabular}

a. Dependent Variable: VariaçãoFaturamento20022005 
Apêndice 1: Estatísticas da Matriz Revisada

\section{Regression}

Variables Entered/Removedp

\begin{tabular}{|l|l|l|l|}
\hline Model & $\begin{array}{l}\text { Variables } \\
\text { Entered }\end{array}$ & $\begin{array}{c}\text { Variables } \\
\text { Removed }\end{array}$ & Method \\
\hline 1 & $\begin{array}{l}\text { Faturamen } \\
\text { tototal2002 }\end{array}$ & & \\
& 2005, \\
Número & & \\
& & & \\
& Empregad & & Enter \\
& os & & \\
\hline
\end{tabular}

a. All requested variables entered.

b. Dependent Variable: VariaçãoFaturamento20022005

Model Summary

\begin{tabular}{|l|r|r|r|r|}
\hline Model & \multicolumn{1}{|c|}{ R } & R Square & $\begin{array}{c}\text { Adjusted } \\
\text { R Square }\end{array}$ & $\begin{array}{r}\text { Std. Error of } \\
\text { the Estimate }\end{array}$ \\
\hline 1 &, $078^{\mathrm{a}}$ &, 006 &,- 003 & 1,40540 \\
\hline
\end{tabular}

a. Predictors: (Constant), Faturamentototal20022005, NúmeroEmpregados

ANOVA

\begin{tabular}{|ll|r|r|r|r|r|}
\hline Model & & $\begin{array}{c}\text { Sum of } \\
\text { Squares }\end{array}$ & df & Mean Square & F & \multicolumn{1}{c|}{ Sig. } \\
\hline 1 & Regression & 2,635 & 2 & 1,317 &, 667 &, $514^{\mathrm{a}}$ \\
& Residual & 428,610 & 217 & 1,975 & & \\
& Total & 431,245 & 219 & & & \\
\hline
\end{tabular}

a. Predictors: (Constant), Faturamentototal20022005, NúmeroEmpregados

b. Dependent Variable: VariaçãoFaturamento20022005

\section{Coefficients $^{\mathrm{a}}$}

\begin{tabular}{|c|c|c|c|c|c|c|}
\hline \multirow[b]{2}{*}{ Model } & & \multicolumn{2}{|c|}{$\begin{array}{l}\text { Unstandardized } \\
\text { Coefficients }\end{array}$} & \multirow{2}{*}{$\begin{array}{c}\begin{array}{c}\text { Standardized } \\
\text { Coefficients }\end{array} \\
\text { Beta }\end{array}$} & \multirow[b]{2}{*}{$\mathrm{t}$} & \multirow[b]{2}{*}{ Sig. } \\
\hline & & B & Std. Error & & & \\
\hline \multirow[t]{3}{*}{1} & (Constant) & 1,166 & ,108 & & 10,831 &, 000 \\
\hline & NúmeroEmpregados & ,000 & ,000 & ,096 & 1,053 & 294 \\
\hline & $\begin{array}{l}\text { Faturamentototal200 } \\
22005\end{array}$ & $-4,0 \mathrm{E}-011$ & ,000 &,- 033 &,- 359 & ,720 \\
\hline
\end{tabular}

a. Dependent Variable: VariaçãoFaturamento20022005 


\section{Regression}

\section{Variables Entered/Removed}

\begin{tabular}{|l|l|l|l|}
\hline Model & $\begin{array}{l}\text { Variables } \\
\text { Entered }\end{array}$ & $\begin{array}{l}\text { Variables } \\
\text { Removed }\end{array}$ & Method \\
\hline 1 & $\begin{array}{l}\text { Faturamen } \\
\text { tototal2002 }\end{array}$ & & \\
& 2005, & & \\
& Número & & Enter \\
& Empregad & & \\
& os & & \\
\hline
\end{tabular}

a. All requested variables entered.

b. Dependent Variable: MargemLucro20022005

Model Summary

\begin{tabular}{|l|r|r|r|r|}
\hline Model & \multicolumn{1}{|c|}{ R } & R Square & $\begin{array}{c}\text { Adjusted } \\
\text { R Square }\end{array}$ & $\begin{array}{r}\text { Std. Error of } \\
\text { the Estimate }\end{array}$ \\
\hline 1 &, $039^{\mathrm{a}}$ &, 001 &,- 008 &, 08095 \\
\hline
\end{tabular}

a. Predictors: (Constant), Faturamentototal20022005, NúmeroEmpregados

\section{ANOVA}

\begin{tabular}{|ll|r|r|r|r|r|}
\hline Model & & \multicolumn{1}{c|}{$\begin{array}{c}\text { Sum of } \\
\text { Squares }\end{array}$} & \multicolumn{1}{c|}{ df } & Mean Square & \multicolumn{1}{c|}{ F } & \multicolumn{1}{c|}{ Sig. } \\
\hline 1 & Regression &, 002 & 2 &, 001 &, 162 &, $851^{\mathrm{a}}$ \\
& Residual & 1,422 & 217 &, 007 & & \\
& Total & 1,424 & 219 & & & \\
\hline
\end{tabular}

a. Predictors: (Constant), Faturamentototal20022005, NúmeroEmpregados

b. Dependent Variable: MargemLucro20022005

\section{Coefficients $^{\mathrm{a}}$}

\begin{tabular}{|c|c|c|c|c|c|c|}
\hline \multirow[b]{2}{*}{ Model } & & \multicolumn{2}{|c|}{$\begin{array}{c}\text { Unstandardized } \\
\text { Coefficients }\end{array}$} & \multirow{2}{*}{$\begin{array}{c}\text { Standardized } \\
\text { Coefficients } \\
\text { Beta }\end{array}$} & \multirow[b]{2}{*}{$\mathrm{t}$} & \multirow[b]{2}{*}{ Sig. } \\
\hline & & $\mathrm{B}$ & Std. Error & & & \\
\hline & (Constant) & ,015 & ,006 & & 2,439 & ,016 \\
\hline & NúmeroEmpregados & $-4,7 E-006$ &, 000 &,- 052 &,- 564 &, 573 \\
\hline & $\begin{array}{l}\text { Faturamentototal200 } \\
22005\end{array}$ & 2,79E-012 & ,000 & ,040 & ,432 & ,666 \\
\hline
\end{tabular}

a. Dependent Variable: MargemLucro20022005 
Apêndice 1: Estatísticas da Matriz Revisada

\section{Regression}

Variables Entered/Removed

\begin{tabular}{|l|l|l|l|}
\hline Model & $\begin{array}{l}\text { Variables } \\
\text { Entered }\end{array}$ & $\begin{array}{c}\text { Variables } \\
\text { Removed }\end{array}$ & Method \\
\hline 1 & $\begin{array}{l}\text { Faturamen } \\
\text { tototal2002 }\end{array}$ & & \\
& 2005, \\
Número & & \\
& Empregad & & Enter \\
& & & \\
\hline
\end{tabular}

a. All requested variables entered.

b. Dependent Variable: MargemLAJIDA20022005

Model Summary

\begin{tabular}{|l|r|r|r|r|}
\hline Model & \multicolumn{1}{|c|}{ R } & R Square & $\begin{array}{c}\text { Adjusted } \\
\text { R Square }\end{array}$ & $\begin{array}{r}\text { Std. Error of } \\
\text { the Estimate }\end{array}$ \\
\hline 1 &, $089^{\mathrm{a}}$ &, 008 &,- 001 &, 10378 \\
\hline
\end{tabular}

a. Predictors: (Constant), Faturamentototal20022005, NúmeroEmpregados

ANOVA

\begin{tabular}{|ll|r|r|r|r|r|}
\hline Model & & $\begin{array}{r}\text { Sum of } \\
\text { Squares }\end{array}$ & $\mathrm{df}$ & Mean Square & \multicolumn{1}{c|}{$\mathrm{F}$} & \multicolumn{1}{c|}{ Sig. } \\
\hline 1 & Regression &, 019 & 2 &, 009 &, 874 &, $419^{\mathrm{a}}$ \\
& Residual & 2,337 & 217 &, 011 & & \\
& Total & 2,356 & 219 & & & \\
\hline
\end{tabular}

a. Predictors: (Constant), Faturamentototal20022005, NúmeroEmpregados

b. Dependent Variable: MargemLAJIDA20022005

\section{Coefficients $^{\mathrm{a}}$}

\begin{tabular}{|c|c|c|c|c|c|c|}
\hline \multirow[b]{2}{*}{ Mod } & & \multicolumn{2}{|c|}{$\begin{array}{c}\text { Unstandardized } \\
\text { Coefficients }\end{array}$} & \multirow{2}{*}{$\begin{array}{c}\begin{array}{c}\text { Standardized } \\
\text { Coefficients }\end{array} \\
\text { Beta }\end{array}$} & \multirow[b]{2}{*}{$\mathrm{t}$} & \multirow[b]{2}{*}{ Sig. } \\
\hline & & B & Std. Error & & & \\
\hline & (Constant) & ,092 & ,008 & & 11,528 &, 000 \\
\hline & NúmeroEmpregados & 5,95E-006 & ,000 & 051 & ,557 & ,578 \\
\hline & $\begin{array}{l}\text { Faturamentototal200 } \\
22005\end{array}$ & 4,23E-012 & ,000 & ,047 & ,510 & 610 \\
\hline
\end{tabular}

a. Dependent Variable: MargemLAJIDA20022005 


\section{Regression}

\section{Variables Entered/Removed}

\begin{tabular}{|l|l|l|l|}
\hline Model & $\begin{array}{l}\text { Variables } \\
\text { Entered }\end{array}$ & $\begin{array}{c}\text { Variables } \\
\text { Removed }\end{array}$ & Method \\
\hline 1 & Notade & & \\
& Sistema, & & \\
& Faturamen & & \\
& tototal2002 & & \multirow{5}{*}{ Enter } \\
& 2005, & & \\
& Número & & \\
& Empregad & & \\
& os & & \\
\hline
\end{tabular}

a. All requested variables entered.

b. Dependent Variable: MargemLucro20022005

Model Summary

\begin{tabular}{|l|r|r|r|r|}
\hline Model & $\mathrm{R}$ & R Square & $\begin{array}{c}\text { Adjusted } \\
\text { R Square }\end{array}$ & $\begin{array}{r}\text { Std. Error of } \\
\text { the Estimate }\end{array}$ \\
\hline 1 &, $099^{\mathrm{a}}$ &, 010 &,- 004 &, 08079 \\
\hline
\end{tabular}

a. Predictors: (Constant), NotadeSistema,

Faturamentototal20022005, NúmeroEmpregados

ANOVA

\begin{tabular}{|rl|r|r|r|r|r|}
\hline \multicolumn{2}{|c|}{} & \multicolumn{1}{c|}{$\begin{array}{c}\text { Sum of } \\
\text { Sodel }\end{array}$} & df & Mean Square & \multicolumn{1}{c|}{$\mathrm{F}$} & \multicolumn{1}{c|}{ Sig. } \\
\hline 1 & Regression &, 014 & 3 &, 005 &, 719 &, $541^{\mathrm{a}}$ \\
& Residual & 1,410 & 216 &, 007 & & \\
& Total & 1,424 & 219 & & & \\
\hline
\end{tabular}

a. Predictors: (Constant), NotadeSistema, Faturamentototal20022005, NúmeroEmpregados

b. Dependent Variable: MargemLucro20022005

\section{Coefficients $^{\mathrm{a}}$}

\begin{tabular}{|c|c|c|c|c|c|c|}
\hline \multirow[b]{2}{*}{ Modt } & & \multicolumn{2}{|c|}{$\begin{array}{l}\text { Unstandardized } \\
\text { Coefficients }\end{array}$} & \multirow{2}{*}{$\begin{array}{c}\begin{array}{c}\text { Standardized } \\
\text { Coefficients }\end{array} \\
\text { Beta }\end{array}$} & \multirow[b]{2}{*}{$\mathrm{t}$} & \multirow[b]{2}{*}{ Sig. } \\
\hline & & $B$ & Std. Error & & & \\
\hline \multirow[t]{4}{*}{1} & (Constant) &, 005 & ,010 & & 541 &, 589 \\
\hline & NúmeroEmpregados & $-6,5 E-006$ & ,000 &,- 072 &,- 777 & ,438 \\
\hline & $\begin{array}{l}\text { Faturamentototal200 } \\
22005\end{array}$ & 1,90E-012 & ,000 & ,027 & ,292 & ,770 \\
\hline & NotadeSistema & ,008 & ,006 & ,097 & 1,354 & 177 \\
\hline
\end{tabular}

a. Dependent Variable: MargemLucro20022005 
Apêndice 1: Estatísticas da Matriz Revisada

\section{Regression}

Variables Entered/Removed

\begin{tabular}{|l|l|l|l|}
\hline Model & $\begin{array}{l}\text { Variables } \\
\text { Entered }\end{array}$ & $\begin{array}{c}\text { Variables } \\
\text { Removed }\end{array}$ & Method \\
\hline 1 & $\begin{array}{l}\text { ISO90012 } \\
000, \\
\text { Montadora, } \\
\text { Idade } \\
\text { Empresa, } \\
\text { Notade a } \\
\text { Sistema }\end{array}$ & & \\
& & & \\
\hline
\end{tabular}

a. All requested variables entered.

b. Dependent Variable: MargemLAJIDA20022005

Model Summary

\begin{tabular}{|l|r|r|r|r|}
\hline Model & $\mathrm{R}$ & R Square & $\begin{array}{c}\text { Adjusted } \\
\text { R Square }\end{array}$ & $\begin{array}{r}\text { Std. Error of } \\
\text { the Estimate }\end{array}$ \\
\hline 1 &, $269^{\mathrm{a}}$ &, 072 &, 055 &, 10084 \\
\hline
\end{tabular}

a. Predictors: (Constant), ISO90012000, Montadora, IdadeEmpresa, NotadeSistema

ANOVA

\begin{tabular}{|c|c|c|c|c|c|c|}
\hline & & $\begin{array}{l}\text { Sum of } \\
\text { Squares }\end{array}$ & df & Mean Square & $\mathrm{F}$ & Sig. \\
\hline & Regression & , 170 & 4 & ,043 & 4,183 &, $003^{a}$ \\
\hline & Residual & 2,186 & 215 & ,010 & & \\
\hline & Total & 2,356 & 219 & & & \\
\hline
\end{tabular}

a. Predictors: (Constant), ISO90012000, Montadora, IdadeEmpresa, NotadeSistema

b. Dependent Variable: MargemLAJIDA20022005

Coefficients $^{\mathrm{a}}$

\begin{tabular}{|c|c|c|c|c|c|c|}
\hline \multirow{2}{*}{\multicolumn{2}{|c|}{ Model }} & \multicolumn{2}{|c|}{$\begin{array}{c}\text { Unstandardized } \\
\text { Coefficients }\end{array}$} & \multirow{2}{*}{$\begin{array}{c}\begin{array}{c}\text { Standardized } \\
\text { Coefficients }\end{array} \\
\text { Beta }\end{array}$} & \multirow[b]{2}{*}{$\mathrm{t}$} & \multirow[b]{2}{*}{ Sig. } \\
\hline & & $\mathrm{B}$ & Std. Error & & & \\
\hline \multirow[t]{5}{*}{1} & (Constant) & ,030 & ,023 & & 1,293 & ,197 \\
\hline & NotadeSistema &,- 001 & ,009 &,- 009 &,- 096 & ,923 \\
\hline & Montadora & ,032 & ,019 & ,119 & 1,644 & ,102 \\
\hline & IdadeEmpresa & ,001 & ,001 & ,078 & 1,164 & ,246 \\
\hline & ISO90012000 & ,045 & ,017 & ,215 & 2,559 & 011 \\
\hline
\end{tabular}

a. Dependent Variable: MargemLAJIDA20022005 


\section{Regression}

Variables Entered/Removed

\begin{tabular}{|l|l|l|l|}
\hline Model & $\begin{array}{l}\text { Variables } \\
\text { Entered }\end{array}$ & $\begin{array}{l}\text { Variables } \\
\text { Removed }\end{array}$ & Method \\
\hline 1 & ISO90012 & & \\
& 000, \\
& Montadora, \\
& Idade \\
& Empresa, \\
& Notade a \\
& Sistema & & \\
& & & Enter \\
& & & \\
\hline
\end{tabular}

a. All requested variables entered.

b. Dependent Variable: MargemLucro20022005

Model Summary

\begin{tabular}{|l|r|r|r|r|}
\hline Model & $\mathrm{R}$ & R Square & $\begin{array}{c}\text { Adjusted } \\
\text { R Square }\end{array}$ & $\begin{array}{r}\text { Std. Error of } \\
\text { the Estimate }\end{array}$ \\
\hline 1 &, $202^{\mathrm{a}}$ &, 041 &, 023 &, 07971 \\
\hline
\end{tabular}

a. Predictors: (Constant), ISO90012000, Montadora, IdadeEmpresa, NotadeSistema

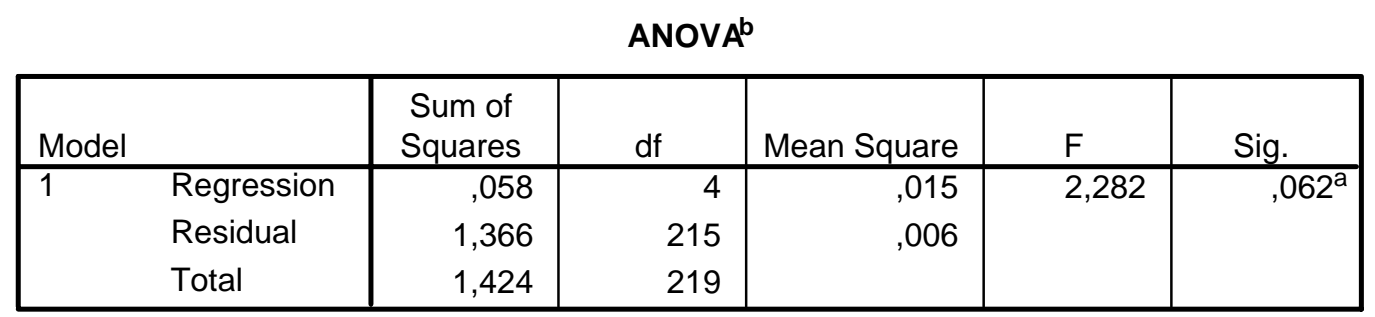

a. Predictors: (Constant), ISO90012000, Montadora, IdadeEmpresa, NotadeSistema

b. Dependent Variable: MargemLucro20022005

Coefficients $^{\mathrm{a}}$

\begin{tabular}{|ll|r|r|r|r|r|}
\hline \multirow{2}{*}{ Model } & \multicolumn{2}{|c|}{$\begin{array}{c}\text { Unstandardized } \\
\text { Coefficients }\end{array}$} & \multicolumn{2}{c|}{$\begin{array}{c}\text { Standardized } \\
\text { Coefficients }\end{array}$} & \multirow{2}{*}{} \\
\cline { 3 - 5 } & & \multicolumn{1}{|c|}{ B } & \multicolumn{1}{c|}{ Std. Error } & \multicolumn{1}{c|}{ Beta } & \multicolumn{1}{c|}{ Sig. } \\
\hline 1 & (Constant) &,- 030 &, 018 & & $-1,658$ &, 099 \\
& NotadeSistema &, 003 &, 007 &, 032 &, 349 &, 727 \\
& Montadora &, 003 &, 015 &, 015 &, 208 &, 835 \\
& IdadeEmpresa &, 001 &, 000 &, 166 & 2,437 &, 016 \\
& ISO90012000 &, 011 &, 014 &, 069 &, 809 &, 419 \\
\hline
\end{tabular}

a. Dependent Variable: MargemLucro20022005 
Apêndice 1: Estatísticas da Matriz Revisada

\section{Regression}

Variables Entered/Removedp

\begin{tabular}{|c|c|c|c|}
\hline Model & $\begin{array}{c}\text { Variables } \\
\text { Entered }\end{array}$ & $\begin{array}{l}\text { Variables } \\
\text { Removed }\end{array}$ & Method \\
\hline 1 & $\begin{array}{l}\text { ISO90012 } \\
\text { 000, } \\
\text { Montadora, } \\
\text { Idade } \\
\text { Empresa, } \\
\text { Notade a } \\
\text { Sistema }\end{array}$ & & Enter \\
\hline
\end{tabular}

a. All requested variables entered.

b. Dependent Variable: VariaçãoFaturamento20022005

Model Summary

\begin{tabular}{|l|r|r|r|r|}
\hline Model & \multicolumn{1}{|c|}{ R } & R Square & $\begin{array}{c}\text { Adjusted } \\
\text { R Square }\end{array}$ & $\begin{array}{r}\text { Std. Error of } \\
\text { the Estimate }\end{array}$ \\
\hline 1 &, $282^{\mathrm{a}}$ &, 080 &, 062 & 1,35878 \\
\hline
\end{tabular}

a. Predictors: (Constant), ISO90012000, Montadora, IdadeEmpresa, NotadeSistema

\begin{tabular}{|ll|r|r|r|r|r|}
\hline \multicolumn{1}{|c|}{ ANOVA $^{\text {b }}$} \\
Model & & $\begin{array}{c}\text { Sum of } \\
\text { Squares }\end{array}$ & df & Mean Square & F & Sig. \\
\hline 1 & Regression & 34,294 & 4 & 8,573 & 4,644 &, $001^{\mathrm{a}}$ \\
& Residual & 396,951 & 215 & 1,846 & & \\
& Total & 431,245 & 219 & & & \\
\hline
\end{tabular}

a. Predictors: (Constant), ISO90012000, Montadora, IdadeEmpresa, NotadeSistema

b. Dependent Variable: VariaçãoFaturamento20022005

Coefficients $^{\mathrm{a}}$

\begin{tabular}{|c|c|c|c|c|c|c|}
\hline \multirow{2}{*}{\multicolumn{2}{|c|}{ Model }} & \multicolumn{2}{|c|}{$\begin{array}{c}\text { Unstandardized } \\
\text { Coefficients }\end{array}$} & \multirow{2}{*}{$\begin{array}{c}\begin{array}{c}\text { Standardized } \\
\text { Coefficients }\end{array} \\
\text { Beta }\end{array}$} & \multirow[b]{2}{*}{$\mathrm{t}$} & \multirow[b]{2}{*}{ Sig. } \\
\hline & & B & Std. Error & & & \\
\hline \multirow[t]{5}{*}{1} & (Constant) & 1,205 & ,307 & & 3,919 &, 000 \\
\hline & NotadeSistema & 200 & 125 & 142 & 1,602 & 111 \\
\hline & Montadora &, 542 & ,258 & 151 & 2,100 & ,037 \\
\hline & IdadeEmpresa &,- 017 & ,007 &,- 152 & $-2,284$ & ,023 \\
\hline & ISO90012000 &,- 385 & 235 &,- 138 & $-1,640$ & 102 \\
\hline
\end{tabular}

a. Dependent Variable: VariaçãoFaturamento20022005 
Apêndice 1: Estatísticas da Matriz Revisada 


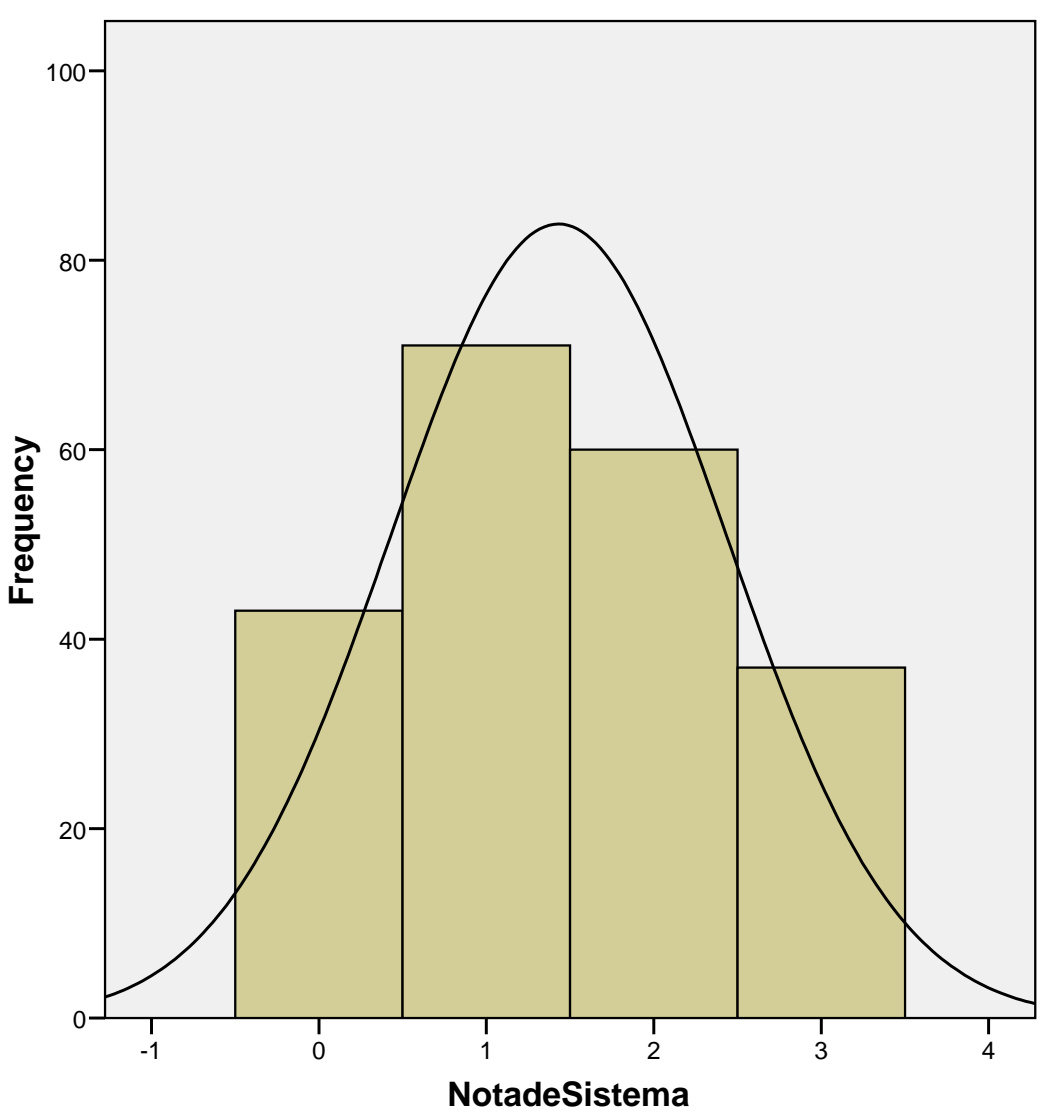
Mean $=1,43$
Std. Dev. $=1,004$

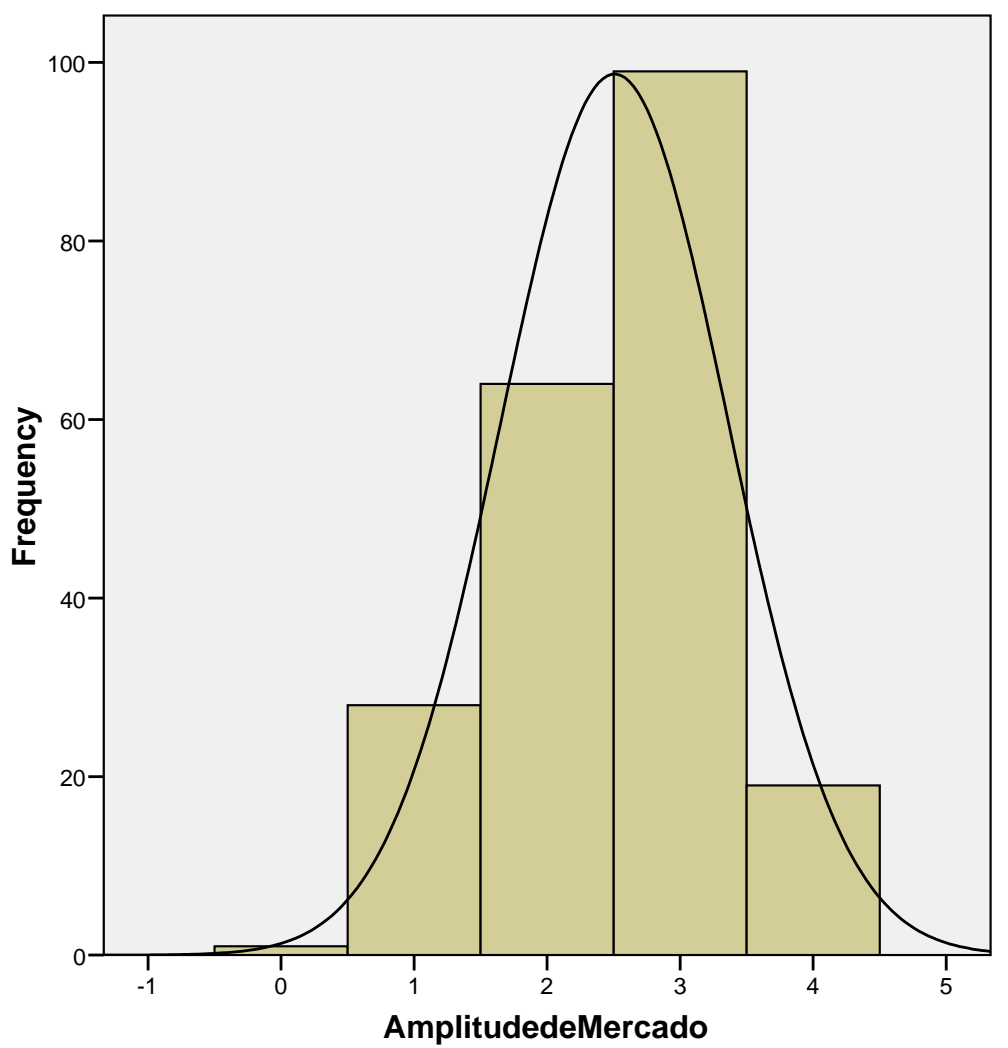




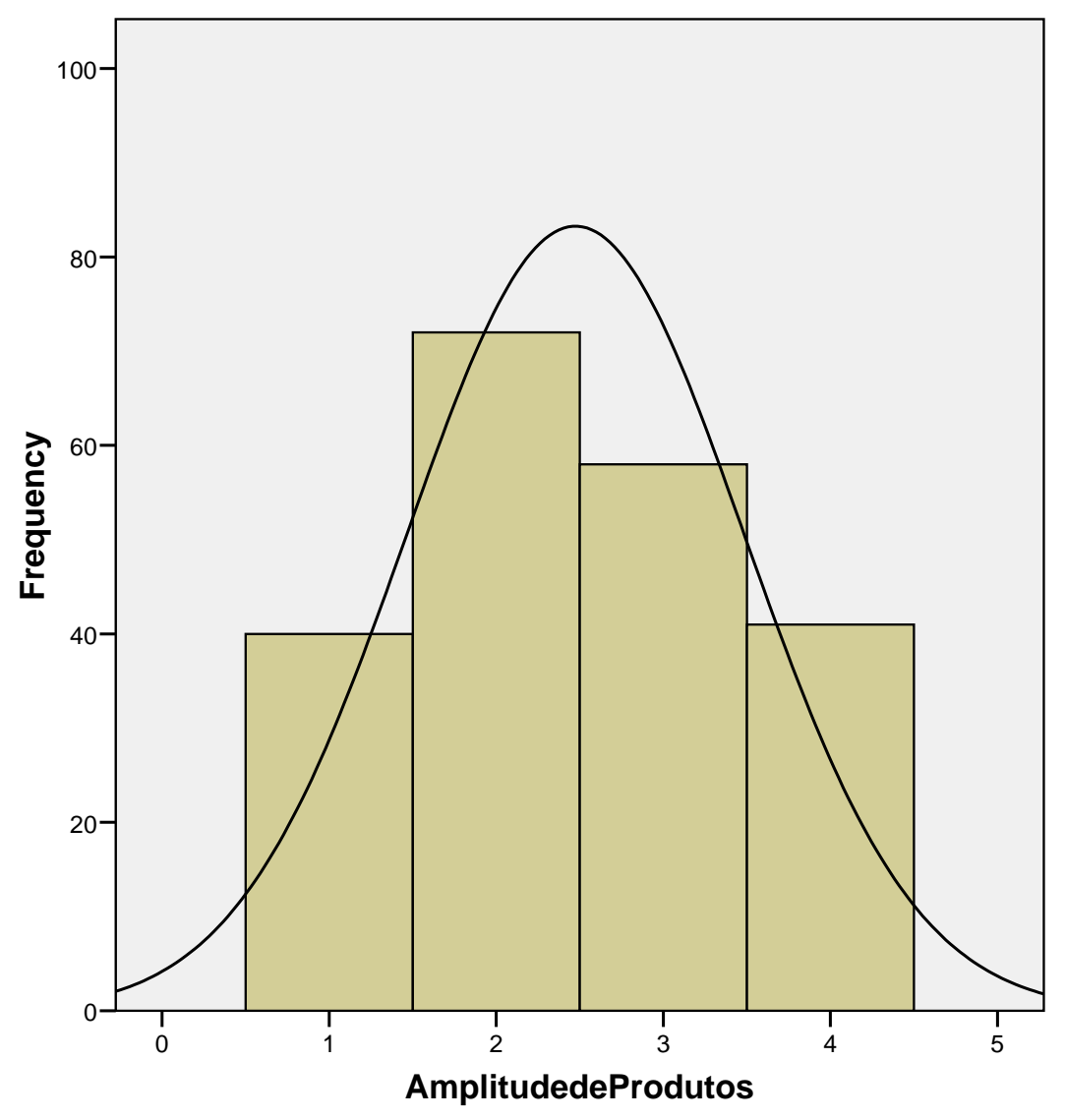
Std. Dev. $=1,011$ $\mathrm{N}=211$

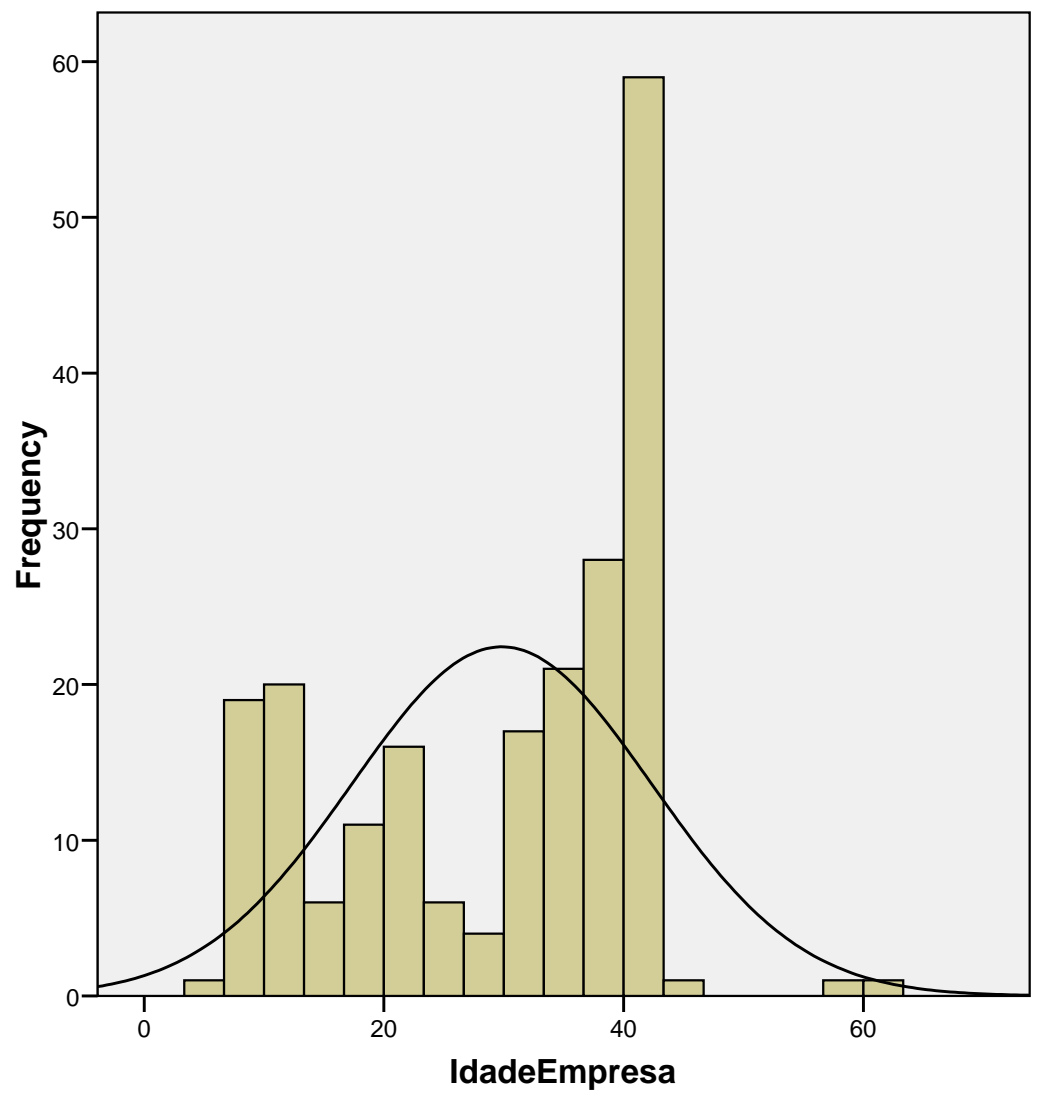

Mean $=29,83$ Mean $=29,83$
Std. Dev. $=12,516$ $\mathrm{N}=211$ 

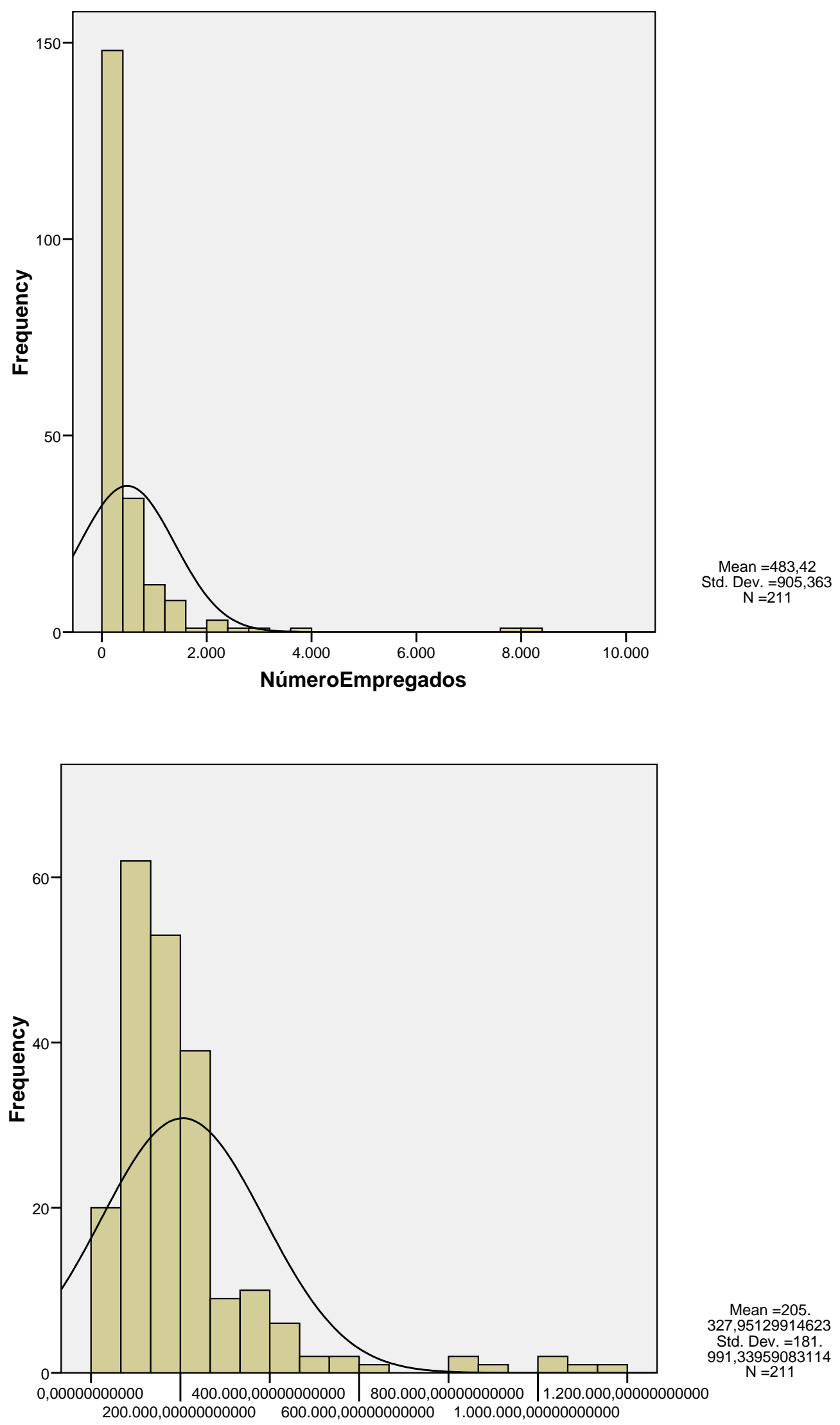

ProdutividadeR2005Empregado 

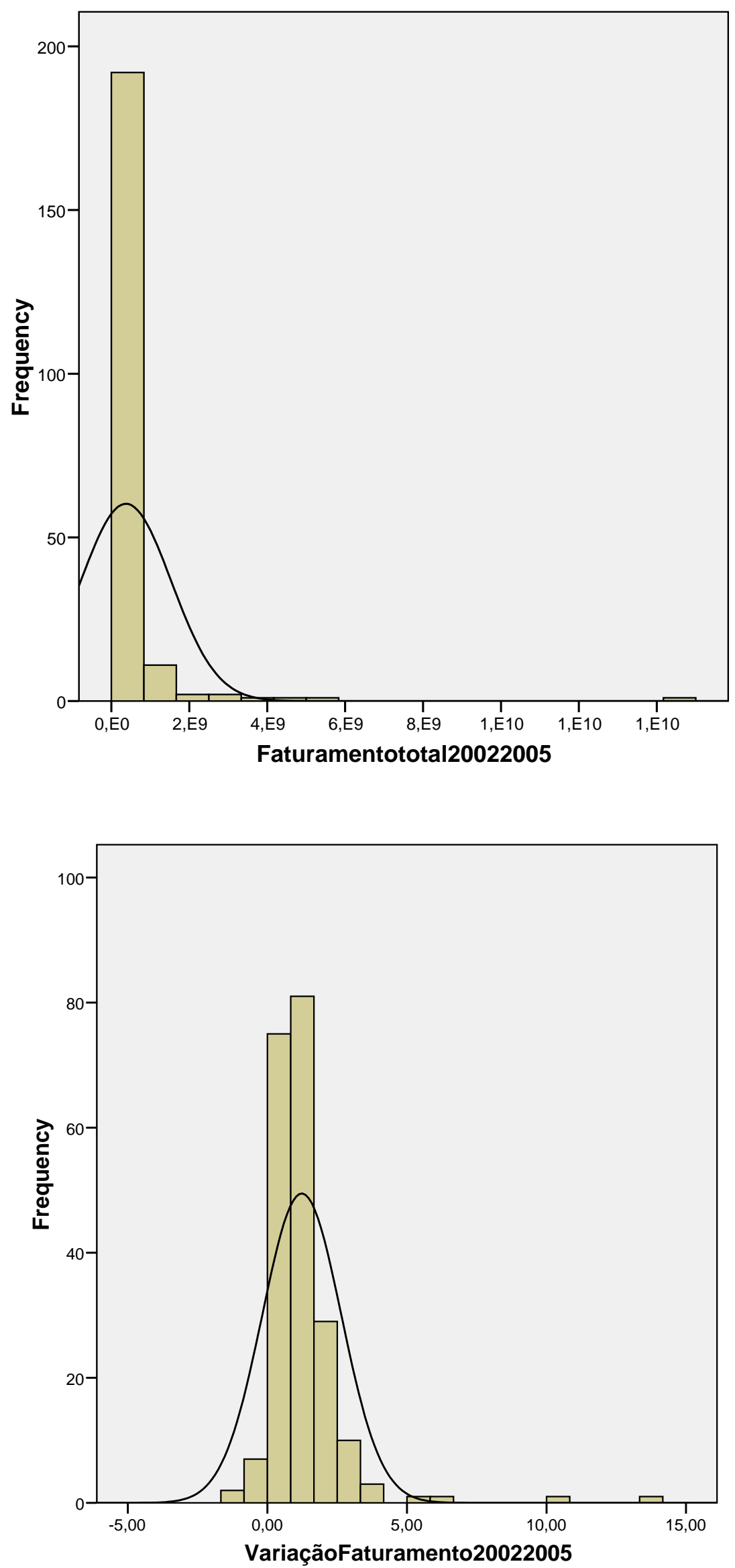

Mean $=1,2318$ Std. Dev. $=1,41787$ $\mathrm{N}=211$ 

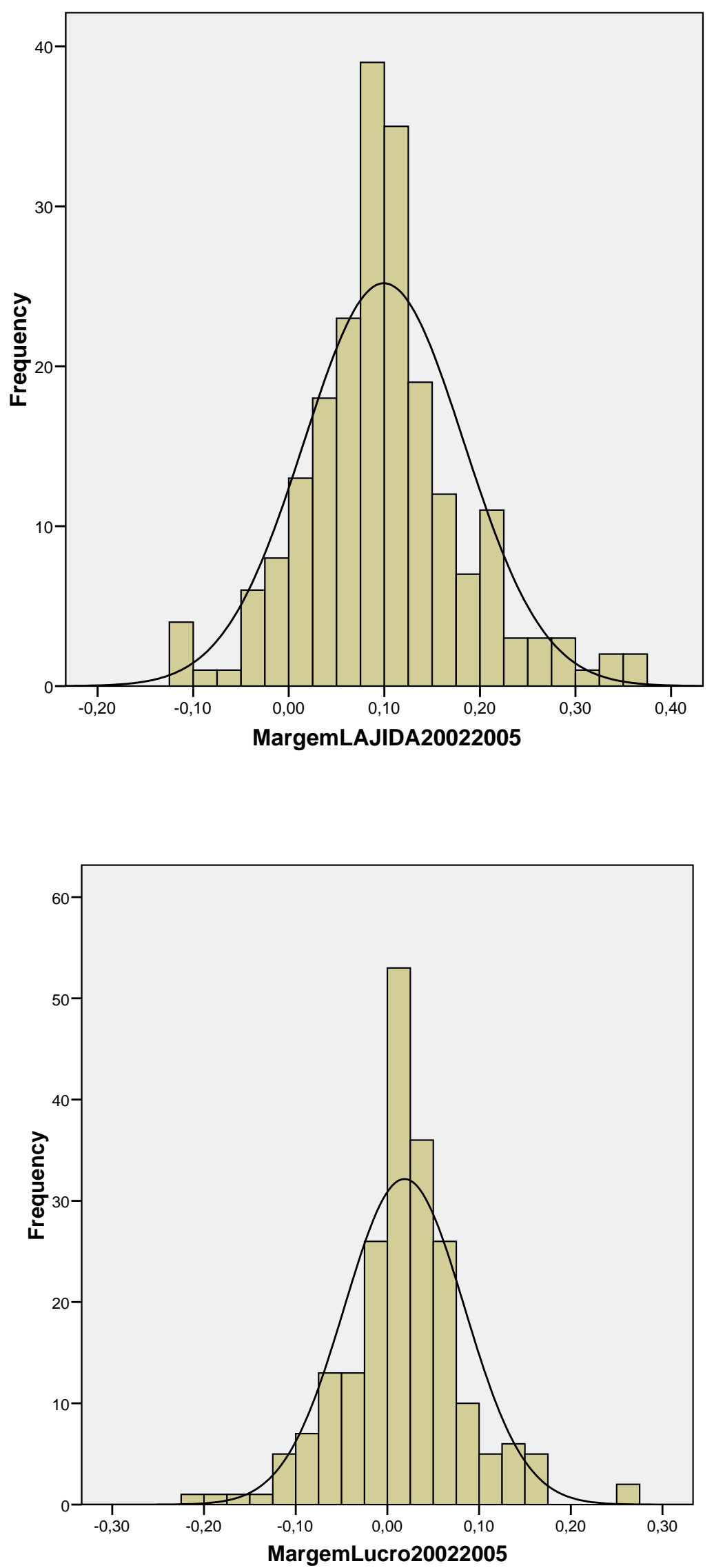


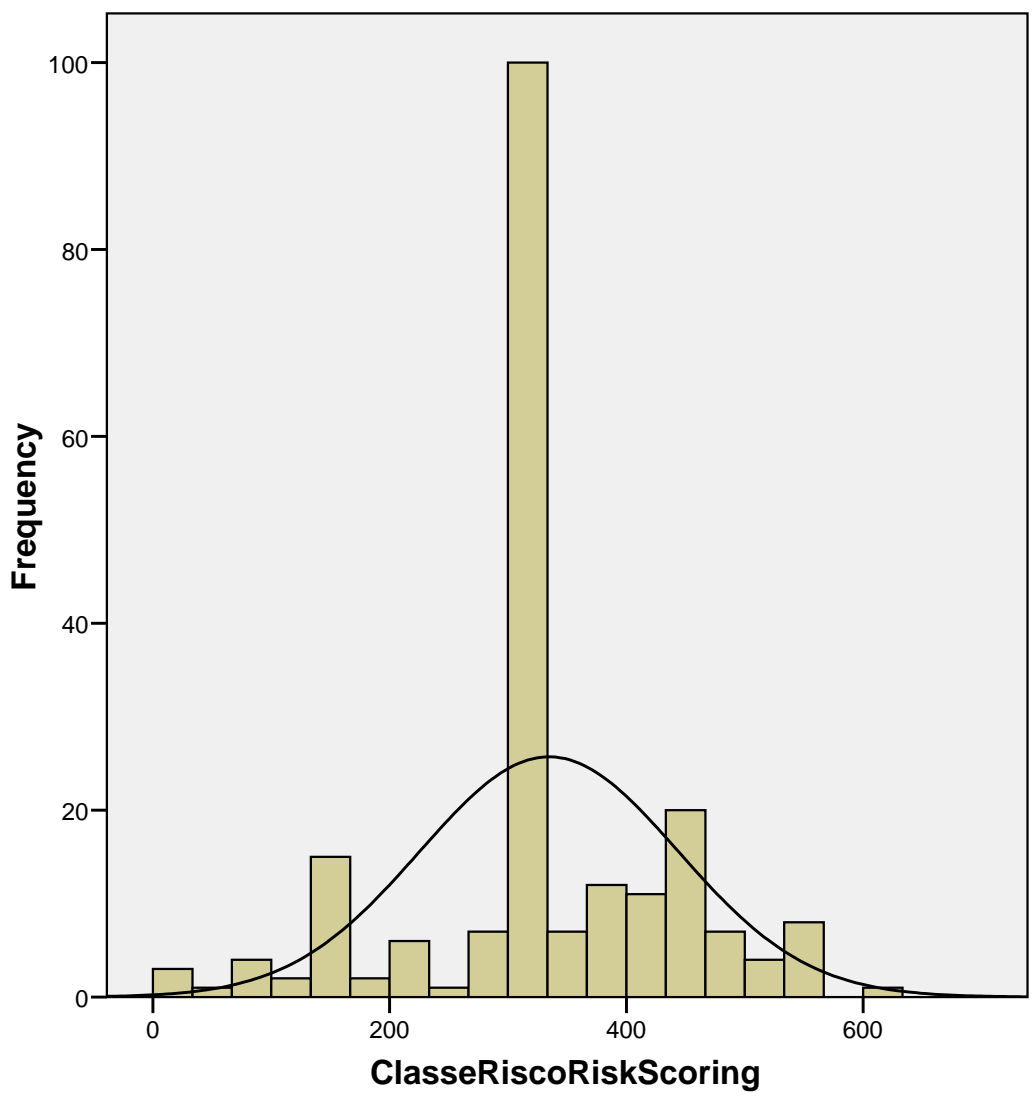

Mean $=334,61$ Std. Dev. $=109,155$ $\mathrm{N}=211$ 

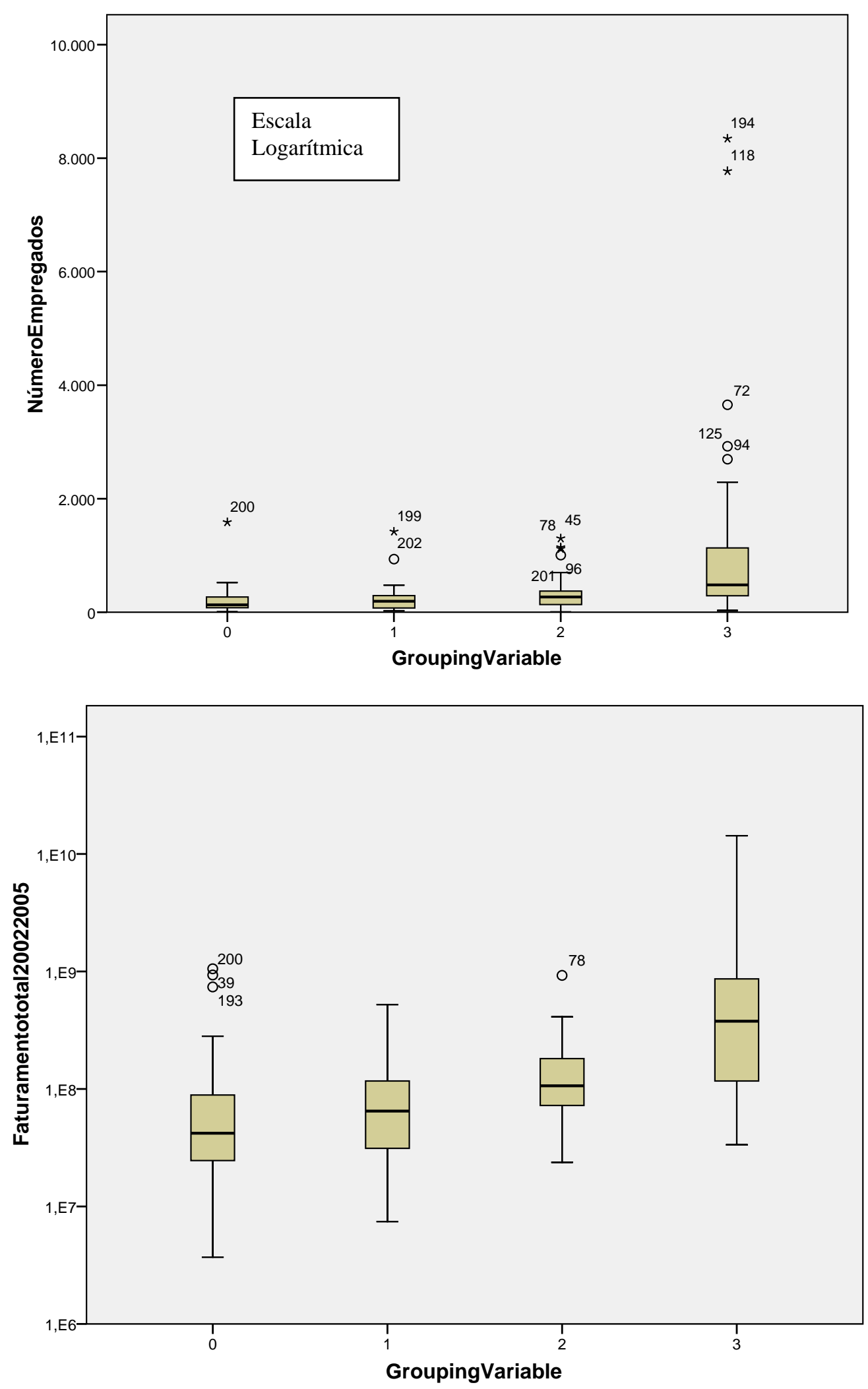

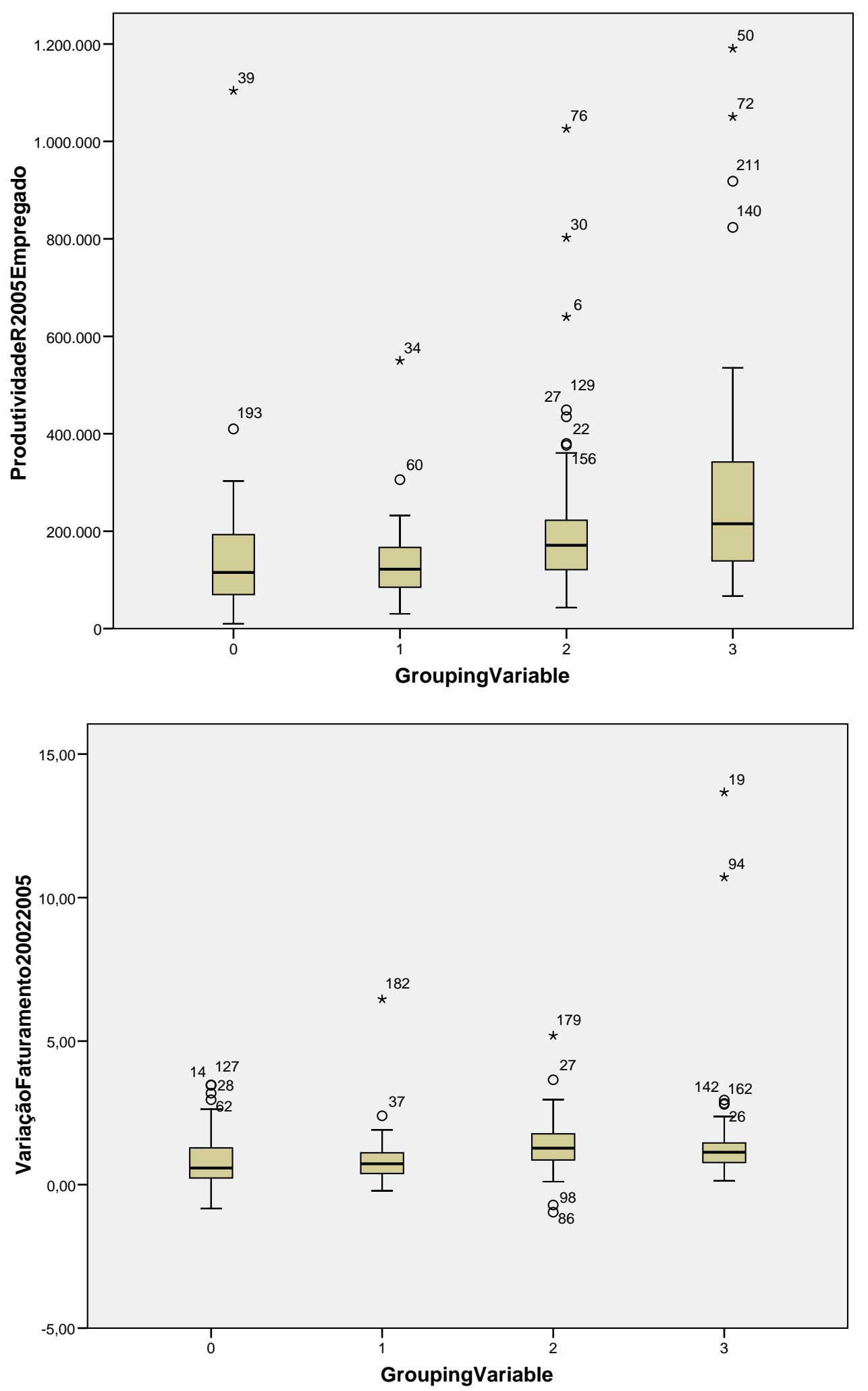

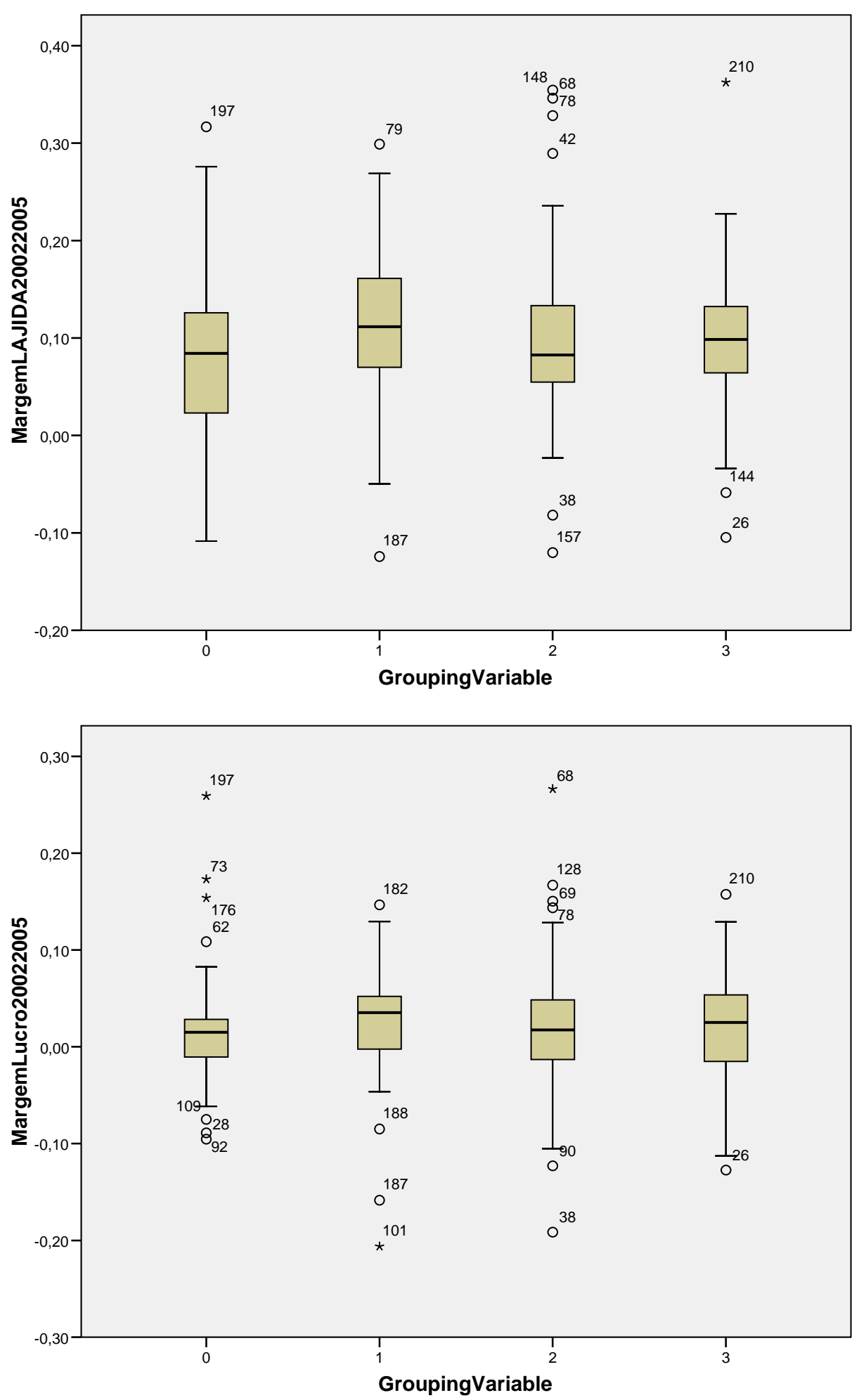


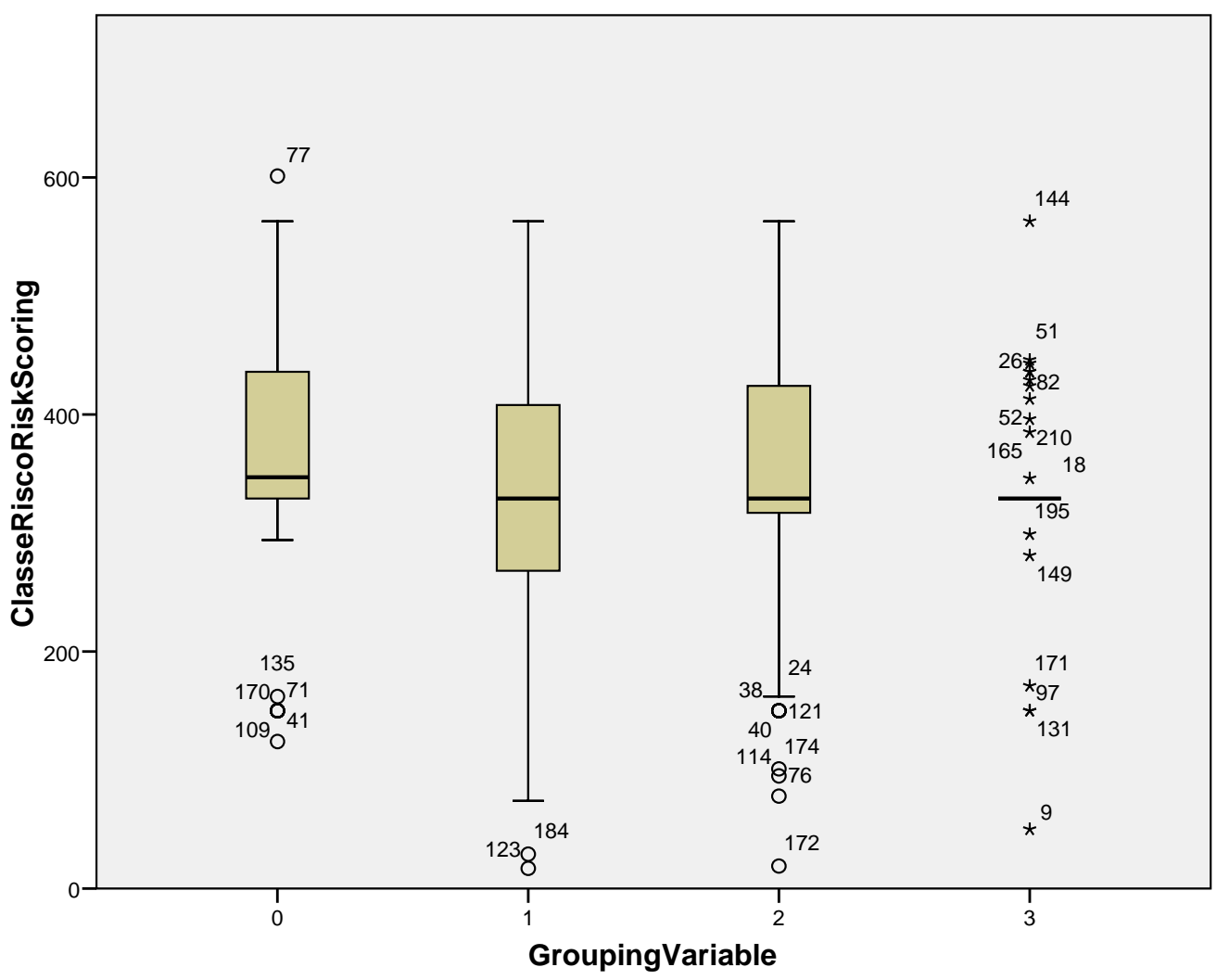


Group Statistics

\begin{tabular}{|ll|r|r|r|r|}
\hline & Grouping Variable & $\mathrm{N}$ & Mean & Std. Deviation & \multicolumn{1}{c|}{$\begin{array}{c}\text { Std. Error } \\
\text { Mean }\end{array}$} \\
\hline Variação Faturamento & Grupo 0 & 43 & $89,9484 \%$ & $101,85102 \%$ & 15,53214 \\
$2002-2005$ & Grupo 1 & 37 & $92,3296 \%$ & $110,95698 \%$ & 18,24122 \\
& & 43 & $7,9256 \%$ & $8,27874 \%$ & $1,26250 \%$ \\
Margem LAJIDA 2002- & Grupo 0 & 37 & $11,6873 \%$ & $8,90916 \%$ & $1,46466 \%$ \\
2005 & Grupo 1 & & & & \\
& & 43 & $1,6821 \%$ & $6,63715 \%$ & $1,01216 \%$ \\
Margem de Lucro 2002- & Grupo 0 & 37 & $2,3558 \%$ & $6,99466 \%$ & $1,14991 \%$ \\
2005 & Grupo 1 & 43 & 360,09 & 113,400 & 17,293 \\
Classe de Risco (Risk & Grupo 0 & 37 & 312,22 & 129,698 & 21,322 \\
Scoring) & Grupo 1 & &
\end{tabular}

Independent Samples Test

\begin{tabular}{|c|c|c|c|c|c|c|c|c|c|c|}
\hline & & \multicolumn{2}{|c|}{$\begin{array}{l}\text { Levene's Test for } \\
\text { Equality of Variances }\end{array}$} & \multicolumn{7}{|c|}{ t-test for Equality of Means } \\
\hline & & \multirow[b]{2}{*}{$\mathrm{F}$} & \multirow[b]{2}{*}{ Sig. } & \multirow[b]{2}{*}{$\mathrm{t}$} & \multirow[b]{2}{*}{ df } & \multirow[b]{2}{*}{ Sig. (2-tailed) } & \multirow{2}{*}{$\begin{array}{c}\text { Mean } \\
\text { Difference }\end{array}$} & \multirow{2}{*}{$\begin{array}{l}\text { Std. Error } \\
\text { Difference }\end{array}$} & \multicolumn{2}{|c|}{$\begin{array}{c}\text { 95\% Confidence Interva } \\
\text { of the Difference }\end{array}$} \\
\hline & & & & & & & & & Upper & Lower \\
\hline $\begin{array}{l}\text { Variação Faturamento } \\
\text { 2002-2005 }\end{array}$ & $\begin{array}{l}\text { Equal variances } \\
\text { assumed } \\
\text { Equal variances } \\
\text { not assumed }\end{array}$ & ,616 & ,435 & $\begin{array}{l}-, 100 \\
-, 099\end{array}$ & 73,851 & ,921 & $\begin{array}{l}-2,38126 \% \\
-2,38126 \%\end{array}$ & $\begin{array}{l}23,80310 \% \\
23,95807 \%\end{array}$ & $\begin{array}{r}- \\
49,76960 \\
\% \\
- \\
50,12036 \\
\%\end{array}$ & $\begin{array}{r}45,00707 \\
\% \\
45,35784 \\
\%\end{array}$ \\
\hline $\begin{array}{l}\text { Margem LAJIDA 2002- } \\
2005\end{array}$ & $\begin{array}{l}\text { Equal variances } \\
\text { assumed }\end{array}$ &, 017 & ,898 & $-1,956$ & 78 &, 054 & $-3,76173 \%$ & $1,92295 \%$ & $-7,59002 \%$ &, $06657 \%$ \\
\hline & $\begin{array}{l}\text { Equal variances } \\
\text { not assumed }\end{array}$ & & & $-1,945$ & 74,240 & ,056 & $-3,76173 \%$ & $1,93368 \%$ & $-7,61446 \%$ & ,09101\% \\
\hline $\begin{array}{l}\text { Margem de Lucro 2002- } \\
2005\end{array}$ & $\begin{array}{l}\text { Equal variances } \\
\text { assumed }\end{array}$ &, 257 &, 614 &,- 442 & 78 & 660 &,$- 67371 \%$ & $1,52583 \%$ & $-3,71140 \%$ & $2,36398 \%$ \\
\hline & $\begin{array}{l}\text { Equal variances } \\
\text { not assumed }\end{array}$ & & &,- 440 & 74,871 & ,661 &,$- 67371 \%$ & $1,53192 \%$ & $-3,72553 \%$ & $2,37811 \%$ \\
\hline $\begin{array}{l}\text { Classe de Risco (Risk } \\
\text { Scoring) }\end{array}$ & $\begin{array}{l}\text { Equal variances } \\
\text { assumed }\end{array}$ &, 557 & ,458 & 1,762 & 78 & ,082 & 47,877 & 27,177 & $-6,227$ & 101,981 \\
\hline & $\begin{array}{l}\text { Equal variances } \\
\text { not assumed }\end{array}$ & & & 1,744 & 72,171 & ,085 & 47,877 & 27,454 & $-6,849$ & 102,602 \\
\hline
\end{tabular}


Group Statistics

\begin{tabular}{|ll|r|r|r|r|}
\hline & Grouping Variable & $\mathrm{N}$ & Mean & Std. Deviation & \multicolumn{1}{c|}{$\begin{array}{c}\text { Std. Error } \\
\text { Mean }\end{array}$} \\
\hline Variação Faturamento & Grupo 0 & 43 & $89,9484 \%$ & $101,85102 \%$ & 15,53214 \\
$2002-2005$ & Grupo 2 & & 134,9233 & $92,42985 \%$ & 11,12725 \\
& & 69 & $\%$ & $\%$ \\
Margem LAJIDA 2002- & Grupo 0 & 43 & $7,9256 \%$ & $8,27874 \%$ & $1,26250 \%$ \\
2005 & Grupo 2 & & & & \\
& & 69 & $10,0774 \%$ & $8,73000 \%$ & $1,05097 \%$ \\
Margem de Lucro 2002-- Grupo 0 & 43 & $1,6821 \%$ & $6,63715 \%$ & $1,01216 \%$ \\
2005 & Grupo 2 & 69 & $1,6242 \%$ & $7,07573 \%$ &, $85182 \%$ \\
Classe de Risco (Risk & Grupo 0 & 43 & 360,09 & 113,400 & 17,293 \\
Scoring) & Grupo 2 & 69 & 332,52 & 121,378 & 14,612 \\
\hline
\end{tabular}

Independent Samples Test

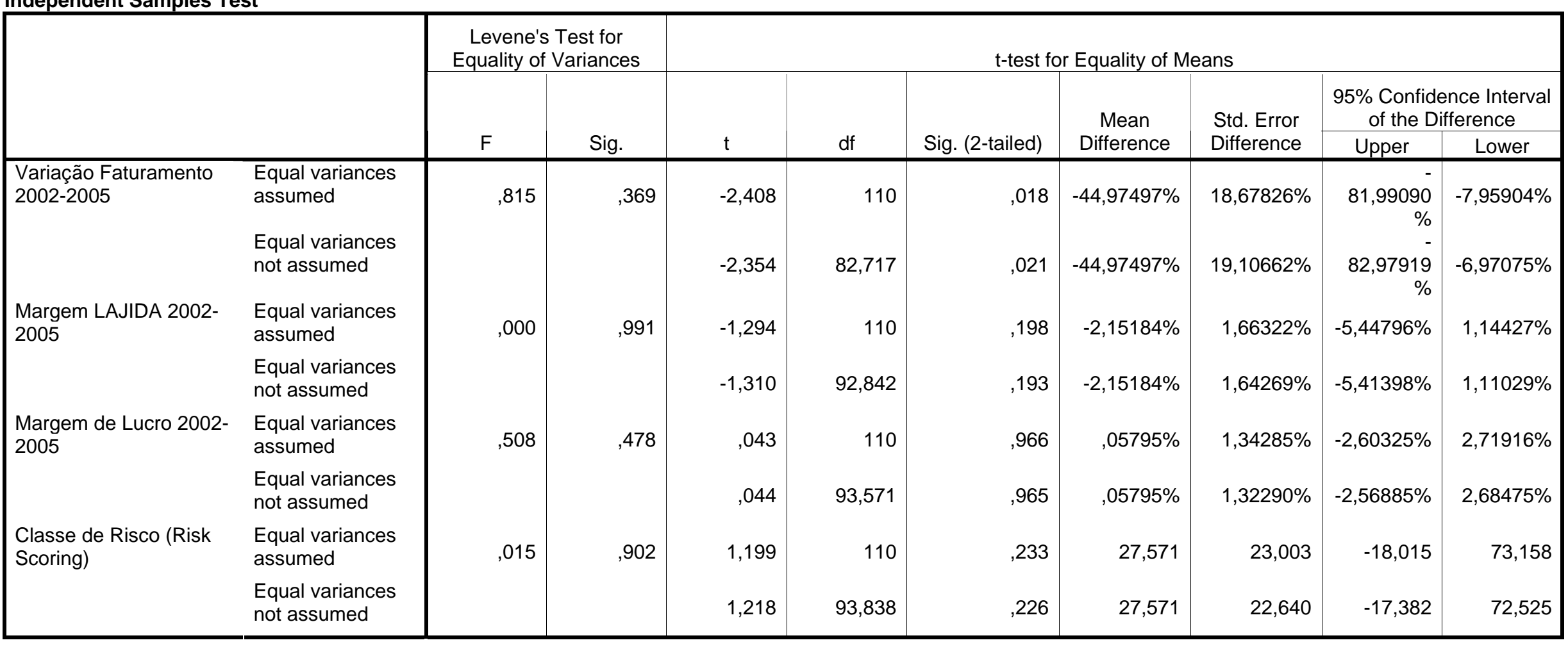


Group Statistics

\begin{tabular}{|c|c|c|c|c|c|}
\hline & Grouping Variable & $\mathrm{N}$ & Mean & Std. Deviation & $\begin{array}{l}\text { Std. Error } \\
\text { Mean }\end{array}$ \\
\hline \multirow{2}{*}{$\begin{array}{l}\text { Variação Faturamento } \\
2002-2005\end{array}$} & Grupo 0 & 43 & $89,9484 \%$ & $101,85102 \%$ & $\begin{array}{r}15,53214 \\
\%\end{array}$ \\
\hline & Grupo 3 & 62 & $\begin{array}{r}151,5678 \\
\%\end{array}$ & $207,23490 \%$ & $\begin{array}{r}26,31886 \\
\%\end{array}$ \\
\hline \multirow{2}{*}{$\begin{array}{l}\text { Margem LAJIDA 2002- } \\
2005\end{array}$} & Grupo 0 & 43 & $7,9256 \%$ & $8,27874 \%$ & $1,26250 \%$ \\
\hline & Grupo 3 & 62 & $10,1912 \%$ & $7,51459 \%$ & ,95435\% \\
\hline \multirow{2}{*}{$\begin{array}{l}\text { Margem de Lucro 2002- } \\
2005\end{array}$} & Grupo 0 & 43 & $1,6821 \%$ & $6,63715 \%$ & $1,01216 \%$ \\
\hline & Grupo 3 & 62 & $1,9385 \%$ & $5,66890 \%$ & ,71995\% \\
\hline \multirow{2}{*}{$\begin{array}{l}\text { Classe de Risco (Risk } \\
\text { Scoring) }\end{array}$} & Grupo 0 & 43 & 360,09 & 113,400 & 17,293 \\
\hline & Grupo 3 & 62 & 332,63 & 71,012 & 9,019 \\
\hline
\end{tabular}

Independent Samples Test

\begin{tabular}{|c|c|c|c|c|c|c|c|c|c|c|}
\hline & & \multicolumn{2}{|c|}{$\begin{array}{l}\text { Levene's Test for } \\
\text { Equality of Variances }\end{array}$} & \multicolumn{7}{|c|}{ t-test for Equality of Means } \\
\hline & & \multirow[b]{2}{*}{$\mathrm{F}$} & \multirow[b]{2}{*}{ Sig. } & \multirow[b]{2}{*}{$\mathrm{t}$} & \multirow[b]{2}{*}{ df } & \multirow[b]{2}{*}{ Sig. (2-tailed) } & \multirow{2}{*}{$\begin{array}{c}\text { Mean } \\
\text { Difference }\end{array}$} & \multirow{2}{*}{$\begin{array}{l}\text { Std. Error } \\
\text { Difference }\end{array}$} & \multicolumn{2}{|c|}{$\begin{array}{c}\text { 95\% Confidence Interval } \\
\text { of the Difference }\end{array}$} \\
\hline & & & & & & & & & Upper & Lower \\
\hline $\begin{array}{l}\text { Variação Faturamento } \\
\text { 2002-2005 }\end{array}$ & $\begin{array}{l}\text { Equal variances } \\
\text { assumed } \\
\text { Equal variances } \\
\text { not assumed }\end{array}$ & ,244 & ,622 & $\begin{array}{l}-1,803 \\
-2,016\end{array}$ & 103 & ,074 & $\begin{array}{l}-61,61943 \% \\
-61,61943 \%\end{array}$ & $\begin{array}{l}34,18072 \% \\
30,56026 \%\end{array}$ & $\begin{array}{r}- \\
129,40882 \\
\% \\
- \\
122,29519 \\
\%\end{array}$ & $\begin{array}{r}6,16997 \% \\
-, 94366 \%\end{array}$ \\
\hline $\begin{array}{l}\text { Margem LAJIDA 2002- } \\
2005\end{array}$ & $\begin{array}{l}\text { Equal variances } \\
\text { assumed }\end{array}$ &, 702 & ,404 & $-1,457$ & 103 & ,148 & $-2,26560 \%$ & $1,55494 \%$ & $-5,34946 \%$ & ,81826\% \\
\hline & $\begin{array}{l}\text { Equal variances } \\
\text { not assumed }\end{array}$ & & & $-1,432$ & 84,677 & ,156 & $-2,26560 \%$ & $1,58262 \%$ & $-5,41244 \%$ & ,88125\% \\
\hline $\begin{array}{l}\text { Margem de Lucro 2002- } \\
2005\end{array}$ & $\begin{array}{l}\text { Equal variances } \\
\text { assumed }\end{array}$ &, 000 & ,996 &,- 212 & 103 & ,832 &,$- 25637 \%$ & $1,20708 \%$ & $-2,65034 \%$ & $2,13759 \%$ \\
\hline & $\begin{array}{l}\text { Equal variances } \\
\text { not assumed }\end{array}$ & & &,- 206 & 80,979 & ,837 &,$- 25637 \%$ & $1,24209 \%$ & $-2,72775 \%$ & $2,21501 \%$ \\
\hline $\begin{array}{l}\text { Classe de Risco (Risk } \\
\text { Scoring) }\end{array}$ & $\begin{array}{l}\text { Equal variances } \\
\text { assumed }\end{array}$ & 14,397 & ,000 & 1,525 & 103 & ,130 & 27,464 & 18,004 & $-8,243$ & 63,171 \\
\hline & $\begin{array}{l}\text { Equal variances } \\
\text { not assumed }\end{array}$ & & & 1,408 & 64,659 & ,164 & 27,464 & 19,504 & $-11,491$ & 66,419 \\
\hline
\end{tabular}


Group Statistics

\begin{tabular}{|c|c|c|c|c|c|}
\hline & Grouping Variable & $\mathrm{N}$ & Mean & Std. Deviation & $\begin{array}{l}\text { Std. Error } \\
\text { Mean }\end{array}$ \\
\hline \multirow[t]{2}{*}{$\begin{array}{l}\text { Variação Faturamento } \\
\text { 2002-2005 }\end{array}$} & Grupo 1 & 37 & $92,3296 \%$ & $110,95698 \%$ & $\begin{array}{r}18,24122 \\
\%\end{array}$ \\
\hline & Grupo 2 & 69 & $\begin{array}{r}134,9233 \\
\%\end{array}$ & $92,42985 \%$ & $\begin{array}{r}11,12725 \\
\%\end{array}$ \\
\hline \multirow{2}{*}{$\begin{array}{l}\text { Margem LAJIDA 2002- } \\
2005\end{array}$} & Grupo 1 & 37 & $11,6873 \%$ & $8,90916 \%$ & $1,46466 \%$ \\
\hline & Grupo 2 & 69 & $10,0774 \%$ & $8,73000 \%$ & $1,05097 \%$ \\
\hline \multirow{2}{*}{$\begin{array}{l}\text { Margem de Lucro 2002- } \\
2005\end{array}$} & Grupo 1 & 37 & $2,3558 \%$ & $6,99466 \%$ & $1,14991 \%$ \\
\hline & Grupo 2 & 69 & $1,6242 \%$ & $7,07573 \%$ &, $85182 \%$ \\
\hline \multirow{2}{*}{$\begin{array}{l}\text { Classe de Risco (Risk } \\
\text { Scoring) }\end{array}$} & Grupo 1 & 37 & 312,22 & 129,698 & 21,322 \\
\hline & Grupo 2 & 69 & 332,52 & 121,378 & 14,612 \\
\hline
\end{tabular}

Independent Samples Test

\begin{tabular}{|c|c|c|c|c|c|c|c|c|c|c|}
\hline & & \multicolumn{2}{|c|}{$\begin{array}{l}\text { Levene's Test for } \\
\text { Equality of Variances }\end{array}$} & \multicolumn{7}{|c|}{ t-test for Equality of Means } \\
\hline & & \multirow[b]{2}{*}{$\mathrm{F}$} & \multirow[b]{2}{*}{ Sig. } & \multirow[b]{2}{*}{$\mathrm{t}$} & \multirow[b]{2}{*}{ df } & \multirow[b]{2}{*}{ Sig. (2-tailed) } & \multirow{2}{*}{$\begin{array}{c}\text { Mean } \\
\text { Difference }\end{array}$} & \multirow{2}{*}{$\begin{array}{l}\text { Std. Error } \\
\text { Difference }\end{array}$} & \multicolumn{2}{|c|}{$\begin{array}{c}\text { 95\% Confidence Interval } \\
\text { of the Difference }\end{array}$} \\
\hline & & & & & & & & & Upper & Lower \\
\hline $\begin{array}{l}\text { Variação Faturamento } \\
\text { 2002-2005 }\end{array}$ & $\begin{array}{l}\text { Equal variances } \\
\text { assumed } \\
\text { Equal variances } \\
\text { not assumed }\end{array}$ & ,024 & ,877 & $\begin{array}{l}-2,106 \\
-1,993\end{array}$ & 104 & ,038 & $\begin{array}{l}-42,59371 \% \\
-42,59371 \%\end{array}$ & $\begin{array}{l}20,22059 \% \\
21,36721 \%\end{array}$ & $\begin{array}{r}- \\
82,69189 \\
\% \\
- \\
85,29071 \\
\%\end{array}$ & $\begin{array}{r}-2,49553 \% \\
, 10330 \%\end{array}$ \\
\hline $\begin{array}{l}\text { Margem LAJIDA 2002- } \\
2005\end{array}$ & $\begin{array}{l}\text { Equal variances } \\
\text { assumed }\end{array}$ & ,021 & ,886 & ,899 & 104 & ,371 & $1,60988 \%$ & $1,79158 \%$ & $-1,94289 \%$ & $5,16266 \%$ \\
\hline & $\begin{array}{l}\text { Equal variances } \\
\text { not assumed }\end{array}$ & & & ,893 & 72,447 & ,375 & $1,60988 \%$ & $1,80271 \%$ & $-1,98337 \%$ & $5,20314 \%$ \\
\hline $\begin{array}{l}\text { Margem de Lucro 2002- } \\
2005\end{array}$ & $\begin{array}{l}\text { Equal variances } \\
\text { assumed }\end{array}$ &, 015 & ,902 &, 509 & 104 & ,611 & ,73166\% & $1,43608 \%$ & $-2,11614 \%$ & $3,57946 \%$ \\
\hline & $\begin{array}{l}\text { Equal variances } \\
\text { not assumed }\end{array}$ & & &, 511 & 74,476 & ,611 & ,73166\% & $1,43105 \%$ & $-2,11946 \%$ & $3,58278 \%$ \\
\hline $\begin{array}{l}\text { Classe de Risco (Risk } \\
\text { Scoring) }\end{array}$ & $\begin{array}{l}\text { Equal variances } \\
\text { assumed }\end{array}$ &, 736 & ,393 &,- 802 & 104 & ,425 & $-20,306$ & 25,332 & $-70,540$ & 29,929 \\
\hline & $\begin{array}{l}\text { Equal variances } \\
\text { not assumed }\end{array}$ & & &,- 786 & 69,624 & ,435 & $-20,306$ & 25,849 & $-71,864$ & 31,253 \\
\hline
\end{tabular}


Apêndice 2: Estatísticas da Matriz sem Extremos (outliers)

Group Statistics

\begin{tabular}{|c|c|c|c|c|c|}
\hline & Grouping Variable & $\mathrm{N}$ & Mean & Std. Deviation & $\begin{array}{l}\text { Std. Error } \\
\text { Mean }\end{array}$ \\
\hline \multirow{2}{*}{$\begin{array}{l}\text { Variação Faturamento } \\
2002-2005\end{array}$} & Grupo 1 & 37 & $92,3296 \%$ & $110,95698 \%$ & $\begin{array}{r}18,24122 \\
\%\end{array}$ \\
\hline & Grupo 3 & 62 & $\begin{array}{r}151,5678 \\
\%\end{array}$ & $207,23490 \%$ & $\begin{array}{r}26,31886 \\
\%\end{array}$ \\
\hline \multirow{2}{*}{$\begin{array}{l}\text { Margem LAJIDA 2002- } \\
2005\end{array}$} & Grupo 1 & 37 & $11,6873 \%$ & $8,90916 \%$ & $1,46466 \%$ \\
\hline & Grupo 3 & 62 & $10,1912 \%$ & $7,51459 \%$ & ,95435\% \\
\hline \multirow{2}{*}{$\begin{array}{l}\text { Margem de Lucro 2002- } \\
2005\end{array}$} & Grupo 1 & 37 & $2,3558 \%$ & $6,99466 \%$ & $1,14991 \%$ \\
\hline & Grupo 3 & 62 & $1,9385 \%$ & $5,66890 \%$ & ,71995\% \\
\hline \multirow{2}{*}{$\begin{array}{l}\text { Classe de Risco (Risk } \\
\text { Scoring) }\end{array}$} & Grupo 1 & 37 & 312,22 & 129,698 & 21,322 \\
\hline & Grupo 3 & 62 & 332,63 & 71,012 & 9,019 \\
\hline
\end{tabular}

Independent Samples Test

\begin{tabular}{|c|c|c|c|c|c|c|c|c|c|c|}
\hline & & \multicolumn{2}{|c|}{$\begin{array}{l}\text { Levene's Test for } \\
\text { Equality of Variances }\end{array}$} & \multicolumn{7}{|c|}{ t-test for Equality of Means } \\
\hline & & \multirow[b]{2}{*}{$\mathrm{F}$} & \multirow[b]{2}{*}{ Sig. } & \multirow[b]{2}{*}{$\mathrm{t}$} & \multirow[b]{2}{*}{ df } & \multirow[b]{2}{*}{ Sig. (2-tailed) } & \multirow{2}{*}{$\begin{array}{c}\text { Mean } \\
\text { Difference }\end{array}$} & \multirow{2}{*}{$\begin{array}{l}\text { Std. Error } \\
\text { Difference }\end{array}$} & \multicolumn{2}{|c|}{$\begin{array}{c}95 \% \text { Confidence Interval } \\
\text { of the Difference }\end{array}$} \\
\hline & & & & & & & & & Upper & Lower \\
\hline $\begin{array}{l}\text { Variação Faturamento } \\
\text { 2002-2005 }\end{array}$ & $\begin{array}{l}\text { Equal variances } \\
\text { assumed } \\
\text { Equal variances } \\
\text { not assumed }\end{array}$ & ,754 & ,387 & $\begin{array}{l}-1,605 \\
-1,850\end{array}$ & 96,104 & ,112 & $\begin{array}{l}-59,23816 \% \\
-59,23816 \%\end{array}$ & $\begin{array}{l}36,91510 \% \\
32,02225 \%\end{array}$ & $\begin{array}{r}- \\
132,50441 \\
\% \\
- \\
122,80094 \\
\%\end{array}$ & $\begin{array}{r}14,02809 \\
\% \\
4,32462 \%\end{array}$ \\
\hline $\begin{array}{l}\text { Margem LAJIDA 2002- } \\
2005\end{array}$ & $\begin{array}{l}\text { Equal variances } \\
\text { assumed }\end{array}$ & ,813 & ,370 & ,893 & 97 & ,374 & $1,49613 \%$ & $1,67446 \%$ & $-1,82722 \%$ & $4,81948 \%$ \\
\hline & $\begin{array}{l}\text { Equal variances } \\
\text { not assumed }\end{array}$ & & & ,856 & 66,033 & ,395 & $1,49613 \%$ & $1,74815 \%$ & $-1,99412 \%$ & $4,98638 \%$ \\
\hline $\begin{array}{l}\text { Margem de Lucro 2002- } \\
2005\end{array}$ & $\begin{array}{l}\text { Equal variances } \\
\text { assumed }\end{array}$ & ,414 &, 522 & ,324 & 97 & ,746 & ,41734\% & $1,28677 \%$ & $-2,13655 \%$ & $2,97122 \%$ \\
\hline & $\begin{array}{l}\text { Equal variances } \\
\text { not assumed }\end{array}$ & & & ,308 & 63,955 & ,759 &, $41734 \%$ & $1,35670 \%$ & $-2,29302 \%$ & $3,12769 \%$ \\
\hline $\begin{array}{l}\text { Classe de Risco (Risk } \\
\text { Scoring) }\end{array}$ & $\begin{array}{l}\text { Equal variances } \\
\text { assumed }\end{array}$ & 18,835 &, 000 & $-1,013$ & 97 & ,314 & $-20,413$ & 20,157 & $-60,418$ & 19,592 \\
\hline & $\begin{array}{l}\text { Equal variances } \\
\text { not assumed }\end{array}$ & & &,- 882 & 49,105 & ,382 & $-20,413$ & 23,151 & $-66,934$ & 26,109 \\
\hline
\end{tabular}


Group Statistics

\begin{tabular}{|c|c|c|c|c|c|}
\hline & Grouping Variable & $\mathrm{N}$ & Mean & Std. Deviation & $\begin{array}{l}\text { Std. Error } \\
\text { Mean }\end{array}$ \\
\hline \multirow[t]{2}{*}{$\begin{array}{l}\text { Variação Faturamento } \\
2002-2005\end{array}$} & Grupo 2 & 69 & $\begin{array}{r}134,9233 \\
\%\end{array}$ & $92,42985 \%$ & $\begin{array}{r}11,12725 \\
\%\end{array}$ \\
\hline & Grupo 3 & 62 & $\begin{array}{r}151,5678 \\
\%\end{array}$ & $207,23490 \%$ & $\begin{array}{r}26,31886 \\
\%\end{array}$ \\
\hline \multirow{2}{*}{$\begin{array}{l}\text { Margem LAJIDA 2002- } \\
2005\end{array}$} & Grupo 2 & 69 & $10,0774 \%$ & $8,73000 \%$ & $1,05097 \%$ \\
\hline & Grupo 3 & 62 & $10,1912 \%$ & $7,51459 \%$ & ,95435\% \\
\hline \multirow{2}{*}{$\begin{array}{l}\text { Margem de Lucro 2002- } \\
2005\end{array}$} & Grupo 2 & 69 & $1,6242 \%$ & $7,07573 \%$ & ,85182\% \\
\hline & Grupo 3 & 62 & $1,9385 \%$ & $5,66890 \%$ & ,71995\% \\
\hline \multirow{2}{*}{$\begin{array}{l}\text { Classe de Risco (Risk } \\
\text { Scoring) }\end{array}$} & Grupo 2 & 69 & 332,52 & 121,378 & 14,612 \\
\hline & Grupo 3 & 62 & 332,63 & 71,012 & 9,019 \\
\hline
\end{tabular}

Independent Samples Test

\begin{tabular}{|c|c|c|c|c|c|c|c|c|c|c|}
\hline & & \multicolumn{2}{|c|}{$\begin{array}{l}\text { Levene's Test for } \\
\text { Equality of Variances }\end{array}$} & \multicolumn{7}{|c|}{ t-test for Equality of Means } \\
\hline & & \multirow[b]{2}{*}{$\mathrm{F}$} & \multirow[b]{2}{*}{ Sig. } & \multirow[b]{2}{*}{$\mathrm{t}$} & \multirow[b]{2}{*}{$d f$} & \multirow[b]{2}{*}{ Sig. (2-tailed) } & \multirow{2}{*}{$\begin{array}{c}\text { Mean } \\
\text { Difference }\end{array}$} & \multirow{2}{*}{$\begin{array}{l}\text { Std. Error } \\
\text { Difference }\end{array}$} & \multicolumn{2}{|c|}{$\begin{array}{c}95 \% \text { Confidence Interval } \\
\text { of the Difference }\end{array}$} \\
\hline & & & & & & & & & Upper & Lower \\
\hline $\begin{array}{l}\text { Variação Faturamento } \\
\text { 2002-2005 }\end{array}$ & $\begin{array}{l}\text { Equal variances } \\
\text { assumed } \\
\text { Equal variances } \\
\text { not assumed }\end{array}$ & 1,195 & ,276 & $\begin{array}{l}-, 604 \\
-, 582\end{array}$ & 129 &, 547 & $\begin{array}{l}-16,64445 \% \\
-16,64445 \%\end{array}$ & $\begin{array}{l}27,56390 \% \\
28,57443 \%\end{array}$ & $\begin{array}{r}- \\
71,18031 \\
\% \\
- \\
73,48402 \\
\%\end{array}$ & $\begin{array}{r}37,89140 \\
\% \\
40,19511 \\
\%\end{array}$ \\
\hline $\begin{array}{l}\text { Margem LAJIDA 2002- } \\
2005\end{array}$ & $\begin{array}{l}\text { Equal variances } \\
\text { assumed }\end{array}$ &, 754 & ,387 &,- 079 & 129 & ,937 &,$- 11375 \%$ & $1,43104 \%$ & $-2,94511 \%$ & $2,71760 \%$ \\
\hline & $\begin{array}{l}\text { Equal variances } \\
\text { not assumed }\end{array}$ & & &,- 080 & 128,774 & ,936 &,$- 11375 \%$ & $1,41962 \%$ & $-2,92256 \%$ & $2,69505 \%$ \\
\hline $\begin{array}{l}\text { Margem de Lucro 2002- } \\
2005\end{array}$ & $\begin{array}{l}\text { Equal variances } \\
\text { assumed }\end{array}$ &, 790 & ,376 &,- 279 & 129 & ,781 &,$- 31432 \%$ & $1,12849 \%$ & $-2,54707 \%$ & $1,91842 \%$ \\
\hline & $\begin{array}{l}\text { Equal variances } \\
\text { not assumed }\end{array}$ & & &,- 282 & 127,387 &, 779 &,$- 31432 \%$ & $1,11531 \%$ & $-2,52126 \%$ & $1,89261 \%$ \\
\hline $\begin{array}{l}\text { Classe de Risco (Risk } \\
\text { Scoring) }\end{array}$ & $\begin{array}{l}\text { Equal variances } \\
\text { assumed }\end{array}$ & 13,067 &, 000 &,- 006 & 129 & ,995 &,- 107 & 17,630 & $-34,989$ & 34,775 \\
\hline & $\begin{array}{l}\text { Equal variances } \\
\text { not assumed }\end{array}$ & & &,- 006 & 111,619 & ,995 &,- 107 & 17,171 & $-34,131$ & 33,917 \\
\hline
\end{tabular}




\begin{tabular}{|c|c|c|c|c|c|c|c|c|c|c|c|c|c|c|}
\hline \multicolumn{15}{|c|}{ Correlations } \\
\hline & & ISO90012000 & ISOTS16949 & ISO14000 & \begin{tabular}{l|} 
Notade \\
Sistema
\end{tabular} & $\begin{array}{l}\text { Amplitudede } \\
\text { Mercado }\end{array}$ & $\begin{array}{l}\text { Amplitudede } \\
\text { Produtos } \\
\end{array}$ & $\begin{array}{l}\text { Número } \\
\text { Empregados }\end{array}$ & $\begin{array}{c}\text { Produtivida } \\
\text { deR2005 } \\
\text { Empregado } \\
\end{array}$ & $\begin{array}{l}\text { Faturamentot } \\
\text { otal20022005 }\end{array}$ & $\begin{array}{c}\text { Variação } \\
\text { Faturament } \\
\text { 020022005 } \\
\end{array}$ & $\begin{array}{c}\text { Margem } \\
\text { LAJIDA20 } \\
022005 \\
\end{array}$ & $\begin{array}{c}\text { Margem } \\
\text { Lucro200 } \\
22005 \\
\end{array}$ & $\begin{array}{c}\text { Classe } \\
\text { RiscoRisk } \\
\text { Scoring } \\
\end{array}$ \\
\hline \multirow[t]{3}{*}{$1 \mathrm{SO} 090012000$} & Pearson Correlation & 1 & \begin{tabular}{|l|}
, 124 \\
\end{tabular} & $\begin{array}{r}092 \\
\end{array}$ & ,587*** &, $142^{\star}$ &, $172^{\star}$ &, 060 &,- 040 & ,076 & $=, 066$ &, $228^{\star \star *}$ &, $161^{\star}$ & ,002 \\
\hline & Sig. (2-tailed) & & ,073 & 182 & ,000 & ,040 & ,012 & ,385 &, 567 & 270 & 337 & ,001 & ,020 & 976 \\
\hline & $\mathrm{N}$ & 211 & 211 & 211 & 211 & 211 & 211 & 211 & 211 & 211 & 211 & 211 & 211 & 211 \\
\hline \multirow[t]{3}{*}{ ISOTS16949 } & Pearson Correlation & $\begin{array}{l}, 124 \\
\end{array}$ & 1 & ,488*x| & ,756*4 & 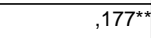 & ,017 & ,224*x| & ,204**| & ,184**| & ,177* & ,054 & ,010 & ,003 \\
\hline & Sig. (2-tailed) & ,073 & & , 000 & ,000 & ,010 & 802 & ,001 & ,003 & ,007 & ,010 & ,437 & ,887 & ,962 \\
\hline & $\mathrm{N}$ & 211 & 211 & 211 & 211 & 211 & 211 & 211 & 211 & 211 & 211 & 211 & 211 & 211 \\
\hline \multirow[t]{3}{*}{15014000} & Pearson Correlation & ,092 & , 488*x & 1 &, $743 \times 4$ & 135 & 104 & ,375*x & ,258*x & $326^{\star \star \star}$ & ,127 & ,017 & ,010 &,- 012 \\
\hline & Sig. (2-tailed) & 182 & ,000 & & ,000 & ,051 & 132 & ,000 & ,000 & ,000 & ,066 & ,806 & ,887 &, 860 \\
\hline & $\mathrm{N}$ & 211 & 211 & 211 & 211 & 211 & 211 & 211 & 211 & 211 & 211 & 211 & 211 & 211 \\
\hline \multirow[t]{3}{*}{ NotadeSistema } & Pearson Correlation &, $587 \times 4$ &, 756 *夫 &, $743^{\star \star \star}$ & 1 &, $222^{\star \star}$ & ,135* &, $306^{* \star}$ &, $220^{* *}$ &, $274^{\star \star *}$ & ,112 &, $135^{*}$ & ,076 &,- 016 \\
\hline & Sig. (2-tailed) & ,000 & ,000 & ,000 & & ,001 & ,049 &, 000 & ,001 & ,000 & 106 & ,050 & ,273 & 819 \\
\hline & $\mathrm{N}$ & 211 & 211 & 211 & 211 & 211 & 211 & 211 & 211 & 211 & 211 & 211 & 211 & 211 \\
\hline \multirow[t]{3}{*}{ AmplitudedeMercado } & Pearson Correlation &, $142^{\star}$ &, $177 \times+$ & ,135 &, $222^{* *}$ & 1 & $283^{* *}$ & 075 & 106 & ,090 &,- 065 & ,072 & ,019 & ,030 \\
\hline & Sig. (2-tailed) & ,040 & ,010 & ,051 & ,001 & & ,000 & 278 & 126 & 191 & ,345 & 296 & 789 & 667 \\
\hline & $\mathrm{N}$ & 211 & 211 & 211 & 211 & 211 & 211 & 211 & 211 & 211 & 211 & 211 & 211 & 211 \\
\hline \multirow[t]{3}{*}{ AmplitudedeProdutos } & Pearson Correlation & ,172* & ,017 & ,104 & ,135* & $283^{* \star}$ & 1 & 114 & $\begin{array}{l}, 058 \\
\end{array}$ & ,056 & $-0,095$ & 131 & ,076 & 101 \\
\hline & Sig. (2-tailed) & ,012 & 802 & 132 & ,049 & ,000 & & 100 & ,402 & 415 & 169 & ,057 & 271 & 145 \\
\hline & $\mathrm{N}$ & 211 & 211 & 211 & 211 & 211 & 211 & 211 & 211 & 211 & 211 & 211 & 211 & 211 \\
\hline \multirow[t]{3}{*}{ NúmeroEmpregados } & Pearson Correlation & ,060 & ,224** & 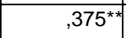 &, $306^{* x}$ & 075 & 114 & 1 & 130 & $680 * x$ & ,076 & 133 &,- 021 &,- 046 \\
\hline & Sig. (2-tailed) & ,385 & ,001 & ,000 & ,000 & 278 & 100 & & ,059 & ,000 & 270 & ,054 & ,757 & ,507 \\
\hline & $\mathrm{N}$ & 211 & 211 & 211 & 211 & 211 & 211 & 211 & 211 & 211 & 211 & 211 & 211 & 211 \\
\hline \multirow{3}{*}{$\begin{array}{l}\text { ProdutividadeR2005 } \\
\text { Empregado }\end{array}$} & Pearson Correlation & $\begin{array}{l}-, 040 \\
-040\end{array}$ & ,204** & ,258*ㅅ &, $220 \times+$ & ,106 &,- 058 & ,130 & 1 &, $461 \times *$ & ,112 & ,039 & ,067 &,- 084 \\
\hline & Sig. (2-tailed) &, 567 & ,003 & ,000 & 001 & 126 & ,402 & 059 & & ,000 & 106 &, 568 & ,336 & ,224 \\
\hline & $\mathrm{N}$ & 211 & 211 & 211 & 211 & 211 & 211 & 211 & 211 & 211 & 211 & 211 & 211 & 211 \\
\hline \multirow{3}{*}{$\begin{array}{l}\text { Faturamentototal2002200 } \\
5\end{array}$} & Pearson Correlation & ,076 & , 184*x & ,326*t & $274^{* *}$ & 090 & ,056 & ,680*+ & $4611^{* *}$ & 1 & ,034 & 105 & ,003 &,- 022 \\
\hline & Sig. (2-tailed) & ,270 & ,007 & ,000 & ,000 & 191 & ,415 & ,000 & , 000 & & ,620 & 128 &, 969 & 748 \\
\hline & $\mathrm{N}$ & 211 & 211 & 211 & 211 & 211 & 211 & 211 & 211 & 211 & 211 & 211 & 211 & 211 \\
\hline \multirow{3}{*}{$\begin{array}{l}\text { Variação } \\
\text { Faturamento20022005 }\end{array}$} & Pearson Correlation &,- 066 & ,177* & ,127 & ,112 &,- 065 &,- 095 & ,076 & $\begin{array}{lll}, 112 & \\
\end{array}$ & ,034 & 1 & ,011 & ,123 & ,001 \\
\hline & Sig. (2-tailed) & ,337 & ,010 & ,066 & 106 & ,345 & 169 & 270 & 106 & ,620 & & 875 & ,075 & 991 \\
\hline & $\mathrm{N}$ & 211 & 211 & 211 & 211 & 211 & 211 & 211 & 211 & 211 & 211 & 211 & 211 & 211 \\
\hline \multirow[t]{3}{*}{ MargemLAJIDA20022005 } & Pearson Correlation &, $228^{* *}$ & ,054 & ,017 &, $135^{*}$ & ,072 & 131 & 133 & ,039 & 105 & 011 & 1 & ,805*^ & ,159* \\
\hline & Sig. (2-tailed) & 001 & ,437 & ,806 & ,050 & ,296 & 057 & 054 &, 568 & 128 & 875 & & ,000 & ,020 \\
\hline & $\mathrm{N}$ & 211 & 211 & 211 & 211 & 211 & 211 & 211 & 211 & 211 & 211 & 211 & 211 & 211 \\
\hline \multirow[t]{3}{*}{ MargemLucro20022005 } & Pearson Correlation & ,161* & ,010 & ,010 & ,076 & ,019 & ,076 &,- 021 & ,067 & ,003 & ,123 &, $805^{* \star}$ & 1 & $245^{\star}$ \\
\hline & Sig. (2-tailed) & ,020 & ,887 & 887 & 273 & ,789 & 271 & ,757 & 336 & ,969 & ,075 & ,000 & & ,000 \\
\hline & $\mathrm{N}$ & 211 & 211 & 211 & 211 & 211 & 211 & 211 & 211 & 211 & 211 & 211 & 211 & 211 \\
\hline \multirow[t]{3}{*}{ ClasseRiscoRiskScoring } & Pearson Correlation & ,002 & ,003 &,- 012 &,- 016 & ,030 & 101 &,- 046 & -084 &,- 022 & ,001 & ,159* &, $245 * \star$ & 1 \\
\hline & Sig. (2-tailed) & ,976 & ,962 & 860 & 819 & 667 & 145 &, 507 & ,224 & ,748 & ,991 & ,020 & ,000 & \\
\hline & $\mathrm{N}$ & 211 & 211 & 211 & 211 & 211 & 211 & 211 & 211 & 211 & 211 & 211 & 211 & 211 \\
\hline
\end{tabular}

**. Correlation is significant at the 0.01 level (2-tailed).

*. Correlation is significant at the 0.05 level (2-tailed). 


\section{Regression}

Variables Entered/Removed

\begin{tabular}{|l|l|l|l|}
\hline Model & $\begin{array}{l}\text { Variables } \\
\text { Entered }\end{array}$ & $\begin{array}{c}\text { Variables } \\
\text { Removed }\end{array}$ & Method \\
\hline 1 & $\begin{array}{l}\text { Número } \\
\text { Empregad } \\
\text { os, }\end{array}$ & & \\
& $\begin{array}{l}\text { Amplitude } \\
\text { de }\end{array}$ & & \\
& Mercado, & & \\
& Notade & & Enter \\
& Sistema, \\
& Faturamen \\
& & & \\
& tototal2002 & & \\
& 2005 & & \\
\hline
\end{tabular}

a. All requested variables entered.

b. Dependent Variable: MargemLucro20022005

Model Summary

\begin{tabular}{|l|r|r|r|r|}
\hline Model & R & R Square & $\begin{array}{c}\text { Adjusted } \\
\text { R Square }\end{array}$ & $\begin{array}{r}\text { Std. Error of } \\
\text { the Estimate }\end{array}$ \\
\hline 1 &, $091^{\mathrm{a}}$ &, 008 &,- 011 &, 06579 \\
\hline
\end{tabular}

a. Predictors: (Constant), NúmeroEmpregados, AmplitudedeMercado, NotadeSistema,

Faturamentototal20022005

ANOVA

\begin{tabular}{|c|c|c|c|c|c|c|}
\hline \multicolumn{2}{|c|}{ Model } & $\begin{array}{l}\text { Sum of } \\
\text { Squares }\end{array}$ & df & Mean Square & $\mathrm{F}$ & Sig. \\
\hline \multirow[t]{3}{*}{1} & Regression & ,007 & 4 & ,002 &, 426 &, $790^{\mathrm{a}}$ \\
\hline & Residual & ,892 & 206 & ,004 & & \\
\hline & Total & ,899 & 210 & & & \\
\hline
\end{tabular}

a. Predictors: (Constant), NúmeroEmpregados, AmplitudedeMercado, NotadeSistema, Faturamentototal20022005

b. Dependent Variable: MargemLucro20022005

\section{Coefficients $^{\mathrm{a}}$}

\begin{tabular}{|c|c|c|c|c|c|c|}
\hline \multirow[b]{2}{*}{ Model } & & \multicolumn{2}{|c|}{$\begin{array}{c}\text { Unstandardized } \\
\text { Coefficients }\end{array}$} & \multirow{2}{*}{$\begin{array}{c}\begin{array}{c}\text { Standardized } \\
\text { Coefficients }\end{array} \\
\text { Beta }\end{array}$} & \multirow[b]{2}{*}{$\mathrm{t}$} & \multirow[b]{2}{*}{ Sig. } \\
\hline & & B & Std. Error & & & \\
\hline \multirow[t]{5}{*}{1} & (Constant) & ,012 & ,015 & & ,801 &, 424 \\
\hline & $\begin{array}{l}\text { Faturamentototal200 } \\
22005\end{array}$ & 1,19E-012 & ,000 & 021 & ,222 & ,824 \\
\hline & AmplitudedeMercado & ,000 & ,005 & ,002 & ,023 & ,981 \\
\hline & NotadeSistema & ,006 & ,005 & ,089 & 1,191 & ,235 \\
\hline & NúmeroEmpregados & $-4,6 E-006$ & ,000 &,- 063 &,- 658 &, 511 \\
\hline
\end{tabular}

a. Dependent Variable: MargemLucro20022005 


\section{Regression}

Variables Entered/RemovedP

\begin{tabular}{|l|l|l|l|}
\hline Model & $\begin{array}{l}\text { Variables } \\
\text { Entered }\end{array}$ & $\begin{array}{l}\text { Variables } \\
\text { Removed }\end{array}$ & Method \\
\hline 1 & $\begin{array}{l}\text { Notade } \\
\text { Sistema, } \\
\text { Amplitude a } \\
\text { deMercado }\end{array}$ & & \\
\hline
\end{tabular}

a. All requested variables entered.

b. Dependent Variable: MargemLucro20022005

\section{Model Summary}

\begin{tabular}{|l|r|r|r|r|}
\hline Model & R & R Square & $\begin{array}{c}\text { Adjusted } \\
\text { R Square }\end{array}$ & $\begin{array}{r}\text { Std. Error of } \\
\text { the Estimate }\end{array}$ \\
\hline 1 &, $076^{\mathrm{a}}$ &, 006 &,- 004 &, 06556 \\
\hline
\end{tabular}

a. Predictors: (Constant), NotadeSistema, AmplitudedeMercado

\section{ANOVA}

\begin{tabular}{|c|c|c|c|c|c|c|}
\hline \multicolumn{2}{|c|}{ Model } & $\begin{array}{l}\text { Sum of } \\
\text { Squares }\end{array}$ & df & Mean Square & $\mathrm{F}$ & Sig. \\
\hline \multirow[t]{3}{*}{1} & Regression & ,005 & 2 & ,003 & ,603 &, $548^{\mathrm{a}}$ \\
\hline & Residual & ,894 & 208 & ,004 & & \\
\hline & Total & ,899 & 210 & & & \\
\hline
\end{tabular}

a. Predictors: (Constant), NotadeSistema, AmplitudedeMercado

b. Dependent Variable: MargemLucro20022005

\section{Coefficients $^{\mathrm{a}}$}

\begin{tabular}{|c|c|c|c|c|c|c|}
\hline \multirow{2}{*}{\multicolumn{2}{|c|}{ Model }} & \multicolumn{2}{|c|}{$\begin{array}{l}\text { Unstandardized } \\
\text { Coefficients }\end{array}$} & \multirow{2}{*}{$\begin{array}{c}\text { Standardized } \\
\text { Coefficients }\end{array}$} & \multirow[b]{2}{*}{$\mathrm{t}$} & \multirow[b]{2}{*}{ Sig. } \\
\hline & & $B$ & Std. Error & & & \\
\hline & (Constant) & ,011 & ,014 & & ,771 &, 442 \\
\hline & AmplitudedeMercado & ,000 & ,005 & ,002 & ,026 & ,979 \\
\hline & NotadeSistema & ,005 & ,005 & ,075 & 1,065 & ,288 \\
\hline
\end{tabular}

a. Dependent Variable: MargemLucro20022005 


\section{Regression}

Variables Entered/Removed

\begin{tabular}{|l|l|l|l|}
\hline Model & $\begin{array}{l}\text { Variables } \\
\text { Entered }\end{array}$ & $\begin{array}{l}\text { Variables } \\
\text { Removed }\end{array}$ & Method \\
\hline 1 & $\begin{array}{l}\text { Notade } \\
\text { Sistema, } \\
\text { Amplitude aa } \\
\text { deMercado }\end{array}$ & & \\
\hline
\end{tabular}

a. All requested variables entered.

b. Dependent Variable: VariaçãoFaturamento20022005

\section{Model Summary}

\begin{tabular}{|l|r|r|r|r|}
\hline Model & R & R Square & $\begin{array}{c}\text { Adjusted } \\
\text { R Square }\end{array}$ & $\begin{array}{r}\text { Std. Error of } \\
\text { the Estimate }\end{array}$ \\
\hline 1 &, $145^{\mathrm{a}}$ &, 021 &, 012 & 1,40962 \\
\hline
\end{tabular}

a. Predictors: (Constant), NotadeSistema, AmplitudedeMercado

ANOVA

\begin{tabular}{|c|c|c|c|c|c|c|}
\hline & & $\begin{array}{l}\text { Sum of } \\
\text { Squares }\end{array}$ & $d f$ & Mean Square & $\mathrm{F}$ & Sig. \\
\hline \multirow[t]{3}{*}{1} & Regression & 8,873 & 2 & 4,437 & 2,233 &, $110^{\mathrm{a}}$ \\
\hline & Residual & 413,302 & 208 & 1,987 & & \\
\hline & Total & 422,175 & 210 & & & \\
\hline
\end{tabular}

a. Predictors: (Constant), NotadeSistema, AmplitudedeMercado

b. Dependent Variable: VariaçãoFaturamento20022005

\section{Coefficients $^{\mathrm{a}}$}

\begin{tabular}{|ll|r|r|r|r|r|}
\hline \multirow{2}{*}{ Model } & \multicolumn{2}{|c|}{$\begin{array}{c}\text { Unstandardized } \\
\text { Coefficients }\end{array}$} & $\begin{array}{c}\text { Standardized } \\
\text { Coefficients }\end{array}$ & & \\
\cline { 3 - 5 } & & \multicolumn{1}{|c|}{ B } & Std. Error & Beta & \multicolumn{1}{c|}{ t } & Sig. \\
\hline 1 & (Constant) & 1,359 &, 312 & & 4,359 &, 000 \\
& AmplitudedeMercado &,- 158 &, 117 &,- 095 & $-1,347$ &, 180 \\
& NotadeSistema &, 187 &, 099 &, 133 & 1,886 &, 061 \\
\hline
\end{tabular}

a. Dependent Variable: VariaçãoFaturamento20022005 


\section{Regression}

Variables Entered/RemovedP

\begin{tabular}{|l|l|l|l|}
\hline Model & $\begin{array}{l}\text { Variables } \\
\text { Entered }\end{array}$ & $\begin{array}{l}\text { Variables } \\
\text { Removed }\end{array}$ & Method \\
\hline 1 & $\begin{array}{l}\text { Número } \\
\text { Empregad } \\
\text { os, } \\
\text { Faturamen } \\
\text { tototal2002 } \\
2005\end{array}$ & & \\
& & & \\
& & Enter \\
\hline
\end{tabular}

a. All requested variables entered.

b. Dependent Variable: VariaçãoFaturamento20022005

Model Summary

\begin{tabular}{|l|r|r|r|r|}
\hline Model & R & R Square & $\begin{array}{c}\text { Adjusted } \\
\text { R Square }\end{array}$ & $\begin{array}{r}\text { Std. Error of } \\
\text { the Estimate }\end{array}$ \\
\hline 1 &, $080^{\mathrm{a}}$ &, 006 &,- 003 & 1,42011 \\
\hline
\end{tabular}

a. Predictors: (Constant), NúmeroEmpregados,

Faturamentototal20022005

\section{ANOVA}

\begin{tabular}{|c|c|c|c|c|c|c|}
\hline \multicolumn{2}{|c|}{ Model } & $\begin{array}{l}\text { Sum of } \\
\text { Squares }\end{array}$ & df & Mean Square & $\mathrm{F}$ & Sig. \\
\hline \multirow[t]{3}{*}{1} & Regression & 2,697 & 2 & 1,348 & ,669 &, $514^{\mathrm{a}}$ \\
\hline & Residual & 419,478 & 208 & 2,017 & & \\
\hline & Total & 422,175 & 210 & & & \\
\hline
\end{tabular}

a. Predictors: (Constant), NúmeroEmpregados, Faturamentototal20022005

b. Dependent Variable: VariaçãoFaturamento20022005

\section{Coefficients $^{\mathrm{a}}$}

\begin{tabular}{|c|c|c|c|c|c|c|}
\hline \multirow{2}{*}{\multicolumn{2}{|c|}{ Model }} & \multicolumn{2}{|c|}{$\begin{array}{c}\text { Unstandardized } \\
\text { Coefficients }\end{array}$} & \multirow{2}{*}{$\begin{array}{c}\text { Standardized } \\
\text { Coefficients }\end{array}$} & \multirow[b]{2}{*}{$t$} & \multirow[b]{2}{*}{ Sig. } \\
\hline & & $\mathrm{B}$ & Std. Error & & & \\
\hline \multirow[t]{3}{*}{1} & (Constant) & 1,172 & ,111 & & 10,557 &, 000 \\
\hline & $\begin{array}{l}\text { Faturamentototal200 } \\
22005\end{array}$ & $-4,0 \mathrm{E}-011$ & ,000 &,- 033 &,- 347 & ,729 \\
\hline & NúmeroEmpregados & ,000 & ,000 & ,098 & 1,045 & ,297 \\
\hline
\end{tabular}

a. Dependent Variable: VariaçãoFaturamento20022005 


\section{Regression}

Variables Entered/Removed

\begin{tabular}{|l|l|l|l|}
\hline Model & $\begin{array}{l}\text { Variables } \\
\text { Entered }\end{array}$ & $\begin{array}{l}\text { Variables } \\
\text { Removed }\end{array}$ & Method \\
\hline 1 & $\begin{array}{l}\text { Número } \\
\text { Empregad } \\
\text { os, } \\
\text { Faturamen } \\
\text { tototal2002 } \\
2005\end{array}$ & & \\
& & & \\
& & Enter \\
\hline
\end{tabular}

a. All requested variables entered.

b. Dependent Variable: MargemLucro20022005

Model Summary

\begin{tabular}{|l|r|r|r|r|}
\hline Model & $\mathrm{R}$ & R Square & $\begin{array}{c}\text { Adjusted } \\
\text { R Square }\end{array}$ & $\begin{array}{r}\text { Std. Error of } \\
\text { the Estimate }\end{array}$ \\
\hline 1 &, $032^{\mathrm{a}}$ &, 001 &,- 009 &, 06571 \\
\hline
\end{tabular}

a. Predictors: (Constant), NúmeroEmpregados,

Faturamentototal20022005

ANOVA

\begin{tabular}{|c|c|c|c|c|c|c|}
\hline \multicolumn{2}{|c|}{ Model } & $\begin{array}{l}\text { Sum of } \\
\text { Squares }\end{array}$ & df & Mean Square & $\mathrm{F}$ & Sig. \\
\hline \multirow[t]{3}{*}{1} & Regression & ,001 & 2 & ,000 & ,105 &, $900^{\mathrm{a}}$ \\
\hline & Residual & ,898 & 208 & ,004 & & \\
\hline & Total & ,899 & 210 & & & \\
\hline
\end{tabular}

a. Predictors: (Constant), NúmeroEmpregados, Faturamentototal20022005

b. Dependent Variable: MargemLucro20022005

\section{Coefficients $^{\mathrm{a}}$}

\begin{tabular}{|c|c|c|c|c|c|c|}
\hline \multirow{2}{*}{\multicolumn{2}{|c|}{ Model }} & \multicolumn{2}{|c|}{$\begin{array}{c}\text { Unstandardized } \\
\text { Coefficients }\end{array}$} & \multirow{2}{*}{$\begin{array}{c}\begin{array}{c}\text { Standardized } \\
\text { Coefficients }\end{array} \\
\text { Beta }\end{array}$} & \multirow[b]{2}{*}{$\mathrm{t}$} & \multirow[b]{2}{*}{ Sig. } \\
\hline & & $\mathrm{B}$ & Std. Error & & & \\
\hline \multirow[t]{3}{*}{1} & (Constant) & ,019 & ,005 & & 3,777 &, 000 \\
\hline & $\begin{array}{l}\text { Faturamentototal200 } \\
22005\end{array}$ & 1,81E-012 & ,000 & ,032 & ,340 & ,734 \\
\hline & NúmeroEmpregados & $-3,1 E-006$ & ,000 &,- 043 &,- 458 & ,648 \\
\hline
\end{tabular}

a. Dependent Variable: MargemLucro20022005 


\section{Regression}

Variables Entered/Removed

\begin{tabular}{|l|l|l|l|}
\hline Model & $\begin{array}{l}\text { Variables } \\
\text { Entered }\end{array}$ & $\begin{array}{l}\text { Variables } \\
\text { Removed }\end{array}$ & Method \\
\hline 1 & $\begin{array}{l}\text { Número } \\
\text { Empregad } \\
\text { os, } \\
\text { Faturamen } \\
\text { tototal2002 } \\
2005\end{array}$ & & \\
& & & \\
& & Enter \\
\hline
\end{tabular}

a. All requested variables entered.

b. Dependent Variable: MargemLAJIDA20022005

Model Summary

\begin{tabular}{|l|r|r|r|r|}
\hline Model & \multicolumn{1}{|c|}{$\mathrm{R}$} & R Square & $\begin{array}{c}\text { Adjusted } \\
\text { R Square }\end{array}$ & $\begin{array}{r}\text { Std. Error of } \\
\text { the Estimate }\end{array}$ \\
\hline 1 &, $134^{\mathrm{a}}$ &, 018 &, 009 &, 08318 \\
\hline
\end{tabular}

a. Predictors: (Constant), NúmeroEmpregados,

Faturamentototal20022005

\section{ANOVA ${ }^{b}$}

\begin{tabular}{|c|c|c|c|c|c|c|}
\hline & & $\begin{array}{l}\text { Sum of } \\
\text { Squares }\end{array}$ & $d f$ & Mean Square & $\mathrm{F}$ & Sig. \\
\hline \multirow[t]{3}{*}{1} & Regression & ,026 & 2 & ,013 & 1,912 &, $150^{\mathrm{a}}$ \\
\hline & Residual & 1,439 & 208 & ,007 & & \\
\hline & Total & 1,466 & 210 & & & \\
\hline
\end{tabular}

a. Predictors: (Constant), NúmeroEmpregados, Faturamentototal20022005

b. Dependent Variable: MargemLAJIDA20022005

\section{Coefficients $^{\mathrm{a}}$}

\begin{tabular}{|c|c|c|c|c|c|c|}
\hline \multirow{2}{*}{\multicolumn{2}{|c|}{ Model }} & \multicolumn{2}{|c|}{$\begin{array}{c}\text { Unstandardized } \\
\text { Coefficients }\end{array}$} & \multirow{2}{*}{$\begin{array}{c}\begin{array}{c}\text { Standardized } \\
\text { Coefficients }\end{array} \\
\text { Beta }\end{array}$} & \multirow[b]{2}{*}{$t$} & \multirow[b]{2}{*}{ Sig. } \\
\hline & & $\mathrm{B}$ & Std. Error & & & \\
\hline \multirow[t]{3}{*}{1} & (Constant) & ,094 & ,007 & & 14,411 &, 000 \\
\hline & $\begin{array}{l}\text { Faturamentototal200 } \\
22005\end{array}$ & 1,99E-012 & ,000 & ,028 & ,296 & ,768 \\
\hline & NúmeroEmpregados & 1,05E-005 & ,000 & ,114 & 1,216 & ,225 \\
\hline
\end{tabular}

a. Dependent Variable: MargemLAJIDA20022005 


\section{Regression}

Variables Entered/Removed

\begin{tabular}{|l|l|l|l|}
\hline Model & $\begin{array}{l}\text { Variables } \\
\text { Entered }\end{array}$ & $\begin{array}{c}\text { Variables } \\
\text { Removed }\end{array}$ & Method \\
\hline 1 & Notade & & \\
& Sistema, \\
& Faturamen \\
& tototal2002 & & \\
& 2005, & & \\
& Número \\
& Empregad & & Enter \\
& & & \\
& os & & \\
\hline
\end{tabular}

a. All requested variables entered.

b. Dependent Variable: MargemLucro20022005

\section{Model Summary}

\begin{tabular}{|l|r|r|r|r|}
\hline Model & R & R Square & $\begin{array}{c}\text { Adjusted } \\
\text { R Square }\end{array}$ & $\begin{array}{r}\text { Std. Error of } \\
\text { the Estimate }\end{array}$ \\
\hline 1 &, $091^{\mathrm{a}}$ &, 008 &,- 006 &, 06563 \\
\hline
\end{tabular}

a. Predictors: (Constant), NotadeSistema,

Faturamentototal20022005, NúmeroEmpregados

ANOVA

\begin{tabular}{|c|c|c|c|c|c|c|}
\hline Model & & $\begin{array}{l}\text { Sum of } \\
\text { Squares }\end{array}$ & $d f$ & Mean Square & $\mathrm{F}$ & Sig. \\
\hline \multirow[t]{3}{*}{1} & Regression & ,007 & 3 & ,002 &, 570 &, $635^{\mathrm{a}}$ \\
\hline & Residual & ,892 & 207 & ,004 & & \\
\hline & Total & ,899 & 210 & & & \\
\hline
\end{tabular}

a. Predictors: (Constant), NotadeSistema, Faturamentototal20022005, NúmeroEmpregados

b. Dependent Variable: MargemLucro20022005

\section{Coefficients $^{\mathrm{a}}$}

\begin{tabular}{|c|c|c|c|c|c|c|}
\hline \multirow[b]{2}{*}{ Mode } & & \multicolumn{2}{|c|}{$\begin{array}{l}\text { Unstandardized } \\
\text { Coefficients }\end{array}$} & \multirow{2}{*}{$\begin{array}{c}\begin{array}{c}\text { Standardized } \\
\text { Coefficients }\end{array} \\
\text { Beta }\end{array}$} & \multirow[b]{2}{*}{$\mathrm{t}$} & \multirow[b]{2}{*}{ Sig. } \\
\hline & & B & Std. Error & & & \\
\hline \multirow[t]{4}{*}{1} & (Constant) & ,012 & ,008 & & 1,510 & ,132 \\
\hline & $\begin{array}{l}\text { Faturamentototal200 } \\
22005\end{array}$ & 1,19E-012 & ,000 & 021 & ,224 & ,823 \\
\hline & NúmeroEmpregados & $-4,6 E-006$ & ,000 &,- 063 &,- 660 & ,510 \\
\hline & NotadeSistema & ,006 & ,005 & ,089 & 1,225 & ,222 \\
\hline
\end{tabular}

a. Dependent Variable: MargemLucro20022005 


\section{Regression}

Variables Entered/Removedp

\begin{tabular}{|l|l|l|l|}
\hline Model & $\begin{array}{l}\text { Variables } \\
\text { Entered }\end{array}$ & $\begin{array}{c}\text { Variables } \\
\text { Removed }\end{array}$ & Method \\
\hline 1 & Idade & & \\
& $\begin{array}{l}\text { Empresa, } \\
\text { Notade } \\
\text { Sistema, } \\
\text { Montadora, } \\
\text { ISO90012 } \\
\text { 000 }\end{array}$ & & \\
& & & \\
& & & \\
\hline
\end{tabular}

a. All requested variables entered.

b. Dependent Variable: MargemLAJIDA20022005

Model Summary

\begin{tabular}{|l|r|r|r|r|}
\hline Model & $\mathrm{R}$ & R Square & $\begin{array}{c}\text { Adjusted } \\
\text { R Square }\end{array}$ & $\begin{array}{r}\text { Std. Error of } \\
\text { the Estimate }\end{array}$ \\
\hline 1 &, $260^{\mathrm{a}}$ &, 067 &, 049 &, 08145 \\
\hline
\end{tabular}

a. Predictors: (Constant), IdadeEmpresa,

NotadeSistema, Montadora, ISO90012000

ANOVA

\begin{tabular}{|c|c|c|c|c|c|c|}
\hline Model & & $\begin{array}{l}\text { Sum of } \\
\text { Squares }\end{array}$ & df & Mean Square & $F$ & Sig. \\
\hline \multirow[t]{3}{*}{1} & Regression & ,099 & 4 & ,025 & 3,726 &, $006^{\mathrm{a}}$ \\
\hline & Residual & 1,367 & 206 & ,007 & & \\
\hline & Total & 1,466 & 210 & & & \\
\hline
\end{tabular}

a. Predictors: (Constant), IdadeEmpresa, NotadeSistema, Montadora, ISO90012000

b. Dependent Variable: MargemLAJIDA20022005

Coefficients $^{\mathrm{a}}$

\begin{tabular}{|c|c|c|c|c|c|c|}
\hline \multirow{2}{*}{\multicolumn{2}{|c|}{ Model }} & \multicolumn{2}{|c|}{$\begin{array}{l}\text { Unstandardized } \\
\text { Coefficients }\end{array}$} & \multirow{2}{*}{$\begin{array}{c}\text { Standardized } \\
\text { Coefficients }\end{array}$} & \multirow[b]{2}{*}{$\mathrm{t}$} & \multirow[b]{2}{*}{ Sig. } \\
\hline & & B & Std. Error & & & \\
\hline \multirow[t]{5}{*}{1} & (Constant) & ,051 & ,019 & & 2,730 &, 007 \\
\hline & NotadeSistema &,- 001 & ,008 &,- 016 &,- 176 & ,861 \\
\hline & ISO90012000 & ,036 & ,014 & ,218 & 2,512 & ,013 \\
\hline & Montadora & ,012 & ,016 & ,055 & ,742 & ,459 \\
\hline & IdadeEmpresa & ,001 & ,000 & 112 & 1,630 & 105 \\
\hline
\end{tabular}

a. Dependent Variable: MargemLAJIDA20022005 


\section{Regression}

Variables Entered/Removed

\begin{tabular}{|l|l|l|l|}
\hline Model & $\begin{array}{l}\text { Variables } \\
\text { Entered }\end{array}$ & $\begin{array}{l}\text { Variables } \\
\text { Removed }\end{array}$ & Method \\
\hline 1 & $\begin{array}{l}\text { ISO90012 } \\
\text { 000, } \\
\text { Montadora, } \\
\text { Idade } \\
\text { Empresa, } \\
\text { Notade a } \\
\text { Sistema }\end{array}$ & & \\
& & & \\
& & & \\
& & & \\
\hline
\end{tabular}

a. All requested variables entered.

b. Dependent Variable: MargemLucro20022005

Model Summary

\begin{tabular}{|l|r|r|r|r|}
\hline Model & R & R Square & $\begin{array}{c}\text { Adjusted } \\
\text { R Square }\end{array}$ & $\begin{array}{r}\text { Std. Error of } \\
\text { the Estimate }\end{array}$ \\
\hline 1 &, $239^{\mathrm{a}}$ &, 057 &, 039 &, 06415 \\
\hline
\end{tabular}

a. Predictors: (Constant), IdadeEmpresa,

NotadeSistema, Montadora, ISO90012000

ANOVA

\begin{tabular}{|rl|r|r|r|r|r|}
\hline \multicolumn{2}{|c|}{} & $\begin{array}{c}\text { Sum of } \\
\text { Model }\end{array}$ & & & & \\
\hline 1 & Squares & df & Mean Square & F & Sig. \\
& Regression &, 051 & 4 &, 013 & 3,120 &, $016^{\mathrm{a}}$ \\
& Residual &, 848 & 206 &, 004 & & \\
& Total &, 899 & 210 & & & \\
\hline
\end{tabular}

a. Predictors: (Constant), IdadeEmpresa, NotadeSistema, Montadora, ISO90012000

b. Dependent Variable: MargemLucro20022005

\section{Coefficients $^{\mathrm{a}}$}

\begin{tabular}{|c|c|c|c|c|c|c|}
\hline \multirow{2}{*}{\multicolumn{2}{|c|}{ Model }} & \multicolumn{2}{|c|}{$\begin{array}{c}\text { Unstandardized } \\
\text { Coefficients }\end{array}$} & \multirow{2}{*}{$\begin{array}{c}\text { Standardized } \\
\text { Coefficients } \\
\text { Beta }\end{array}$} & \multirow[b]{2}{*}{$\mathrm{t}$} & \multirow[b]{2}{*}{ Sig. } \\
\hline & & $\mathrm{B}$ & Std. Error & & & \\
\hline \multirow[t]{5}{*}{1} & (Constant) &,- 018 & ,015 & & $-1,256$ &, 210 \\
\hline & NotadeSistema &,- 001 & ,006 &,- 019 &,- 205 & ,837 \\
\hline & ISO90012000 & ,019 & ,011 & ,143 & 1,641 & ,102 \\
\hline & Montadora & ,002 & ,012 & 011, & 154, & ,878 \\
\hline & IdadeEmpresa & ,001 & ,000 & , 177 & 2,572 & ,011 \\
\hline
\end{tabular}

a. Dependent Variable: MargemLucro20022005 


\section{Regression}

Variables Entered/Removed

\begin{tabular}{|c|c|c|c|}
\hline Model & $\begin{array}{l}\text { Variables } \\
\text { Entered }\end{array}$ & $\begin{array}{l}\text { Variables } \\
\text { Removed }\end{array}$ & Method \\
\hline 1 & $\begin{array}{l}\text { Idade } \\
\text { Empresa, } \\
\text { Notade } \\
\text { Sistema, } \\
\text { Montadora, } \\
\text { ISO90012 } \\
000\end{array}$ & 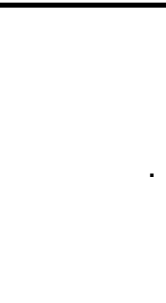 & Enter \\
\hline
\end{tabular}

a. All requested variables entered.

b. Dependent Variable: VariaçãoFaturamento20022005

Model Summary

\begin{tabular}{|l|r|r|r|r|}
\hline Model & R & R Square & $\begin{array}{c}\text { Adjusted } \\
\text { R Square }\end{array}$ & $\begin{array}{r}\text { Std. Error of } \\
\text { the Estimate }\end{array}$ \\
\hline 1 &, $295^{\mathrm{a}}$ &, 087 &, 069 & 1,36793 \\
\hline
\end{tabular}

a. Predictors: (Constant), IdadeEmpresa, NotadeSistema, Montadora, ISO90012000

ANOVA

\begin{tabular}{|ll|r|r|r|r|r|}
\hline \multicolumn{2}{|c|}{} & & Sum of & & & \\
Model & & Squares & df & Mean Square & F & Sig. \\
\hline 1 & Regression & 36,704 & 4 & 9,176 & 4,904 &, $001^{\mathrm{a}}$ \\
& Residual & 385,471 & 206 & 1,871 & & \\
& Total & 422,175 & 210 & & & \\
\hline
\end{tabular}

a. Predictors: (Constant), IdadeEmpresa, NotadeSistema, Montadora, ISO90012000

b. Dependent Variable: VariaçãoFaturamento20022005

\section{Coefficients $^{\mathrm{a}}$}

\begin{tabular}{|c|c|c|c|c|c|c|}
\hline \multirow{2}{*}{\multicolumn{2}{|c|}{ Model }} & \multicolumn{2}{|c|}{$\begin{array}{c}\text { Unstandardized } \\
\text { Coefficients }\end{array}$} & \multirow{2}{*}{$\begin{array}{c}\begin{array}{c}\text { Standardized } \\
\text { Coefficients }\end{array} \\
\text { Beta }\end{array}$} & \multirow[b]{2}{*}{$\mathrm{t}$} & \multirow[b]{2}{*}{ Sig. } \\
\hline & & B & Std. Error & & & \\
\hline \multirow[t]{5}{*}{1} & (Constant) & 1,261 &, 314 & & 4,018 & ,000 \\
\hline & NotadeSistema & ,189 & ,128 & ,134 & 1,481 & 140 \\
\hline & ISO90012000 &,- 349 & ,243 &,- 123 & $-1,440$ & 151 \\
\hline & Montadora &, 583 & ,264 & ,161 & 2,207 & ,028 \\
\hline & IdadeEmpresa &,- 020 & ,008 &,- 175 & $-2,583$ & , 010 \\
\hline
\end{tabular}

a. Dependent Variable: VariaçãoFaturamento20022005 


\section{Analysis Summary}

Date and Time

Date: quarta-feira, 8 de outubro de 2008

Time: 21:33:47

Title

Modelo c 20081008: quarta-feira, 8 de outubro de 2008 09:33

\section{Notes for Group (Group number 1)}

The model is recursive.

Sample size $=220$

\section{Variable Summary (Group number 1)}

Your model contains the following variables (Group number 1)

Observed, endogenous variables

AmplitudedeMercado

NotadeSistema

NúmeroEmpregados

Faturamentototal20022005

VariaçãoFaturamento20022005

MargemLucro20022005

Unobserved, endogenous variables

Adoção_de PSGs

Desempenho_da_Empresa

Tamanho_da Empresa

Unobserved, exogenous variables

E1

D2

E2

E3

E4

E6

D1

D3

E5

\section{Variable counts (Group number 1)}

Number of variables in your model: 18

Number of observed variables: $\quad 6$

Number of unobserved variables: 12

Number of exogenous variables: 9

Number of endogenous variables: 9 
Parameter summary (Group number 1)

\begin{tabular}{|r|rrrrrr|}
\hline & Weights & Covariances & Variances & Means & Intercepts & Total \\
\hline Fixed & 12 & 0 & 0 & 0 & 0 & 12 \\
Labeled & 0 & 0 & 0 & 0 & 0 & 0 \\
Unlabeled & 6 & 0 & 9 & 0 & 6 & 21 \\
Total & 18 & 0 & 9 & 0 & 6 & 33 \\
\hline
\end{tabular}

Assessment of normality (Group number 1)

\begin{tabular}{|l|rrrrrr|}
\hline Variable & min & max & skew & c.r. & kurtosis & c.r. \\
\hline MargemLucro20022005 &,- 353 &, 329 &,- 753 & $-4,558$ & 5,081 & 15,384 \\
VariaçãoFaturamento20022005 &,- 960 & 13,673 & 4,969 & 30,089 & 36,560 & 110,690 \\
Faturamentototal20022005 & 3695905,000 & 14316415000,000 & 9,057 & 54,844 & 100,405 & 303,990 \\
NúmeroEmpregados & 5,000 & 8344,000 & 6,213 & 37,623 & 47,428 & 143,595 \\
NotadeSistema &, 000 & 3,000 &, 090 &, 548 & $-1,041$ & $-3,152$ \\
AmplitudedeMercado &, 000 & 4,000 &,- 329 & $-1,992$ &,- 466 & $-1,410$ \\
Multivariate & & & & & 246,002 & 186,202 \\
\hline
\end{tabular}


Observations farthest from the centroid (Mahalanobis distance) (Group number 1)

\begin{tabular}{|c|c|c|c|}
\hline Observation number & Mahalanobis d-squared & $\mathrm{p} 1$ & $\mathrm{p} 2$ \\
\hline 13 & 189,217 & 000 & 000 \\
\hline 34 & 87,662 & ,000 & ,000 \\
\hline 42 & 81,668 & ,000 & ,000 \\
\hline 56 & 77,644 & ,000 & ,000 \\
\hline 15 & 50,815 & 000 & ,000 \\
\hline 85 & 25,244 & ,000 & ,000 \\
\hline 185 & 19,440 & ,003 & 000 \\
\hline 165 & 18,896 & ,004 & ,000 \\
\hline 50 & 18,145 & ,006 & ,000 \\
\hline 105 & 15,422 & ,017 & ,005 \\
\hline 98 & 14,563 & 024 & ,018 \\
\hline 218 & 12,648 & ,049 & ,393 \\
\hline 72 & 12,596 & ,050 & 306 \\
\hline 155 & 11,961 & ,063 & ,520 \\
\hline 19 & 11,697 & ,069 & ,559 \\
\hline 95 & 11,413 & ,076 & 618 \\
\hline 204 & 9,923 & 128 & 994 \\
\hline 8 & 9,857 & 131 & 991 \\
\hline 189 & 9,459 & 149 & 998 \\
\hline 114 & 9,361 & 154 & 998 \\
\hline 4 & 8,355 & 213 & 1,000 \\
\hline 186 & 8,050 & 234 & 1,000 \\
\hline 179 & 7,873 & 248 & 1,000 \\
\hline 21 & 7,642 & 266 & 1,000 \\
\hline 219 & 7,533 & 274 & 1,000 \\
\hline 177 & 7,427 & 283 & 1,000 \\
\hline 1 & 7,285 & 295 & 1,000 \\
\hline 51 & 7,268 & 297 & 1,000 \\
\hline 37 & 7,066 & ,315 & 1,000 \\
\hline 198 & 6,848 & ,335 & 1,000 \\
\hline 65 & 6,279 & 393 & 1,000 \\
\hline 18 & 6,207 & ,400 & 1,000 \\
\hline 212 & 6,007 & ,422 & 1,000 \\
\hline 28 & 5,967 & 427 & 1,000 \\
\hline 31 & 5,918 & 432, & 1,000 \\
\hline 35 & 5,664 & 462, & 1,000 \\
\hline 203 & 5,614 & 468, & 1,000 \\
\hline 45 & 5,585 & 471, & 1,000 \\
\hline 64 & 5,426 & 490, & 1,000 \\
\hline 193 & 5,386 & 495, & 1,000 \\
\hline 33 & 5,377 & 496, & 1,000 \\
\hline 78 & 5,305 & 505, & 1,000 \\
\hline 116 & 5,148 & 525, & 1,000 \\
\hline 23 & 5,056 & 537, & 1,000 \\
\hline 169 & 5,011 & ,542 & 1,000 \\
\hline 30 & 4,919 & ,554 & 1,000 \\
\hline 97 & 4,899 & 557, & 1,000 \\
\hline 196 & 4,849 & 563, & 1,000 \\
\hline 93 & 4,783 & ,572 & 1,000 \\
\hline 150 & 4,717 & 581, & 1,000 \\
\hline
\end{tabular}




\begin{tabular}{|c|c|c|c|}
\hline Observation number & Mahalanobis d-squared & $\mathrm{p} 1$ & $\mathrm{p} 2$ \\
\hline 115 & 4,684 & ,585 & 1,000 \\
\hline 145 & 4,676 & ,586 & 1,000 \\
\hline 181 & 4,488 & 611 & 1,000 \\
\hline 59 & 4,452 & 616 & 1,000 \\
\hline 9 & 4,433 & 618, & 1,000 \\
\hline 180 & 4,424 & 619, & 1,000 \\
\hline 205 & 4,382 & 625 & 1,000 \\
\hline 129 & 4,377 & ,626 & 1,000 \\
\hline 69 & 4,358 & 628, & 1,000 \\
\hline 111 & 4,327 & 632, & 1,000 \\
\hline 17 & 4,320 & 633, & 1,000 \\
\hline 187 & 4,310 & 635, & 1,000 \\
\hline 106 & 4,309 & 635, & 1,000 \\
\hline 5 & 4,284 & 638, & 1,000 \\
\hline 159 & 4,277 & 639, & 1,000 \\
\hline 197 & 4,274 & 640, & 1,000 \\
\hline 2 & 4,217 & 647, & 1,000 \\
\hline 22 & 4,199 & 650, & 1,000 \\
\hline 107 & 4,184 & 652, & 1,000 \\
\hline 142 & 4,179 & 652, & 1,000 \\
\hline 61 & 4,173 & 653, & 1,000 \\
\hline 139 & 4,172 & 653, & 1,000 \\
\hline 88 & 4,150 & 656, & 1,000 \\
\hline 76 & 4,101 & 663, & 1,000 \\
\hline 73 & 4,077 & 666, & 1,000 \\
\hline 10 & 4,047 & 670, & 1,000 \\
\hline 24 & 4,039 & 671 & 1,000 \\
\hline 123 & 3,998 & 677, & 1,000 \\
\hline 46 & 3,981 & 679, & 1,000 \\
\hline 63 & 3,981 & 679, & 1,000 \\
\hline 20 & 3,965 & 681 & 1,000 \\
\hline 137 & 3,964 & 682, & 1,000 \\
\hline 131 & 3,914 & 688, & 1,000 \\
\hline 3 & 3,899 & 690, & 1,000 \\
\hline 117 & 3,877 & 693, & 1,000 \\
\hline 202 & 3,821 & 701 & 1,000 \\
\hline 174 & 3,815 & 702 & 1,000 \\
\hline 176 & 3,782 & 706 & 1,000 \\
\hline 25 & 3,764 & 709, & 1,000 \\
\hline 91 & 3,695 & 718, & 1,000 \\
\hline 140 & 3,674 & ,721 & 1,000 \\
\hline 26 & 3,674 & 721 & 1,000 \\
\hline 11 & 3,619 & 728 & 1,000 \\
\hline 7 & 3,583 & 733, & 1,000 \\
\hline 6 & 3,575 & 734 & 1,000 \\
\hline 29 & 3,574 & 734, & 1,000 \\
\hline 213 & 3,570 & 735, & 1,000 \\
\hline 168 & 3,545 & 738 & 1,000 \\
\hline 119 & 3,537 & 739, & 1,000 \\
\hline 207 & 3,519 & ,741 & 1,000 \\
\hline
\end{tabular}


Notes for Model (Default model)

Computation of degrees of freedom (Default model)

Number of distinct sample moments: 27

Number of distinct parameters to be estimated: 21

Degrees of freedom (27 - 21): 6

Result (Default model)

Minimum was achieved

Chi-square $=3,066$

Degrees of freedom $=6$

Probability level $=, 801$ 
Scalar Estimates (Group number 1 - Default model)

Maximum Likelihood Estimates

Regression Weights: (Group number 1 - Default model)

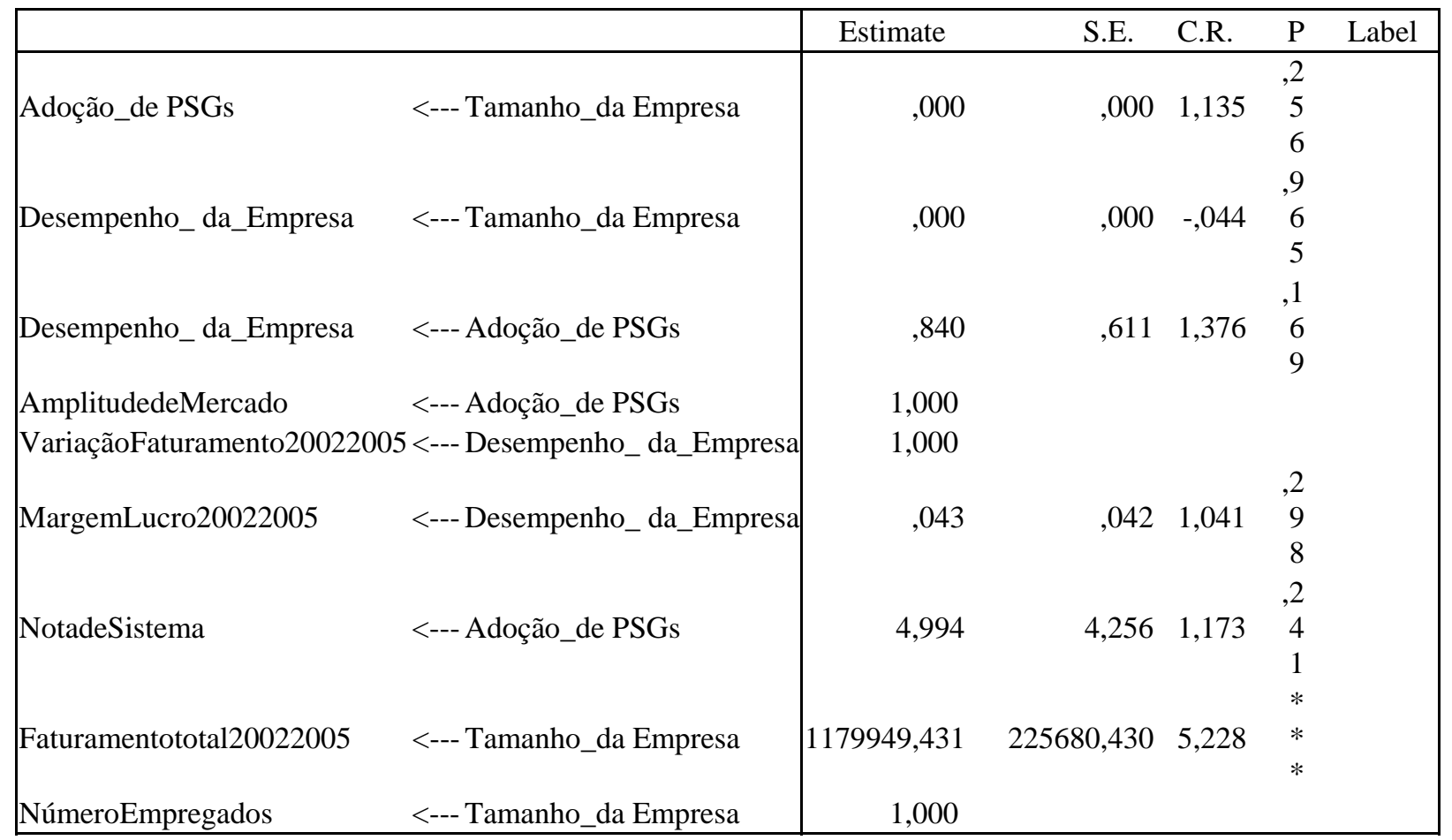

Standardized Regression Weights: (Group number 1 - Default model)

\begin{tabular}{|lll|r|}
\hline & & & Estimate \\
\hline Adoção_de PSGs & $<---$ & Tamanho_da Empresa &, 362 \\
Desempenho_da_Empresa & $<---$ & Tamanho_da Empresa &,- 009 \\
Desempenho_da_Empresa & $<---$ & Adoção_de PSGs &, 292 \\
AmplitudedeMercado & $<---$ & Adoção_de PSGs &, 222 \\
VariaçãoFaturamento20022005 & $<---$ & Desempenho_da_Empresa &, 395 \\
MargemLucro20022005 & $<---$ & Desempenho_da_Empresa &, 298 \\
NotadeSistema & $<---$ & Adoção_de PSGs &, 964 \\
Faturamentototal20022005 & $<---$ & Tamanho_da Empresa &, 786 \\
NúmeroEmpregados & $<---$ & Tamanho_da Empresa &, 858 \\
\hline
\end{tabular}

Intercepts: (Group number 1 - Default model)

\begin{tabular}{|c|c|c|c|c|c|}
\hline & Estimate & S.E. & C.R. & $\mathrm{P}$ & Label \\
\hline MargemLucro20022005 & 014 & ,005 & $\begin{array}{r}2,56 \\
2\end{array}$ & $\begin{array}{l}, 0 \\
1 \\
0\end{array}$ & \\
\hline VariaçãoFaturamento20022005 & 1,223 & ,095 & $\begin{array}{r}12,9 \\
31\end{array}$ & $\begin{array}{l}* \\
* \\
*\end{array}$ & \\
\hline AmplitudedeMercado & 2,505 & ,059 & $\begin{array}{r}42,7 \\
98\end{array}$ & $\begin{array}{l}* \\
* \\
*\end{array}$ & \\
\hline NotadeSistema & 1,427 & ,067 & $\begin{array}{r}21,2 \\
26\end{array}$ & $\begin{array}{l}* \\
* \\
*\end{array}$ & \\
\hline
\end{tabular}




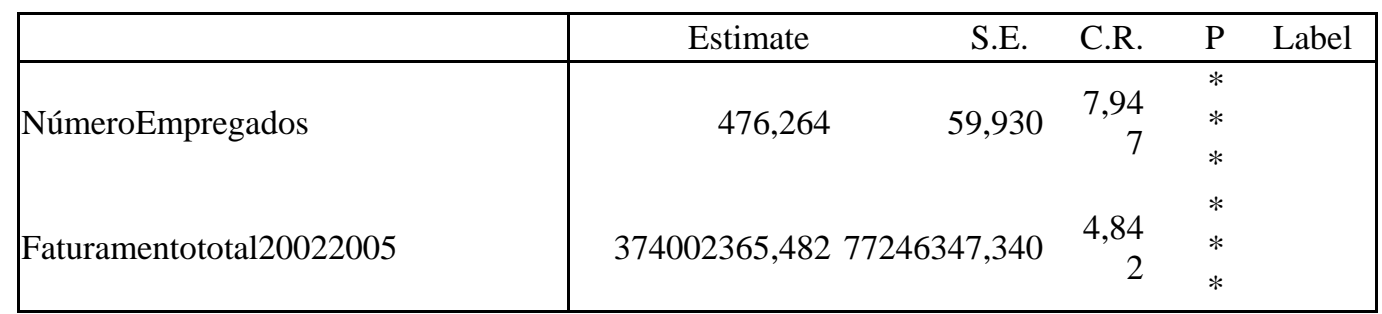

Variances: (Group number 1 - Default model)

\begin{tabular}{|c|c|c|c|c|c|}
\hline & Estimate & S.E. & C.R. & $\mathrm{P}$ & Label \\
\hline D3 & 579360,17 & 127977,634 & $\begin{array}{r}4,52 \\
7\end{array}$ & $\begin{array}{l}* \\
* \\
*\end{array}$ & \\
\hline D2 & ,032 & ,029 & $\begin{array}{r}1,09 \\
6\end{array}$ & $\begin{array}{r}, 2 \\
7 \\
3\end{array}$ & \\
\hline D1 & ,280 & ,322 & ,869 & $\begin{array}{r}3 \\
8 \\
5\end{array}$ & \\
\hline E1 & ,713 & ,074 & $\begin{array}{r}9,59 \\
5\end{array}$ & $\begin{array}{l}* \\
* \\
*\end{array}$ & \\
\hline $\mathrm{E} 2$ &, 065 & ,739 & ,094 & $\begin{array}{r}9 \\
2 \\
5\end{array}$ & \\
\hline E3 & 207205,95 & 107295,666 & $\begin{array}{r}1,93 \\
1\end{array}$ & $\begin{array}{r}, 0 \\
5 \\
3\end{array}$ & \\
\hline E4 & 500140634803503000,000 & 154403426478400000,000 & $\begin{array}{r}3,23 \\
9\end{array}$ & $\begin{array}{r}, 0 \\
0 \\
1\end{array}$ & \\
\hline E6 &, $00 €$ & ,001 & $\begin{array}{r}7,14 \\
7\end{array}$ & $\begin{array}{l}* \\
* \\
*\end{array}$ & \\
\hline E5 & 1,65 & ,358 & $\begin{array}{r}4,62 \\
0\end{array}$ & $\begin{array}{l}* \\
* \\
*\end{array}$ & \\
\hline
\end{tabular}

Squared Multiple Correlations: (Group number 1 - Default model)

\begin{tabular}{|l|r|}
\hline & Estimate \\
\hline Tamanho_da Empresa &, 000 \\
Adoção_de PSGs &, 131 \\
Desempenho_da_Empresa &, 084 \\
MargemLucro20022005 &, 089 \\
VariaçãoFaturamento20022005 &, 156 \\
Faturamentototal20022005 &, 617 \\
NúmeroEmpregados &, 737 \\
NotadeSistema &, 930 \\
AmplitudedeMercado &, 049 \\
\hline
\end{tabular}


Modification Indices (Group number 1 - Default model)

Covariances: (Group number 1 - Default model)

M.I. Par Change

Variances: (Group number 1 - Default model)

M.I. Par Change

Regression Weights: (Group number 1 - Default model)

M.I. Par Change

Means: (Group number 1 - Default model)

M.I. Par Change

Intercepts: (Group number 1 - Default model)

M.I. Par Change 


\section{Model Fit Summary}

CMIN

\begin{tabular}{|l|rrrrr|}
\hline Model & NPAR & CMIN & DF & P & CMIN/DF \\
\hline Default model & 21 & 3,066 & 6 &, 801 &, 511 \\
Saturated model & 27 &, 000 & 0 & & \\
Independence model & 12 & 175,890 & 15 &, 000 & 11,726 \\
\hline
\end{tabular}

Baseline Comparisons

\begin{tabular}{|l|rrrrr|}
\hline Model & NFI & RFI & $\begin{array}{r}\text { IFI } \\
\text { TLI }\end{array}$ & \multirow{2}{*}{ CFI } \\
& Delta1 & rho1 & Delta2 & rho2 & \\
\hline Default model &, 983 &, 956 & 1,017 & 1,046 & 1,000 \\
Saturated model & 1,000 & & 1,000 & & 1,000 \\
Independence model &, 000 &, 000 &, 000 &, 000 &, 000 \\
\hline
\end{tabular}

Parsimony-Adjusted Measures

\begin{tabular}{|l|rrr|}
\hline Model & PRATIO & PNFI & PCFI \\
\hline Default model &, 400 &, 393 &, 400 \\
Saturated model &, 000 &, 000 &, 000 \\
Independence model & 1,000 &, 000 &, 000 \\
\hline
\end{tabular}

NCP

\begin{tabular}{|l|rrr|}
\hline Model & NCP & LO 90 & HI 90 \\
\hline Default model &, 000 &, 000 & 4,133 \\
Saturated model &, 000 &, 000 &, 000 \\
Independence model & 160,890 & 121,866 & 207,369 \\
\hline
\end{tabular}

FMIN

\begin{tabular}{|l|rrrr|}
\hline Model & FMIN & F0 & LO 90 & HI 90 \\
\hline Default model &, 014 &, 000 &, 000 &, 019 \\
Saturated model &, 000 &, 000 &, 000 &, 000 \\
Independence model &, 803 &, 735 &, 556 &, 947 \\
\hline
\end{tabular}

RMSEA

\begin{tabular}{|l|rrrr|}
\hline Model & RMSEA & LO 90 & HI 90 & PCLOSE \\
\hline Default model &, 000 &, 000 &, 056 &, 933 \\
Independence model &, 221 &, 193 &, 251 &, 000 \\
\hline
\end{tabular}


AIC

\begin{tabular}{|l|rrrr|}
\hline Model & AIC & BCC & BIC & CAIC \\
\hline Default model & 45,066 & 46,452 & & \\
Saturated model & 54,000 & 55,783 & & \\
Independence model & 199,890 & 200,682 & & \\
\hline
\end{tabular}

ECVI

\begin{tabular}{|l|rrrr|}
\hline Model & ECVI & LO 90 & HI 90 & MECVI \\
\hline Default model &, 206 &, 219 &, 238 &, 212 \\
Saturated model &, 247 &, 247 &, 247 &, 255 \\
Independence model &, 913 &, 735 & 1,125 &, 916 \\
\hline
\end{tabular}

HOELTER

\begin{tabular}{|l|rr|}
\hline \multirow{2}{*}{ Model } & HOELTER & HOELTER \\
& .05 & .01 \\
\hline Default model & 900 & 1201 \\
Independence model & 32 & 39 \\
\hline
\end{tabular}

\section{Execution time summary}

Minimization: ,031

Miscellaneous: , ,125

Bootstrap: $\quad, 000$

Total: $\quad$, 156 